UNIVERSIDADE DE BRASÍLIA

FACULDADE DE AGRONOMIA E MEDICINA VETERINÁRIA

PROGRAMA DE PÓS-GRADUAÇÃO EM AGRONOMIA

\title{
AVALIAÇÃO DA PRODUTIVIDADE INICIAL E CARACTERES AGRONÔMICOS DE BANANEIRA (PRATA ANÃ E BRS CONQUISTA) EM FUNÇÃO DE DIFERENTES NÍVEIS DE ÁGUA E ADUBAÇÃO.
}

GUSTAVO PIRES DE OLIVEIRA

DISSERTAÇÃO DE MESTRADO EM AGRONOMIA

BRASÍLIA/DF

JULHO/2015 


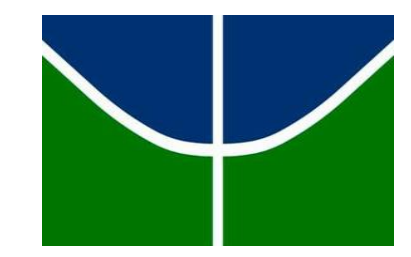

UNIVERSIDADE DE BRASÍLIA

FACULDADE DE AGRONOMIA E MEDICINA VETERINÁRIA PROGRAMA DE PÓS-GRADUAÇÃO EM AGRONOMIA

AVALIAÇÃO DA PRODUTIVIDADE INICIAL E CARACTERES AGRONÔMICOS DE BANANEIRA (PRATA ANÃ E BRS CONQUISTA) EM FUNÇÃO DE DIFERENTES NÍVEIS DE ÁGUA E ADUBAÇÃO.

GUSTAVO PIRES DE OLIVEIRA

ORIENTADOR: JOSÉ RICARDO PEIXOTO

CO-ORIENTADOR: CÍCERO LOPES DA SILVA

DISSERTAÇÃO DE MESTRADO EM AGRONOMIA

PUBLICAÇÃO 95/2015

BRASÍLIA/DF

JULHO/2015 


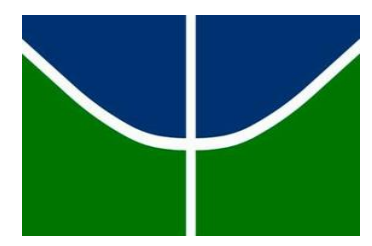

UNIVERSIDADE DE BRASÍLIA

FACULDADE DE AGRONOMIA E MEDICINA VETERINÁRIA

PROGRAMA DE PÓS-GRADUAÇÃO EM AGRONOMIA (11)

AVALIAÇÃO DA PRODUTIVIDADE INICIAL E CARACTERES AGRONÔMICOS DE BANANEIRA (PRATA ANÃ E BRS CONQUISTA) EM FUNÇÃO DE DIFERENTES NÍVEIS DE ÁGUA E ADUBAÇÃO.

GUSTAVO PIRES DE OLIVEIRA

DiSSERTAÇÃO DE MESTRAdO SUBMETIDA AO PROGRAMA DE PÓSGRADUAÇÃO EM AGRONOMIA, COMO PARTE DOS REQUISITOS NECESSÁRIOS À OBTENÇÃO DO GRAU DE MESTRE EM AGRONOMIA.

APROVADA POR:

JOSÉ RICARDO PEIXOTO (Orientador). Eng. Agrônomo. Doutor. Professor. Faculdade de Agronomia e Medicina Veterinária. Universidade de Brasília.CPF:35435623634. E-mail: peixoto@unb.br

MÁrcio de CARVAlHo PIRES (Examinador interno). Eng. Agrônomo. Doutor. Professor. Faculdade de Agronomia e Medicina Veterinária. Universidade de Brasília.CPF: 844.256.601-53. E-mail: mcpires@unb.br

OMAR CRUZ ROCHA (Examinador externo). Eng. Agrônomo. Doutor. Pesquisador. Embrapa Cerrados, Planaltina-DF. CPF: 579.134.475-91. E-mail: omar.rocha@embrapa

BRASÍLIA/DF, 10 de JULHO de 2015 


\section{FICHA CATALOGRÁFICA}

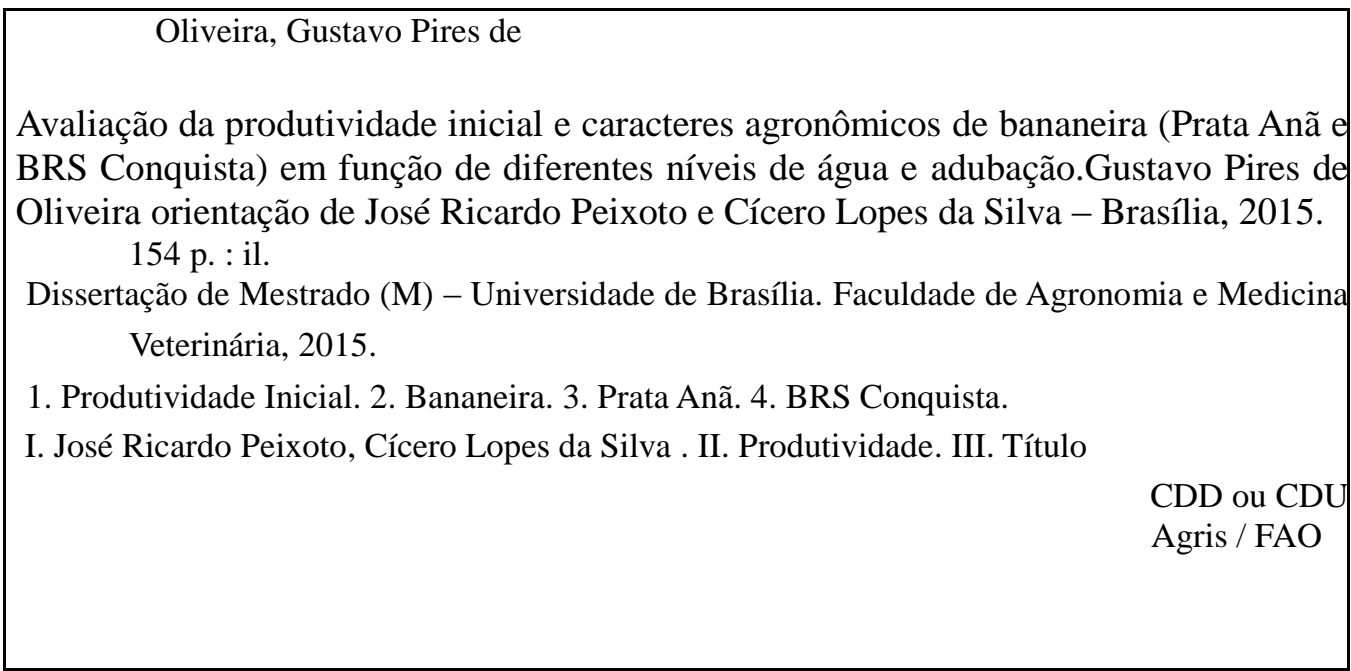

\section{REFERÊNCIA BIBLIOGRÁFICA}

OLIVEIRA, G. P. Avaliação da produtividade inicial e caracteres agronômicos de bananeira (Prata Anã e BRS Conquista) em função de diferentes níveis de água e adubação.

Brasília: Faculdade de Agronomia e Medicina Veterinária, Universidade de Brasília, 2015,154p. Dissertação de Mestrado.

\section{CESSÃO DE DIREITOS}

NOME DO AUTOR: Gustavo Pires de Oliveira

TÍTULO DA DISSERTAÇÃO: Avaliação da produtividade inicial e caracteres agronômicos de bananeira (Prata Anã e BRS Conquista) em função de diferentes níveis de água e adubação.

GRAU: Mestrado

ANO: 2015

É concedida à Universidade de Brasília de Brasília permissão para reproduzir cópias desta dissertação de mestrado para única e exclusivamente propósitos acadêmicos e científicos. $\mathrm{O}$ autor reserva para si os outros direitos autorais, de publicação. Nenhuma parte desta dissertação de mestrado pode ser reproduzida sem a autorização por escrito do autor. Citações são estimuladas, desde que citada à fonte.

Nome: Gustavo Pires de Oliveira

CPF: 72652225120

Endereço: Universidade de Brasília

Tel.: (61) 3107-7130

Email: gustavo@unb.br 
A Deus.

Aos meus pais, Getulino e Cleonice

Ao meu irmão Geovane.

À minha esposa Camila.

DEDICO. 
Agradecimentos

A Deus pela cruz que Ele me deu.

Aos Professores e a UnB, pelo apoio e pela contribuição no desenvolvimento do curso.

Aos colaboradores da Fazenda Água Limpa-UnB pelo apoio e pela amizade.

A minha família pelo apoio incondicional. 


\section{RESUMO}

No Brasil a banana é a segunda fruta em volume produzido e foram colhidas 7,1 milhões de toneladas em 2014, correspondentes a $16,7 \%$ do volume das frutas. O elevado custo de cultivo nas regiões produtoras aliado ao custo de transporte para regiões consumidoras têm levado produtores a buscarem novas fronteiras para produção de bananas incluindo o planalto central brasileiro. As taxas de crescimento da produção agrícola mundial, superadas pelas dos incrementos populacionais nos últimos anos, vêm causando certa intranquilidade com relação à segurança alimentar. Ao lado da oferta de alimentos, está a degradação dos solos, a baixa resposta positiva da produtividade ao uso de fertilizante e a escassez de água, principais entraves que inviabilizam o aumento da produção agrícola compatível com a população. O presente trabalho teve como objetivo a avaliação da produtividade inicial e caracteres agronômicos de bananeira (Prata Anã e BRS Conquista) em função de diferentes níveis de água e adubação. Os experimentos foram implantados na Estação experimental Fazenda Água Limpa-UnB (FAL-UnB), no Distrito Federal no ano de 2012. Iniciado o período produtivo, colheitas semanais foram realizadas para avaliação de peso de pencas por hectare (PPH), número médio de pencas por cacho (NMPC), número médio de bananas por penca (NMBP), número médio de bananas por cacho (NMBC), comprimento médio de bananas (CMB) e diâmetro médio de bananas (DMB) e foram estimados números de cachos por hectare $(\mathrm{NCH})$, peso médio de bananas (PMB) e a relação comprimento/diâmetro (CD). Após uma semana de amadurecimento a terceira penca de cada cacho foi avaliada com penetrômetro analógico para averiguação da firmeza média da polpa (FMP). Durante o período de avaliações, os dados climáticos foram coletados pela estação meteorológica da FAL-UnB. Utilizou-se o delineamento experimental de blocos ao acaso, em arranjo de parcela subdividida, com quatro blocos. As parcelas foram constituídas pelos cinco volumes de irrigação e as subparcelas constituídas pelas cinco doses de adubação com fósforo dentro da cultivar 'Prata Anã' e cinco doses de magnésio dentro da cultivar 'BRS Conquista', cada parcela constituída por quatro covas úteis. As variáveis obtidas foram submetidas à análise de variância e a teste para ajustar polinômios de regressão. Não houve efeitos médios significativos da interação entre volumes de água e doses dos adubos fósforo e magnésio. Os efeitos médios de água foram significativos nos parâmetros de produtividade para as duas cultivares. Não houve efeitos médios significativos para os adubos estudados neste primeiro ciclo de avaliação. No ensaio com a cultivar 'Prata Ana' os volumes de 6.540 e 8.720 L.cova $^{-1}$ proporcionaram maiores valores para os caracteres relacionados à produtividade e qualidade de frutos. $\mathrm{O}$ uso de $\mathrm{P}_{2} \mathrm{O}_{5}$ parcelado no solo proporcionou aumento na relação $\mathrm{CD}$, com efeito linear indicando aumento do comprimento e diâmetro do fruto. $\mathrm{O}$ número de cachos aumentou na presença de doses de água com doses de fósforo. O número médio de pencas por cacho e número médio de bananas por cacho apresentaram maiores valores com a interação água versus fósforo. No ensaio com a cultivar 'Conquista' os volumes de irrigação de $6.540 \mathrm{e}$ $8.720{\mathrm{~L} . \mathrm{cova}^{-1}}^{-1}$ proporcionaram os maiores valores em produtividade e qualidade de frutos. A maior produtividade foi observada com a dose de $6.540 \mathrm{~L}_{\text {.cova }}{ }^{-1}$ de água e $330 \mathrm{~kg} \mathrm{de} \mathrm{Mg}^{2+}$.ha${ }^{1}$. As doses de 220 e $110 \mathrm{~kg}$ de $\mathrm{Mg}^{2+} \cdot \mathrm{ha}^{-1}$ proporcionaram os maiores valores em número médio de bananas por cacho. A relação comprimento/diâmetro apresentou maiores valores com a dose de 1.090 L.cova $^{-1}$ de água, na ausência de magnésio, indicando baixos valores do comprimento.

Palavras-chave: Produção de bananas, doses de adubação, lâminas de irrigação. 


\begin{abstract}
Banana is the second fruit in the volume produced in Brazil. In 2014 Brazil harvested 7.1 million tonnes of banana, corresponding to $16.7 \%$ of the volume of fruit. The high cost of cultivation in producing areas plus the cost of transport to consuming regions have led producers to seek new frontiers for banana production including the Brazilian central plateau. The growth rates of world agricultural production surpassed by the population increases in recent years have caused certain uneasiness with respect to food safety. Next to the food supply, it is land degradation, low productivity positive response to the use of fertilizer and water scarcity, major obstacles that made it impossible to increased agricultural production compatible with the population. This study aimed to evaluate the initial development and productivity leading banana cultivars cycle Prata Anã and BRS Conquista under different doses of fertilizer and irrigation. The experiment was established on experimental station Fazenda Água Limpa-UnB (UnB-FAL), in Distrito Federal in 2012. When started the production period, weekly samples were collected for evaluation bunch weight, number of bunches per bunch, number of fruits per bunch, number of fruits per bunch, fruit length and diameter and were estimated number of bunches per hectare and average fruit weight. After a week of maturing the third bunch of each bunch was evaluated with analog penetrometer for investigation of firmness. During the evaluation period, the climatic data were collected by the weather station of FAL-UNB. We used the experimental design of randomized blocks in a split plot arrangement with four blocks. The plots were constituted by five irrigation levels and five subplots comprise the fertilizer levels to match within cultivate Prata Anã and magnesium doses within cultivate BRS Conquista, each plot had four working pits. The values obtained were submitted to variance analysis and testing to adjust regression polynomial. There were no significant mean effects of the interaction between water volumes and doses of the phosphorus and magnesium fertilizers. The average water effects were significant in productivity parameters for both cultivars. There were no significant average effects for fertilizers studied in the first year of assessment. In the experiment with the banana 'Prata Anã' the volumes of 6.540 and $8.720 \mathrm{~L}^{\text {pit }}{ }^{-1}$ provided higher values for the productivity and the fruit quality. The use of $\mathrm{P}_{2} \mathrm{O}_{5}$ shared on the land provided an increase in $\mathrm{CD}$, with a linear effect showing an increase in length and diameter of the fruit. The median number of hands per bunch and the median number of banana for bunch presented highest values with the water interaction versus phosphorus. The median number of hands per bunch and median number of bananas per bunch presented highest values with water interaction versus phosphorus. In the experiment of the banana 'BRS Conquista' the volumes of irrigation of 6.540 and $8.720 \mathrm{~L}^{-}$pit $^{-1}$ provided highest values in the productivity and fruit quality. The highest productivity was observed with the dose of 6.540 L.pit $^{-1}$ of water and $330 \mathrm{~kg}$ of $\mathrm{Mg}^{2+} \cdot \mathrm{ha}^{-1}$. The relation between length/diameter presented highest values with the dose of 1.090 L.pit ${ }^{-1}$ of water, without magnesium, indicating low levels of the length.
\end{abstract}

Keywords: Production of bananas, fertilizer levels, irrigation levels. 


\section{SUMÁRIO}

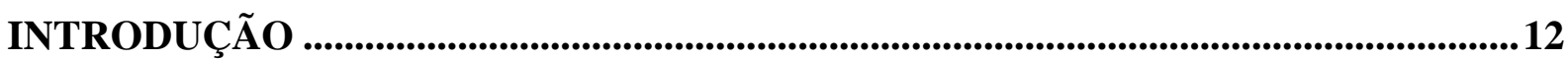

PROBLEMÁTICA E RELEVÂNCIA...............................................................................15

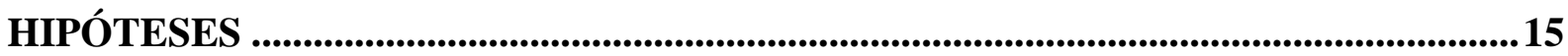

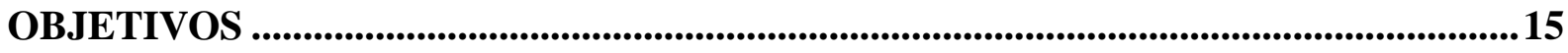

OBJETIVO GERAL...................................................................................................15

OBJETIVOS ESPECÍFICOS .......................................................................................15

REFERENCIAL TEÓRICO ........................................................................................17

IMPORTÂNCIA ECONÔMICA …...................................................................................17

ORIGEM E CLASSIFICAÇÃO BOTÂNICA ………………….....................................................................18

ESTRUTURA DA PLANTA ........................................................................................................... 19

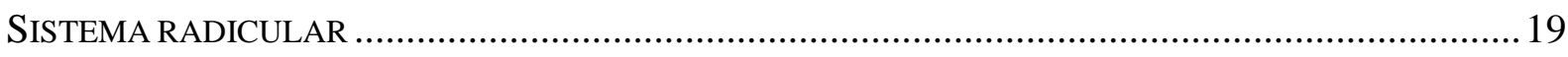

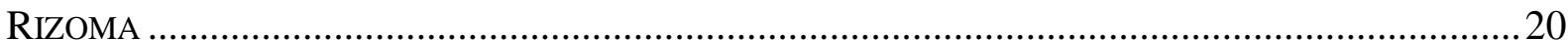

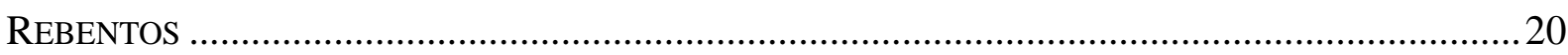

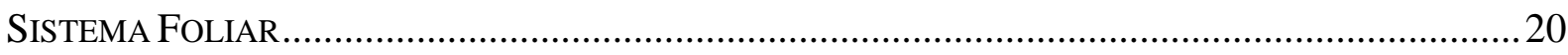

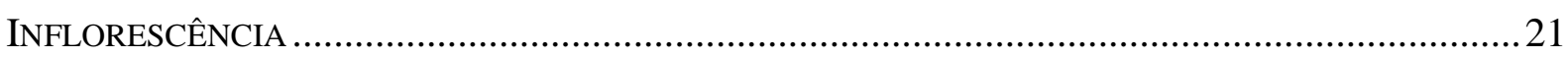

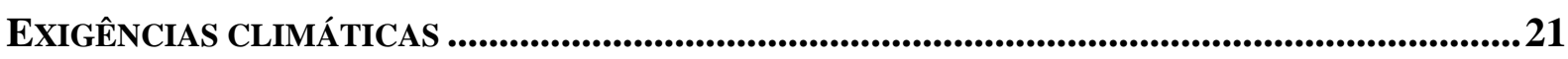

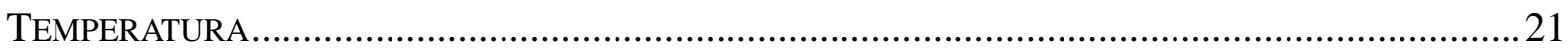

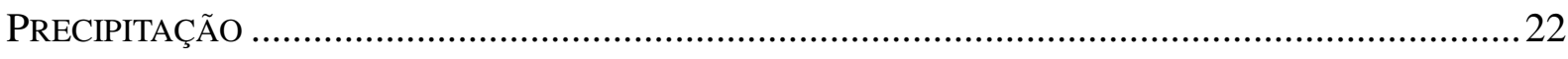

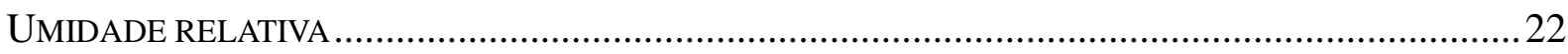

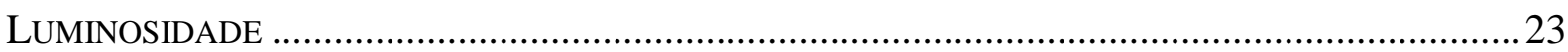

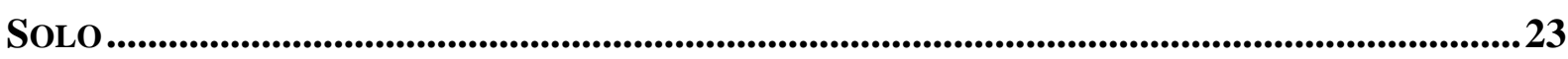

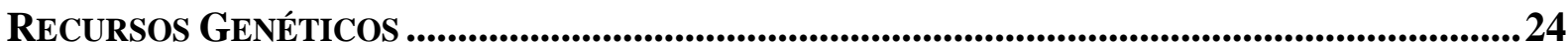

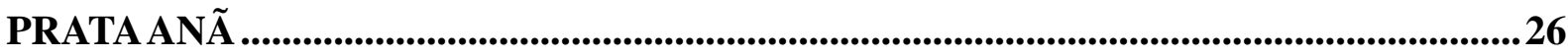

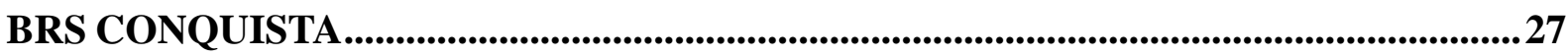

ADUBAÇÃO .................................................................................................................27

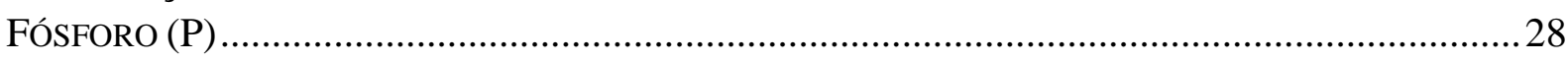

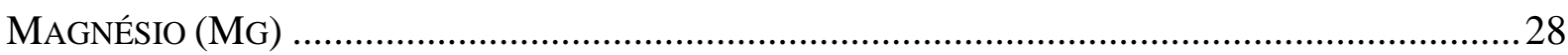

IRRIGAÇÃO ..................................................................................................................................30

REFERÊNCIAS BIBLIOGRÁFICAS ..............................................................................33

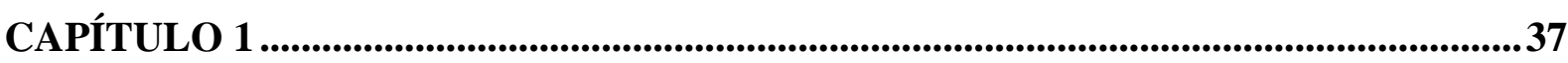


AVALIAÇÃO DA PRODUTIVIDADE INICIAL E CARACTERES AGRONÔMICOS DA CULTIVAR DE BANANEIRA 'PRATA ANÃ' EM FUNÇÃO DE DIFERENTES NÍVEIS DE ÁGUA E ADUBAÇÃO FOSFATADA.

ABSTRACT 39

INTRODUÇÃO 40

MATERIAIS E MÉTODOS 42

LOCALIZAÇÃO E CARACTERÍSTICAS DA ÁREA ............................................................................42

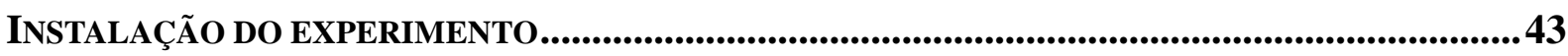

DELINEAMENTO E CONDUÇÃO EXPERIMENTAL ............................................................................44

AVALIAÇÃ DO EXPERIMENTO...............................................................................................52

ANÁLISE DE VARIÂNCIA ..................................................................................................................54

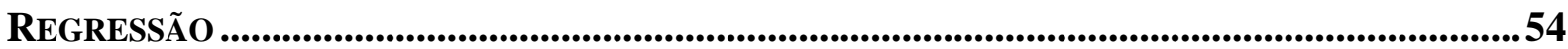

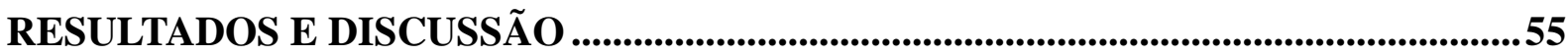

NÚMERO DE CACHOS POR HECTARE (NCH) ...............................................................55

PESO DE PENCAS POR HECTARE (PPH) ...................................................................................58

NÚMERO MÉDIO DE PENCAS POR CACHO (NMPC) ....................................................................59

NÚMERO MÉDIO DE BANANAS POR CACHO (NMBC) .................................................................60

PESO MÉDIO DE BANANA(PMB) ..............................................................................................62

NÚMERO MÉDIO DE BANANAS POR PENCA (NMBP) .................................................................63

COMPRIMENTO MÉDIO DE BANANAS (CMB).........................................................................65

DIÂMETRO MÉDIO DE BANANAS (DMB) ......................................................................................66

RELAÇÃO COMPRIMENTO/DIÂMETRO (CD)...................................................................................67

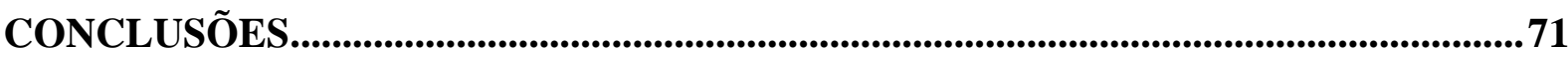

REFERÊNCIAS BIBLIOGRÁFICAS ...................................................................................72

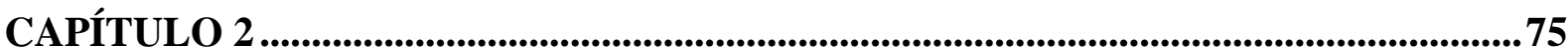

AVALIAÇÃO DAPRODUTIVIDADE INICIAL E CARACTERES AGRONÔMICOS DA CULTIVAR DE BANANEIRA 'BRS CONQUISTA' EM FUNÇÃO DE DIFERENTES NÍVEIS DE ÁGUA E ADUBAÇÃ̃ MAGNESIANA. .................................75

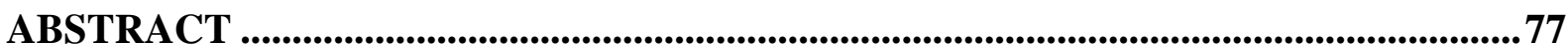

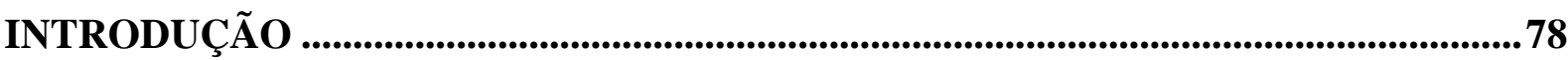




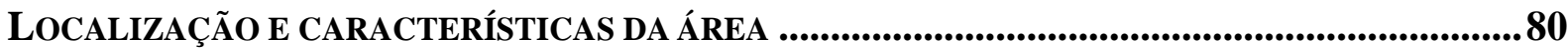

INSTALAÇÃO DO EXPERIMENTO ..............................................................................................................8 81

DELINEAMENTO E CONDUÇÃO EXPERIMENTAL .........................................................................82

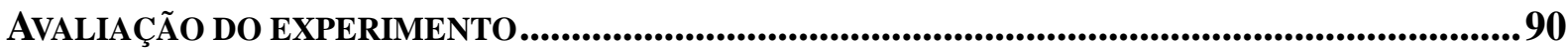

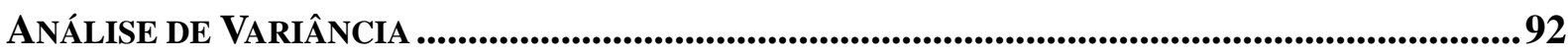

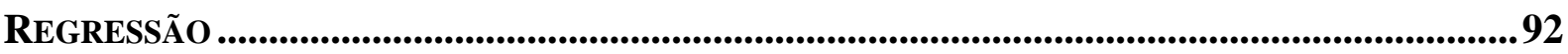

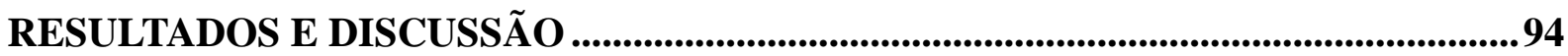

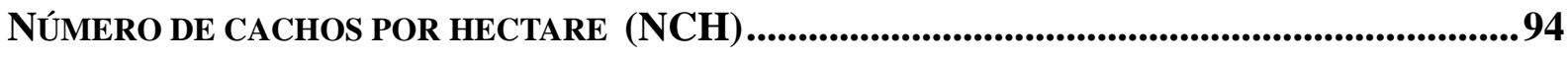

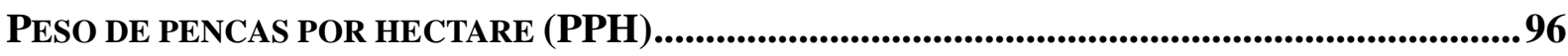

NÚMERO MÉDIO DE BANANAS POR CACHO (NMBC) ....................................................97

NÚMERO MÉDIO DE BANANAS POR PENCA (NMBP) ..............................................................98

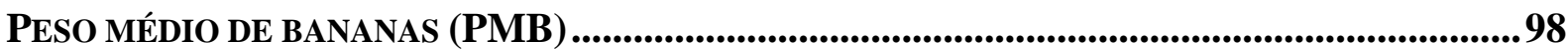

COMPRIMENTO MÉDIO DA BANANA (CMB) ....................................................................103

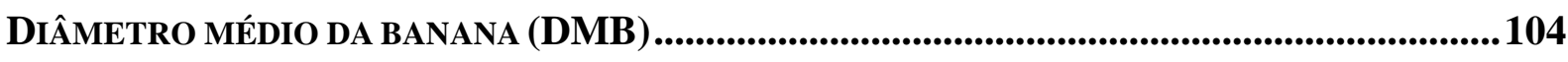

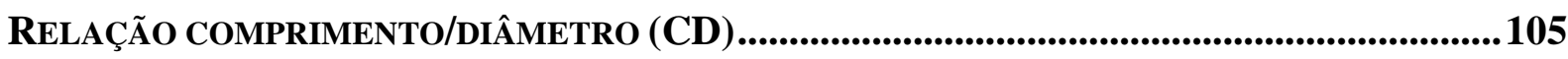

FIRMEZA MÉDIA DA POLPA (FMP) ........................................................................................................ 106

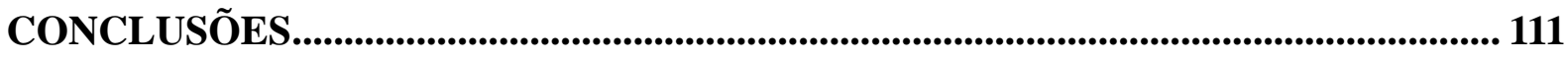

REFERÊNCIAS BIBLIOGRÁFICAS .......................................................................112

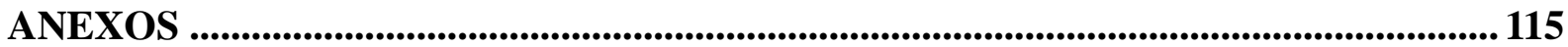




\section{INTRODUÇÃO}

A bananicultura é uma atividade de grande importância econômica e social e é praticada na maioria das vezes por pequenos agricultores. No mundo a produção anual fica em torno de 106 milhões de toneladas e a banana ocupa a segunda posição mundial na produção de fruteiras. Os frutos não são usados somente in natura, sendo também processados de diversas formas, tais como: passas, doces, chips, polpas, cerveja, vinho e álcool (FAO, 2013). A banana, o arroz, o trigo e o milho são considerados as fontes alimentares mais importantes do planeta (PERRIER et al., 2011).

Quase a metade de todo o comércio internacional de frutas frescas corresponde à comercialização de banana e cítricos, sendo que a banana é considerada a fruta fresca detentora de maior mercado no mundo. A participação brasileira no mercado internacional de banana é muito tímida representado apenas $0,3 \%$ do valor total em dólares comercializados (FAO, 2013). Aproximadamente $97 \%$ da produção brasileira são consumidas pelo mercado interno, propiciando uma pequena participação brasileira no mercado externo. Atribui-se esta pequena parcela aos altos índices de perdas, à incidência de pragas e doenças na cultura, à precária estrutura comercial e de escoamento da produção, à baixa qualidade da produção e à preferência do consumidor brasileiro por variedades do grupo Prata, enquanto no mercado externo a demanda é por variedades do grupo Cavendish (SARAIVA et al., 2013).

O crescimento, o desenvolvimento e a produtividade da bananeira variam com o solo, clima, nível de manejo, genótipo, entre outros. Para um genótipo expressar o seu potencial genético em produtividade, necessita-se de manejo tecnológico e ambiente propício (ROBINSON \& GALÁN SAÚCO, 2010).

Entretanto, a produtividade brasileira tem se mostrado muito aquém de seu potencial, principalmente em razão de problemas nutricionais e de suprimento hídrico, apesar da existência de condições favoráveis para o seu cultivo em quase todo o país. Desse modo, o correto manejo da irrigação e a quantidade adequada de água a ser aplicada vêm sendo avaliada por vários autores (COELHO et al., 2006; FIGUEIREDO et al., 2007; AZEVEDO \& BEZERRA, 2008; BRAGA FILHO et al., 2008), uma vez que tanto o déficit como o excesso de água no solo provocam quedas na produção da bananeira acarretando queda na produtividade como um todo (JAIMEZ et al., 2005). 
As bananeiras são plantas muito sensíveis ao estresse hídrico e suas folhas possuem elevado índice de área foliar, o que resulta em alta transpiração e consequente perda de água. A produtividade tende a aumentar linearmente com a transpiração, sendo que esta depende da disponibilidade de água no solo, a qual pode ser controlada pela irrigação (FIGUEIREDO et al., 2006). O sistema radicular é pouco profundo, razão pela qual a bananeira é uma espécie que apresenta considerável resposta fisiológica à pouca disponibilidade de água (VOSSELEN et al., 2005), além disso, demandam água ao longo de todo o ano por se tratar de cultivo perene com produção constante.

As variações consideradas entre os métodos de irrigação acarretam mudanças na distribuição vertical e horizontal das raízes no solo, o que influencia a maior ou menor área de absorção de água e nutrientes, e tem consequências para o fluxo difusivo de nutrientes no solo que causa alterações na fisiologia da bananeira. Isso pode ser expresso por mudança nas relações parte aérea-raiz (TAIZ \& ZEIGER, 2009), pelo maior teor de nutrientes nas folhas e pela maior produtividade de um determinado genótipo (DONATO et al., 2010).

A região dos cerrados apresenta uma sazonalidade na distribuição pluviométrica, com aproximadamente seis meses chuvosos e seis meses secos. Dessa forma, a produção de banana é sazonal, aumentando ou diminuindo em função dos níveis pluviométricos anuais. Para se alcançar melhor produtividade e maior rentabilidade desses bananais, é necessário buscar alternativas para incrementar os indicadores de produção e de qualidade da fruta. A adoção da irrigação, assim como o seu manejo adequado, é imprescindível em regiões onde há estacionalidade na distribuição de chuvas (SILVA et al., 2004).

A bananeira é uma planta herbácea de rápido crescimento e de grande porte, que chega a produzir mais de 300 toneladas de matéria fresca por hectare, por safra. Assim, é uma cultura que consomem altos volumes de água e de nutrientes. Dos nutrientes absorvidos, a maior parte retorna ao solo e é reciclada. Mesmo assim, é alta a necessidade de adubação, para repor a quantidade de nutrientes exportada pelas colheitas e as perdas no ciclo dos nutrientes no solo (LICHTEMBERG L. A.; LICHTEMBERG P. S. F., 2011).

De acordo com Novais et al., (2007), o nível crítico de P no solo correlaciona-se com as características do solo que refletem a capacidade tampão de fósforo, como o fósforo remanescente, que é a medida da quantidade de fósforo que permanece em solução de equilíbrio, em resposta a uma concentração de fósforo adicionada ao solo. Quanto menor o valor do fósforo remanescente de determinado solo, maior é o seu potencial de adsorção de 
fósforo. Maiores valores de fósforo remanescente indicam maiores níveis de disponibilidade desse nutriente para as plantas.

Entre os macronutrientes, o fósforo é o menos exigido pela bananeira. De acordo com Hoffmann et al. (2010) e Borges \& Oliveira (2000), os nutrientes mais absorvidos pela bananeira são: $\mathrm{K}>\mathrm{N}>\mathrm{Ca}>\mathrm{Mg}>\mathrm{S}>\mathrm{P}$.

$\mathrm{O}$ fósforo é absorvido pelas plantas nas formas de $\mathrm{HPO}_{4}{ }^{-2}$ ou $\mathrm{H}_{2} \mathrm{PO}_{4}{ }^{-}$. Nos solos ácidos, há predomínio da forma $\mathrm{H}_{2} \mathrm{PO}_{4}^{-}$, isso em decorrência das reações de equilíbrio do fósforo no solo. Segundo Furtini Neto, et al. (2001), o pH que favorece maior disponibilidade de fósforo está entre 6,0 e 6,5. Nessa faixa de $\mathrm{pH}$, ocorre o equilíbrio entre as duas formas de fósforo absorvidas pelas plantas.

A carência do nutriente magnésio $(\mathrm{Mg})$ ocorre em solos de baixa fertilidade, ácidos e ainda, pelo excesso de adubação potássica. Esse é um aspecto importante, uma vez que a bananeira é muito exigente em potássio. O conteúdo de $\mathrm{Mg}$ deve estar presente no solo em quantidade suficiente para impedir o aparecimento do sintoma "azul da bananeira", uma deficiência de $\mathrm{Mg}$ induzida pelo excesso de $\mathrm{K}$, sendo caracterizado por manchas pardovioláceas nos pecíolos. A deficiência de Mg ocorre nas folhas mais velhas, caracterizando-se pelo amarelecimento no meio das folhas, descolamento da bainha foliar e por deformações e irregularidades nas emissões florais. O sintoma mais comum no campo é a clorose da parte interna do limbo, também conhecida como clorose magnesiana, com a nervura central e os bordos permanecendo verdes. Quando os sintomas atingem os cachos, esses se tornam raquíticos e deformados, a maturação dos frutos é irregular, a polpa é mole, viscosa, de sabor desagradável e de apodrecimento rápido. $\mathrm{O}$ excesso de $\mathrm{Mg}$ leva à cor azulada no pecíolo e clorose irregular seguida de necrose nas folhas (BORGES et al., 2002).

O cultivo de banana Prata anã no primeiro ano de implantação, os gastos na compra de insumos são os que mais pesam sobre os custos, representando $78 \%$ do custo total. No segundo ano de cultivo o gasto com insumos chega a 65\% do total (SANTANA, 2004). Estudos que busquem minimizar o custo com uso eficiente de insumos aliando sustentabilidade econômica e ambiental são importantes para o desenvolvimento da cadeia produtiva, para agregação de valor ao produto e para a garantia da rentabilidade em todos os elos envolvidos na produção de bananas. 


\section{PROBLEMÁTICA E RELEVÂNCIA}

O Distrito Federal carece de estudos que possibilitem subsidiar o desenvolvimento de cultivos de banana de forma adequada para a região, desta forma, a produtividade fica aquém tanto do potencial produtivo da cultura quanto da área de cultivo.

Além disso, o cultivo da banana no Distrito Federal e no Brasil ainda é demasiadamente onerado devido aos altos custos da adubação mineral, o que torna imperiosa a busca por soluções que garantam maximizar economicamente e a sustentabilidade ambiental da cultura.

\section{HIPÓTESES}

É possível obter elevada produtividade e frutos de alta qualidade das cultivares de banana Prata Anã e BRS Conquista com o uso racional de fertilizantes e um manejo adequado da irrigação.

\section{OBJETIVOS}

\section{OBJETIVO GERAL}

Avaliação da produtividade inicial e caracteres da qualidade de frutos, em primeiro ciclo, das cultivares de banana Prata Anã e BRS Conquista sob diferentes doses de adubação e de irrigação, no Distrito Federal.

\section{OBJETIVOS ESPECÍFICOS}

1. Avaliar a produtividade e a qualidade de frutos, em primeiro ciclo, da cultivar de banana Prata Anã sob cinco níveis de irrigação.

2. Avaliar a produtividade e a qualidade de frutos, em primeiro ciclo, da cultivar de banana BRS Conquista sob cinco níveis de irrigação.

3. Avaliar a produtividade e a qualidade de frutos, em primeiro ciclo, da cultivar de banana Prata Anã sob cinco doses de fósforo.

4. Avaliar a produtividade e a qualidade de frutos, em primeiro ciclo, da cultivar de banana BRS Conquista sob cinco doses de magnésio.

5. Avaliar a produtividade e a qualidade de frutos, em primeiro ciclo, da cultivar de banana Prata Anã sob cinco níveis de irrigação e cinco doses de fósforo. 
6. Avaliar a produtividade e a qualidade de frutos, em primeiro ciclo, da cultivar de banana BRS Conquista sob cinco níveis de irrigação e cinco doses de magnésio. 


\section{REFERENCIAL TEÓRICO}

\section{IMPORTÂNCIA ECONÔMICA}

A China é o maior produtor mundial de frutas com 224,8 milhões de toneladas, seguida da Índia com 88,03 milhões de ton. e o Brasil com 45 milhões de ton, contribuindo com aproximadamente 5,5\% da produção mundial de 822,3 milhões de ton. (ANUÁRIO BRASILEIRO DA FRUTICULTURA, 2013).

No Brasil as frutas são cultivadas numa área aproximada de 2,0 milhões de hectares, gera mais de 5 milhões de empregos que corresponde a $34 \%$ da força de trabalho no campo e possui valor bruto de produção superior a $\mathrm{R} \$ 23$ bilhões. Apesar da importância brasileira na produção mundial de frutas, sua participação no mercado internacional é baixa. O país possui grande destaque na produção de cítricos e banana, porém ainda ocupa baixos níveis no ranking de países exportadores. Um grande exemplo de especialização é caso do Equador que apesar de não ser o maior produtor de bananas mundial ocupa $1^{\circ}$ lugar no ranking de países exportadores desta fruta (ANUÁRIO BRASILEIRO DA FRUTICULTURA, 2014).

O consumo de frutas no Brasil chega a $65 \mathrm{~kg} / \mathrm{hab} / \mathrm{ano}$, mas ainda é um número aquém do recomendado pela Organização Mundial de Saúde que indica um consumo de 100kg/hab/ano. O consumo de frutas no Brasil tem crescido a taxas amenas. A melhoria no poder aquisitivo da população e a disseminação de hábitos culturais saudáveis tendem a estimular a presença de frutas no cardápio do dia a dia dos brasileiros. Apesar da grande importância que é a produção de frutas para o país os índices quanto às perdas são alarmantes: $23 \%$ para laranja, $32 \%$ para mamão, $40 \%$ para morango e $42 \%$ para banana (ANUÁRIO BRASILEIRO DA FRUTICULTURA, 2014).

Mais de 125 países cultivam banana no mundo. Em alguns deles a atividade se destaca como a principal fonte de emprego e renda. O continente asiático lidera a produção da fruta com $58 \%$ do volume produzido, seguido pelo continente americano com $26 \%$ e o continente africano com 14\%. A banana lidera o ranking mundial de produção de frutas com 106,5 milhões de toneladas (ANUÁRIO BRASILEIRO DA FRUTICULTURA, 2013).

A banana (Musa spp) é uma das frutas mais consumidas do mundo, e no Brasil sua área plantada chega a 523,7 mil ha e seu consumo chega a $31 \mathrm{~kg} / \mathrm{hab}$ por ano. A Índia é o 
maior produtor mundial da fruta, e o Brasil fica em $4^{\circ}$ lugar, tendo produzido mais de 7,1 milhões de toneladas em 2014. Entretanto, a produtividade da banana no país ainda é baixa, em torno de 14,6 toneladas por hectare (ANUÁRIO BRASILEIRO DA FRUTICULTURA, 2013).

No Distrito Federal, localizado no Centro Oeste brasileiro, o cultivo da banana ainda apresenta pequeno potencial explorado. Com uma área de 190 ha e uma produção de 3,6 mil ton. Apresenta produtividade de 18,9 ton/ha superior à média nacional (IBGE, 2014).

\section{ORIGEM E CLASSIFICAÇÃO BOTÂNICA}

A maioria dos cultivares de banana originou-se do Continente Asiático, embora existam centros secundários de origem na África Oriental e nas ilhas do Pacífico, Além de um importante centro de diversidade na África Ocidental.

As cultivares comerciais apresentam três níveis cromossômicos: diplóide, triplóide e tetraplóide, com dois, três e quatro múltiplos do número básico de cromossomos de 11 ( $\mathrm{x}=\mathrm{n})$ (ALVES, 1997). As bananas comestíveis originaram-se do cruzamento das espécies diplóides Musa acuminata e Musa Balbisiana e cada cultivar procedente contem combinações variadas de genomas dessas espécies progenitoras. Os genomas são caracterizados pelas letras A ( $M$. acuminata) e B (M. balbisiana), e as combinações resultam os grupos: AA, BB, AB, AAB, ABB, AAAA, AAAB, AABB, ABBB (SIMMONDS \& SHEPHERD, 1955).

A banana (Musa spp) pertence à classe das Monocotiledôneas, ordem Scitaminales, família Musaceae, onde estão as subfamílias Heliconioideae, Strelitzioideae e Musoideae. Na subfamília Musoideae estão os gêneros Ensete e Musa. Este último constituído por quatro seções: Australimusa, Callimusa, Rhodochlamys e Eu-Musa (SIMMONDS, 1973). A seção Eu-Musa é a mais importante, pois é formada pelo maior número de espécies do gênero, possui distribuição geográfica ampla e abriga as espécies de bananas comestíveis incluídas as cultivares de Musa acuminata e Musa balbisiana (diplóides, triplóides, tetraplóides e seus híbridos).

A ausência de sementes é frequentemente associada à esterilidade feminina em bananeiras triplóides cultivadas, pois durante a meiose, ocorre a produção de gametas estéreis. As cultivares do subgrupo Cavendish (Nanica e Nanicão) não produzem sementes ao serem polinizadas com diplóides, entretanto a banana maçã produz um pequeno número de sementes 
que não germinam (SILVA et al., 1999). Existe cultivares diplóides que não produzem sementes indicando que não apenas triplóides possuem esta característica, sendo fator determinado pelo processo de domesticação e intensa seleção humana a favor da partenocarpia e ausência de sementes (SHEPHERD et al., 1986).

\section{ESTRUTURA DA PLANTA}

A bananeira é uma planta herbácea, caracterizada pela exuberância de suas formas e dimensões das folhas. Possui tronco curto e subterrâneo, denominado de rizoma, que constitui um órgão de reserva, onde se inserem as raízes adventícias e fibrosas. O pseudocaule, resultante da união das bainhas foliares, termina com uma copa de folhas longas e largas, com nervura central desenvolvida. Do centro da copa emerge a inflorescência com brácteas ovaladas de coloração normalmente roxo-avermelhada, em cujas axilas nascem as flores. Cada grupo de flores reunidas forma uma penca (mão) com um número variável de frutos (dedos), originados por partenocarpia. Os frutos inicialmente são verdes, tornando-se amarelos com a maturação, posteriormente começam a escurecer. Entretanto, durante o desenvolvimento há formação de rebentos (filhos), que surgem na base da planta, possibilitando a constante renovação e a vida permanente dos bananais (ALVES, 1997).

\section{Sistema radicular}

A bananeira durante seu crescimento possui número variável de raízes, que são relacionadas com o cultivar, vigor vegetativo da planta, volume do rizoma, tipo de muda (chifre, chifrinho, chifrão ou mudas oriundas de micropropagação), fatores edafoclimáticos, estado fitossanitário e tratos culturais. A radícula embrionária da bananeira originada da semente morre logo, imediatamente substituída por um sistema radicular adventício. Nas plantas oriundas de mudas o sistema radicular é genuinamente adventício. A maioria das raízes origina-se da parte superior do rizoma e aparece ligeiramente abaixo do meristema central, crescem através da zona cortical, saem ao exterior e estendem-se na camada superficial do solo. As raízes primárias da bananeira são em forma de corda, brancas, carnosas e tenras quando novas. Quando envelhecidas tornam-se amarelas, suberosas e endurecem. O diâmetro depende da cultivar e varia entre 5 a $8 \mathrm{~mm}$, com um comprimento de 3 a 4 metros em solos profundos. Estas raízes secundárias possuem numerosas radicelas providas de pêlos absorventes responsáveis pela absorção de água e nutrientes (SUMMERVILLE, 1984). 


\section{Rizoma}

O rizoma apresenta-se geralmente com um diâmetro superior a $30 \mathrm{~cm}$ onde todos os órgãos da planta estão inseridos: raízes, gemas, rebentos, pseudocaule, folhas e frutos. O rizoma é constituído por uma parte externa carnosa e aquosa denominada córtex e internamente é fibroso denominado cilindro central (SIMMONDS, 1973; MOREIRA, 1975).

\section{Rebentos}

O rizoma de uma planta adulta possui um número variável de gemas. Estas gemas possuem uma parte saliente, na forma de um calo, formada por escamas triangulares fortemente unidas (CHAMPION, 1975).

A gema inicialmente desenvolve-se lateralmente, quase perpendicular à superfície do rizoma e antes da emergência endireita-se por geotropismo negativo (GALAN SAUCO et al., 1984). A bananeira apresenta geralmente tantas gemas laterais quantas forem as folhas geradas (SOTO BALLESTERO, 1992). Quando o diâmetro da gema atinge entre 6 a $8 \mathrm{~cm}$ o rebento já está quase estruturado, separando-se da zona cortical por uma zona estreita onde o cilindro central do rebento une-se ao cilindro central do rizoma principal. Com o aumento das reservas do rizoma principal causado pelo desenvolvimento vegetativo, partes destas reservas passam para o novo rebento que por sua vez aumenta o crescimento vegetativo e passa por alongamento do pseudocaule (MANICA, 1998).

\section{Sistema Foliar}

As folhas da bananeira são formadas por bainha foliar, pseudopecíolos, nervura e limbo foliar. Na parte superior do rizoma está implantado o pseudocaule (falso tronco da bananeira), formado pelas bainhas das folhas que sobrepostas concentricamente dão o aspecto cilíndrico deste órgão. Numa determinada altura, a bainha se afasta do pseudocaule e assume o formato da letra U onde recebe o nome de pseudopecíolo da folha (CHAMPION, 1967). O prolongamento do pseudopecíolo origina a nervura central foliar sem ponto de transição entre os dois. O limbo da folha da bananeira é composto por duas metades denominadas semilimbos separados pela nervura central. O limbo possui coloração verde intenso na face superior e verde mais claro na parte abaxial, onde encontram-se geralmente o maior número de estômatos (SKUTCH, 1930). O intervalo de emissão de folhas varia com condições edafoclimáticas e com a cultivar. Uma planta de banana pode emitir entre 30 a 70 folhas característica também determinada pela genética e por condições de solo e clima 
(CHAMPION, 1975; MOREIRA, 1987). A produção de folhas cessa completamente quando iniciado o processo de diferenciação floral (SIMMONDS, 1973). A diferenciação floral é determinada por fatores como superfície foliar funcional e desenvolvimento do rizoma. $\mathrm{O}$ número de folhas presentes no pseudocaule, no momento da iniciação floral é regularmente constante sob várias condições (STOVER \& SIMMONDS, 1987).

\section{Inflorescência}

A inflorescência é uma espécie de espiga simples, terminal, que emerge do centro das bainhas foliares, protegida por uma grande bráctea (MOREIRA, 1987). A inflorescência e posteriormente cacho é formado por pedúnculo (engaço), ráquis, pencas ou mãos (flores femininas), frutos ou dedos (flores femininas desenvolvidas) e botão floral (coração). O engaço ou pedúnculo é o alongamento do cilindro central do rizoma, inicia-se no ponto de fixação da última folha e termina na inserção da primeira penca. A continuação do engaço é denominada de ráquis, onde estão inseridas flores. A ráquis inicia no ponto de inserção da primeira penca e termina no coração (MEDINA, 1990). A penca é o conjunto de frutos reunidos pelos seus pedúnculos, em uma estrutura chamada de almofada, em duas fileiras paralelas (MOREIRA, 1987). Os frutos partenocárpicos são bagas alongadas e triloculares. O pericarpo corresponde à casca e o mesocarpo é polpa comestível. Existe uma grande variedade de tamanhos, número e formatos de frutos que dependem da cultivar e das condições vegetativas da planta. Existem frutos retos e curvos, podem alcançar até $50 \mathrm{~cm}$ de comprimento e $10 \mathrm{~cm}$ de diâmetro. A casca pode apresentar coloração creme-palha a quase preta, além de verde clara, amarela e vermelha. A coloração da polpa varia entre branca, creme, amarela e rósea (MOREIRA, 1987).

\section{EXIGÊNCIAS CLIMÁTICAS}

\section{Temperatura}

A banana é uma planta tipicamente tropical exige calor constante, precipitações bem distribuídas ao longo do ano e elevada umidade para o bom desenvolvimento vegetativo e produtivo. Os principais componentes climáticos: temperatura, precipitação, umidade relativa e luminosidade influenciam no estabelecimento e desenvolvimento da cultura. A faixa de temperatura ótima para desenvolvimento da cultura situa-se entre $28-30^{\circ} \mathrm{C}$, mas pode ser cultivada em regiões com temperatura variando de 15 a $35^{\circ} \mathrm{C}$. Temperatura muito baixa em período curto danifica as raízes da bananeira, dificulta a nutrição, reduz ou paralisa o metabolismo, queima a superfície foliar diminuindo a fotossíntese diminuindo de uma 
maneira geral a capacidade vegetativa e produtiva da planta (CHAMPION, 1975). Temperaturas inferiores a $12^{\circ} \mathrm{C}$ causam o distúrbio fisiológico conhecido como "chilling" ou "friagem" que afetam os tecidos dos frutos, principalmente os da casca. $\mathrm{O}$ "chilling" acontece quando a temperatura mínima noturna atinge a faixa de 4,5 a $12^{\circ} \mathrm{C}$, provocando o fechamento de estômatos e coagulação da seiva que prejudica o processo de maturação. Este distúrbio também pode acontecer durante o transporte dos cachos ou na câmara de climatização. Já em temperaturas acima da faixa ideal podem ocasionar desidratação dos tecidos principalmente em cultivos em que não se usa nenhum método de irrigação (BORGES, 2004).

\section{Precipitação}

Para o desenvolvimento pleno, quando dentro da faixa de temperatura ideal, a bananeira necessita do fornecimento constante de água. A quantidade que o pomar precisa depende do estádio de desenvolvimento da planta, número de mudas por hectare, tipo de solo, época do ano, tratos culturais e do componente genético que são os cultivares. Trabalhos experimentais em todo mundo indicam a quantidade de 1800 a $2800 \mathrm{~mm}$ por ano. No Brasil boas produtividades estão associadas a um fornecimento hídrico total de $1900 \mathrm{~mm}$ bem distribuída no ano, ou seja, contabilizando $160 \mathrm{~mm} / \mathrm{mês}$ e $5 \mathrm{~mm} / \mathrm{dia}$ (COLOMBIA, 1974; BORGES, 2004). A falta de água para planta pode determinar o fechamento dos estômatos ocasionando uma menor taxa fotossintética. Com menor acúmulo de fotoassimilados a planta forma um menor número de folhas resultando em diminuição de órgãos florais, cachos, frutos e torna a planta tardia (MANICA, 1998). A deficiência hídrica é mais grave no período de diferenciação floral e frutificação. Com severa restrição de água no solo, a roseta foliar se comprime dificultando ou impedindo o lançamento da inflorescência (CHAMPION, 1975). O suprimento hídrico está intimamente relacionado com o tipo de solo. Em solos profundos com boa capacidade de retenção de umidade o limite de precipitação de $100 \mathrm{~mm}$ por mês já seria suficiente. Em solos com menor capacidade de retenção este limite pode chegar a 180 mm/mês (SOTO BALLESTERO, 1992). O ideal seria que o solo disponibilize água não menos que $75 \%$ de sua capacidade de retenção e não mais para não provocar saturação o que seria prejudicial à aeração. Em condições naturais de chuva isso raramente ocorre, porém devem-se tomar precauções com o uso da irrigação (POSSIDIO, 1984).

\section{Umidade relativa}

A bananeira por ser uma espécie típica de regiões tropicais úmidas, apresenta desenvolvimento favorável onde a umidade relativa anual média situa-se acima de $80 \%$. A 
alta umidade favorece a emissão de folhas, prolonga a longevidade foliar, induz o lançamento da inflorescência e uniformiza a coloração dos frutos. Porém, em conjunto com chuvas e variações de temperatura, aumenta a incidência de doenças fúngicas, principalmente sigatoka amarela Mycosphaerella musicola (Moreira, 1987).

\section{Luminosidade}

A bananeira é uma planta que requer alta luminosidade e o fotoperíodo não influencia no seu crescimento e frutificação (CHAMPION, 1975). O plantio feito em local de baixa luminosidade as bainhas foliares aumentam o tamanho, os pseudocaules são mais desenvolvidos em comprimento, cachos são mais longos menos resistentes ao transporte e a planta é mais tardia para produzir (ARSCOTT, 1965). De uma forma geral regiões com alta luminosidade o cacho chega ao ponto de colheita com 85 dias após emissão floral em média. Em regiões de baixa luminosidade ou períodos de baixa luminosidade essa média sobe para algo em torno dos 100 dias após emissão floral. A atividade fotossintética é acelerada quando a iluminação encontra-se na faixa entre 2000 a 10000 lux e é reduzida quando se encontra na faixa de 10000 a 30000 lux que foi o limite superior da intensidade estudada (CHAMPION, 1975). Valores inferiores a 1000 lux são insuficientes para o bom desenvolvimento das bananeiras. Valores muito além da faixa ótima para o desenvolvimento podem provocar queima das folhas novas e da inflorescência. Quando cultivada em condições ideais de luminosidade a planta acelera seu desenvolvimento e consequentemente reduz o ciclo produtivo (MOREIRA, 1987).

SOLO

A Bananeira é cultivada em solos das mais diversas origens geológicas e com ampla diversidade das condições químicas e físicas. A quantidade de nutrientes presentes em determinados solos não é fator limitante para o cultivo, pois deficiências podem ser corrigidas com o uso de adubações. As características físicas são muito importantes porque dificilmente podem ser corrigidas e quando feitas são muito onerosas. Geralmente requere-se apenas uma exigência em qualquer solo: que seja boa a drenagem no horizonte onde se desenvolve o sistema radicular absorvente que é relativamente superficial.

O ideal do $\mathrm{pH}$ do solo para a bananeira é 6,5, porém as terras cultivadas com banana no Brasil apresentam acidez acentuada com pH muito baixo, portanto a correção dos solos ácidos é uma medida necessária para melhor aproveitamento dos nutrientes. Solos arenosos 
devem ser manejados com maior rigor, pois apresentam baixa fertilidade natural, baixa capacidade de retenção de água além de favorecerem a disseminação de nematóides (ITAL, 1990).

A matéria orgânica é importante na estrutura do solo por proporcionar boa granulação, aumentar a capacidade de armazenamento de água e a capacidade de troca de nutrientes. Solos com maiores porcentagens de matéria orgânica proporcionam um melhor desenvolvimento do sistema radicular, aumenta o diâmetro e altura do pseudocaule e produz folhas vigorosas. A cobertura do solo ajuda a controlar as plantas daninhas e diminui o ataque por nematóides e auxilia no controle da erosão. Essa matéria orgânica no solo pode apresentar um efeito semelhante ao da calagem corrigindo a acidez e neutralizando níveis tóxicos de alumínio (Al). A matéria orgânica no solo exerce excelente armazenamento de nitrogênio $(\mathrm{N})$, pois as formas minerais estão sujeitas as perdas por volatilização (amoniacal) ou lavagem (nítrica).

As realizações dos tratos culturais de forma adequada e na época correta são também de grande importância para o bom desenvolvimento e produção dos pomares. Dentre as principais atividades de manejo estão: coroamento das plantas, roçagem das entrelinhas ou aplicação de herbicidas para eliminação das plantas invasoras, manejo fitossanitário do pomar (MANICA, 1997).

\section{RECURSOS GENÉTICOS}

No melhoramento genético da bananeira alguns objetivos devem ser visados para obtenção de cultivares mais adaptados. São citados: resistência a sigatoka-negra Mycosphaerella fijiensis, sigatoka-amarela Mycosphaerella musicola, Mal-do-Panamá Fusarium oxysporum f. sp. cubense, aos diversos vírus, tolerância ao ataque dos nematóides, broca-da-bananeira Cosmopolites sordidus, originar plantas do tipo anã ou semi-anã que facilitam os tratos culturais e a colheita, plantas vigorosas de alto potencial de produção e grande potencial de adaptabilidade. Espera-se que as novas variedades possuam frutos grandes em tamanho e menor grau de curvatura, bem formados, dedos compridos, resistentes ao amassamento durante a colheita e transporte. De uma maneira geral existe predileção por plantas com menor ciclo de produção, maior número de pencas, maior número de frutos por pencas, maior peso de cacho, ou seja, características que resultem em maior produtividade (MANICA, 1997). 
Apesar do número expressivo de variedades de banana existentes no Brasil restam poucas variedades com potencial agronômico para o cultivo comercial, ou seja, que aliem alta produtividade à tolerância a pragas e doenças, ao porte reduzido, a um ciclo de produção menor e à produção de frutos com boas características sensoriais e de vida útil pós-colheita (Ramos et al., 2009). As cultivares de banana mais plantadas no Brasil são: Prata, Pacovan, Prata Anã, Maçã, Mysore, Terra e D’Angola pertencentes ao grupo AAB e utilizadas unicamente para o mercado interno. As bananas do grupo genômico AAA: Nanica, Nanicão e Grande Naine são usadas, em maioria das vezes, para exportação e são utilizadas na industrialização. Em menor escala, também são plantadas a Ouro (AA), Figo Cinza e Figo Vermelho (ABB), Caru Verde e Caru Roxa (AAA).

Dentre estas variedades Prata, Prata Anã e Pacovan são responsáveis por aproximadamente $60 \%$ da área cultivada com banana no Brasil (Embrapa Semiárido, 2009). As cultivares são reunidas em subgrupos de acordo com grupo genômico em que estão inseridas. São citadas as principais cultivares plantadas no Brasil: Nanica, Nanicão, Grand Naine pertencem ao subgrupo Cavendish. As cultivares Prata, Branca, Pacovan, Prata-anã pertencem ao subgrupo prata. As cultivares Terra e D'Angola pertencem ao subgrupo Terra.

As cultivares Prata-anã, Nanica, Nanicão e Grande Naine apresentam porte médiobaixo. Os espaçamentos simples recomendados variam de $2,5 \times 2,5 \mathrm{~m}$ a $3,0 \times 3,0 \mathrm{~m}$ para todas cultivares. As cultivares do subgrupo Cavendish apresentam média capacidade de perfilhamento comparadas com o grupo prata que apresentam boa capacidade prolífica. A cultivar Prata anã e as cultivares do subgrupo Cavendish são mais precoces completando um ciclo vegetativo por volta de 285 dias. Em relação às principais pragas e doenças que atacam os pomares de banana todas cultivares são suscetíveis ao moko Ralstonia solanacearum raça 2. Com exceção das cultivares Maçã, Mysore, Terra e D'Angola todas outras cultivares são suscetíveis a sigatoka amarela Mycosphaerella musicola. As cultivares Mysore e Ouro são moderadamente resistentes a sigatoka negra Mycosphaerella fijiensis. As cultivares do grupo Prata são suscetíveis ao Mal-do-Panamá Fusarium oxysporum f.sp. cubense por outro lado apresentam boa resistência a nematóides e a broca do rizoma Cosmopolites sordidus (Alves, 1999). Seguem na Tabela 1 os indicadores dos dois subgrupos mais cultivados no país. 
Tabela 1. Indicadores de produtividade dos dois subgrupos mais cultivados no país.

\begin{tabular}{ccc}
\hline Indicadores & Subgrupo Prata & Subgrupo Cavendish \\
\hline Peso /cacho $(\mathrm{kg})$ & 15 & 28 \\
$\mathrm{~N}^{\circ}$ frutos/cacho & $80-100$ & $200-220$ \\
$\mathrm{~N}^{\mathrm{o}}$ pencas/cacho & 8 & 11 \\
Comprimento do fruto $(\mathrm{cm})$ & 14 & 22 \\
Produtividade ton/ha/ciclo & $14(35)^{*}$ & $25(75)^{*}$ \\
\hline
\end{tabular}

Fonte: ALVES (1999), modificado.

*Para produtividade, números entre parênteses indicam uso de irrigação.

PRATA ANÃ

No final do século XIX e início do século XX já existia uma bananicultura comercial no estado de Santa Catarina. A cultura era baseada quase que exclusivamente na cultivar Branca, produtora de frutos do tipo comercial prata, de polpa branca e sabor muito agradável, mas que por sua altura era muito suscetível aos ventos. Da variedade Branca, de porte alto, surgiu por mutação espontânea uma planta de porte médio, que foi selecionada. A hipótese mais provável é que o seu surgimento teria ocorrido próximo à virada dos séculos XIX para XX, na região entre os municípios de Imaruí e Imbituba, em Santa Catarina. Outras versões indicam as proximidades de Criciúma, também no sul de Santa Catarina. O surgimento dessa cultivar despertou interesse entre os produtores, por ela apresentar características diferentes da banana branca, quanto à altura e a à resistência aos ventos. Como no local onde surgiu havia touceiras de diferentes cultivares de banana, estas características fizeram com que os agricultores imediatamente a batizassem com o nome de enxerto. A teoria hoje aceita é que a cultivar tenha se originado de uma mutação de gema da bananeira branca. A partir desta planta a cultivar foi multiplicada e distribuída pelo sul de Santa Catarina, pelos produtores que viram nela uma série de vantagens (LICHTEMBERG \& LICHTEMBERG, 2011). Posteriormente essa cultivar receberia a nomenclatura de Prata-anã.

A cultivar pertence ao grupo genômico AAB, subgrupo cultural Prata. Apresenta pseudocaule vigoroso de cor verde clara brilhante, apresenta poucas manchas escuras próximas à roseta foliar. A altura varia de 2,0 até $3,5 \mathrm{~m}$ e o pseudocaule varia de 20 a $30 \mathrm{~cm}$ de diâmetro, mas pode chegar até $50 \mathrm{~cm}$, medido a $30 \mathrm{~cm}$ da superfície do solo. A roseta é compacta, as pencas são mais juntas e as bananas são mais curtas e roliças que as da Prata. A ráquis é coberta por flores masculinas e brácteas persistentes e o botão floral (coração) é bastante desenvolvido. O cultivar é tolerante ao frio e dispensa o uso de escoramento divido ao vigor da planta (parruda). A planta é muito sensível ao Mal-da-sigatoka (Mycosphaerella musicola; Mycosphaerella fijiensis ), Mal-do-panamá (Fusarium oxysporum f.sp. cubense) e a 
broca-da-bananeira (Cosmopolites sordidus). A cultivar apresenta bom potencial de produtividade podendo chegar a 30-35 ton.ha ${ }^{-1} \cdot$ ano $^{-1}$ em condições de irrigação (ALVES, 1999).

\section{BRS CONQUISTA}

A cultivar BRS Conquista pertence ao grupo genômico AAB, subgrupo cultural Conquista. Foi obtida por mutação natural em uma população de plantas da cultivar Thap Maeo no campo experimental da Embrapa Amazônia Ocidental em Manaus-Amazonas. A cultivar é resistente ao mal-do-panamá Fusarium oxysporum f.sp.cubense, sigatoka-negra Mycosphaerella fijiensis e sigatoka-amarela Mycosphaerella musicola. Apresenta boa produtividade podendo chegar até $48 \mathrm{t}^{\mathrm{h}} \mathrm{ha}^{-1} \cdot \mathrm{ano}^{-1}$. Os frutos apresentam coloração amarelo clara, polpa creme, boa relação entre açúcares/ácidos, alta relação polpa/casca e, sobretudo aroma agradável. A cultivar apresenta pseudocaule e folhas na cor verde-clara e não apresenta manchas. A cultura apresenta porte médio. As pencas apresentam alta resistência ao despencamento. Apresenta boa tolerância aos nematóides e é suscetível ao moko-da-bananeira Ralstonia solanacearum (PEREIRA \& GASPAROTTO, 2007).

\section{ADUBAÇÃO}

A cultura da bananeira precisa de fertilização abundante devido as quantidades de elementos exportados pelos frutos serem elevadas e pela condição da maioria dos solos das regiões produtoras que são pobres em nutrientes e apresentam acidez elevada. A produtividade da cultura vem aumentando significativamente nos últimos anos com o emprego de mudas de cultivares selecionados, plantios mais densos, desbastes, prática da irrigação, controle de doenças com maior rigor e uso abundante de fertilizantes. O mercado exige frutos de alta qualidade, o produtor precisa aumentar produtividade para baixar custos, o solo geralmente não possui condições de atender as necessidades da cultura tornando obrigatória a prática rotineira de adubação (ALVES, 1999).

Experimentos com a cultura da bananeira constataram ser pequena a absorção de macronutrientes até o quarto mês após o plantio, em função do lento crescimento da planta. Do quarto mês até o florescimento o crescimento é bastante elevado, com grande acúmulo de matéria seca e de nutrientes. Após o florescimento até a colheita é estável a absorção de nutrientes (MONTAGUT \& MARTIN-PRÉVEL, 1965). 


\section{Fósforo (P)}

O fósforo é o macronutriente menos absorvido pela bananeira, porém faz parte de compostos essenciais das células vegetais como fosfato, açúcares, coenzimas intermediárias da respiração e fotossíntese. É componente de nucleotídeos utilizados no metabolismo energético das plantas (adenosina trifosfato-ATP) e no DNA e RNA (MALAVOLTA et al., 1989). A bananeira tem um patamar de maior absorção de fósforo que vai do segundo mês após o plantio ou transplante e cessa na floração, ocasião em que a planta já acumulou todo o fósforo que precisava. A partir da floração a planta passa a utilizar o fósforo que precisa retirando de outros órgãos vegetativos (MANICA, 1997). Em solos com baixo teor de fósforo as plantas apresentam raízes atrofiadas e desenvolvimento vegetativo retardado. A deficiência severa de fósforo limita a absorção de cátions e principalmente do potássio e em novos rebentos há uma forte redução da taxa de crescimento. As folhas apresentam uma coloração verde escura tendendo a azulada. Pode ocorrer uma descoloração marginal estreita irregular e demonstrar pequenas manchas pardas. Logo após, as necroses se desenvolvem em formato de dentes de serra apontados para nervura central. Casos de senescência prematura das folhas acontecem em decorrência das necroses. O peso do cacho só é influenciado em caso de carência acentuada e prolongada (ALVES, 1999).

\section{Magnésio (Mg)}

Em células vegetais os íons magnésio têm um papel específico na ativação de enzimas envolvidas na respiração, absorção iônica, fotossíntese e síntese de DNA e RNA. O magnésio é fundamental na estrutura em anel da molécula de clorofila (MALAVOLTA et al., 1989). O sintoma característico da deficiência de magnésio é a clorose entre as nervuras foliares e ocorre primeiramente nas folhas mais velhas pela translocação do elemento. Esse padrão de clorose ocorre, pois a clorofila nos feixes vasculares permanece inalterada por maior tempo que a clorofila das células entre os feixes (TAIZ \& ZEIGER, 2009).

O magnésio facilita a absorção de outros nutrientes, para se aplicar quantidades elevadas de potássio (nutriente mais requerido pela bananeira) é necessário que exista magnésio suficiente para evitar o aparecimento do distúrbio fisiológico conhecido como azulda-bananeira. O azul-da-bananeira é caracterizado por manchas pardo violáceas nos pecíolos associadas à clorose magnesiana e se manifesta quando a relação $\mathrm{K} / \mathrm{Mg}$ no solo é superior a 0,6 e nas folhas é maior que 2,0 na colheita (CORDEIRO, 2000). 
Os nutrientes nitrogênio e potássio são os mais absorvidos pela cultura da banana. Em bananal comercial irrigado no estado do Ceará foram verificadas produtividades de 24,8 t/ha e 25,9 t/ha para as variedades Prata Anã e Grande Naine, respectivamente. O acúmulo de matéria seca em Prata Anã foi de 20,1 t/ha e em Grand Naine foi de 13,4 t/ha. Os nutrientes mais absorvidos em Prata Anã foram $\mathrm{K}>\mathrm{N}>\mathrm{S}>\mathrm{Mg}>\mathrm{Ca}>\mathrm{P}$ e para a Grand Naine $\mathrm{K}>\mathrm{N}>$ $\mathrm{Ca}>\mathrm{S}>\mathrm{Mg}>\mathrm{P}$. Para os micronutrientes foi verificada a seguinte nas duas cultivares $\mathrm{Mn}>$ $\mathrm{Fe}>\mathrm{B}>\mathrm{Zn}>\mathrm{Cu}$. Foi constatado que para cada tonelada de frutos produzidos pela cultivar Prata Anã houve exportação de 1,04 kg de N; 0,19 kg de P; 4,83 kg de K; 0,10 kg de Ca; 0,28 $\mathrm{Kg}$ de $\mathrm{Mg}$ e $0,55 \mathrm{~kg}$ de $\mathrm{S}$. Com base nos dados citados e uma produtividade de $30 \mathrm{t} / \mathrm{ha}$ a quantidade de elementos exportados em $\mathrm{kg} / \mathrm{ha}$ seria de: $31,2 \mathrm{~kg}$ de $\mathrm{N} ; 5,7 \mathrm{~kg}$ de $\mathrm{P}(13,06 \mathrm{Kg}$ de $\left.\mathrm{P}_{2} \mathrm{O}_{5}\right) ; 144,9 \mathrm{~kg}$ de $\mathrm{K}\left(174,54 \mathrm{~kg}\right.$ de $\left.\mathrm{K}_{2} \mathrm{O}\right) ; 3,0 \mathrm{~kg}$ de $\mathrm{Ca} ; 8,4 \mathrm{~kg}$ de $\mathrm{Mg} ; 16,5 \mathrm{~kg}$ de $\mathrm{S}$. Dessa forma, comparando-se as quantidades de elementos exportados pelos frutos $\mathrm{e}$ as recomendações para diversos pólos produtores brasileiros observa-se que as quantidades recomendadas estão acima da exportada pelos frutos, tal fato acontece pois as recomendações são embasadas na quantidade de nutriente presente no solo e produtividade esperada, considerando que o total dos nutrientes aplicados não são integralmente absorvidos, existindo fixação pelo solo, lixiviação, volatilização. Além disso, o material orgânico que volta ao solo pode não estar decompondo e disponibilizando os nutrientes para as bananeiras (Hoffmann et al, 2007a,b).

O uso da cobertura do solo com resíduos vegetais é utilizado em muitas regiões produtoras de banana por possibilitar proteção contra erosão, reduzir a perda de água por evaporação e pela grande quantidade de nutrientes que adiciona ao solo. O próprio pomar representa uma fonte substancial de material orgânico através dos resíduos constituídos por toda a planta após a colheita do cacho, pelas folhas secas provenientes das desfolhas e pelas raízes e rizoma que se decompõem no solo. Todavia, é necessário conhecer o comportamento de decomposição dos resíduos visando que a adubação seja otimizada para desempenhar função benéfica em estágios críticos da cultura (BUDELMAN, 1988).

O uso da calagem (CaCO3) eleva o pH do solo, neutraliza o Alumínio (Al) trocável, fornece Cálcio $(\mathrm{Ca})$ e Magnésio $(\mathrm{Mg})$, eleva a saturação por bases, equilibra a relação $\mathrm{K}: \mathrm{Ca}: \mathrm{Mg}$ evitando o aparecimento do distúrbio "azul-da-bananeira", contribui para aumentar a disponibilidade de nitrogênio, fósforo, potássio, enxofre e molibdênio e melhora a atividade da microfauna do solo. $\mathrm{O}$ pH do solo sob bananeiras não tem sido muito estudado. As plantas se desenvolvem em solos com $\mathrm{pH}$ de 4,0 a 9,0, mas a faixa considerada mais adequada é de 
5,5 a 6,5. Os campos de cultivo acidificam gradativamente devido a nitrificação do amônio oriundo da mineralização dos resíduos orgânicos e principalmente da uréia e sulfato de amônio aplicados. $\mathrm{O}$ gesso agrícola $\left(\mathrm{CaSO}_{4}\right)$ reduz do teor de alumínio $(\mathrm{Al})$ no perfil devido á formação de sulfato de alumínio além de fornecer cálcio e enxofre. Em solos com baixos teores de $\mathrm{Ca}\left(<0,5 \mathrm{cmolc} / \mathrm{dm}^{3}\right)$ nas camadas subsuperficiais melhora o suprimento e desenvolvimento radicular em profundidade (CORDEIRO, 2000).

\section{IRRIGAÇÃO}

A água faz parte da constituição da bananeira e é elemento essencial para sua manutenção, desenvolvimento e produção. A quantidade de água que a planta precisa depende do seu estágio de desenvolvimento, da cultivar, das condições de solo e clima onde está sendo cultivada. A bananeira é muito sensível às condições de umidade na zona radicular e sua atividade fisiológica normal depende de uma estreita faixa de água disponível no solo. As raízes dependem diretamente da porcentagem de água no solo sendo muito sensíveis ao excesso ou falta de água. A bananeira é uma planta que mantém ritmo de crescimento e desenvolvimento contínuo, em clima tropical e com água suficientemente disponível pode emitir uma folha em intervalos de 5 a 8 dias, portanto necessita de um fornecimento hídrico permanente seja por chuva ou irrigação. O déficit hídrico em solos cultivados com bananeiras diminui o número e o crescimento das raízes, aumenta o tempo para emissão completa de uma folha, a bainha não desenvolve por completo e as folhas ficam amontoadas, o limbo dobra-se sobre a nervura central da folha e em déficit muito intenso o pecíolo pode se romper. Apesar da bananeira apresentar teor de água em torno de $90 \%$ de sua constituição, suas reservas são mínimas e podem ser consumidas em poucas horas de transpiração normal. A planta é obrigada a equilibrar constantemente as perdas nas folhas com os ganhos renovados pela absorção das raízes. A perda de água somente por transpiração pode variar em um dia de 3 a 4 mm dependendo das condições climáticas como: velocidade do vento, grau de insolação e umidade relativa. Uma plantação de bananeiras pode consumir de 900 a $1900 \mathrm{~mm}$ de água do crescimento à colheita do cacho (COLOMBIA, 1974; MANICA, 1997; BORGES, 2004).

A irrigação tem como objetivo principal suprir as necessidades hídricas da planta. Funciona integrada com outras práticas agrícolas para beneficiar a cultura, a sociedade de maneira geral e particularmente o produtor. Faz-se necessária onde os níveis pluviométricos naturais não atendem as necessidades das plantas durante seu ciclo ou parte dele (ALVES, 1999). Em regiões áridas, onde o fator limitante é a água, pesquisas são desenvolvidas visando planejar irrigações para se alcançar a máxima produção por unidade de água aplicada. 
No conceito moderno, a irrigação passou da simples aplicação de água na agricultura para um instrumento no aumento da produtividade e rentabilidade associado ao uso mínino necessário do recurso. Para tanto é preciso fazer uso de métodos de irrigação que possibilitem alta eficiência de uso da água. Alguns princípios devem ser seguidos para alcançar este nível de eficiência. Para o máximo crescimento vegetativo a transpiração de uma superfície vegetal deve ser mantida em sua capacidade potencial, a tensão máxima que água do solo deve atingir, sem prejudicar a produção, é aquela que haverá suficiente absorção de água pela planta prevenindo de progressiva deficiência hídrica. A razão entre a água evapotranspirada pela cultura e a aplicada pela irrigação deve ser próxima de 1, para se ter máxima eficiência de aplicação. Selecionar culturas e práticas culturais que visem o aumento da produtividade e a diminuição do ciclo vegetativo aumenta a eficiência de uso da água. Considerar os fatores de solo, clima, planta e suprimento de água visando sempre à obtenção da melhor função econômica (BERNARDO, 2013).

A escolha correta do método de irrigação é de muita importância dele vai depender a viabilidade econômica do investimento. Na cultura da bananeira não há restrições quanto aos métodos de irrigação de uso corrente, a escolha depende do local de cultivo, tipo de solo, tipo de clima, custo de implantação, custo de operação do sistema e mão de obra.

O sistema de irrigação por gotejamento usa o método em que a água é aplicada diretamente na região radicular em pequenas intensidades (baixa vazão) e alta frequência (turno de rega pequeno) mantendo esse solo próximo à capacidade de campo. A aplicação da água é feita por tubos perfurados com orifícios de pequeno diâmetro ou por gotejadores denominados emissores encontrados de diferentes tipos e modelos. Neste sistema as vazões aplicadas variam de 1 a $20 \mathrm{~L} / \mathrm{h}$ gota a gota, o sistema trabalha com pressões variando de 5 a 25 mca, porém a pressão de serviço da maioria dos gotejadores é em torno de 10 mca. No gotejamento a aplicação de água é na forma de "ponto fonte", a superfície do solo fica com uma área molhada de formato circular e seu volume molhado com forma de bulbo. Com os pontos de gotejamento muito próximos uns dos outros se forma uma faixa molhada contínua. A irrigação por gotejamento é usada com forma de sistema fixo constituído de tantas linhas laterais para suprir a demanda de toda a área, não havendo movimentação das linhas laterais. Entretanto somente determinado número de linhas funciona por vez com finalidade de minimizar a capacidade do cabeçal de controle (BERNARDO, 2013).

O sistema de gotejamento é caracterizado por: possibilidade de controle rigoroso da quantidade de água fornecida às plantas, grande economia de água e energia, redução da 
incidência de pragas e doenças e do desenvolvimento de plantas daninhas, possibilidade de cultivo em áreas com afloramentos rochosos e, ou, com declividades acentuadas, excelente uniformidade de aplicação de água (MANTOVANI, 2012).

A irrigação por gotejamento não molha a parte aérea da bananeira, portanto não cria um ambiente favorável ao desenvolvimento de patógenos, permite maior produtividade, visto que a irrigação localizada, por ser fixa, permite uma frequência elevada de aplicação de água resultando em menores variações nos níveis de umidade do solo. No caso da bananeira, além de maiores produtividade, os frutos desenvolvem-se mais uniformemente, resultando em melhor qualidade (OLIVEIRA, 2000).

No caso do gotejamento as principais limitações são: entupimento dos emissores, causado geralmente pelo uso de água contendo partículas minerais ou orgânicas; concentração da distribuição do sistema radicular provocado pela manutenção constante de um bulbo úmido onde as raízes tendem a permanecer e com isso há diminuição da estabilidade de árvores podendo ocorrer tombamentos (BERNARDO, 2013).

Para o correto planejamento e manejo de um sistema de irrigação o cálculo da quantidade de água necessária a uma cultura é o parâmetro mais importante. Na determinação da quantidade de irrigação necessária a evapotranspiração e a precipitação efetiva são os parâmetros mais importantes. Em regiões onde a precipitação efetiva é pouco expressiva ou os cultivos são realizados em épocas secas a quantidade de irrigação necessária é baseada unicamente na evapotranspiração. A evapotranspiração é a soma dos componentes de transpiração e evaporação durante determinado período. Sua aferição é de grande importância, pois torna visualizável o consumo de água pelas plantas e consequentemente a lâmina de irrigação a ser aplicada pelo sistema (MANTOVANI, 2012). 


\section{REFERÊNCIAS BIBLIOGRÁFICAS}

ALVES, E. J. A cultura da banana: aspectos técnicos, socioeconômicos e agroindustriais. Brasília: Embrapa-SPI/ Cruz das Almas: Embrapa-CNPMF.1997. 585p.

SANTOS, C. E. dos (et al), Anuário brasileiro da fruticultura. Santa Cruz do Sul: Editora Gazeta. 2013. 136p.

REETZ, E. R (et al), Anuário brasileiro da fruticultura. Santa Cruz do Sul: Editora Gazeta Santa Cruz, 2015. 104p.

ARSCOTT, T.; BHANGOO, M.S.; KARON, M.L. Irrigation Investigations of the Giant Cavendishi Banana - A note on the Relationship Between Bunch Weight and Quantity of Supplemental Irrigation. Tropical Agriculture, v 42, n 4, 1965. p.367-68.

BERNARDO, S.; SOARES, A. A.; MANTOVANI, E. C. Manual de irrigação. 8 ed. Viçosa: Editora UFV. v. 1, 2013. 630p.

BORGES, A. L. ; OLIVEIRA, A. M. G. . Nutrição, calagem e adubação. In: CORDEIRO, Z. J. M. Banana- Produção aspectos técnicos. 1ed. Brasília - DF: Embrapa Comunicação para Transferência de Tecnologia. v.1, 2000. p. 47-59.

BORGES, A. L.; SOUZA, L. S. Exigências climáticas. In: O cultivo da bananeira. Embrapa Mandioca e Fruticultura. Cruz das Almas, BA. 2004. p.15-22.

BUDELMAN, A. The composition of leaf mulches of Leucaena leucocephala, Gliricia sepium and Flemingia macrophylla under humid tropical conditions. Agroforest Systems. v. 7.1988.

CHAMPION, J.. El plátano. Barcelona, BLUME. 1975. 247p.

CHAMPION, J. Les bananiers et leur culture. I. Botanique et génétique. Paris: SETCO. 1967. 214p.

CHRISTOFIDIS,D. A água e a crise alimentar. Disponível em: <www.iica.org.br/Aguatrab/ Demetrios20Christofidis/P2TB01.htm. 14p>. Acesso em: jan. 2015. 1997.

COLOMBIA. Cultive bien el plátano. Bogotá, F.N.C.C., 40 p. (Boletim de extension $\mathrm{n}^{\circ}$ 49). 1974. 40p.

CORDEIRO, Z.J. Banana - Produção: aspectos técnicos. Embrapa Comunicação para transferência de tecnologia. 2000. 143p.

DONATO, S.L.R.; et al. Estado nutricional de bananeiras tipo Prata sob diferentes sistemas de irrigação. Pesquisa Agropecuária Brasileira. v. 4, 2010. p. 980-988.

EMBRAPA Semiárido. Sistema de Produção de Banana Irrigada. Sistemas de Produção, 4.ISSN1807-0027.Versãoeletrônicajul2009.Disponívelem:

$<$ http://sistemasdeproducao.cnptia.embrapa.br/FontesHTML/Banana/BananeiraIrrigada/cultiv ares.htm>. Acesso em: jan. 2015. 
FAO. FAOSTAT. In: Food and agriculture organization of the United Nations. 2013. Disponível em: <http://faostat.fao.org/site/567/DesktopDefault. aspx?PageID=567\#ancor>. Acesso em: 7 jan. 2015.

FIGUEIREDO, F. P. et al. Produtividade e qualidade da banana prata anã, influenciada por lâminas de água, cultivada no Norte de Minas Gerais. Campina Grande, PB. Revista Brasileira de Engenharia Agrícola e Ambiental. v.10, n.4,2006. p.798-803.

FURTINI NETO A. E.; et al. Fertilidade do solo. 1 ed. , ESAL/FAEPE. Lavras, MG.2001 $252 \mathrm{p}$.

GALAN SAUCO, V.; SAMARIM, J. G.; CARBONELL, E. Estudio de La práctica del deshijado y la fenología de la platanera em la isla de Tenerife. I- Introducción y revisión bibliográfica. Fruits, Paris, v.39, n.7, 1984. p.453-458.

HOFFMANN R. B.; et al. Acúmulo de matéria seca e de macronutrientes em cultivares de bananeira irrigada. Revista Brasileira de Fruticultura. n. 32, 2010. p. 268-275.

HOFFMANN, R.B.; OLIVEIRA, F.H.T.; SOUZA, A.P.; GHEYI, H.R.; MEDEIROS, J.S.; SILVA, M.B. Acúmulo de matéria seca, absorção e exportação de macronutrientes em seis cultivares de bananeira irrigada. Congresso Brasileiro de Ciência do Solo. 31. 2007a.

HOFFMANN, R.B.; SOUZA JÚNIOR, R.F.; SANTOS, H.C.; SOUZA, J.V.S.; OLIVEIRA, F.H.T. Acúmulo de matéria seca, absorção e exportação de micronutrientes em seis cultivares de bananeira irrigada. Congresso Brasileiro de Ciência do Solo. 31. 2007b.

ITAL. Banana: cultura, matéria prima, aspectos econômicos. 3 ed. Campinas: ITAL. (ITAL. Frutas Tropicais, 3). 1990. 302p.

JAIMEZ, R.E.; RADA, F.; GARCIA-NUNEZ, A.; AZÓCAR, A. Seasonal variations in leaf gas exchange of plantain cv. Hartón (Musa AAB) under different soil water conditions in a humid tropical region. Scientia Horticulturae, v.104, 2005.p.79-89.

Levantamento Sistemático da Produção Agrícola-IBGE. Rio de Janeiro. v.28, n. 12, p. 88. 2014.

LICHTEMBERG L.A.; LICHTEMBERG P.S.F. Avanços na bananicultura brasileira. Revista brasileira de fruticultura. Jaboticabal - SP, Volume Especial, E. 029-036, outubro 2011.

MALAVOLTA, E.; Vitti, G.C.; OLIVEIRA, S.A. Avaliação do estado nutricional das plantas: princípios e aplicações. Piracicaba, SP: Associação Brasileira para Pesquisa do Potássio e do Fósforo. 1989. 201p.

MANICA, I. Bananas: do plantio ao amadurecimento. Porto Alegre: Cinco continentes. 1998. 99p.

MANICA, I. Fruticultura Tropical 4, Banana. Editora Cinco Continentes. Porto Alegre. 1997. 485p.

MANTOVANI, E. C.; BERNARDO, S.; PALARETTI, L.F. . Irrigação - Princípios e Métodos. 3 ed. Viçosa: Editora UFV. v. 1, 2012. 355p. 
MATSUURA, F. C. A. U. et al. Marketing de banana: preferências do consumidor quanto aos atributos de qualidade dos frutos. Revista Brasileira de Fruticultura. Jaboticabal, SP. v. 26, n. 1, 2004. p. 48-52.

MEDINA, J.C. Cultura. In: ITAL (Campinas, SP). Banana: Cultura, matéria-prima, processamento e aspectos econômicos. 2 ed. Campinas,SP: (ITAL. Série Frutas Tropicais 3). 1990. p. 1-131.

MONTAGUT, G.; MARTIN-PREVEL, P. Besoins en engrains dês bananeraies antillaises. Fruits, Paris. v. 20, n. 6, 1965. p. 265-273.

MOREIRA, R. S. Banana: teoria e prática de cultivo. Campinas, SP: Fundação Cargill. 1987. 335p.

MOREIRA, R. S. Curso de bananicultura. São Gonçalo. Minter. 1975. 95p.

NOVAIS R. F. et al. Fósforo. In: Novais R. F.; Alvarez V. H.; Barros N. F.; Fontes R. L. F.; Cantarutti R. B.; Neves, J. C. L. Fertilidade do solo. Sociedade Brasileira de Ciência do Solo. 1. ed. Viçosa, MG. 2007.p. 471-550.

OLIVEIRA, S. L. de. Irrigação e Fertirrigação. In: CORDEIRO, Z. J. M. Banana. Produção: aspectos técnicos. 1ed. Brasília, DF: Embrapa. v. 1, 2000. p. 60-73.

PEREIRA J.R.C.; GASPAROTTO, L. Cultivar de bananeira-BRS Conquista. 2007.

PERRIER, X.; LANGHEB, E. De.; DONOHUEC, M.; LENTFERD, C. et al. Multidisciplinary perspectives on banana (Musa spp.) domestication. Panamá: PNAS Early Edition. v. 108, n. 28, 2011. p.11311-11318.

POSSIDIO, E.L. Demanda de água em bananeira. Petrolina: Embrapa-CPATSA (Documentos, 5). 1984. 36p.

RAMOS, D. P.; LEONEL, S.; MISCHA, M.M.; DAMATTO JÚNIOR, E.R. Avaliação de genótipos de bananeira em Botucatu - SP. Revista Brasileira de Fruticultura. Jaboticabal, SP. v. 31, n. 4, 2009. p.1092-1101.

RANGEL, A.; et al. Cultura da banana. 2. ed. Campinas, SP: CATI. 2002. 91 p.

PINHEIRO, A. C. M.; et al. Amadurecimento de bananas 'maçã' submetidas ao 1meilciclopropeno (1-MCP). Revista Brasileira de Fruticultura. Jaboticabal, SP. v. 29, n. 1, 2007.p.1-4.

ROBINSON, J.C.; GALÁN SAÚCO, V. Bananas and plantains. Crop production science in horticulturae series, 19. 2 ed. Oxford: CAB International. 2010. 311p.

SANTANA, M. A. ; ALMEIDA, C. O. ; SOUZA, J. S.. Custo e rentabilidade. In: Ana Lúcia Borges; Luciano da Silva Souza. (Org.). O cultivo da bananeira. Cruz das Almas - BA: Embrapa Mandioca e Fruticultura Tropical. 2004. 279p.

SARAIVA, L. de A.; CASTELAN, F. P.; SHITAKUBO, R.; HASSIMOTO, N. M. A.; PURGATO, E.; CHILLET, M.; CORDENUNSI, B. R. Black leaf streak disease affects starch metabolism in 
banana fruit. Journal of Agricultural and Food Chemistry, Easton, n. 61, 2013 p. $5582-5589$.

SHEPHERD, K.; DANTAS, J.LL.; ALVES, E.J. Melhoramento Genético da Bananeira. Informe Agropecuário, Belo Horizonte, v.12, 1986. p.11-19.

SILVA, L. B.; et al. Comportamento vegetativo de cultivares de banana sob diferentes lâminas de irrigação. Pesquisa Agropecuária Tropical. v. 32. n. 2. 2004. p. 93-98.

SILVA, S. de O.; CARVALHO, P.C.L.de; SHEPHERD. K.; ALVES, E.J.; OLIVEIRA, C.A.P.de; CARVALHO, J.A.B.S. Catálogo de Germoplasma de Bananeira (Musa spp.). Embrapa Mandioca e Fruticultura, Cruz das Almas-BA,1999.100p.

SIMMONDS, N. W. Los platanos. Barcelona: Blume, 1973. 539 p.

SIMMONDS, N.W.; SHEPHERD, K. The taxonomy and origins of the cultivated bananas. The journal of the Linnean Society of London, London, v 55, 1955. p.302-312.

SKUTCH, A. F. On development and morphology of the leaf of the banana. American Journal of Botany, Ames, n.17, 1930. p. 252-271.

SOTO BALLESTERO, M. Bananos: cultivo y comercialización. 2 ed. San José, Costa Rica: Litografia e Imprenta LIL, 1992. 674 p.

STOVER, R. H.; SIMMONDS, N.W. Bananas. 3. Ed. Englad: Longman Scientific \& Technical, 1987. p. 1-50.

SUMMERVILLE, W. A. Studies on nutrition as qualified by development in Musa Cavendish L. The Queensland Agric. Sci. 1:1-149, 1984.

TAIZ, L.; ZEIGER, E. Fisiologia vegetal. 4.ed. Porto Alegre: Artmed, 2009. 848p.

VOSSELEN, V. A.; et al. Assessing water consumption of banana: Traditional versus modelling approach. Agricultural Water Management, v. 74. 2005. p. 201-218. 


\section{CAPÍTULO 1}

AVALIAÇÃO DA PRODUTIVIDADE INICIAL E CARACTERES AGRONÔMICOS DA CULTIVAR DE BANANEIRA 'PRATA ANÃ' EM FUNÇÃO DE DIFERENTES NÍVEIS DE ÁGUA E ADUBAÇÃo FOSFATADA. 


\section{Resumo}

A bananeira precisa, para bons índices de produtividade, de uma satisfatória e permanente disponibilidade de água e nutrientes no solo. Sendo assim, o objetivo deste trabalho foi avaliar a produtividade inicial e qualidade de frutos da cultivar de bananeira 'Prata Anã', em primeiro ciclo, sob diferentes níveis de fósforo e volumes de irrigação, no Distrito Federal. Foram utilizados cinco volumes de irrigação 1.090 - 2.177 - 4.300 - 6.540 8.720 litros.cova ${ }^{-1}$, e cinco doses de $\mathrm{P}_{2} \mathrm{O}_{5} 0-50-100-150-200 \mathrm{Kg}$.ha ${ }^{-1}$. O experimento foi conduzido em delineamento em blocos casualizados e arranjo em parcelas subdivididas. Foi avaliada a produtividade inicial $(\mathrm{PPH})$, número de cachos por hectare $(\mathrm{NCH})$, número médio de pencas por cacho (NMPC), número médio de bananas por cacho (NMBC), peso médio de bananas (PMB), número médio de bananas por penca (NMBP), comprimento médio de bananas $(\mathrm{CMB})$, diâmetro médio de bananas (DMB), relação comprimento/diâmetro $(\mathrm{CD}) \mathrm{e}$ firmeza média da polpa (FMP). Os dados coletados foram submetidos à análise de variância e á analise de regressão polinomial. Foram verificados efeitos significativos dos tratamentos na análise de todas variáveis com exceção da FMP. Os níveis de água apresentaram diferenças significativas em todas variáveis, a exceção de NMBP, CD e FMP. As doses de fósforo não apresentaram diferenças significativas, a exceção da relação $\mathrm{CD}$. A interação água $\mathrm{x}$ fósforo foi significativa em todas variáveis, a exceção de PPH, PMB, CD e FMP. Os volumes de 6.540 e 8.720 L.cova $^{-1}$ proporcionaram maiores valores para os caracteres relacionados à produtividade e qualidade de frutos. $\mathrm{O}$ uso de $\mathrm{P}_{2} \mathrm{O}_{5}$ parcelado no solo proporcionou aumento na relação $\mathrm{C} / \mathrm{D}$, com efeito linear indicando aumento do comprimento e diâmetro do fruto. $\mathrm{O}$ número de cachos aumentou na presença de doses de água com doses de fósforo. O número médio de pencas por cacho e número médio de bananas por cacho apresentaram maiores valores com a interação água versus fósforo.

Palavras chave: 'Prata Anã', volumes de irrigação, doses de $\mathrm{P}_{2} \mathrm{O}_{5}$ 


\begin{abstract}
Banana needs, for good productivity rates, a satisfactory and permanent availability of water and nutrients in the soil. The objective of this study was to estimate the productivity and fruit quality of banana cultivar, Prata Anã, first cycle under different levels of phosphorus and irrigation volumes in the Distrito Federal. Five volumes of irrigation were used: 1090, 2177, 4300, 6540, 8720 liters.pit ${ }^{-1}$ and five doses of $\mathrm{P}_{2} \mathrm{O}_{5}:$ 0, 50, 100, 150, $200 \mathrm{Kg} \cdot \mathrm{Ka}^{-1}$. The experiment was conducted in a randomized block design and a split plot arrangement. Productivity was estimated (PPH), the number of bunches per hectare $(\mathrm{NCH})$, the average number of bunches per bunch (NMPC), the average number of bananas per cluster (NMBP), the average weight of bananas (PMB), the average number by bunch of bananas (NMBC), banana the average length (CMB), diameter medium banana (DMB), the length/diameter (CD) and the average firmness (FMP). Data were subjected to analysis of variance and will analyze polynomial regression. Significant treatment effects were observed in the analysis of all variables except for the FMP. Water levels showed significant differences in all variables, except for NMBP, CD and FMP. The phosphorus levels were not significantly different, except for the $C D$. The interaction water $x$ phosphorus was significant in all variables, except PCH, PMB, CD and FMP. The volumes of 6.540 and $8.720 \mathrm{~L}^{-p^{-1}}{ }^{-1}$ provided highest values for the productivity and fruit quality. The use of $\mathrm{P}_{2} \mathrm{O}_{5}$ shared on the land provided an increase in $\mathrm{CD}$, with a linear effect showing an increase in length and diameter of the fruit. The number of brunch increased in the presence of water doses of phosphorus. The median number of hands per bunch and median number of bananas per bunch presented highest values with water interaction versus phosphorus.
\end{abstract}

Keywords: Prata Anã, irrigation volumes, $\mathrm{P}_{2} \mathrm{O}_{5}$ doses. 


\section{INTRODUÇÃO}

A bananicultura possui papel de destaque na fruticultura brasileira e quando somada com a produção citrícola representam $60 \%$ do mercado consumidor nacional (ANUÁRIO BRASILEIRO DA FRUTICULTURA, 2013). Além da importância econômica e social, por gerar renda e evitar o êxodo rural, esta fruta possui grande valor nutricional como fonte de vitaminas $\mathrm{A}, \mathrm{B}$ e altos teores de potássio.

Para consumo no mercado interno existe a prevalência de cultivo de bananeiras do subgrupo Prata com destaque para a cultivar Prata-anã que por tradição possui boa aceitação no mercado (DONATO et al., 2009).

A bananeira é uma planta herbácea de grande porte e rápido crescimento, em condições de cultivo adequado chega a produzir 300 toneladas de matéria fresca por hectare por ano. Dos nutrientes absorvidos grande parte volta ao solo e é reciclado, porém ainda é alta a necessidade de adubação para repor as quantidades extraídas pela colheita e nutrientes perdidos durante o ciclo no solo (LICHTEMBERG \& LICHTEMBERG, 2011). Dentre os macronutrientes, o fósforo é o menos exigido pela cultura. Os nutrientes mais absorvidos pela bananeira seguem a seguinte ordem: $\mathrm{K}>\mathrm{N}>\mathrm{S}>\mathrm{Mg}>\mathrm{Ca}>\mathrm{P}$ (HOFFMANN et al, 2010). Apesar de o fósforo ser o macronutriente menos absorvido por ciclo da cultura é componente importante das vias metabólicas de fotossíntese, respiração e nucleotídeos componentes do RNA e DNA (TAIZ \& ZEIGER, 2009).

A cultura da banana possui grande demanda hídrica e o crescimento e produtividade tendem a responder linearmente a transpiração que depende diretamente da água disponível no solo passível de ser controlada pelo uso da irrigação (COELHO et al., 2006). Por ser uma cultura exigente em água a deficiência hídrica causa redução na clorofila e morte prematura das folhas. Este déficit torna-se ainda mais grave no período de iniciação floral e frutificação, pois com menor área foliar e redução na produção de fotoassimilados fica prejudicado o florescimento e enchimento de frutos consequentemente menor produção (TURNER et al., 2007).

Informações gerais e regionalizadas tendem a aumentar a eficiência de cultivo aumentando a produtividade e suprindo a demanda interna. Bons índices de produção e qualidade de frutos podem gerar aumento de renda através da exportação. A avaliação do comportamento de cultivares de bananeiras em diferentes ecossistemas é essencial para subsidiar o planejamento dos produtores locais. Por essas razões foi conduzido trabalho com 
objetivo de avaliar a produtividade inicial e qualidade de frutos da cultivar Prata-anã, em primeiro ciclo, submetida a diferentes doses de fósforo e diferentes volumes de água, no Distrito Federal-DF. 


\section{MATERIAIS E MÉTODOS}

\section{LOCALIZAÇÃO E CARACTERÍSTICAS DA ÁREA}

O experimento foi conduzido, no período de dezembro de 2012 a dezembro de 2014, na Fazenda Experimental Água Limpa (FAL-UnB) de propriedade da Universidade de Brasília, numa área de coordenadas geográficas médias em torno de $15^{\circ} 56^{\prime} \mathrm{S}$ e $47^{\circ} 56^{\prime} \mathrm{W}$ e altitude de $1.080 \mathrm{~m}$. A classificação climática da região, pelo método de Köppen, é do tipo CWa e apresenta duas estações climáticas bem definidas: a estação seca, que se inicia no final do mês de abril e se estende até setembro, e uma estação chuvosa, que se inicia em outubro e vai até meados do mês de abril. O solo da área do experimento é um Latossolo VermelhoAmarelo de relevo suave com $4 \%$ de declividade.

Apesar do Distrito Federal apresentar uma temperatura média favorável ao cultivo de banana em quase toda totalidade do ano, há ocorrência de temperaturas noturnas subótimas, abaixo de $12^{\circ} \mathrm{C}$ (ANEXO) durante o inverno seco (junho a setembro), coincidente com florescimento e enchimento de frutos de parte das plantas, o que favorece a ocorrência de "chilling", resultando em baixa produtividades. De acordo com Moreira (1987) a temperatura mínima suportada pela cultura está na casa dos $15^{\circ} \mathrm{C}$, dessa forma as plantas podem ter tido o seu desenvolvimento limitado pela baixa temperatura, não respondendo aos tratamentos. As baixas temperaturas, coincidindo com as fases de estabelecimento da cultura podem desfavorecer o desenvolvimento das plantas.

Amostras do solo foram coletadas nas profundidades de 0-20 cm e $20-40 \mathrm{~cm}$, para determinação das características químicas e físicas. Os resultados podem ser visualizados na Tabela 2.

De acordo com a análise físico-química, o solo onde o experimento foi implantado apresentou um elevado teor de argila (602,3 g. $\mathrm{Kg}^{-1}$ de solo), sendo classificado como um solo argiloso, de acordo com o triângulo textural proposto por Lemos \& Santos (1984). Contudo, segundo Campos et al., (2010), esse Latossolo apresenta uma condutividade hidráulica saturada $\left(\mathrm{K}_{\mathrm{s}}\right)$ de $12,7 \mathrm{~cm} \cdot \mathrm{h}^{-1}$, caracterizando-se como sendo de velocidade de infiltração básica (VIB) muito alta (VIB > 3,0 cm.h ${ }^{-1}$ ), segundo Bernardo et al., 2013. 
Tabela 2: Resultado da análise físico-química do Latossolo Vermelho-Amarelo utilizado no experimento. Brasília, 2014.

\begin{tabular}{|c|c|c|c|c|c|c|c|c|c|}
\hline Prof & $\overline{\mathrm{pH}}$ & $\overline{\mathrm{pH}}$ & $\mathrm{H}+\mathrm{Al}$ & $\mathrm{Al}$ & $\mathrm{P}$ & $\overline{\mathrm{K}}$ & $\mathrm{Ca}$ & $\mathrm{Mg}$ & M.O \\
\hline $\mathrm{Cm}$ & $\mathrm{H}_{2} \mathrm{O}$ & $\mathrm{CaCl}_{2}$ & $\mathrm{Me} / 100 \mathrm{cc}$ & ---- & ------ & $--m$ & ----- & ---- & $(\%)$ \\
\hline $0-20$ & 5,45 & 4,96 & 5,68 & 1,26 & 0 & 62 & 306 & 62,4 & 3,9 \\
\hline $20-40$ & 5,42 & 4,96 & 5,52 & 1,08 & 1,33 & 32 & 210 & 80,4 & 3,08 \\
\hline \multicolumn{10}{|c|}{ Granulometria } \\
\hline \multicolumn{3}{|c|}{ Areia } & \multicolumn{3}{|c|}{ Silte } & & \multicolumn{2}{|c|}{ Argila } & \\
\hline \multicolumn{10}{|c|}{ 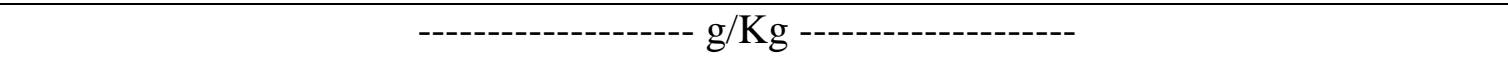 } \\
\hline \multicolumn{3}{|c|}{277,35} & \multicolumn{3}{|c|}{120,29} & & \multicolumn{2}{|c|}{602,36} & \\
\hline
\end{tabular}

INSTALAÇÃO DO EXPERIMENTO

No ensaio, foram utilizadas mudas da variedade de banana Prata Anã, oriunda de cultura de tecidos. Estas, inicialmente, foram plantadas em sacos de polietileno, com capacidade de 2 litros de solo, e conduzidas em um viveiro telado da FAL-UnB. Durante esse período, as mudas foram irrigadas por aspersão convencional 3 vezes por semana, e com uma lâmina liquida de $3 \mathrm{~mm}$, totalizando uma lâmina liquida de irrigação de $9 \mathrm{~mm}$. Além disso, foram desbastadas folhas com sintomas de doenças e amareladas.

As mudas foram transplantadas em uma área previamente preparada por meio de gradagem. As covas foram abertas, com o auxílio de retroescavadeira, com um espaçamento de 3,0 m x 3,0 m e dimensões de 1,0 m x 1,0 m x 1,0 m. De acordo com os resultados da análise de solo foi realizada a correção do solo com 200 gramas de calcário dolomítico por cova e a adubação de plantio com 500 gramas de Superfostato Simples, 400 gramas de Termofosfato Magnesino e 50 gramas de FTE por cova. As doses dos nutrientes adicionados ao solo pela adubação de plantio podem ser visualizadas na Tabela 3.

Tabela 3: Doses dos nutrientes adicionados ao solo pela adubação de plantio da cultivar 'PRATA ANÃ' em um ensaio de campo sob latossolo Vermelho-Amarelo.

\begin{tabular}{|c|c|c|c|c|c|c|c|c|c|c|}
\hline $\mathrm{Cao}$ & $\mathrm{MgO}$ & $\mathrm{P}_{2} \mathrm{O}_{5}$ & $S$ & $\mathrm{~B}$ & $\mathrm{Cu}$ & $\mathrm{Mn}$ & $\mathrm{SiO}$ & $\mathrm{Zn}$ & $\mathrm{Fe}$ & Mo \\
\hline & & - & & 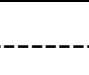 & 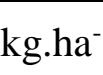 & & & & & \\
\hline 44,7 & 64,3 & 178 & 44 & 0,54 & 0,666 & 2,42 & 44,4 & 7,39 & 1,92 & 0,055 \\
\hline
\end{tabular}

Após o transplantio das mudas, foi instalado o sistema de irrigação que foi composto por 4 unidades operacionais. Cada unidade operacional foi disposta de 40 linhas laterais, sendo 2 linhas para cada fileira de plantas, e 2 linhas de derivação. Cada linha lateral foi constituída por tubos de polietileno com diâmetro interno de $16 \mathrm{~mm}$. Nas linhas laterais foram 
inseridos gotejadores cujas vazões são de 2, 4 e 8 litros por hora. Esses gotejadores foram dispostos para possibilitar as vazões de 4 ( 2 gotejadores de 2 litros por hora), 8 (4 gotejadores de 2 litros por hora), 16 (4 gotejadores de 4 litros por hora), 24 (2 gotejadores de 8 litros por hora mais 2 gotejadores de 4 litros por hora) e 32 (4 gotejadores de 8 litros por hora) litros por hora. Nas linhas de derivação foram utilizados tubos de PVC soldável com o diâmetro interno de $32 \mathrm{~mm}$.

Além disso, são partes integrantes do sistema uma linha principal, um cabeçal de controle e um conjunto moto-bomba. Na linha principal, foram utilizados tubos soldáveis de PVC com diâmetro interno de $50 \mathrm{~mm}$. O cabeçal de controle foi composto por um filtro de discos de 120 mesh e capacidade de filtragem de $12 \mathrm{~m}^{3} \cdot \mathrm{h}^{-1}$, quatro curvas de $90^{\circ}$ com diâmetro de $50 \mathrm{~mm}$ e dois registros de gaveta. O conjunto moto-bomba foi constituído por um motor trifásico de $10 \mathrm{cv}$ e uma bomba centrífuga. Também fizeram parte desse conjunto, uma válvula de pé com crivo, um mangote de sucção de diâmetro interno de $62 \mathrm{~mm}$, uma curva de $90^{\circ}$, um registro de gaveta e uma válvula de retenção.

Pela avaliação dos índices de dano econômico e pela realidade de pouco uso de agrotóxicos pela agricultura familiar do Distrito Federal não houve necessidade de aplicação de defensivos agrícolas para o controle de pragas e doenças. Contudo, o controle de plantas daninhas foi realizado por meio da aplicação do herbicida Paraquat (200g i.a./L) na dosagem de 2 litros por hectare realizado quando as plantas daninhas apresentavam-se em nível de controle. As pulverizações foram realizadas utilizando-se de pulverizador costal com capacidade de armazenar 20 litros de calda. Folhas amareladas e com sintomas de doenças foram eliminadas. No período inicial do desenvolvimento das plantas não houve o desbaste dos perfilhos. Posteriormente o desbaste foi realizado com finalidade de adequar a condução do pomar.

\section{DELINEAMENTO E CONDUÇÃO EXPERIMENTAL}

O experimento foi conduzido em 4 blocos inteiramente casualizados e 25 tratamentos conforme disposto em anexo. $\mathrm{O}$ arranjo experimental foi em parcelas subdivididas, sendo a parcela formada pelos 5 volumes de irrigação $(\mathrm{V})$ e as subparcelas formadas pelos 5 níveis de adubação fosfatada (P). Cada subparcela consistiu-se de 4 covas úteis, totalizando 400 covas.

Dentre os macronutrientes primários exigidos pelas plantas, o fósforo $(\mathrm{P})$ foi escolhido como fonte de variação para a variedade Prata Anã. Os níveis de P utilizados e as doses do demais nutrientes, nitrogênio (N) e potássio (K) estão descritos na Tabela 4. As doses de N, P 
e $\mathrm{K}$ foram obtidas com a média das recomendações de adubação para bananeira dos estados de Goiás (CFSG, 1988), Minas Gerais (CFSEMG, 1998), Santa Catarina (CFS, 2004) e São Paulo (Raij et al., 1996).

As adubações foram realizadas em cobertura mensal e de forma manual, o que possibilitava a variação nas doses de P. Os adubos foram aplicados em círculo a uma distância de $50 \mathrm{~cm}$ do pseudocaule da planta. Os fertilizantes utilizados como fonte de $\mathrm{N}, \mathrm{P}$ e $\mathrm{K}$ foram uréia, superfosfato simples e cloreto de potássio, respectivamente. As doses dos nutrientes N, $\mathrm{P}$ e K aplicados em cobertura podem ser visualizadas na Tabela 4.

Tabela 4: Doses de nutrientes N, P e K utilizados em cobertura na Banana 'PRATA ANÃ' em um ensaio de campo sob um Latossolo Vermelho-Amarelo.

\begin{tabular}{ccc}
\hline Níveis de $\mathrm{P}_{2} \mathrm{O}_{5}\left(\mathrm{~kg}_{\mathrm{h}} \mathrm{ha}^{-1}\right)$ & Dose de $\mathrm{N}\left(\mathrm{Kg}^{-1} \mathrm{ha}^{-1}\right)$ & Dose de $\mathrm{K}_{2} \mathrm{O}\left(\mathrm{Kg}^{-h^{-1}}\right)$ \\
\hline 0 & & \\
50 & 163 & \\
100 & & \\
150 & & \\
200 & & \\
\hline
\end{tabular}

O manejo da irrigação teve início logo após o final do período chuvoso e foi estendido até o início da estação chuvosa de cada ano. Portanto, no ano de 2013, as irrigações foram realizadas de 01 de julho a 10 de outubro. No ano de 2014, o intervalo em que ocorreu a irrigação foi de 01 de maio a 30 de novembro. Mesmo em período chuvoso se ocorresse alguma estiagem prolongada a irrigação suplementar era retomada. O turno de rega, nos meses irrigados, foi de 2 dias permanecendo constantes em ambos os anos. No entanto, o tempo de irrigação e consequentemente a dose de água foi variável de acordo com o estágio de desenvolvimento da cultura.

O número total de irrigações, o tempo de irrigação, bem como os volumes de água aplicados nos anos de 2013 e de 2014 estão descritos na Tabela 5. O aumento no tempo de irrigação visou o ajuste dos volumes de água aplicados na bananeira de acordo com o coeficiente da cultura $(\mathrm{Kc})$ na tentativa de obter volumes deficientes, adequado e em excesso em relação a demanda hídrica da cultura.

Devido à ocorrência de veranicos, período de seca dentro da estação chuvosa, ocorreu o uso da irrigação suplementar quando a precipitação pluvial semanal foi menor que $30 \mathrm{~mm}$ nos meses de janeiro e fevereiro de 2014. A obtenção de colheitas economicamente viáveis 
está relacionadas a precipitações de 100 a 180 mm.mês ${ }^{-1}$ (ALVES,1999). Logo, 6 irrigações foram realizadas no mês de janeiro e 2 irrigações no mês de fevereiro, conforme descrito na Tabela 5. O controle da precipitação pluvial foi de acordo com os dados meteorológicos oriundos da estação de agrometeorologia da FAL-UnB localizada próxima ao experimento.

Tabela 5: Volumes de irrigação utilizados, em função da vazão aplicada por cova, do número total de irrigações, tempo de irrigação e evapotranspiração de referência $\left(\mathrm{ET}_{0}\right)$ nos períodos irrigados para Brasília nos anos de 2013 e 2014.

\begin{tabular}{|c|c|c|c|c|c|c|c|c|}
\hline \multirow{3}{*}{ Mês/ano } & \multirow{3}{*}{$\begin{array}{c}\mathrm{N}^{\circ} \text { de } \\
\text { irrigações/ } \\
\text { mês }\end{array}$} & \multirow{3}{*}{$\begin{array}{l}\text { Evapotranspiração de } \\
\text { referência - ET } 0 \text { (mm) } \\
\text { nos períodos de } \\
\text { irrigação }\end{array}$} & \multirow{3}{*}{$\begin{array}{l}\text { Tempo de } \\
\text { irrigação } \\
\text { em horas }\end{array}$} & \multicolumn{5}{|c|}{$\begin{array}{c}\text { Vazões utilizadas por cova } \\
\text { (Litros/hora) }\end{array}$} \\
\hline & & & & 4 & 8 & 16 & 24 & 32 \\
\hline & & & & \multicolumn{5}{|c|}{ Volumes aplicados por cova (litros) } \\
\hline $\mathrm{Jul} / 2013$ & 16 & 79,89 & 1,00 & 64 & 128 & 256 & 384 & 512 \\
\hline Ago/2013 & 15 & 103,19 & 1,25 & 75 & 150 & 300 & 450 & 600 \\
\hline Set/2013 & 15 & 107,87 & 1,50 & 90 & 180 & 360 & 540 & 720 \\
\hline Out/2013 & 6 & 25,87 & 1,75 & 42 & 84 & 168 & 252 & 336 \\
\hline Jan/2014 & 6 & 58,87 & 1,75 & 42 & 84 & 168 & 252 & 336 \\
\hline Fev/2014 & 2 & 45,40 & 1,75 & 14 & 28 & 56 & 84 & 112 \\
\hline Mai/2014 & 16 & 79,09 & 1,75 & 112 & 224 & 448 & 672 & 896 \\
\hline Jun/2014 & 15 & 66,26 & 1,75 & 105 & 210 & 420 & 630 & 840 \\
\hline Jul/2014 & 16 & 71,23 & 1,75 & 112 & 224 & 448 & 672 & 896 \\
\hline Ago/2014 & 15 & 98,84 & 1,75 & 105 & 210 & 420 & 630 & 840 \\
\hline Set/2014 & 16 & 113,64 & 1,75 & 112 & 224 & 448 & 672 & 896 \\
\hline Out/2014 & 15 & 117,67 & 1,75 & 105 & 210 & 420 & 630 & 840 \\
\hline Nov/2014 & 16 & 93,67 & 1,75 & 112 & 224 & 448 & 672 & 896 \\
\hline Total & - & 1061,49 & - & 1090 & 2177 & 4300 & 6540 & 8720 \\
\hline
\end{tabular}

Para obter a lâmina de irrigação aplicada (LIA) em mm, em função dos volumes de água aplicados (Tabela 5), utilizou-se a seguinte equação:

$$
\operatorname{LIA}=\frac{\mathrm{VAA}}{\mathrm{A}_{\mathrm{t}} \times \mathrm{K}_{\mathrm{L}}}
$$

em que:

VAA: Volume de água aplicado (litros);

$\mathrm{A}_{\mathrm{t}}$ : Área ocupada pela planta $\left(9 \mathrm{~m}^{2}\right)$; 
$\mathrm{K}_{\mathrm{L}}$ : Fator de ajuste obtido em função do percentual da área molhada.

O manejo previsto da irrigação foi realizado pela a demanda evapotranspirométrica da cultura. Para isso, foi calculada a evapotranspiração de referência $\left(\mathrm{ET}_{0}\right)$, utilizando-se os dados climatológicos da Estação de Agroclimatologia localizada na própria FAL - UnB. De posses desses dados, a $\mathrm{ET}_{0}$ foi calculada a partir da equação de Penman-Monteith-FAO proposta por Allen et al., (2006). Os valores da $\mathrm{ET}_{0}$ calculado para os meses dos anos de 2013 e 2014 estão na Tabela 5 e os dados climatológicos utilizados encontram-se em anexo.

Como a irrigação localizada não molhou toda a área ocupada pela cova de bananeira, foi necessário considerar um fator de ajuste $\left(\mathrm{K}_{\mathrm{L}}\right)$ que leva em consideração a porcentagem da área molhada (PAM) (BERNARDO et al., 2013). Portanto, o $\mathrm{K}_{\mathrm{L}}$ foi calculado conforme as equações de Fereres (1981), abaixo:

Se $P A M \geq 65 \% \rightarrow K_{L}=1 ;$

Se $20 \%<P A M<65 \% \rightarrow \mathrm{K}_{\mathrm{L}}=1,09 \frac{\mathrm{PAM}}{100}+0,30$;

Se PAM $\leq 20 \% \rightarrow \mathrm{K}_{\mathrm{L}}=1,94 \frac{\mathrm{PAM}}{100}+0,1$;

$\mathrm{O}$ coeficiente da cultura $\left(\mathrm{K}_{\mathrm{c}}\right)$ foi utilizada para ajustar os valores da $\mathrm{ET}_{0}$ com a demanda hídrica da cultura. Os valores de $\mathrm{K}_{\mathrm{c}}$ variam com o tipo da cultura, o seu estádio de desenvolvimento e as condições climáticas locais (BERNARDO et. al., 2013). Foram ajustados os valores de $\mathrm{K}_{\mathrm{c}}$ iguais a 0,70; 0,85; 1,00 e 1,10 respectivamente para os meses de julho, agosto, setembro e outubro de 2013, e constante a partir do maior valor até o mês de novembro de 2014 segundo Allen et al., (2006).

Considerando esses fatores a $\mathrm{ET}_{\mathrm{Loc}}$ foi calculada pela equação:

$E T_{L o c}=E T_{0} \times K_{c} \times K_{L}$

onde:

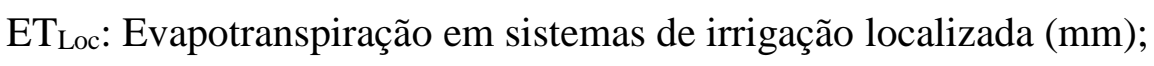

$\mathrm{ET}_{0}$ : Evapotranspiração de referência $(\mathrm{mm})$;

$\mathrm{K}_{\mathrm{c}}$ : Coeficiente da cultura;

$\mathrm{K}_{\mathrm{L}}$ : Fator de ajuste. 
$\mathrm{O}$ valor de PAM foi obtido pela divisão da área molhada $\left(\mathrm{A}_{\mathrm{m}}\right)$ pela área total $\left(9 \mathrm{~m}^{2}\right)$. As áreas molhadas foram determinadas pelas medidas realizadas no campo. Foram medidos os dois maiores diâmetros do bulbo úmido ao final do tempo de irrigação e tirado sua média e determinado a sua área.

Os valores de PAM calculados, em função das vazões dos gotejadores utilizados (2, 4 e 8 litros.hora ${ }^{-1}$ ), foram obtidos pela a seguinte equação:

$\mathrm{PAM}=\frac{\mathrm{P}_{1} \times \mathrm{S}_{1}+\mathrm{P}_{2} \times \mathrm{S}_{2}}{\mathrm{~S}_{\mathrm{f}}} \times \frac{\mathrm{S}_{\mathrm{G} \text { rec }}}{\mathrm{S}_{\mathrm{G} \text { uti }}}$

em que:

$\mathrm{P}_{1}$ : proporção 1 , para o valor de $\mathrm{S}_{1}$;

$\mathrm{S}_{1}$ : maior espaçamento entre as linhas laterais que resulta em $\mathrm{P}_{1}(\mathrm{~m})$;

$\mathrm{P}_{2}$ : proporção 2, para o valor de $\mathrm{S}_{2}$;

$\mathrm{S}_{2}$ : espaçamento entre pares de laterais $\left(\mathrm{S}_{2}=\mathrm{S}_{\mathrm{f}}-\mathrm{S}_{1}\right)(\mathrm{m})$;

$\mathrm{S}_{\mathrm{f}}$ : espaçamento entre fileiras de plantas (3 metros);

$S_{\mathrm{g} \mathrm{rec}}$ : espaçamento entre gotejadores recomendado $(\mathrm{m})$

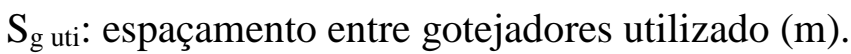

Os valores de $\mathrm{P}_{1}, \mathrm{P}_{2}, \mathrm{~S}_{2}$ e $\mathrm{S}_{\mathrm{g} \text { rec }}$ utilizados foram propostos por Keller \& kamelli (1975). O espaçamento entre as linhas laterais $\left(S_{1}\right)$ foi de 1,2 metros. O uso da expressão $\left(\frac{S_{G} \text { rec }}{S_{G} \text { uti }}\right)$ foi para ajustar o valor de PAM, já que o valor recomendado entre os gotejadores $\left(S_{\mathrm{g}}\right.$ rec $)$ diferiu do espaçamento utilizado $\left(\mathrm{S}_{\mathrm{g}}\right.$ uti $)$.

Ressalta-se que o valor de PAM calculado para o tratamento com a vazão de 24 litros.hora ${ }^{-1}$, composto por dois gotejadores de 4 litros.hora $^{-1}$ e dois gotejadores de 8 litros.hora ${ }^{-1}$, foi obtido pela média dos valores de PAM calculados para os gotejadores com vazões de 4 e 8 litros.hora ${ }^{-1}$.

Como os valores de $\mathrm{K}_{\mathrm{L}}$, dados pelas equações 2,3 e 4, são dependentes apenas de PAM, encontraram-se diversos valores de $\mathrm{K}_{\mathrm{L}}$, tendo em vista que os valores de PAM calculados foram em função das vazões dos gotejadores utilizados. Em função desse fato, diversos valores de lâminas foram calculados para satisfazer a demanda evapotranspirométrica da cultura. 
A partir dos valores obtidos para $\mathrm{ET}_{\mathrm{L}}, \mathrm{K}_{\mathrm{c}}$ e $\mathrm{K}_{\mathrm{L}}$, foi possível calcular as lâminas de irrigação necessária para satisfazer a demanda evapotranspirométrica da cultura. Com isso, as lâminas de irrigação totais necessárias, em mm, (LTN) foram calculadas, para cada tratamento, pela seguinte expressão:

$\mathrm{LTN}=\frac{\mathrm{ET}_{0} \times \mathrm{K}_{\mathrm{C}} \times \mathrm{K}_{\mathrm{L}}}{\mathrm{CUC}}$

em que:

$\mathrm{ET}_{0}$ : Evapotranspiração de referência $(\mathrm{mm})$

$\mathrm{K}_{\mathrm{c}}$ : Coeficiente da cultura;

$\mathrm{K}_{\mathrm{L}}$ : Fator de ajuste.

CUC: Coeficiente de uniformidade de Christiansen

O CUC foi obtido a partir da mensuração das vazões dos gotejadores utilizados pelo sistema de irrigação instalado no campo, obtendo, assim um CUC de 94\%.

A obtenção dos volumes totais necessários por cova (VTN), em litros, considerando as LTN corresponde a cada tratamento, foi calculado pela seguinte fórmula:

$\mathrm{VTN}=\mathrm{LTN} \times \mathrm{A}_{\mathrm{t}}$

em que:

LTN: lâmina total necessária $(\mathrm{mm})$;

$\mathrm{A}_{\mathrm{t}}$ área ocupada pela planta $\left(9 \mathrm{~m}^{2}\right)$.

O solo onde o experimento foi implantado apresentou um alto teor de argila, porém comportou-se como um solo arenoso devido ao fato de ter apresentado uma elevada condutividade hidráulica saturada $\left(\mathrm{K}_{\mathrm{s}}\right)$. Diante do exposto, justifica-se o fato dos valores de PAM observados serem aquém dos valores de PAM calculados, conforme a Tabela 6.

Na Tabela 6, estão apresentados os valores de PAM calculados e seus respectivos $\mathrm{K}_{\mathrm{L}}$ calculados; de PAM observados e seus respectivos $\mathrm{K}_{\mathrm{L}}$ observados. Os valores de PAM calculados, em função dos tratamentos utilizados, diferiram entre si, sendo que o menor PAM calculado foi de $13 \%$ para o tratamento de 4 litros.hora $^{-1}$ e o maior foi de $81,50 \%$ para o tratamento de 32 litros.hora ${ }^{-1}$. Observando os valores de PAM calculados e PAM observados, notou-se que os PAM calculados foram superiores a todos os PAM observados. 
Consequentemente, os valores de $\mathrm{K}_{\mathrm{L}}$ calculados foram superiores aos $\mathrm{K}_{\mathrm{L}}$ observados, tendo em vista que $\mathrm{K}_{\mathrm{L}}$ é dependente exclusivamente de PAM. Os valores idênticos de $\mathrm{K}_{\mathrm{L}}$ calculados, para os tratamentos Q 24 e Q 32, justifica-se pelo fato de PAM calculado apresentar um valor superior a $65 \%$, e com isso, foi considerado $\mathrm{K}_{\mathrm{L}}$ igual a 1 , conforme a equação 2 . $\mathrm{O}$ fato dos $\mathrm{K}_{\mathrm{L}}$ observados serem idênticos nos tratamentos Q16 e Q24 explica-se devido os PAM observados estarem muito próximos entre si.

Considerando as lâminas calculadas notou-se que seus valores foram inferiores às das lâminas aplicadas. Isso se justifica pelo fato dos valores de $\mathrm{K}_{\mathrm{L}}$ calculados serem superiores aos valores de $\mathrm{K}_{\mathrm{L}}$ observados. As lâminas calculadas para os tratamentos Q24 e Q32 foram idênticas devido ao fato dos valores de $\mathrm{K}_{\mathrm{L}}$ desses tratamentos serem iguais $\left(\mathrm{K}_{\mathrm{L}}=1\right)$. As lâminas aplicadas nos tratamentos Q8 e Q16 foram semelhantes para essas vazões já que Q16 equivale ao dobro de Q8 e o valor de PAM para Q16 ser o dobro de PAM relativo ao tratamento Q8, apesar da diferença existente entre as vazões nesses tratamentos. Contudo, os volumes de água calculados foram superiores a todos os volumes de água aplicados. Além disso, os volumes de água aplicados foram todos distintos entre si, com o intervalo de 1090 a 8720 litros.cova $^{-1}$ (Tabela 7). Pelas razões expostas, decidiu-se apresentar os resultados e discutir o presente trabalho em função dos volumes de água aplicados.

Tabela 6: Percentual de área molhada calculada $\left(\mathrm{PAM}_{\mathrm{s}}\right)$ e observada $\left(\mathrm{PAM}_{\mathrm{o}}\right)$ e coeficiente de ajuste da evapotranspiração da cultura para irrigação localizada de acordo com $\operatorname{PAM}_{\mathrm{s}}\left(\mathrm{K}_{\mathrm{Ls}}\right)$ e $\mathrm{PAM}_{\mathrm{o}}\left(\mathrm{K}_{\mathrm{Lo}}\right)$.

\begin{tabular}{ccccc}
\hline $\begin{array}{c}\text { Vazões utilizadas } \\
\left(\text { Litros.hora }^{-1}\right)\end{array}$ & PAM $_{\mathrm{S}}(\%)$ & $\mathrm{K}_{\mathrm{Ls}}$ & $\mathrm{PAM}_{\mathrm{o}}(\%)$ & $\mathrm{K}_{\mathrm{Lo}}$ \\
\hline 4 & 13,00 & 0,35 & 4,07 & 0,18 \\
8 & 26,00 & 0,58 & 8,95 & 0,27 \\
16 & 54,60 & 0,89 & 22,18 & 0,54 \\
24 & 68,00 & 1,00 & 23,33 & 0,54 \\
32 & 81,50 & 1,00 & 38,86 & 0,72 \\
\hline
\end{tabular}


Tabela 7: Volumes e lâminas de água necessários em função do $\mathrm{K}_{\mathrm{Lc}} \mathrm{e}$ Volumes e lâminas água aplicados, em função da vazão utilizada no referido experimento.

\begin{tabular}{|c|c|c|c|c|c|c|c|c|c|c|c|c|c|c|c|c|c|c|c|c|}
\hline \multirow{3}{*}{ Mês/ano } & \multicolumn{5}{|c|}{ Vazões utilizadas (Litros/hora) } & \multicolumn{5}{|c|}{ Vazões utilizadas (Litros/hora) } & \multicolumn{5}{|c|}{ Vazões utilizadas (Litros/hora) } & \multicolumn{5}{|c|}{ Vazões utilizadas (Litros/hora) } \\
\hline & 4 & 8 & 16 & 24 & 32 & 4 & 8 & 16 & 24 & 32 & 4 & 8 & 16 & 24 & 32 & 4 & 8 & 16 & 24 & 32 \\
\hline & \multicolumn{5}{|c|}{ Volumes de água calculados (L) } & \multicolumn{5}{|c|}{ Lâminas de água calculadas (mm) } & \multicolumn{5}{|c|}{ Volumes de água aplicados (L) } & \multicolumn{5}{|c|}{ Lâminas de água aplicadas (mm) } \\
\hline $\mathrm{Jul} / 2013$ & 188 & 312 & 479 & 535 & 535 & 20,9 & 34,7 & 53,2 & 59,5 & 59,5 & 64 & 128 & 256 & 384 & 512 & 39,7 & 51,9 & 52,5 & 77,0 & 78,68 \\
\hline Ago/2013 & 296 & 490 & 751,2 & 840 & 840 & 32,8 & 54,4 & 83,5 & 93,3 & 93,3 & 75 & 150 & 300 & 450 & 600 & 46,5 & 60,8 & 61,5 & 90,2 & 92,21 \\
\hline Set/2013 & 363 & 602 & 924 & 1033 & 1033 & 40,4 & 66,9 & 102,7 & 114,8 & 114,8 & 90 & 180 & 360 & 540 & 720 & 55,9 & 73,0 & 73,8 & 108,3 & 110,65 \\
\hline Out/2013 & 96 & 159 & 244 & 272 & 272 & 10,7 & 17,6 & 27,1 & 30,3 & 30,3 & 42 & 84 & 168 & 252 & 336 & 26,1 & 34,1 & 34,4 & 50,5 & 51,64 \\
\hline $\operatorname{Jan} / 2014$ & 218 & 361 & 555 & 620 & 620 & 24,2 & 40,2 & 61,7 & 68,9 & 68,9 & 42 & 84 & 168 & 252 & 336 & 26,1 & 34,1 & 34,4 & 50,5 & 51,64 \\
\hline $\mathrm{Fev} / 2014$ & 168 & 279 & 428 & 478 & 478 & 18,7 & 31,0 & 47,5 & 53,1 & 53,1 & 14 & 28 & 56 & 84 & 112 & 8,7 & 11,3 & 11,5 & 16,8 & 17,21 \\
\hline Mai/2014 & 293 & 486 & 745 & 832 & 833 & 32,6 & 54,0 & 82,8 & 92,5 & 92,5 & 112 & 224 & 448 & 672 & 896 & 69,5 & 90,8 & 91,8 & 134,8 & 137,70 \\
\hline Jun/2014 & 246 & 407 & 625 & 698 & 698 & 27,3 & 45,2 & 69,4 & 77,5 & 77,5 & 105 & 210 & 420 & 630 & 840 & 65,2 & 83,2 & 86,1 & 126,3 & 129,09 \\
\hline Jul/2014 & 264 & 437 & 671 & 750 & 750 & 29,3 & 48,6 & 74,6 & 83,3 & 83,3 & 112 & 224 & 448 & 672 & 896 & 69,5 & 90,8 & 91,8 & 134,8 & 137,70 \\
\hline Ago/2014 & 366 & 607 & 932 & 1041 & 1041 & 40,7 & 67,4 & 103,5 & 115,7 & 115,7 & 105 & 210 & 420 & 630 & 840 & 65,2 & 83,2 & 86,1 & 126,3 & 129,09 \\
\hline Set/2014 & 421 & 698 & 1071 & 1197 & 1197 & 46,8 & 77,5 & 119,0 & 133,0 & 133,0 & 112 & 224 & 448 & 672 & 896 & 69,5 & 90,8 & 91,8 & 134,8 & 137,70 \\
\hline Out/2014 & 436 & 722 & 1109 & 1239 & 1239 & 48,5 & 80,3 & 123,2 & 137,7 & 137,7 & 105 & 210 & 420 & 630 & 840 & 65,2 & 83,2 & 86,1 & 126,5 & 129,09 \\
\hline Nov/2014 & 347 & 575 & 883 & 986 & 986 & 38,6 & 63,9 & 98,1 & 109,6 & 109,6 & 112 & 224 & 448 & 672 & 896 & 69,5 & 90,8 & 91,8 & 134,8 & 137,70 \\
\hline Total & 3704 & 6135 & 9418 & 10523 & 10523 & 411,6 & 681,7 & 1046,5 & 1169,2 & 1169,2 & 1090 & 2177 & 4300 & 6540 & 8720 & 676,6 & 882,8 & 881,5 & 1311,7 & 1340,0 \\
\hline
\end{tabular}




\section{AVALIAÇÃO DO EXPERIMENTO}

Para a avaliação do desempenho agronômico da bananeira cv. Prata anã sob diferentes níveis de água e doses de fósforo foram realizadas colheitas dos cachos quando os frutos atingiram o pleno desenvolvimento fisiológico, com base na redução e/ou desaparecimento das quinas ou angulosidades da superfície dos frutos (ALVES et al., 1999). Os cachos foram colhidos com um corte, realizado com um facão, na altura do engaço. Em plantas de maior porte, foi realizado um corte no pseudocaule tombando, primeiramente, a planta antes do corte do cacho. O cacho foi apoiado por um trabalhador da FAL-UnB evitando que este caísse diretamente no solo, e em seguida, foi realizado o corte do cacho. As operações de colheita ocorreram do período de 1 de julho de 2014 a 30 de dezembro de 2014 com o intervalo semanal entre as colheitas, totalizando 27 colheitas. No momento da colheita, os cachos foram identificados com uma etiqueta de papel na qual trazia informações sobre o bloco e os tratamentos de água e adubo a qual o cacho pertencia.

Após a colheita, os cachos foram conduzidos a um galpão onde seriam despencados. As pencas de cada cacho e os frutos de cada penca foram contados, e os valores anotados em uma ficha desenvolvida para o projeto. As pencas foram acondicionadas em caixas plásticas, com a primeira penca, a penca média e a penúltima penca em posição de destaque dentro da caixa (Figura 1). Em seguida, as caixas plásticas contendo apenas as pencas foram pesadas em uma balança analógica (não foram pesados engaço, raquis e coração). Os pesos das pencas, desconsiderando o peso das caixas, foram anotados na mesma ficha onde foram anotadas as quantidades de pencas e frutos.

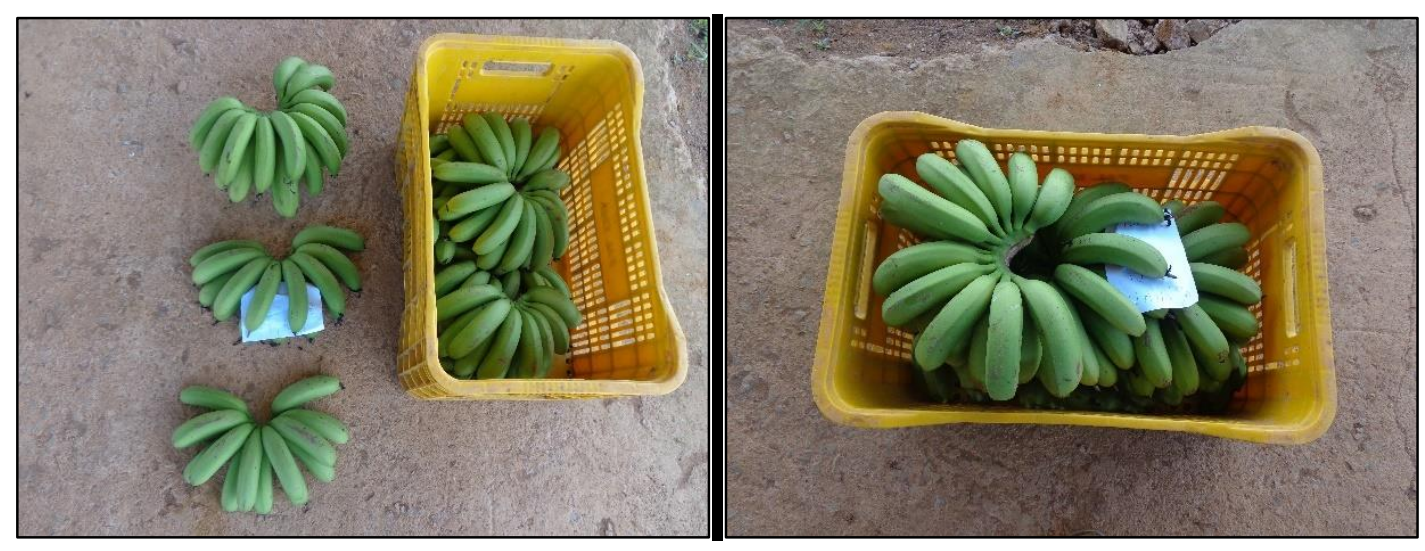

Figura 1: Acondicionamento de pencas de banana, em caixas plásticas, evidenciando a primeira penca, a penca média e penúltima penca. Brasília, 2014.

Depois da pesagem, os frutos seguiram para a avaliação do comprimento e diâmetro. Foram retirados 5 frutos, ao acaso, da primeira penca, da penca média e da penúltima penca, 
totalizando 15 frutos. O comprimento do fruto foi medido, no sentido longitudinal, com o auxílio de um paquímetro digital. Quando o fruto teve um comprimento maior que a escala do paquímetro $(150 \mathrm{~mm})$, o fruto foi medido com uma régua graduada. $\mathrm{O}$ diâmetro do fruto foi obtido medindo a região central do fruto com o auxílio de um paquímetro digital (Figura 2).

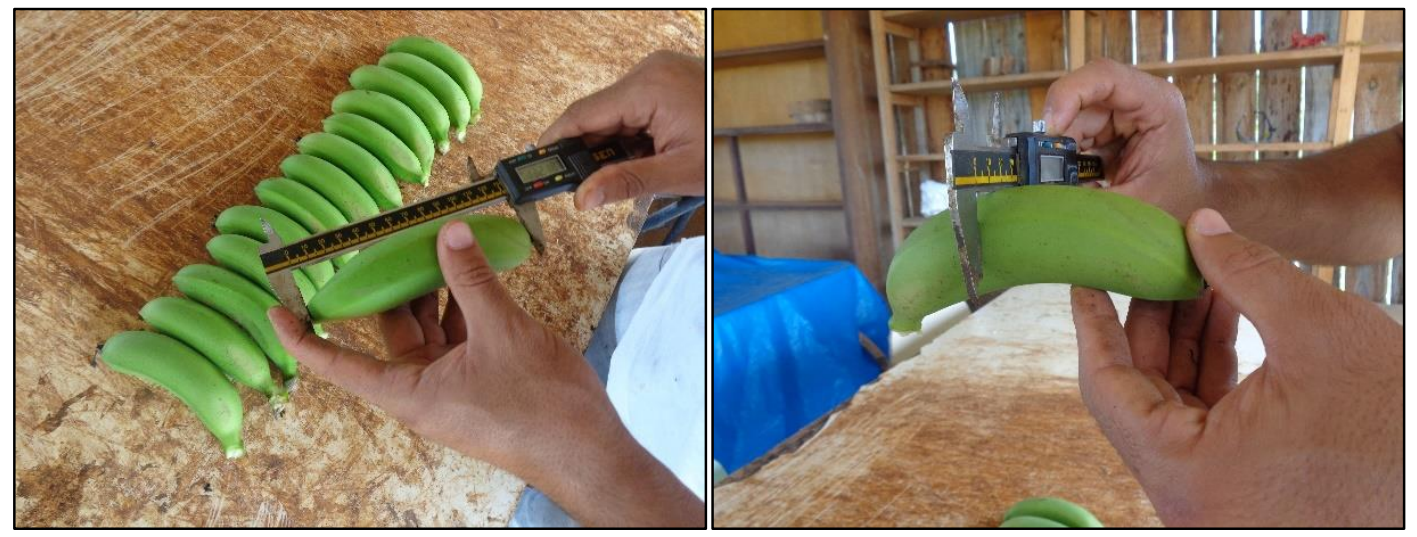

Figura 2: À esquerda: avaliação do comprimento da banana com o auxílio de um paquímetro digital. À direita: avaliação do diâmetro do fruto, na região central, com o auxílio de um paquímetro digital. Brasília, 2014.

Para avaliar a firmeza média da polpa (FMP), 10 frutos da penca média foram acondicionados em uma caixa plástica - sendo que cada caixa comportou 5 pencas - e identificados com a etiqueta do cacho correspondente. As caixas foram cobertas com uma lona plástica, com o objetivo de facilitar o amadurecimento dos frutos. As pencas, cujos frutos estavam maduros, foram retiradas e avaliadas após uma semana. Os frutos foram descascados e perfurados com um penetrômetro analógico de ponteira de $11 \mathrm{~mm}$ na sua porção central (Figura 3).

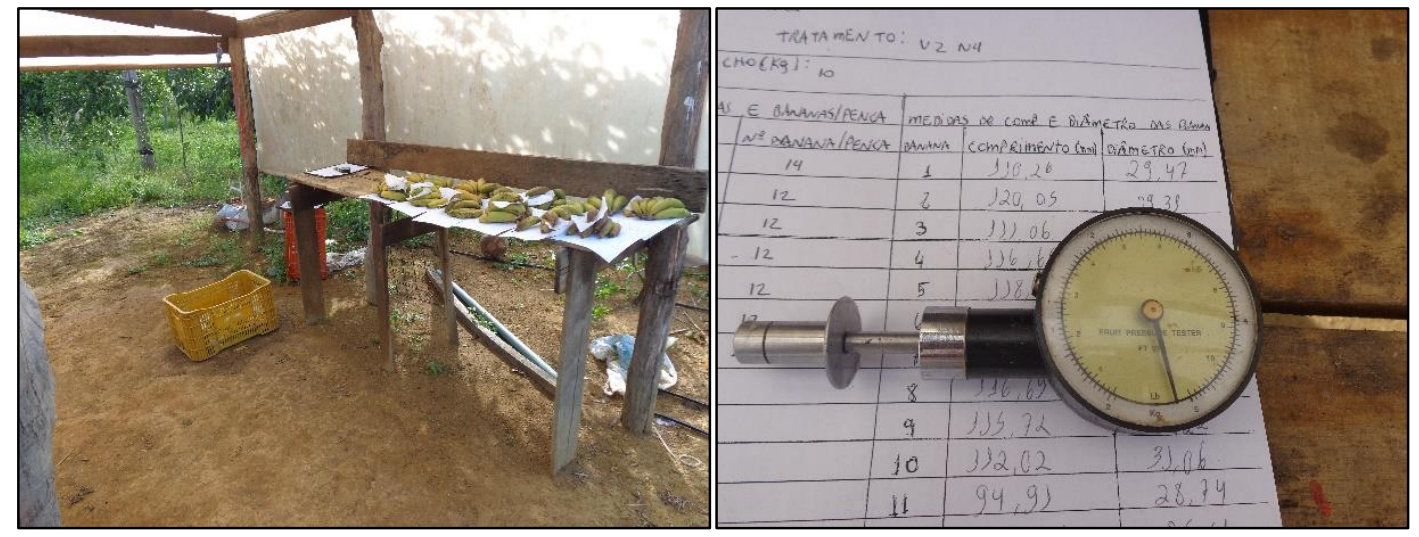

Figura 3: À esquerda: pencas de bananas com frutos madurados a serem avaliadas pelo penetrômetro. À direita: penetrômetro utilizado na avaliação da firmeza da polpa da banana. Brasília, 2014. 
A produtividade de peso de pencas por hectare (PPH), em Kg.ha ${ }^{-1}$, foi obtida a partir da soma dos pesos das pencas colhidas na parcela multiplicada pelo número de parcelas contidas no hectare (278 parcelas.ha $\left.{ }^{-1}\right)$. $\mathrm{O}$ número de cachos por hectare $(\mathrm{NCH})$ foi obtido pela multiplicação da soma do número de cachos colhidos por parcela pelo número de parcelas contidas no hectare.

O número médio de pencas por cacho (NMPC) foi obtido pela média de pencas obtidas nos cachos colhidos na parcela. O número médio de bananas por cacho (NMBC) foi obtida pela média da quantidade de bananas obtidas em cada cacho colhido na parcela. A partir da divisão do NMBC pelo NMPC determinou-se a variável número de bananas por penca (NMBP).

O peso médio de banana (PMB), expresso em gramas, foi obtido pela relação entre o peso de pencas (PP) e total de bananas produzidas no cacho (BC). A relação (CD) entre o comprimento e o diâmetro foi obtida dividindo o comprimento médio (CMB) pelo diâmetro médio (DMB) do fruto obtido na parcela.

\section{ANÁLISE DE VARIÂNCIA}

Os dados originais coletados de todas as características foram submetidos à análise de variância (ANAVA) pelo teste de F, ao nível de 5\% de probabilidade, e as médias agrupadas pelo teste de Scott Knott $(\mathrm{P}<0,05)$. As análises foram realizadas utilizando o programa estatístico SISVAR (FERREIRA, 1998).

\section{REGRESSÃO}

Regressões polinomiais foram ajustadas para características de produção e de qualidade de fruto em função das doses de fósforo (P) e em função dos volumes de água (V). As equações foram selecionadas baseando-se na significância de seus coeficientes (ao nível de 5\% de significância) utilizando o programa SANEST (ZONTA e MACHADO, 1995).

Ressalta-se que Y pode assumir a variável produtividade (PPH), número de cachos por hectare $(\mathrm{NCH})$, número médio de pencas por cacho (NMPC), número médio de bananas por cacho (NMBC), número médio de bananas por penca (NMBP), peso médio de banana (PMB), comprimento médio de banana $(\mathrm{CMB})$, diâmetro médio de banana (DMB), relação comprimento diâmetro (CD) e firmeza média da polpa (FMP).

As análises de correlação linear (Pearson), entre todas as variáveis, basearam-se na significância de seus coeficientes. A classificação de intensidade da correlação para $\mathrm{p} \leq 0,05$ foi: muito forte $(r \pm 0,91$ a $\pm 1,00)$, forte $(r \pm 0,71$ a $\pm 0,9)$, média $(r \pm 0,51$ a $\pm 0,70)$ e fraca $(r$ $\pm 0,31$ a $\pm 0,50)$ (CARVALHO et al., 2004). 


\section{RESULTADOS E DISCUSSÃO}

As variáveis foram agrupadas da seguinte forma: NCH, PPH, NMPC, NMBC, PMB e NMBP considerados como indicadores de produtividade. CMB, DMB, CD e FMP considerados como indicadores de qualidade de fruto.

Pelo resumo da análise de variância verificam-se efeitos significativos dos tratamentos na análise de todas variáveis com exceção da FMP. Os níveis de água apresentaram diferenças significativas em todas variáveis, a exceção de NMBP, CD e FMP. As doses de fósforo não apresentaram diferenças significativas, a exceção da relação C/D. A interação água x fósforo foi significativa em todas variáveis, a exceção de PPH, PMB, CD e FMP (Tabela 8). Os resumos das análises de variância bem como as médias de todos os tratamentos encontram-se em anexo.

\section{NÚMERO DE CACHOS POR HECTARE (NCH)}

Os volumes de água 4.300, 6.540 e 8.720 L.cova $^{-1}$ proporcionaram maiores valores de $\mathrm{NCH}$. A regressão polinomial quadrática ajusta os valores de $\mathrm{NCH}$ em função dos volumes de água e apontou ponto de máximo em 1664 cachos.ha $^{-1}$ com 6.050 litros.cova $^{-1}$ como observado na Figura 4.

A interação água x fósforo evidenciou efeito significativo nos níveis de $100 \mathrm{~kg} \cdot \mathrm{ha}^{-1} \mathrm{de}$ $\mathrm{P}_{2} \mathrm{O}_{5}$ e 150 kg.ha ${ }^{-1}$ de $\mathrm{P}_{2} \mathrm{O}_{5}$.

Os volumes de água de 4.300 e 6.540 L.cova ${ }^{-1}$ x 100 Kg.ha- ${ }^{-1}$ de $\mathrm{P}_{2} \mathrm{O}_{5}$ proporcionaram maiores valores de NCH como demonstrado na Figura 5. 
Tabela 8: Resumo da análise de variância da cultivar 'Prata Anã'. Brasília, 2014.

\begin{tabular}{|c|c|c|c|c|c|c|c|c|c|c|c|}
\hline $\mathrm{FV}$ & GL & $\mathrm{PPH}$ & $\mathrm{NCH}$ & NMPC & NMBC & NMBP & PMB & CMB & DMB & $\mathrm{CD}$ & FMP \\
\hline BLOCO & 3 & $86611408,9^{\mathrm{NS}}$ & $967338,0^{\mathrm{NS}}$ & $0,20^{\mathrm{NS}}$ & $48,5 \mathrm{NS}$ & $0,05^{\mathrm{NS}}$ & $445^{\mathrm{NS}}$ & $51,9^{\mathrm{NS}}$ & $5,95^{\mathrm{NS}}$ & $0,02^{\mathrm{NS}}$ & $0,17^{\mathrm{NS}}$ \\
\hline VOLUME & 4 & $132849909,1 *$ & $1246977,3^{*}$ & $1,04 * *$ & $382 *$ & $0,92^{\mathrm{NS}}$ & $676^{* *}$ & $219 * *$ & $20 * *$ & $0,001^{\mathrm{NS}}$ & $0,15^{\mathrm{NS}}$ \\
\hline FÓSFORO & 4 & $18541450,5^{\mathrm{NS}}$ & $211371,7^{\mathrm{NS}}$ & $0,14^{\mathrm{NS}}$ & $43,5 \mathrm{NS}$ & $0,16^{\mathrm{NS}}$ & $92^{\mathrm{NS}}$ & $20,7^{\mathrm{NS}}$ & $4,1^{\mathrm{NS}}$ & $0,07 *$ & $0,24^{\mathrm{NS}}$ \\
\hline INTERAÇÃO & 16 & $19812412,1^{\mathrm{NS}}$ & $245666,5^{\mathrm{NS}}$ & $0,18^{\mathrm{NS}}$ & $78,4 \mathrm{NS}$ & $0,27^{\mathrm{NS}}$ & $84^{\mathrm{NS}}$ & $18,4^{\mathrm{NS}}$ & $2,9^{\mathrm{NS}}$ & $0,01^{\mathrm{NS}}$ & $0,14^{\mathrm{NS}}$ \\
\hline \multicolumn{12}{|c|}{ DESDOBRAMENTOS } \\
\hline $\mathrm{V} \times \mathrm{P}$ & 4 & NS & $\begin{array}{l}\mathrm{P}_{3}-564173,2^{*} \\
\mathrm{P}_{4}-589290,5^{*}\end{array}$ & $\begin{array}{r}\mathrm{P}_{1}-0,59^{*} \\
\mathrm{P}_{3}-0,73^{* *}\end{array}$ & $\begin{array}{l}\mathrm{P} 1-291 * * \\
\mathrm{P} 3-211 * *\end{array}$ & $\mathrm{P}_{1}-1,06^{* *}$ & NS & $\mathrm{P}_{1}-114^{* *}$ & $\mathrm{P}_{2}-11,17 *$ & NS & NS \\
\hline $\mathrm{P} \times \mathrm{V}$ & 4 & NS & NS & NS & NS & NS & NS & NS & NS & NS & NS \\
\hline CV1\% & & 42 & 37 & 5,2 & 9,4 & 5,2 & 11,9 & 4,9 & 5,1 & 4,3 & 17,2 \\
\hline $\mathrm{CV} 2 \%$ & & 37 & 30 & 5,6 & 8,2 & 3,5 & 13,9 & 5 & 5,8 & 4,8 & 17,3 \\
\hline MÉDIA & & 12376,7 & 1448,3 & 7,6 & 95,5 & 12,4 & 86,8 & 109,06 & 33,9 & 3,2 & 2,05 \\
\hline
\end{tabular}

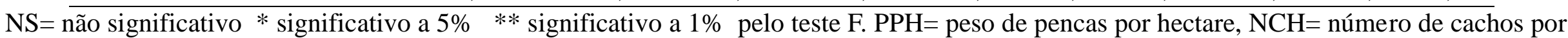
hectare, $\mathrm{NMPC}=$ número médio de pencas por cacho, $\mathrm{NMBC}=$ número médio de bananas por cacho, $\mathrm{NMBP}=$ número médio de bananas por penca, $\mathrm{PMB}=$ peso médio de bananas, $\mathrm{CMB}=$ comprimento médio de bananas, $\mathrm{DMB}=$ diâmetro médio de bananas, $\mathrm{CD}=$ relação comprimento sobre diâmetro, FMP= firmeza média da polpa. $\mathrm{P}_{1}=0$ Kg.ha ${ }^{-1}$ de $\mathrm{P}_{2} \mathrm{O}_{5} ; \mathrm{P}_{2}=50$ Kg.ha ${ }^{-1}$ de $\mathrm{P}_{2} \mathrm{O}_{5} ; \mathrm{P}_{3}=100 \mathrm{Kg} \cdot \mathrm{ha}^{-1}$ de $\mathrm{P}_{2} \mathrm{O}_{5} ; \mathrm{P}_{4}=150 \mathrm{Kg} \cdot h a^{-1}$ de $\mathrm{P}_{2} \mathrm{O}_{5} ; \mathrm{P}_{5}=200$ Kg.ha $^{-1}$ de $\mathrm{P}_{2} \mathrm{O}_{5}$ 


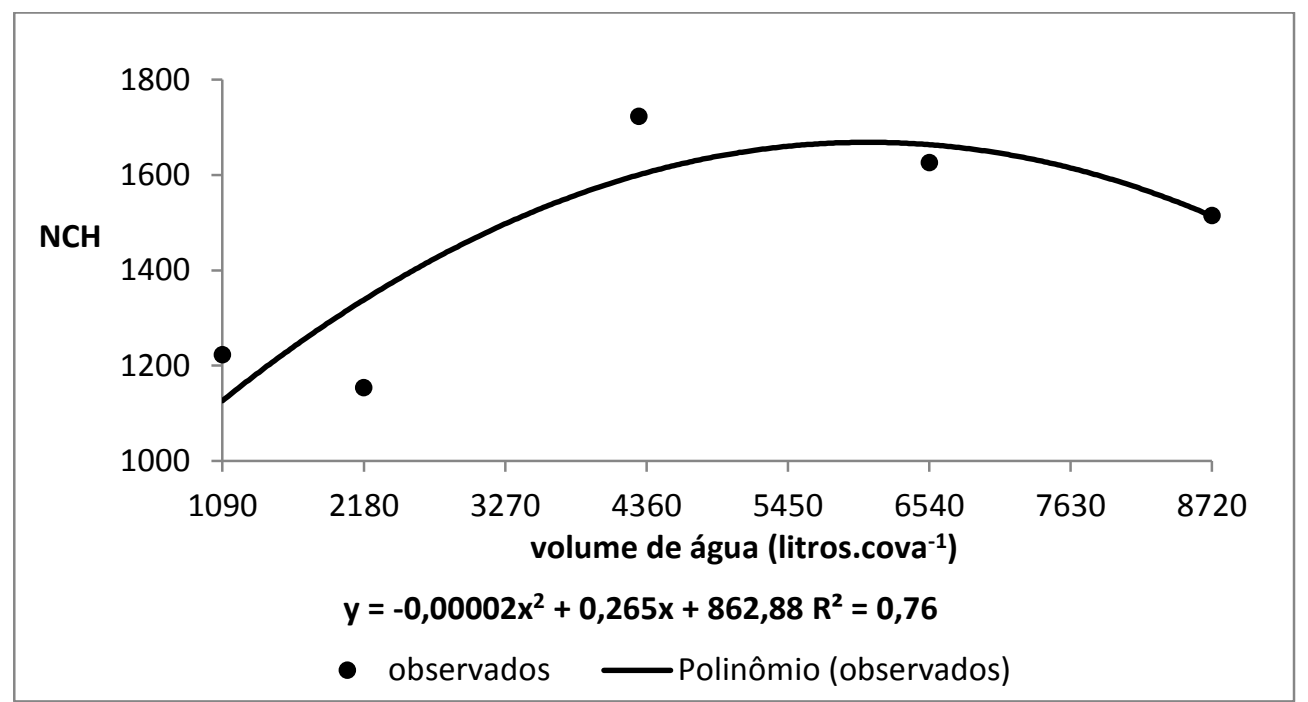

Figura 4: Números de cachos por hectare observados e ajustados da cultivar 'Prata Anã' em função de cinco volumes de irrigação (1.090-2.177-4.300-6.540-8.720 litros.cova ${ }^{-1}$ ). Brasília, 2014.

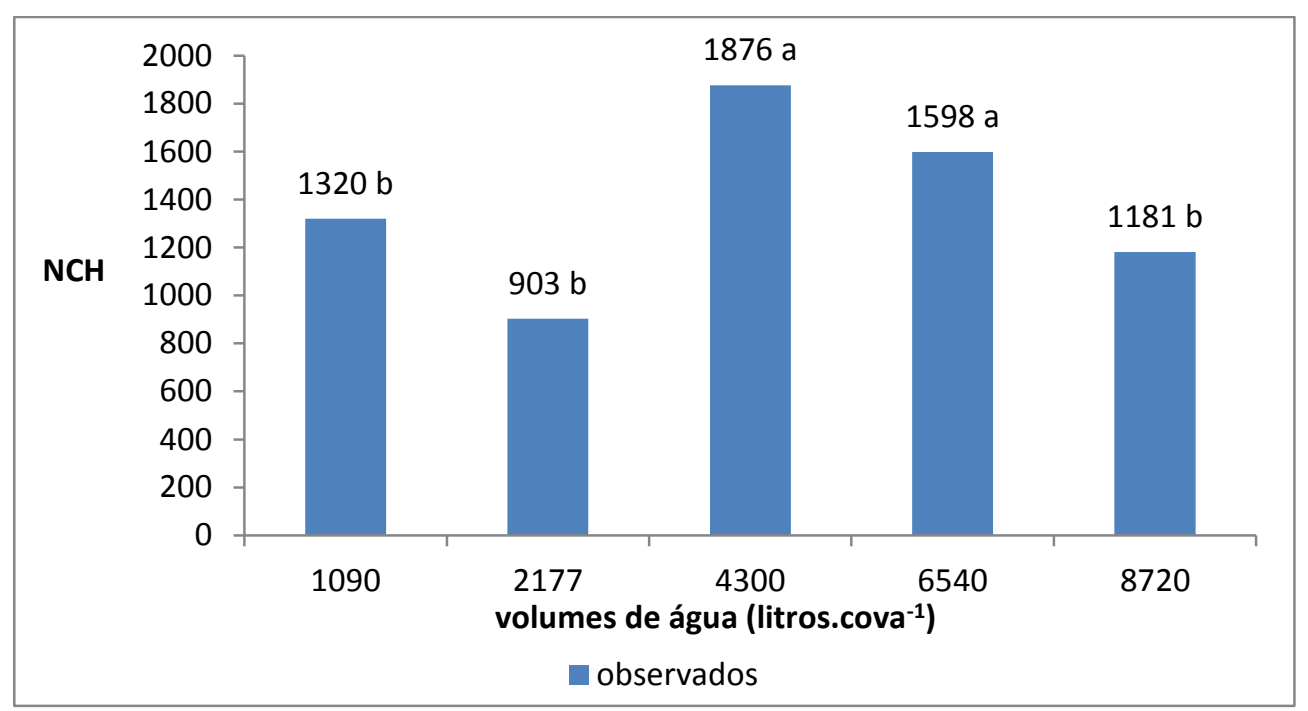

Figura 5: Números de cachos por hectare da cultivar 'Prata Anã' observados em função da dose de adubação de $100 \mathrm{~kg}$.ha ${ }^{-1}$ de $\mathrm{P}_{2} \mathrm{O}_{5}$ e cinco volumes de irrigação (1.090-2.177-4.3006.540-8.720 litros.cova ${ }^{-1}$ ). Brasília, 2014.

A interação volume de água de 4.300 L.cova $^{-1}$ x $150 \mathrm{~kg} \cdot \mathrm{ha}^{-1}$ de $\mathrm{P}_{2} \mathrm{O}_{5}$ exibiu valor superior de NCH conforme observado na Figura 6: 


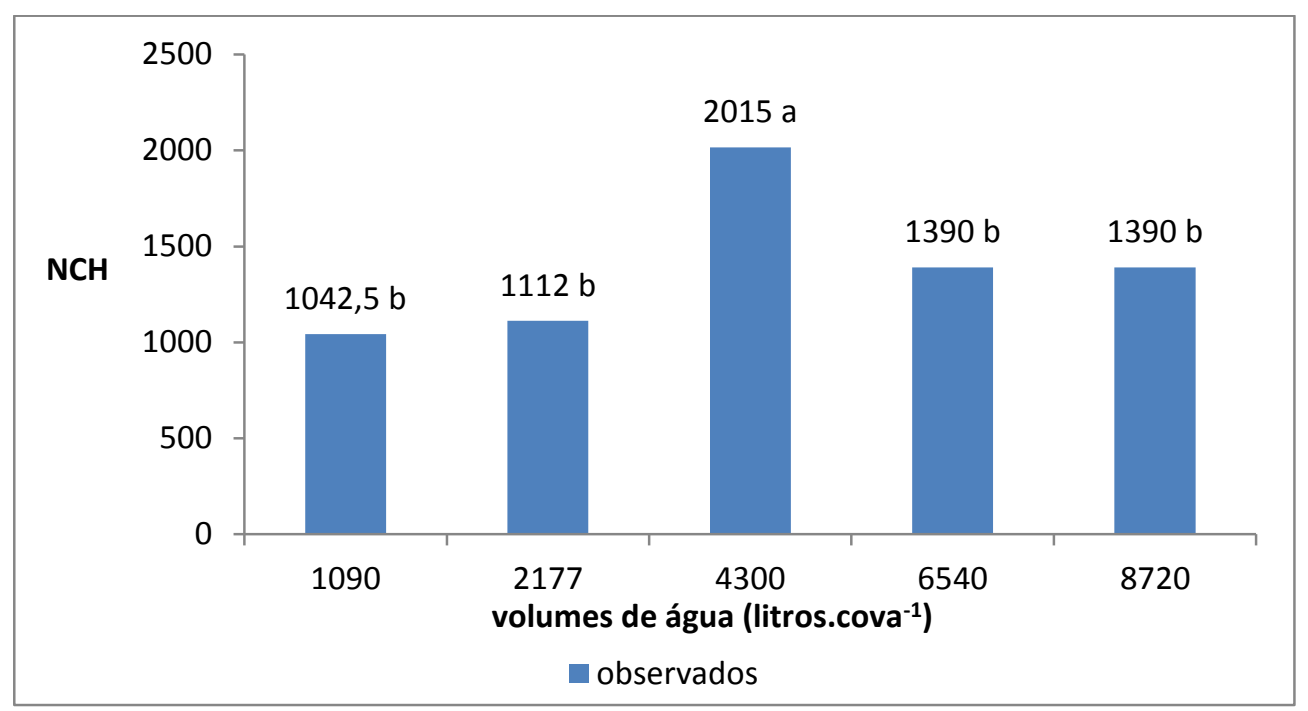

Figura 6: Números de cachos por hectare da cultivar 'Prata Anã' observados em função da dose de adubação de 150 kg.ha ${ }^{-1}$ de $\mathrm{P}_{2} \mathrm{O}_{5}$ e cinco volumes de irrigação (1.090-2.177-4.3006.540-8.720 litros.cova $\left.{ }^{-1}\right)$. Brasília, 2014.

\section{PESO DE PENCAS POR HECTARE (PPH)}

Foi observado que os volumes 6.540, 8.720 e 4.300 L.cova ${ }^{-1}$ denotaram resultados superiores aos demais. A equação de regressão linear ajusta os valores de PPH em função dos volumes de água aplicados conforme a Figura 7. Com aumento de 1.000 litros no volume de água aplicado por cova espera-se um aumento de aproximadamente $622 \mathrm{~kg}$ em PPH.

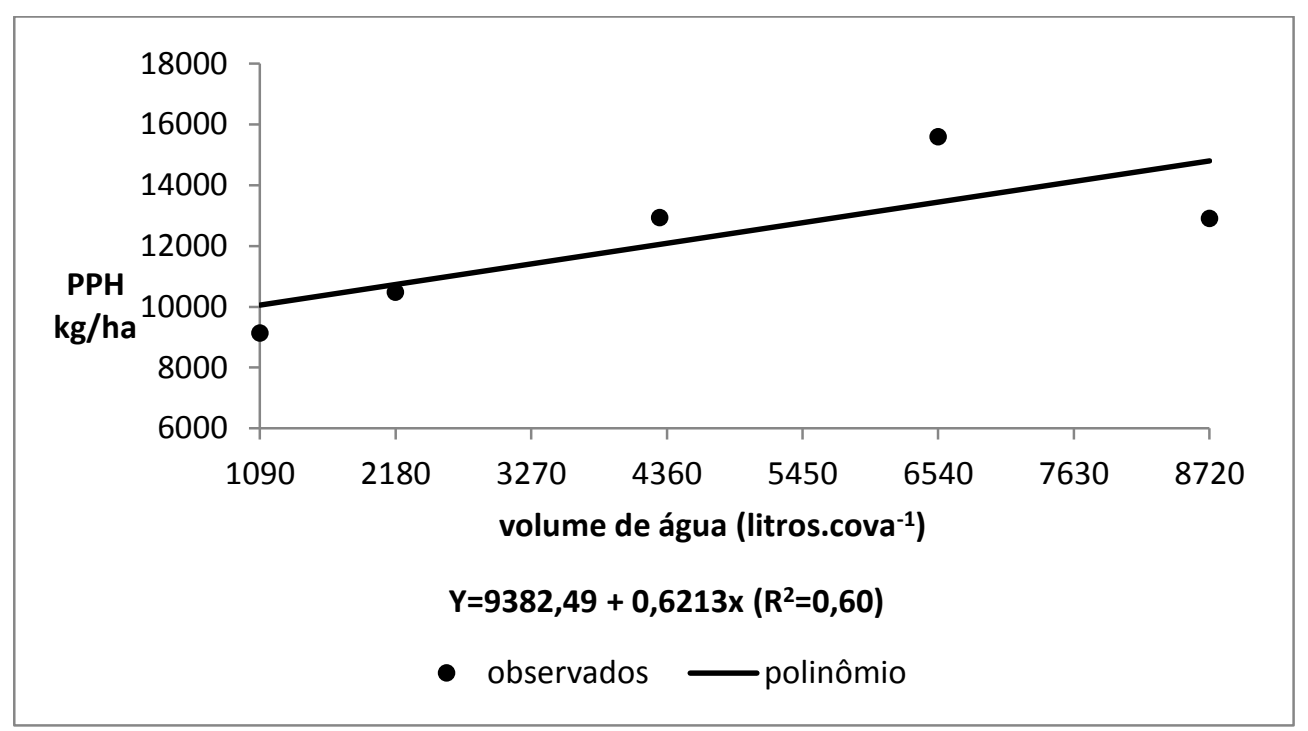

Figura 7: Pesos de cacho por hectare da cultivar 'Prata Anã' observados e ajustados em função de cinco volumes de irrigação (1.090-2.177-4.300-6.540-8.720 litros.cova ${ }^{-1}$ ). Brasília, 2014. 


\section{NÚMERO MÉDIO DE PENCAS POR CACHO (NMPC)}

Os volumes de água 6.540 e 8.720 L.cova $^{-1}$ proporcionaram valores para a variável número médio de pencas por cacho superiores. A equação de regressão linear ajusta o NMPC em função dos volumes de irrigação conforme a Figura 8. Com aumento de 1.000 litros no volume aplicado por cova observa-se um aumento de 0,0595 no NMPC.

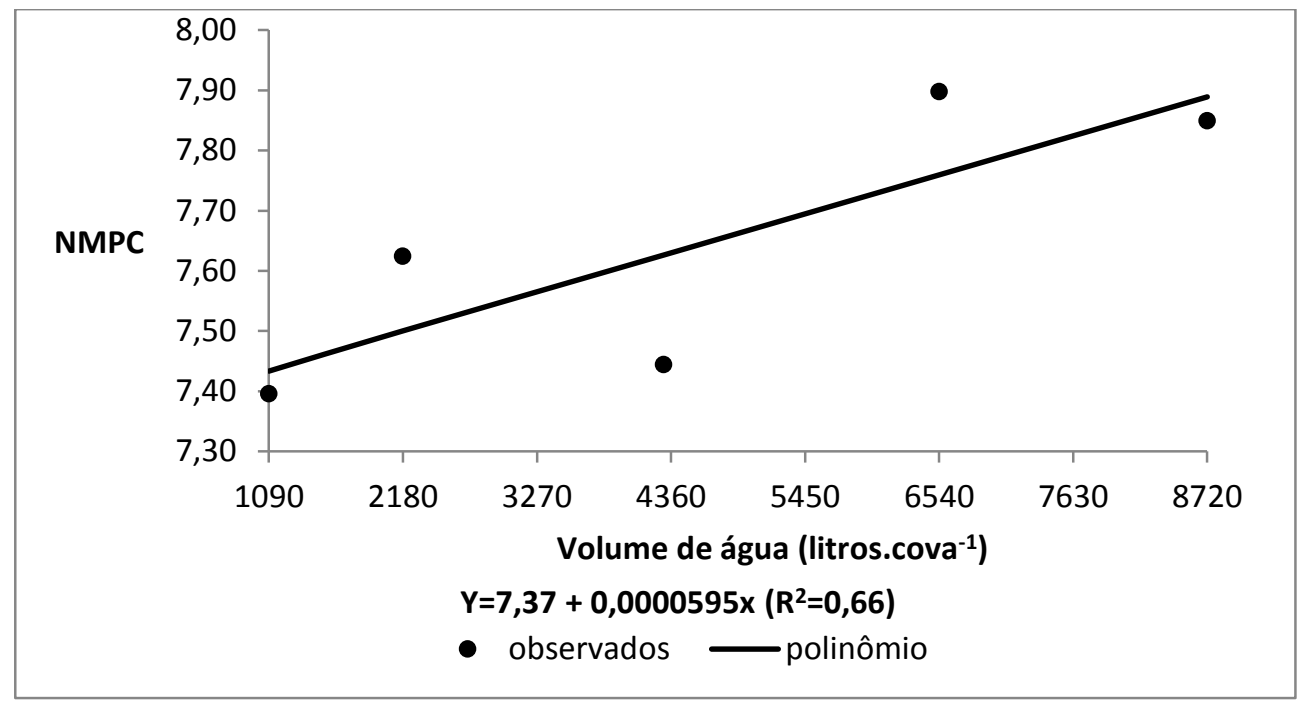

Figura 8: Números médios de pencas por cacho da cultivar 'Prata Anã' observados e ajustados em função de cinco volumes de irrigação (1.090-2.177-4.300-6.540-8.720 litros.cova $\left.{ }^{-1}\right)$. Brasília, 2014.

As interações de água x fósforo mostraram efeitos dentro da dose 0 kg.ha ${ }^{-1}$ de $\mathrm{P}_{2} \mathrm{O}_{5} \mathrm{e}$ dentro da dose $100 \mathrm{~kg} \cdot \mathrm{ha}^{-1}$ de $\mathrm{P}_{2} \mathrm{O}_{5}$. A interação dos volumes de 6.540 e 8.720 L.cova $^{-1}$ x 0 kg.ha- ${ }^{-1}$ de $\mathrm{P}_{2} \mathrm{O}_{5}$ proporcionaram valores superiores do NMPC. A equação de regressão linear ajusta os valores de NMPC em função dos volumes de água aplicados dentro da dose 0 kg.ha

${ }^{1}$ de $\mathrm{P}_{2} \mathrm{O}_{5}$ conforme a Figura 9. Com aumento de 1.000 litros no volume aplicado por cova espera-se aumento de 0,118 no NMPC.

Os tratamentos de 8.720, 6.540 e 2.177 L.cova ${ }^{-1}$ x 100 kg.ha-1 de $\mathrm{P}_{2} \mathrm{O}_{5}$ retrataram valores de NMPC superiores. A equação de regressão linear ajusta os valores de NMPC em função dos volumes de água aplicados quando usada a dose de100 kg.ha ${ }^{-1}$ de $\mathrm{P}_{2} \mathrm{O}_{5}$ conforme a Figura 10. Com aumento de 1.000 litros no volume aplicado por cova espera-se aumento de 0,108 no NMPC. 


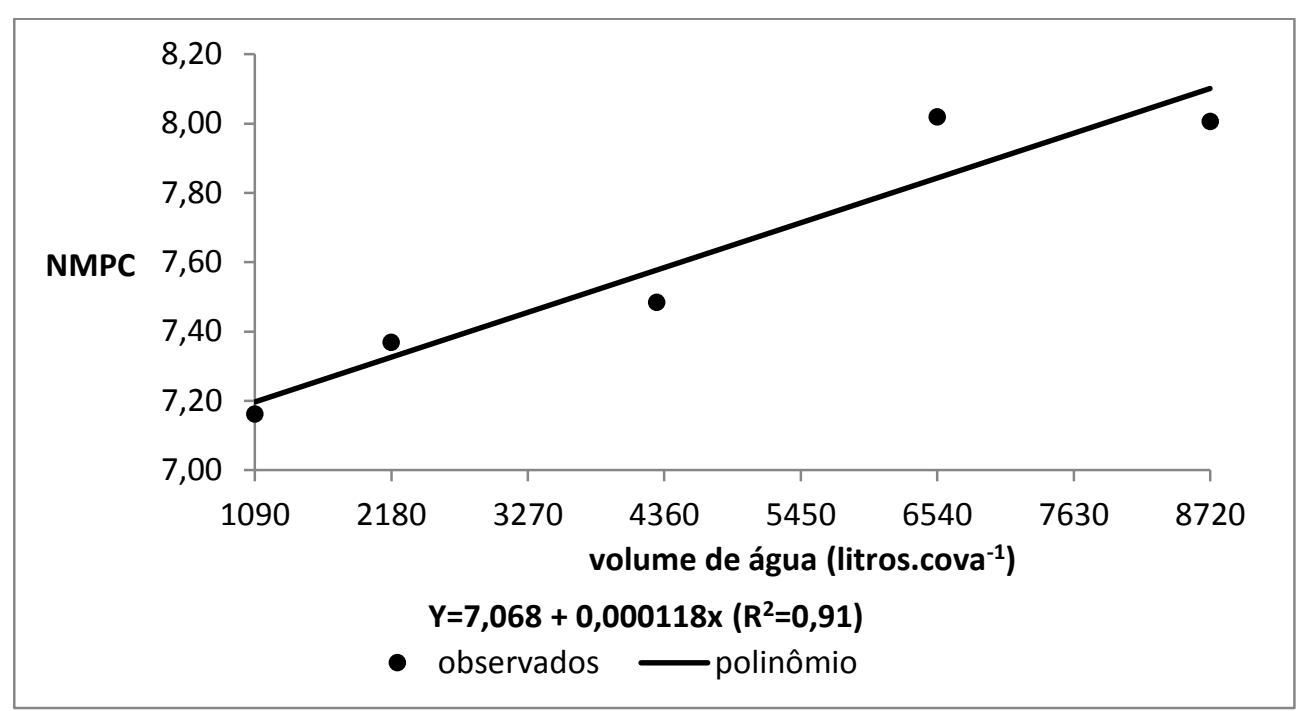

Figura 9: Números médios de pencas por cacho da cultivar 'Prata Anã' observados e ajustados em função dos volumes de irrigação (1.090-2.177-4.300-6.540-8.720 litros.cova $\left.{ }^{-1}\right)$ dentro da dose $0 \mathrm{~kg} \cdot \mathrm{ha}^{-1}$ de $\mathrm{P}_{2} \mathrm{O}_{5}$. Brasília, 2014.

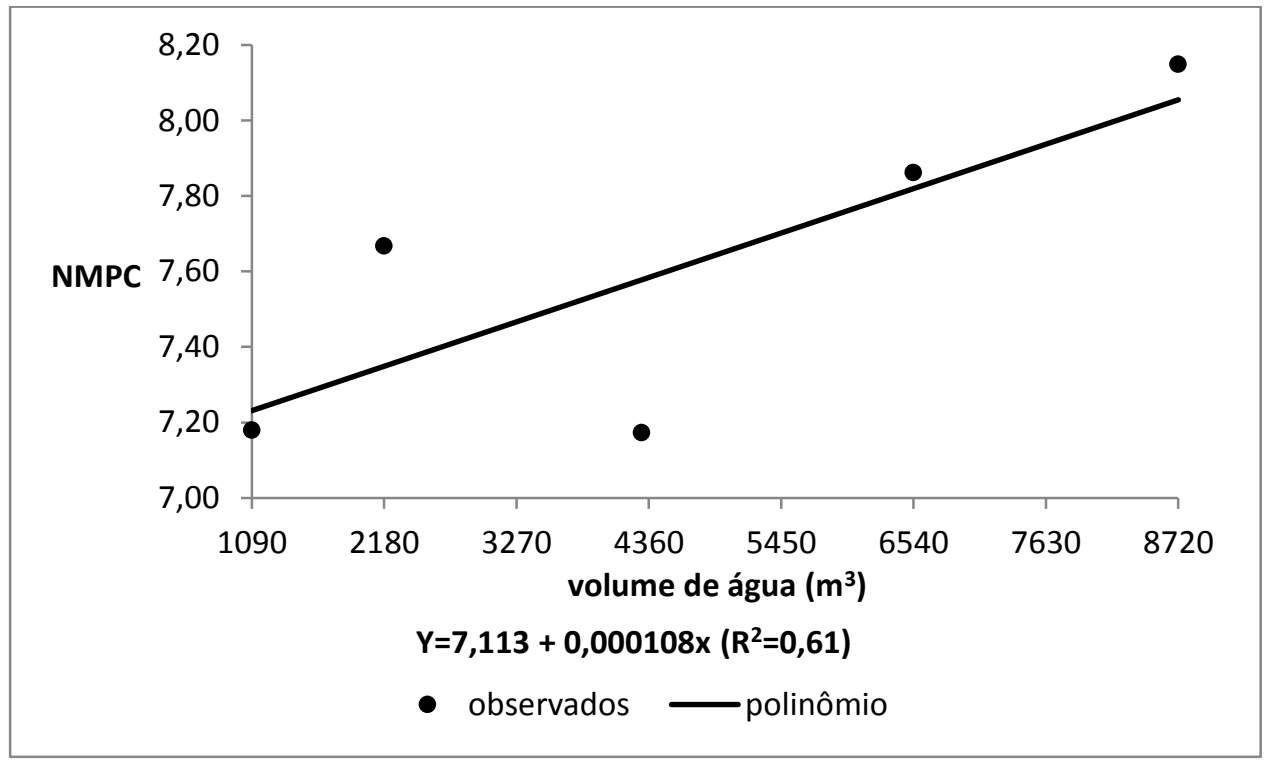

Figura 10: Números médios de pencas por cacho da cultivar 'Prata Anã' observados e ajustados em função de cinco volumes de irrigação (1.090-2.177-4.300-6.540-8.720 litros.cova ${ }^{-1}$ ) dentro da dose de 100 kg.ha ${ }^{-1}$ de $\mathrm{P}_{2} \mathrm{O}_{5}$. Brasília, 2014.

\section{NÚMERO MÉDIO DE BANANAS POR CACHO (NMBC)}

Os volumes de água de 6.540 e 8.720 L.cova $^{-1}$ apresentaram NMBC superiores. A equação de regressão linear ajusta os valores de NMBC em função dos volumes de água aplicados conforme a Figura 11. Com aumento de 1.000 litros aplicados por cova espera-se aumento de 1,11 no NMBC. 


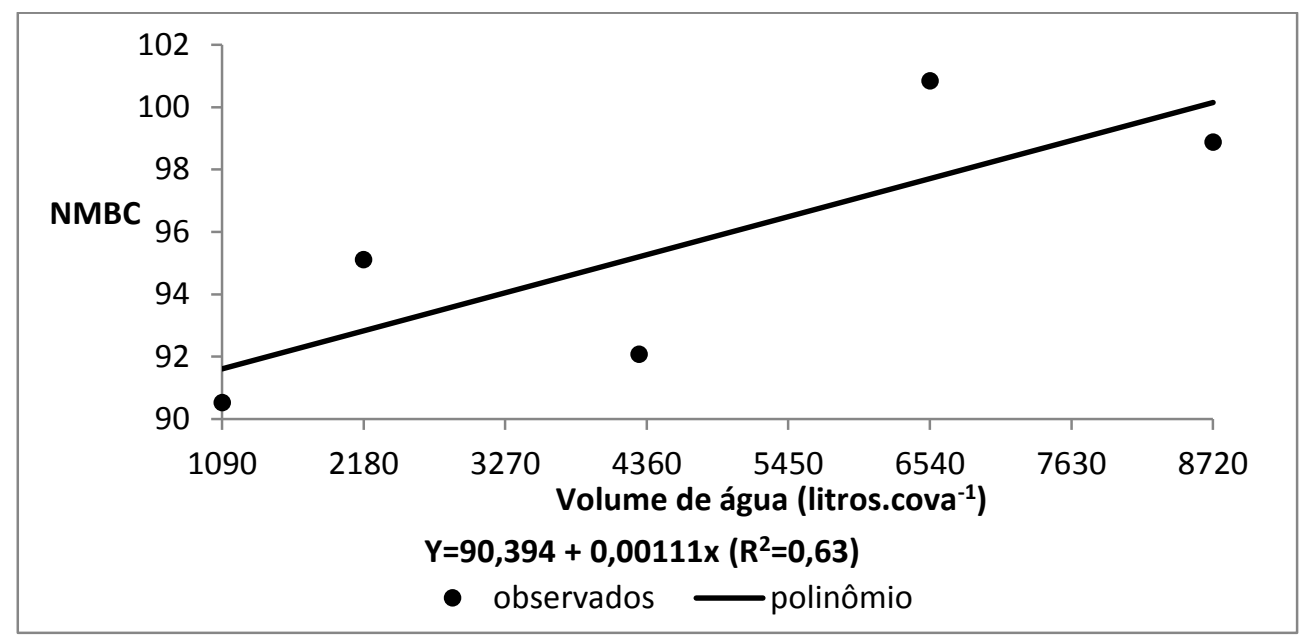

Figura 11: Números médios de bananas por cacho da cultivar 'Prata Anã' observados e ajustados em função de cinco volumes de irrigação (1.090-2.177-4.300-6.540-8.720 litros.cova $\left.{ }^{-1}\right)$. Brasília, 2014.

A interação de água $x$ fósforo mostrou efeitos significativos dentro da dose $0 \mathrm{~kg} \cdot \mathrm{ha}^{-1}$ de $\mathrm{P}_{2} \mathrm{O}_{5}$ e dentro da dose de $100 \mathrm{~kg} \cdot \mathrm{ha}^{-1}$ de $\mathrm{P}_{2} \mathrm{O}_{5}$.

Os tratamentos de 6.540 e 8.720 L.cova ${ }^{-1}$ x 0 kg.ha ${ }^{-1}$ de $\mathrm{P}_{2} \mathrm{O}_{5}$ explicitaram NMBC superiores aos demais. A equação de regressão linear ajusta os valores de NMBC em função dos volumes de água aplicados dentro da dose 0 kg.ha- ${ }^{-1}$ de $\mathrm{P}_{2} \mathrm{O}_{5}$ conforme a Figura 12. Com aumento de 1.000 litros aplicados por cova observa-se aumento de 2,47 no NMBC.

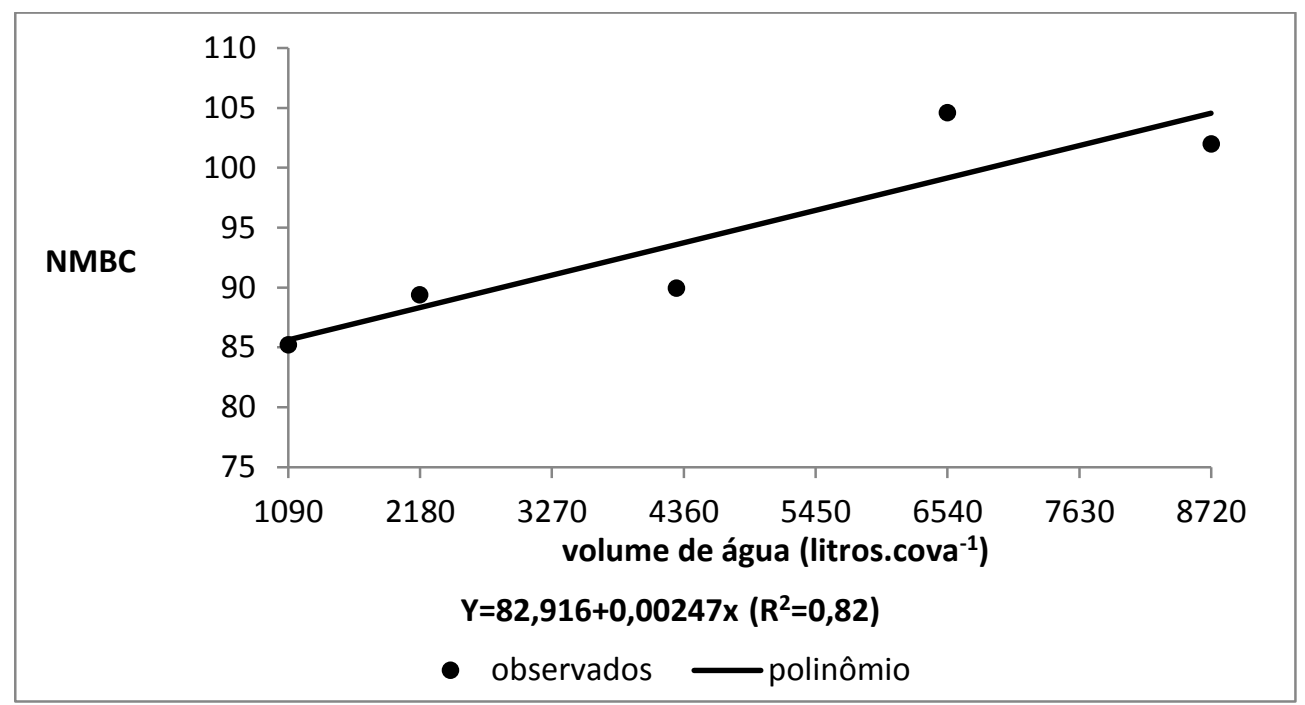

Figura 12: Números médios de bananas por cacho da cultivar 'Prata Anã' observados e ajustados em função de cinco volumes de irrigação (1.090-2.177-4.300-6.540-8.720 litros.cova ${ }^{-1}$ ) dentro da dose de 0 kg.ha- ${ }^{-1}$ de $\mathrm{P}_{2} \mathrm{O}_{5}$. Brasília, 2014.

Os volumes de 8.720, 6.540 e 2.177 L.cova ${ }^{-1}$ x 100 kg.ha ${ }^{-1}$ de $\mathrm{P}_{2} \mathrm{O}_{5}$ indicaram valores de NMBC superiores. A equação de regressão linear ajusta os valores de NMBC em função dos volumes de água aplicados dentro da dose de 100 kg.ha ${ }^{-1}$ de $\mathrm{P}_{2} \mathrm{O}_{5}$ conforme a Figura 13. 
Com aumento de 1.000 litros no volume aplicado por cova espera-se aumento de 1,94 no NMBC.

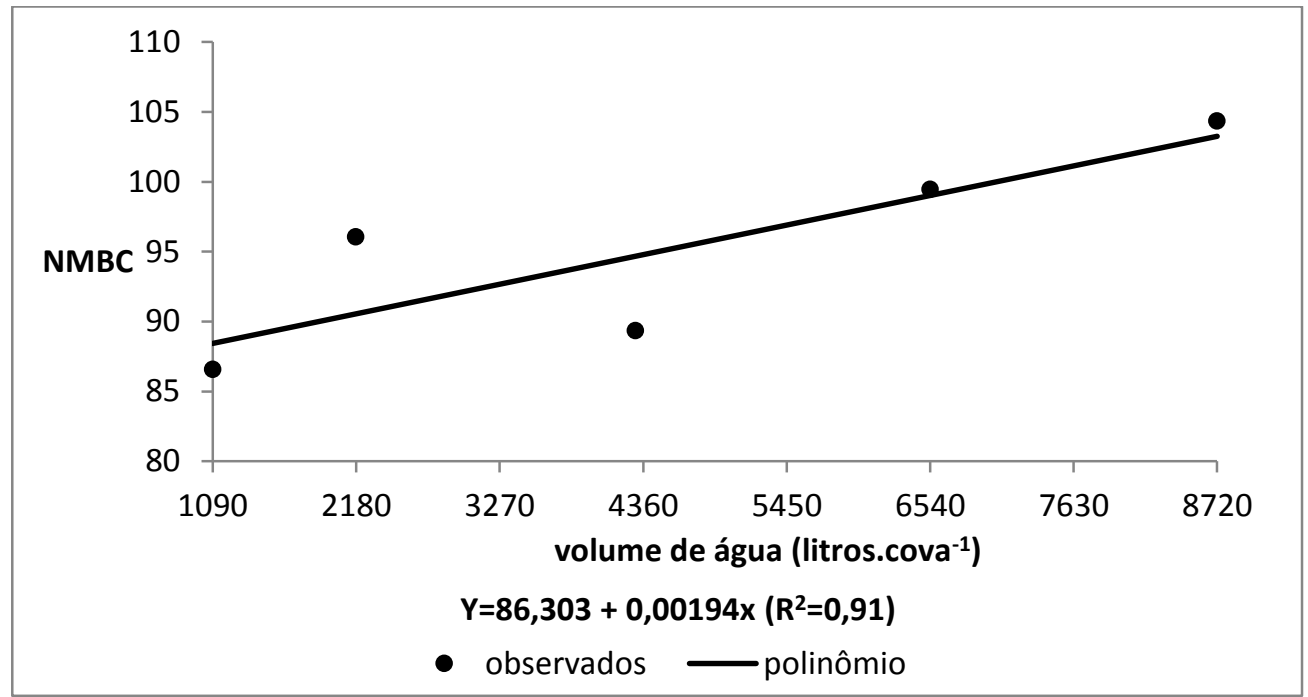

Figura 13: Números médios de bananas por cacho da cultivar 'Prata Anã' em função de cinco volumes de irrigação (1.090-2.177-4.300-6.540-8.720 litros.cova $\left.{ }^{-1}\right)$ dentro da dose de 100 kg.ha ${ }^{-1}$ de $\mathrm{P}_{2} \mathrm{O}_{5}$. Brasília, 2014.

\section{PESO MÉDIO DE BANANA(PMB)}

Os volumes de água de 6.540 e 8.720 L.cova $^{-1}$ demonstraram valores de PMB superiores. A equação de regressão linear ajusta os valores de PMB em função dos volumes de água aplicados conforme a Figura 14. Com aumento de 1.000 litros por cova espera-se aumento de $1,3 \mathrm{~g}$ no PMB.

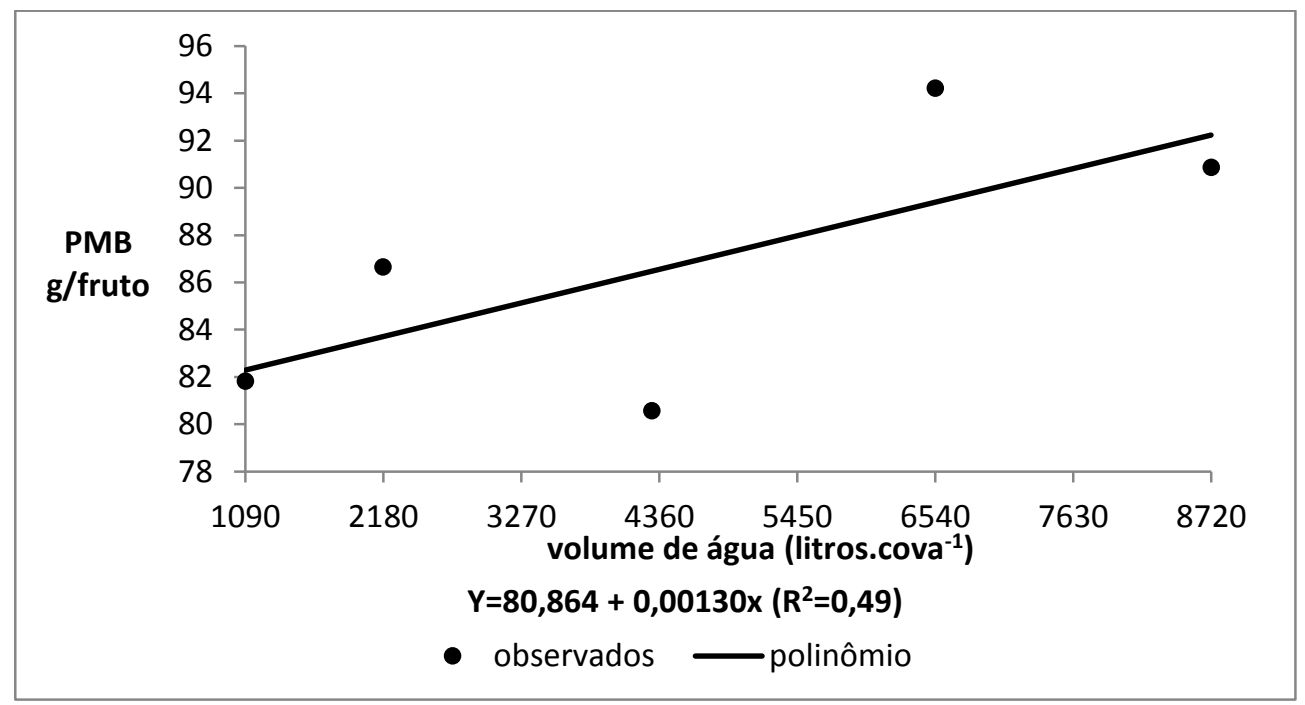

Figura 14: Pesos médios de bananas da cultivar 'Prata Anã' observados e ajustados em função de cinco volumes de irrigação (1.090-2.177-4.300-6.540-8.720 litros.cova ${ }^{-1}$ ). Brasília, 2014. 


\section{NÚMERO MÉDIO DE BANANAS POR PENCA (NMBP)}

A interação dos volumes de 6.540 e 8.720 L.cova ${ }^{-1}$ x 0 kg.ha ${ }^{-1}$ de $\mathrm{P}_{2} \mathrm{O}_{5}$ exibiram NMBP superiores. A equação de regressão linear ajusta os valores de NMBP em função dos volumes de água aplicados dentro da dose de 0 kg.ha- ${ }^{-1}$ de $\mathrm{P}_{2} \mathrm{O}_{5}$ conforme a Figura 15. Com aumento de 1.000 litros no volume de água aplicado espera-se aumento de 0,136 no NMBP.

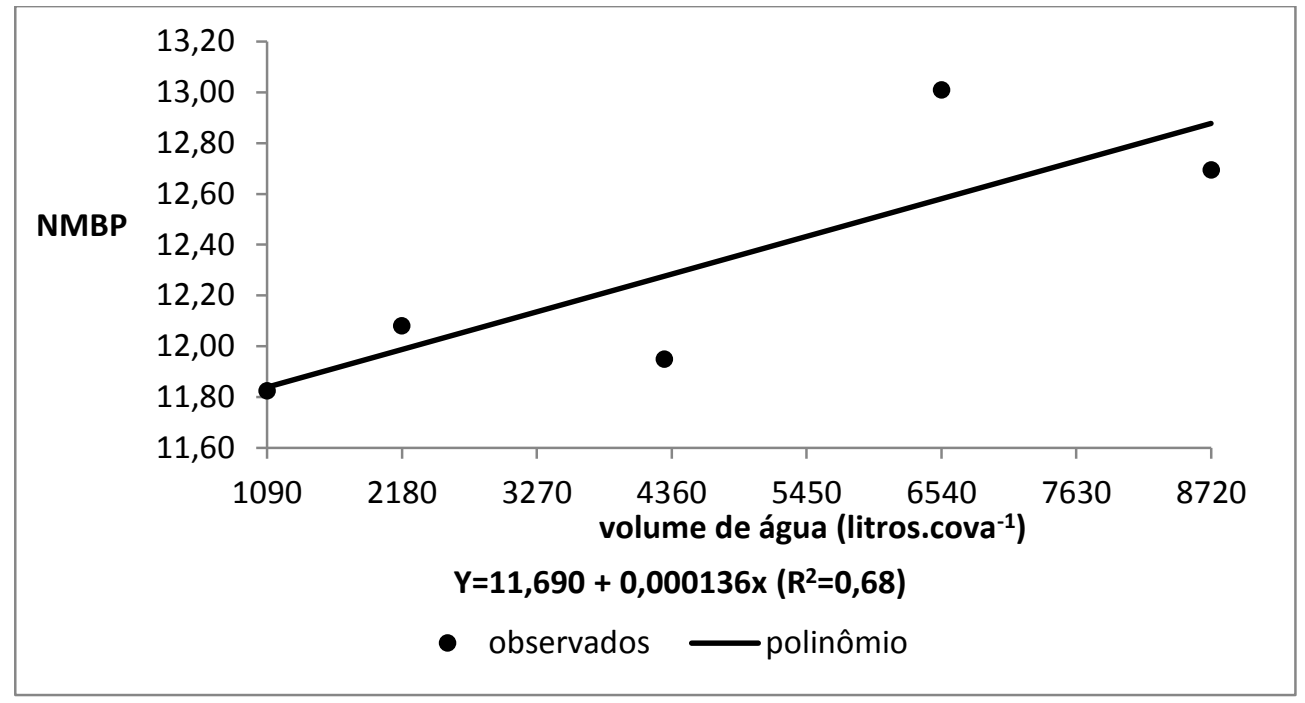

Figura 15: Número médio de bananas por penca da cultivar 'Prata Anã' observados e ajustados em função de cinco volumes de água (1.090-2.177-4.300-6.540-8.720 litros.cova ${ }^{-1}$ ) dentro da dose de 0 kg.ha ${ }^{-1}$ de $\mathrm{P}_{2} \mathrm{O}_{5}$. Brasília, 2014.

Para as variáveis de produção nota-se que os volumes acumulados de 6.540 e 8.720 $\mathrm{L} . c o v a^{-1}$ proporcionaram maiores valores para NCH, PPH, NMPC, NMBC e PMB em relação aos demais volumes aplicados. A interação de água com a dose $0 \mathrm{~kg}$ de $\mathrm{P}_{2} \mathrm{O}_{5} \cdot \mathrm{ha}^{-1}$ os volumes de 6.540 e 8.720 L.cova $^{-1}$ também proporcionaram maiores valores do NMBP. Isso vem de acordo com o apresentado por Costa et al., (2012) que apresenta $1.337 \mathrm{~mm}$ como lâmina que apresenta maior massa de cacho por hectare. Em relação à PPH percebe-se o comportamento linear crescente com o aumento dos níveis de água aplicados alcançando produtividade de 15.000 Kg.ha ${ }^{-1}$, com volume de 6.540 L não diferindo significativamente do volume de 8.720

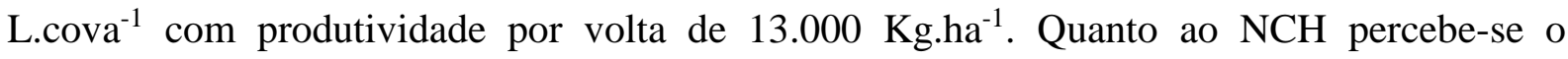
comportamento quadrático decrescente com o aumento dos níveis de água com volume de

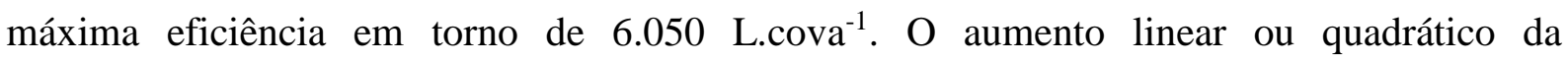
produtividade, com o aumento da lâmina, também foi observado em outros trabalhos com cultivares de bananeiras (COELHO et al., 2006; FIGUEIREDO et al., 2006). A interação de 4.300 L.cova ${ }^{-1}$ x $150 \mathrm{~kg}$ de $\mathrm{P}_{2} \mathrm{O}_{5} \cdot \mathrm{ha}^{-1}$ proporcionou maiores valores de $\mathrm{NCH}$ indicando otimização dos recursos. Para a maior parte das características de produção analisadas neste trabalho fica evidente pelas respostas lineares obtidas que a cultura da bananeira, nas 
condições do planalto central, requer suprimento constante e adequado de água para obtenção de bons índices de produtividade.

Os resultados também são próximos dos encontrados por Goenaga et al., (1995) que obtiveram maiores produtividades de plátanos com lâminas iguais ou maiores que $75 \%$ da evaporação do tanque classe $\mathrm{A}$, ou seja, valores próximos ou superiores aos da evapotranspiração da cultura. O volume de 6.540 L.cova ${ }^{-1}$ apresentou índices de produtividade mais adequados para a cultivar 'Prata Anã' nas condições pesquisadas, pois está respaldada em bons índices de produção e suprimento da demanda hídrica.

Silva et al., (2007) classificam a produtividade da bananeira 'Prata Anã' como: baixa $<25$ t.ha' ${ }^{-1}$.ano ${ }^{-1}$; média de 25 a 32 t.ha $^{-1}$.ano ${ }^{-1}$; alta $>32$ t.ha $^{-1}$.ano ${ }^{-1}$. Normalmente os valores de produção no primeiro ciclo de produção são menores comparados aos ciclos subsequentes. Silva et al. (2000) argumentam que o primeiro ciclo de produção não deve ser considerado como momento ideal para analisar a produtividade visto que esta característica, na maioria das cultivares utilizadas, tende a aumentar até o quarto ciclo de produção.

Pela classificação proposta por Silva et al. (2007) os valores de produtividade apresentados neste trabalho enquadram-se como baixa produtividade.

De acordo com Costa et al. (2008) características vegetativas e de produção, em três ciclos de produção, de maneira geral apresentam-se menores em plantação sob gotejamento, quando comparada com sistema de aspersão convencional e microaspersão. Provavelmente esses dois últimos sistemas proporcionam maior expansão do sistema radicular, por apresentarem área de molhamento maior, com reflexos no crescimento e desenvolvimento da planta.

Sant'ana (2011) avaliou a distribuição do sistema radicular e a extração de água pela bananeira 'Prata-Anã', nas fases de florescimento do primeiro ciclo e final do crescimento dos frutos do primeiro e do segundo ciclo. $\mathrm{O}$ autor verificou maior densidade de comprimento radicular das plantas sob gotejamento e menor profundidade efetiva naquelas sob microaspersão e aspersão, o que indica que estes sistemas proporcionam maior área com disponibilidade de água superficial, enquanto o gotejamento disponibiliza água no solo a profundidades maiores, o que facilita o aprofundamento radicular.

Donato et al. (2009) trabalhando com bananeiras tipo 'Prata' sob diferentes sistemas de irrigação, aspersão, microaspersão e gotejamento não encontraram diferenças significativas nos teores foliares médios de fósforo aos 90, 180 e 360 dias após o plantio para o primeiro 
ciclo da cultura. Este trabalho corrobora com os resultados encontrados, indicando que a cultura da bananeira em primeiro ciclo é pouco influenciada pelos tratamentos de fósforo, sendo esperadas respostas diferentes para avaliações de ciclos posteriores. No mesmo trabalho o autor conclui que a irrigação por gotejamento proporciona os menores teores foliares de micronutrientes em bananeiras tipo 'Prata' no primeiro ciclo de produção, em comparação à irrigação por aspersão e microaspersão.

Trabalho realizado por Coelho et al. (2006) indicam que o peso médio de frutos das cultivares 'Prata Anã' e 'Grand Naine' em terceiro ciclo de produção, foi influenciado pelas lâminas de água, apresentando uma função quadrática com máxima PMB com lâminas em torno de $100 \%$ da evapotranspiração da cultura.

No presente trabalho foi utilizado frequência de irrigação de dois dias, respaldado por trabalho realizado por Coelho et al. (2006) onde afirmam não haver efeito significativo na produtividade das pencas em frequências de irrigação de quatro e seis dias em sistema de irrigação localizada.

Com relação ao NMPC este estudo teve resultados semelhantes aos encontrados por Costa et al. (2008) no qual indicam respostas apenas aos níveis crescentes de irrigação.

\section{COMPRIMENTO MÉDIO DE BANANAS (CMB)}

Os diferentes volumes de água apresentaram efeitos médios significativos onde os volumes 6.540, 8.720 e 2.177 L.cova $^{-1}$ proporcionaram CMB superiores. A equação de regressão linear ajusta os valores de $\mathrm{CMB}$ em função dos volumes de água aplicados conforme a Figura 16. Com aumento de 1.000 litros no volume de água aplicada observa-se aumento de $0,753 \mathrm{~mm}$ no CMB.

As interações de 8.720, 6.540 e 2.177 L.cova ${ }^{-1}$ x 0 kg.ha-1 de $\mathrm{P}_{2} \mathrm{O}_{5}$ apresentaram valores de CMB superiores. A equação de regressão linear ajusta os valores de CMB em função dos volumes de água aplicados dentro da dose 0 kg.ha- ${ }^{-1}$ de $\mathrm{P}_{2} \mathrm{O}_{5}$ conforme a Figura 17. Com aumento de 1.000 litros no volume de água aplicado espera-se aumento de 1,36 mm no CMB. 


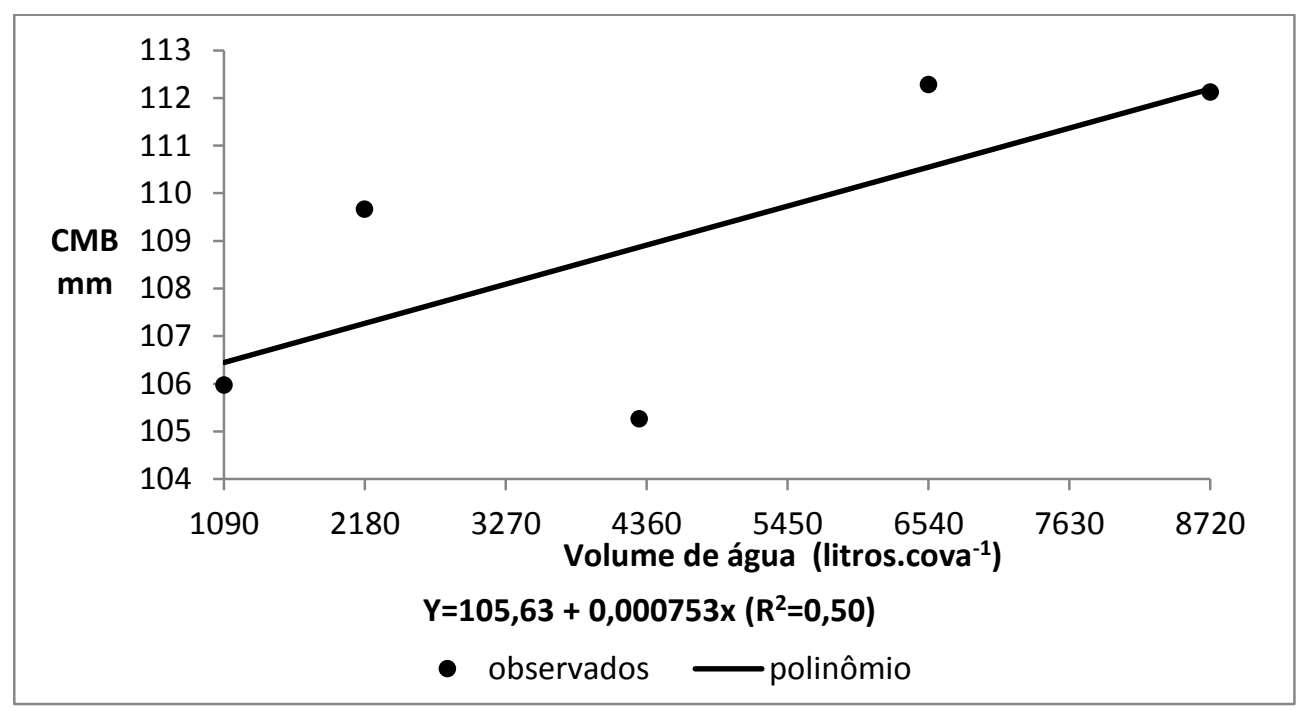

Figura 16: Comprimentos médios de bananas da cultivar 'Prata Anã' observados e ajustados em função de cinco volumes de irrigação (1.090-2.177-4.300-6.540-8.720 litros.cova ${ }^{-1}$ ). Brasília, 2014.

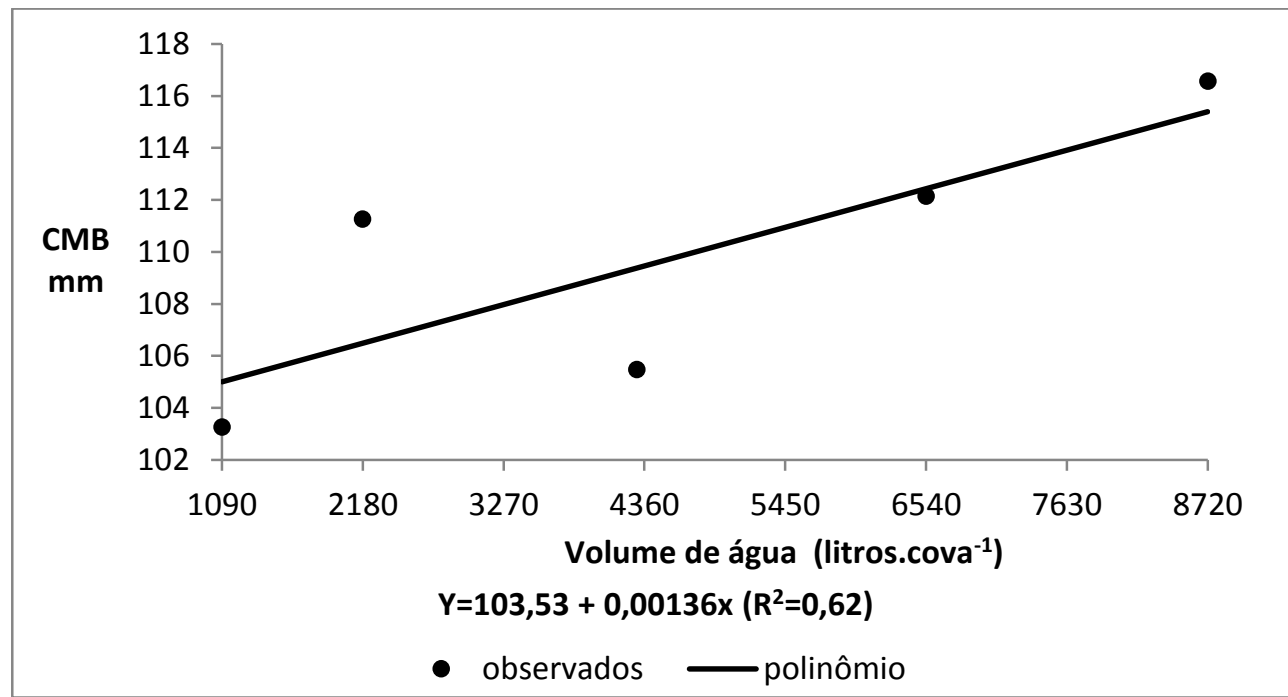

Figura 17: Comprimentos médios de bananas da cultivar 'Prata Anã' observados e ajustados em função de cinco volumes de irrigação (1.090-2.177-4.300-6.540-8.720 litros.cova $\left.{ }^{-1}\right)$ dentro da dose de $0 \mathrm{~kg} \cdot \mathrm{ha}^{-1}$ de $\mathrm{P}_{2} \mathrm{O}_{5}$. Brasília, 2014.

DIÂMETRO MÉDIO DE BANANAS (DMB)

Os volumes de 6.540, 8.720 e 2.177 L.cova $^{-1}$ proporcionaram valores de DMB superiores. A equação de regressão linear ajusta os valores de DMB em função dos volumes de água aplicados conforme a Figura 18.

As interações de 6.540 e 8.720 L.cova $^{-1}$ x 50 kg.ha ${ }^{-1}$ de $\mathrm{P}_{2} \mathrm{O}_{5}$ apresentaram valores de DMB superiores conforme a Figura 19. 


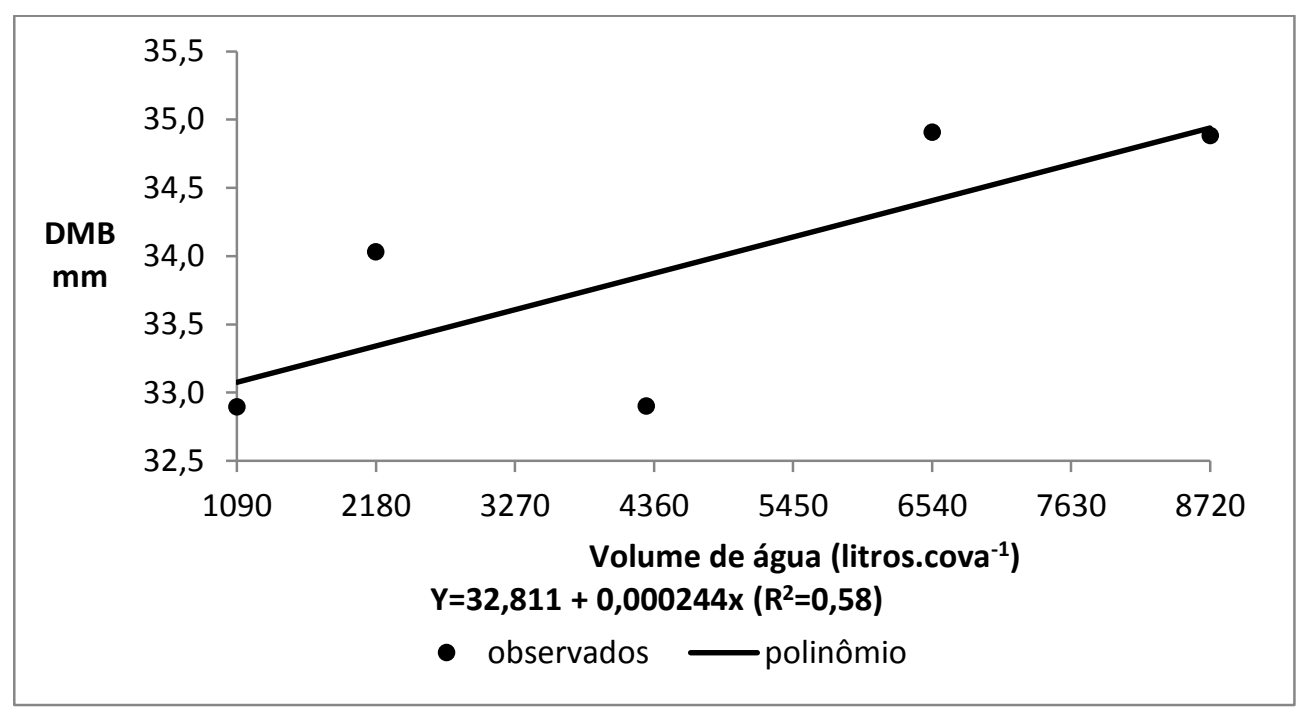

Figura 18: Diâmetros médios de bananas da cultivar 'Prata Anã' observados e ajustados em função de cinco volumes de irrigação (1090-2177-4300-6540-8720 litros.cova ${ }^{-1}$ ). Brasília, 2014.

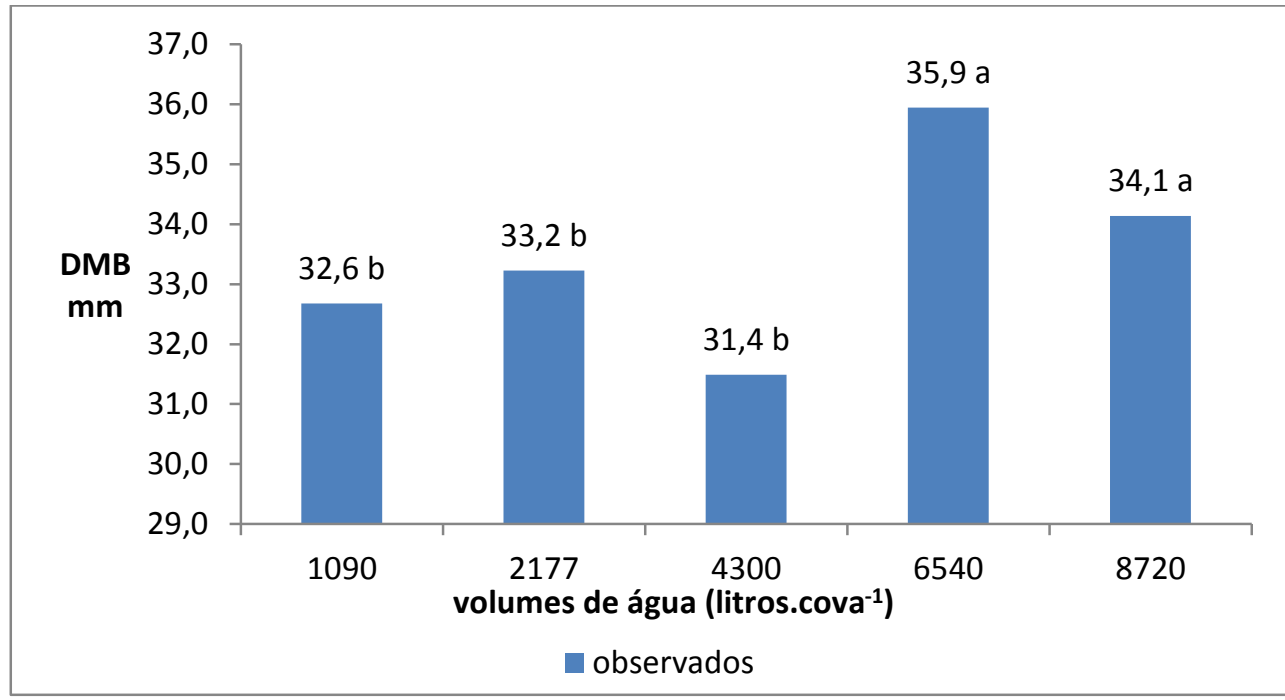

Figura 19: Diâmetros médios de bananas da cultivar 'Prata Anã' observados em função de cinco volumes de irrigação (1.090-2.177-4.300-6.540-8.720 litros.cova $\left.^{-1}\right)$ dentro da dose de $50 \mathrm{~kg} \cdot \mathrm{ha}^{-1}$ de $\mathrm{P}_{2} \mathrm{O}_{5}$. Brasília, 2014.

\section{RELAÇÃO COMPRIMENTO/DIÂMETRO (CD)}

As doses de fósforo de $0 \mathrm{~kg} \cdot \mathrm{ha}^{-1}$ de $\mathrm{P}_{2} \mathrm{O}_{5}$ e $50 \mathrm{~kg} \cdot \mathrm{ha}^{-1}$ de $\mathrm{P}_{2} \mathrm{O}_{5}$ proporcionaram maiores valores de $\mathrm{CD}$. A equação de regressão linear ajusta os valores de $\mathrm{CD}$ em função das doses de fósforo conforme a Figura 20. 


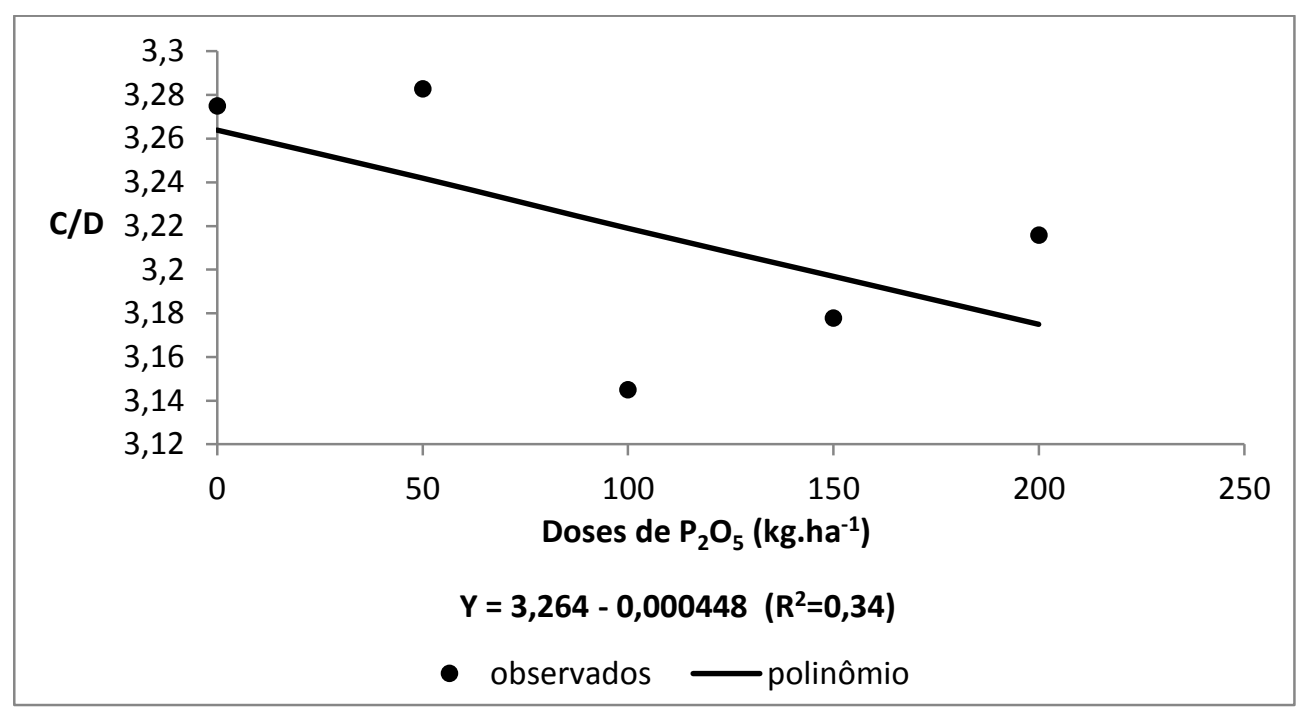

Figura 20: Relações comprimentos/diâmetros dos frutos da cultivar 'Prata Anã' observados e ajustados em função das cinco doses de fósforo (0-50-100-150-200 kg.ha-1 de $\mathrm{P}_{2} \mathrm{O}_{5}$ ). Brasília, 2014.

Quanto às características que indicam qualidade de frutos CMB e DMB apresentaram efeitos médios significativos em resposta aos incrementos nos volumes de água aplicados. $\mathrm{O}$ CMB respondeu de forma linear aos incrementos nos volumes de água, apresentando maior comprimento de $112 \mathrm{~mm}$ com volume de $8.720 \mathrm{~L} . c o v a^{-1}$, não diferindo significativamente dos volumes de 6.540 e 2.177 L.cova ${ }^{-1}$.

Além de serem componentes do rendimento da produção do bananal (t.ha $\left.{ }^{-1}\right)$, as dimensões dos frutos compõem os itens de classificação da fruta, resultando no valor final da produção. De acordo com Frutiséries (2000), frutos do subgrupo Prata são classificados em três categorias quanto ao comprimento e diâmetro: Exportação: $>16$ cm e $>38$ mm; Primeira: $>14 \mathrm{~cm}$ e > $32 \mathrm{~mm}$; e Segunda: > $12 \mathrm{~cm}$ e > $29 \mathrm{~mm}$, respectivamente.

As doses de $\mathrm{P}_{2} \mathrm{O}_{5}$ não influenciaram significativamente a produção e nem a qualidade de fruto. Maia et al. (2003), ao avaliar a bananeira 'Prata Anã' cultivada em solo arenoso, com teor de $\mathrm{P}$ disponível pelo extrator Mehlich ${ }^{-1}$ de $1,3 \mathrm{mg} \cdot \mathrm{dm}^{-3}$, observaram que a massa do cacho, o número de pencas por cacho, a massa média da penca, o número de frutos por cacho, a massa média do fruto, o comprimento e o diâmetro do fruto no primeiro ciclo de produção não foram dependentes da dose de $\mathrm{P}$, o que indica baixo requerimento do nutriente pela cultura. Entretanto Silva et al. (2007) relataram que solos com bananeiras altamente produtivas apresentavam teores significativamente maiores de P (39,2mg.dm ${ }^{-3}$, Mehlich-1) do que solos com bananeiras pouco produtivas $\left(23 \mathrm{mg} \cdot \mathrm{dm}^{-3}\right)$, o que sugere que esses fatores estão associados. 
Vale ressaltar que os experimentos foram conduzidos sem aplicação de defensivos para controle de sigatoka e isso influencia de forma direta a quantidade de folhas viáveis durante todo ciclo da cultura acarretando em menores índices de produtividade. De acordo com Azevedo (2010) a quantidade de folhas presente num genótipo, num determinado momento do ciclo fenológico pode ser influenciada pela severidade das sigatokas e velocidade do vento, fatores que causam a destruição foliar e consequente perda na capacidade de produção de fotoassimilados.

Alguns argumentos podem justificar a similaridade estatística para maioria das variáveis analisadas neste primeiro ciclo de produção: melhor aproveitamento de umidade e nutrientes do solo pelas raízes, pois se concentram mais próximas ao pseudocaule, no primeiro ciclo, junto à região de umedecimento dos gotejadores; maior uniformidade da cultura no primeiro ciclo, por se tratar de mudas micropropagadas e menor variabilidade inerente ao ciclo (DONATO et al., 2009) e maior aprofundamento radicular proporcionado pelo gotejamento devido à formação de bulbo de molhamento mais estreito.

Observa-se que a produtividade expressa pela característica PPH possui correlação positiva forte com NCH (Tabela 8). Também como indicador de produtividade nota-se correlação positiva muito forte entre NMBP e NMBC. O PPH apresentou correlação positiva média com o PMB que por sua vez demonstrou correlação média positiva com CMB, demonstrando possíveis indicadores de produtividade. 
Tabela 8: Coeficientes de correlações lineares de Pearson entre as características de produtividade e qualidade de fruto. FAL/FAV/UnB, 2014

\begin{tabular}{|c|c|c|c|c|c|c|c|c|c|c|}
\hline & $\mathrm{PPH}$ & NMPC & NMBC & PMB & CMB & $\mathrm{DMB}$ & FMP & $\mathrm{CD}$ & NMBP & $\mathrm{NCH}$ \\
\hline PPH & 1 & $0.32^{* *}$ & $0.35^{* *}$ & $0.57^{* *}$ & $0.51^{* *}$ & $0.44^{* *}$ & $0.09^{\mathrm{ns}}$ & $0.009^{\mathrm{ns}}$ & $0.33^{* *}$ & $0.87^{* *}$ \\
\hline NMPC & & 1 & $0.95^{* *}$ & $0.31^{* *}$ & $0.35^{* *}$ & $0.31^{\text {** }}$ & $-0.21^{*}$ & $-0.01^{\mathrm{ns}}$ & $0.69^{* *}$ & $0.09^{\mathrm{ns}}$ \\
\hline NMBC & & & 1 & $0.33^{* *}$ & $0.37^{* *}$ & $0.28^{* *}$ & $-0.22^{*}$ & $0.06^{\mathrm{ns}}$ & $0.88^{* *}$ & $0.11^{\mathrm{ns}}$ \\
\hline PMB & & & & 1 & $0.74^{* *}$ & $0.68^{* *}$ & $0.15^{\mathrm{ns}}$ & $-0.04^{\mathrm{ns}}$ & $0.31^{* *}$ & $0.33^{* *}$ \\
\hline $\mathrm{CMB}$ & & & & & 1 & $0.68^{* *}$ & $0.12^{\mathrm{ns}}$ & $0.25^{* *}$ & $0.34^{* *}$ & $0.28^{* *}$ \\
\hline DMB & & & & & & 1 & $0.12^{\mathrm{ns}}$ & $-0.52^{* *}$ & $0.18^{*}$ & $0.25^{* *}$ \\
\hline FMP & & & & & & & 1 & $0.03^{\mathrm{ns}}$ & $-0.18^{\mathrm{ns}}$ & $0.11^{\mathrm{ns}}$ \\
\hline $\mathrm{CD}$ & & & & & & & & 1 & $0.16^{\mathrm{ns}}$ & $-0.01^{\mathrm{ns}}$ \\
\hline NMBP & & & & & & & & & 1 & $0.11^{\mathrm{ns}}$ \\
\hline $\mathrm{NCH}$ & & & & & & & & & & 1 \\
\hline
\end{tabular}

$\mathrm{NS}=$ não significativo, $*$ significativo a $5 \%$, ** significativo a $1 \%$ pelo teste $\mathrm{t}, \mathrm{PPH}=$ peso de pencas por hectare, $\mathrm{NMPC}=$ número médio de pencas por cacho, $\mathrm{NMBC}=$ número médio de bananas por cacho, $\mathrm{PMB}=$ peso médio de bananas, $\mathrm{CMB}=$ comprimento médio de bananas, $\mathrm{DMB}=$ diâmetro médio de bananas, $\mathrm{FMP}=$ firmeza média da polpa, $\mathrm{CD}=$ relação comprimento sobre diâmetro, $\mathrm{NMBP}=$ número médio de bananas por penca, $\mathrm{NCH}=$ número de cachos por hectare. 


\section{CONCLUSÕES}

Os volumes de 6.540 e 8.720 L.cova $^{-1}$ proporcionaram maiores valores para os caracteres relacionados à produtividade e qualidade de frutos.

$\mathrm{O}$ uso de $\mathrm{P}_{2} \mathrm{O}_{5}$ parcelado no solo proporcionou aumento na relação $\mathrm{C} / \mathrm{D}$, com efeito linear indicando aumento do comprimento e diâmetro do fruto.

O número de cachos aumentou na presença de doses de água com doses de fósforo.

O número médio de pencas por cacho e número médio de bananas por cacho apresentaram maiores valores com a interação água versus fósforo. 


\section{REFERÊNCIAS BIBLIOGRÁFICAS}

ALLEN, R.G.; PEREIRA, L.S.; RAES, D.; SMITH, M. Crop evapotranspiration: guidelines for computing crop water requirements. Rome: FAO, Irrigation and Drainage Paper 56, 301 p. 2006.

ALVES, E. J. A cultura da banana: aspectos técnicos, socioeconômicos e agroindustriais. Brasília, DF: Embrapa - SPI / Cruz das Almas: Embrapa - CNPMF. 2. ed revisada. 1999.585p.

Anuário brasileiro da fruticultura 2014. Santa Cruz do Sul Editora Gazeta 2013. 136 p.

AZEVEDO, V.F. Avaliação de bananeira tipo prata, de porte alto, no semiárido. Ciência e Agrotecnologia, Lavras, v.34, n.6, nov./dez., 2010. p. 1372-1380.

BERNARDO, S.; SOARES, A.A. \& MANTOVANI, E. C. Manual de irrigação. 8.ed. Viçosa: Editora UFV, 2009. v. 1, p 630.

BERNARDO, S.; SOARES, A. A.; MANTOVANI, E. C. . Manual de irrigação. 8. ed. Viçosa: Editora UFV. v. 1. 2013. 630p.

CAMPOS, P. M; LACERDA, M. P. C; SILVA, C. L. da; SÁ, M. A. C. de; SOUSA, D. M. G. de. Drenagem interna como fator de diferenciação de Latossolos no Distrito Federal. Pesquisa Agropecuária Brasileira. Brasília, v.45, n.3. 2010. p. 306-314.

CARVALHO, F. I. F. et al. Estimativas e implicações da correlação no melhoramento vegetal. Pelotas: Ed. Universitária da UFPel, 2004. 142 p.

COELHO E. F.; COSTA É.L da; SILVA, C. A. L da; SILVA, S. de O; Produtividade e eficiência de uso de água das bananeiras 'prata anã' e 'grand naine' sob irrigação no terceiro ciclo no norte de Minas Gerais. Irriga, Botucatu, v.11. out.-dez. 2006. p. 460-468.

Coelho, E. F.; Costa, E. L. da; Ledo, C. A. da S.; Silva, S. de O. e; Produtividade e eficiência de uso de água das bananeiras 'Prata Anã' e 'Grand Naine' sob irrigação no terceiro ciclo no norte de Minas Gerais. Revista Irriga. v.11, 2006a. p.460-468.

COELHO, E.F.; LEDO, C.A. da S.; SILVA, S. de O. Produtividade da bananeira 'Prata-anã' e 'Grande Naine' no terceiro ciclo sob irrigação por microaspersão em tabuleiros costeiros da Bahia. Revista Brasileira de Fruticultura, v.28, 2006. p.435-438.

COSTA, É.L. da; COELHO, E.F.; SIMÃO, F.R.; COELHO FILHO, M.A.; OLIVEIRA, P.M. de. Irrigação da bananeira. Informe Agropecuário, v.29, 2008. p. 38-46.

COSTA, F. da S.; SUASSUNA, J. F.; MELO, A. S. de; BRITO, M. E. B.; MESQUITA, E. F. de. Crescimento, produtividade e eficiência no uso da água em bananeira irrigada no semiárido parai-bano Revista Caatinga, Mossoró, v. 25, n. 4. out-dez. 2012. p. 26-33.

COSTA, S. C.; SOARES, A. A.; SEDIYAMA, G. C.; VIANA, T. V. de A.; MOREIRA, F. V. de O. Comportamento dos parâmetros indicativos de produção da bananeira pacovan submetida a diferentes lâminas de irrigação e doses de potássio na chapada do apodi Limoeiro do Norte-CE. Revista Caatinga, Mossoró, v.22, n.4. out.-dez. 2009. p. 46-52. 
CUI, N.B.; DU, T.S.; KANG, S.Z.; LI, F.S.; ZHANG, J.H.; WANG, M.X.; LI, Z.J. Regulated deficit irrigation improved fruit quality and water use efficiency in pear-jujube trees. Agricultural Water Management, Amsterdam, v.95. n. 4. 2008. p.489-497.

DOMINGO, R.; RUIZ-SÁNCHEZ, M.C.; SÁNCHEZ-BLANCO, M.J.; TORRECILLAS, A. Water relations, growth and yield of fino lemon trees under regulated deficit irrigation. Irrigation Science, New York, v.16. 1996. p.115-123.

Donato, S. L. R.; Lédo, A. A.; Pereira, M. C. T.; Coelho, E. F.; Cotrim, C. E.; Filho, M. A. C. Estado nutricional de bananeiras tipo Prata Pesquisa agropecuária brasileira, Brasília, v.45, n.9. set. 2010. p.980-988.

DONATO, S.L.R.; ARANTES, A.M.; SILVA, S.O.; CORDEIRO, Z.J. Comportamento fitotécnico da bananeira 'Prata-Anã' e de seus híbridos. Pesquisa Agropecuária Brasileira, Brasília, v.44, n.12, dez. 2009. p.1508-1515.

EUGENIO FERREIRA COELHO , CARLOS ALBERTO DA SILVA LEDO, SEBASTIÃO DE OLIVEIRA E SILVA. Produtividade da bananeira 'prata-anã' e 'grande naine' no terceiro ciclo sob irrigação por microaspersão em tabuleiros costeiros da bahia1 Rev. Bras. Frutic., Jaboticabal - SP, v. 28, n. 3, dez. 2006. p. 435-438.

FERERES, E. Papel de la fisiología vegetal en la microirrigación. Recomendaciones para el manejomejorado.PonenciaenIV Seminario Latinoamericano de Microirrigación.Barquisi meto, Venezuela, 1981.

FERREIRA, D. F. SISVAR - Sistema de análise de variância para dados balanceados. Lavras: UFLA, 1998. 19 p.

FIGUEIREDO, F.P. de; MANTOVANI, E.; SOARES, A.A.; COSTA, L.C.; RAMOS, M.M.; OLIVEIRA, F.G. Produtividade e qualidade da banana 'Prata-Anã', influenciada por lâminas de água, cultivada no Norte de Minas Gerais. Revista Brasileira Engenharia Agrícola e Ambiental, v.10, 2006.p. 798-803.

Frutiseries-6. 2000. <http://www.ceinfo.cnpat.embrapa.br/arquivos/artigo_1528.pdf>.

GOENAGA, R.; IRIZARRY, H.; COLEMAN, B.; ORTIZ, E. Dripirrigation recommendations for plantain and banana grown on the semiarid southern coast of Porto Rico. The Journal of Agriculture of the University of Porto Rico. v.79. 1995. p.13-27.

Goiás CFSG (1988), Minas Gerais CFSEMG (1998), Santa Catarina CFS (2004) e São Paulo Raij et al. (1996).

GONZÁLEZ-ALTOZANO, P.; CASTEL, J.R. Regulated deficit irrigation in 'Clementin a Nules' citrus tree. I Yield nad fruit quality effects. Journal of Horticultural Science \& Biotechnology, Ashford, v. 74. n.6. 1999. p.706-713.

HOFFMANN R. B.; et al. Acúmulo de matéria seca e de macronutrientes em cultivares de bananeira irrigada. Revista Brasileira de Fruticultura. n. 32. 2010. p. 268-275.

KELLER, J.; KARMELI, D. Trickle irrigation design. Glendora, California: Rain Bird Sprinkler. 1975. 133p.

LEMOS, R.C.; SANTOS, R.D. Manual de descrição e coleta de solo no campo. 2.ed.Campinas: Sociedade Brasileira de Ciência do Solo; Embrapa-SNLCS, 1984, 46p. 
LICHTEMBERG, L.A.; LICHTEMBERG, P.dos S.F.; Avanços da bananicultura brasileira. Revista Brasileira de Fruticultura, Jaboticabal - SP, Volume Especial, E. Out. 2011. p. 29-36.

MAIA, V.M.; SALOMÃO, L.C.C.; CANTARUTTI, R.B.; ALVAREZ VENEGAS, V.H.; COUTO, F.A.D'A. Efeitos de dose de nitrogênio, fósforo e potássio sobre os componentes da produção e a qualidade de bananas 'Prata Anã' no distrito agroindustrial de Jaíba. Revista Brasileira de Fruticultura, v.25, 2003. p.319-322.

MOREIRA, R. S. Banana: teoria e prática de cultivo. Campinas: Fundação Cargill, 1987. $335 \mathrm{p}$.

PBMH \& PIF - Programa brasileiro para a modernização da horticultura \& produção integrada de frutas. Normas de Classificação de Banana. São Paulo: CEAGESP, 2006. (Documentos, 29).

PEREZ-PASTOR, A.; DOMINGO, R.; TORRECILLAS, A.; RUIZ-SANCHEZ, C. Response of apricot trees to deficit irrigation strategies. Irrigation Science, New York, v.27. 2009. p.231-242.

ROBINSON, J.C.; GALÁN SAÚCO, V. Bananas and plantains. 2nd ed. Oxford: CAB International, 2010. 311p. (Crop Production Science in Horticulturae Series, 19).

SAENGPOOK, C.; KETSA, S.; VAN DOORN, W.G. Effects of relative humidity on banana fruit drop. Postharvest Biology and Technology, Amsterdam, v. 45, n.1, 2007. p. 151-154.

SANT'ANA, J.A.V. do. Distribuição de raízes de bananeira 'Prata-Anã' sob diferentes sistemas de irrigação em condições semiáridas. 2011. 92p. Dissertação (Mestrado) Universidade Federal de Lavras, Lavras.

SILVA, J.T.A. da; PACHECO, D.D.; COSTA, É.L. da. Atributos químicos e físicos de solos cultivados com bananeira 'Prata-Ana' (AAB), em três níveis de produtividade, no norte de Minas Gerais. Revista Brasileira de Fruticultura, v.29. 2007. p.102-106.

SILVA, S.O.; ROCHA, S.A.; ALVES, E.J.; CREDICO, M.D.I.; PASSOS, A.R. Caracterização morfológica e avaliação de cultivares e híbridos de bananeira. Revista Brasileira de Fruticultura, Jaboticabal, v.22. n.2. ago. 2000. p.161- 169.

SOTIROPOULOS, T.; KALFOUNTZOS, D.; ALEKSIOU, I.; KOTSOPOULOS, S.; KOUTINAS, N. Response of a clingstone peach cultivar to regulated deficit irrigation. Scientia Agricola, Piracicaba, v.67, n.2, 2010. p.164-169.

TAIZ, L.; ZEIGER, E. Fisiologia vegetal. 4.ed. Porto Alegre: Artmed, 2009. 848p.

TURNER, D. W.; FORTESCUE, J. A.; THOMAS, D. S. Environmental physiology of the bananas (Musa spp.). Brazilian Journal Plant Physiology, Rio de Janeiro, v. 19, n. 4. 2007. p. $463-484$.

ZONTA, E.P.; MACHADO, A.A. Sistemas de análises estatísticas (SANEST) para microcomputadores. In: Simpósio de estatística aplicada à experimentação. Piracicaba, 1995. Resumos. Campinas: Fundação Cargill, 1995. p. 17-18. 
Capítulo 2

AVALIAÇÃO DAPRODUTIVIDADE INICIAL E CARACTERES AGRONÔMICOS DA CULTIVAR DE BANANEIRA 'BRS CONQUISTA' EM FUNÇÃO DE DIFERENTES NÍVEIS DE ÁGUA E ADUBAÇÃO MAGNESIANA. 


\section{Resumo}

A adoção de eficientes sistemas de cultivo com uso racional de água e fertilizantes impulsiona as cadeias produtivas exportadoras e amplia a oferta de frutas para a população brasileira. Sendo assim, objetivo deste trabalho foi avaliar a produtividade inicial e qualidade de frutos da cultivar de bananeira 'BRS Conquista', em primeiro ciclo, sob diferentes doses de magnésio e volumes de irrigação, no Distrito Federal. Foram utilizados cinco volumes de irrigação $1.090-2.177-4.300-6.540-8.720$ litros.cova ${ }^{-1}$ e cinco doses de $\mathrm{Mg}^{2+} 0-110-$ 220 - 330 - $440 \mathrm{~kg} \cdot \mathrm{ha}^{-1}$. O experimento foi conduzido em delineamento em blocos casualizados e arranjo em parcelas subdivididas. Foi estimada a produtividade ( $\mathrm{PPH})$, número de cachos por hectare $(\mathrm{NCH})$, número médio de pencas por cacho (NMPC), número médio de bananas por cacho (NMBC), peso médio de bananas (PMB), número médio de bananas por penca (NMBP), comprimento médio de bananas (CMB), diâmetro médio de bananas (DMB), a relação comprimento/diâmetro (CD) e a firmeza média da polpa (FMP). Os dados coletados foram submetidos à análise de variância e á analise de regressão polinomial. Foram verificados efeitos significativos dos tratamentos na análise de todas variáveis com exceção de NMPC. Os níveis de água apresentaram diferenças significativas para as variáveis: NCH, PPH e PMB. As doses de Magnésio apresentaram diferenças significativas para a variável NBC. A interação água $x$ magnésio foi significativa em todas variáveis, a exceção de $\mathrm{NCH}$, NMPC e NMBC. A interação magnésio x água não foi significativa em NCH, PPH, NMPC e NMBC. Os volumes de irrigação de 6.540 e 8.720 L.cova $^{-1}$ proporcionaram os maiores valores em produtividade e qualidade de frutos. A maior produtividade foi observada com a dose de $6.540 \mathrm{~L} \cdot$ cova $^{-1}$ de água e $330 \mathrm{~kg}$ de $\mathrm{Mg}^{2+} \cdot \mathrm{ha}^{-1}$. As doses de 220 e $110 \mathrm{~kg} \mathrm{de} \mathrm{Mg}^{2+} \cdot \mathrm{ha}^{-1}$ proporcionaram os maiores valores em número médio de bananas por cacho. A relação comprimento/diâmetro apresentou maiores valores com a dose de 1.090 L.cova $^{-1}$ de água, na ausência de magnésio, indicando baixos valores do comprimento.

Palavras chave: Musa spp., volumes de irrigação, doses de $\mathrm{Mg}^{2+}$ 


\begin{abstract}
The adoption of efficient cropping systems with rational use of water and fertilizer boosts export supply chains and increases the supply of fruit for the Brazilian population. The objective of this study was to estimate the productivity and fruit quality of banana cultivar 'BRS Conquista', first cycle, under different doses of irrigation volumes and in Distrito Federal. Five volumes of irrigation were used: 1090, 2177, 4300, 6540, 8720 liters.pit $^{-1}$ and five doses of $\mathrm{Mg}^{2+}: 0,110,220,330,440 \mathrm{~kg} \cdot \mathrm{ha}^{-1}$. The experiment was conducted in a randomized block design and a split plot arrangement. Productivity was estimated (PPH), the number of bunches per hectare (NCH), the average number of bunches per bunch (NMPC), the average number of bananas per cluster (NMBP), the average weight of bananas (PMB), the average number by bunch of bananas (NMBC), banana the average length (CMB), diameter medium banana (DMB), the length/diameter (CD) and the average firmness (FMP). Data were subjected to analysis of variance and will analyze polynomial regression. Significant treatment effects were observed in the analysis of all variables except for MPC. Water levels showed significant differences for the variables: $\mathrm{NCH}, \mathrm{PCH}$ and $\mathrm{PMB}$. The Magnesium doses showed significant differences for $\mathrm{NBC}$ variable. The interaction water $\mathrm{x}$ magnesium was significant in all variables, except for NCH, MPC and NMBC. Magnesium $\mathrm{x}$ water interaction was not significant in $\mathrm{NCH}, \mathrm{PCH}, \mathrm{NMPC}$ and $\mathrm{NMBC}$. The irrigation volumes of 6.540 and $8.720 \mathrm{~L}^{\mathrm{p}} \mathrm{pit}^{-1}$ provided the highest values in productivity and fruit

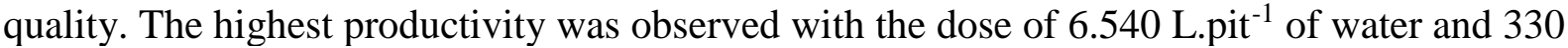
$\mathrm{kg}$ of $\mathrm{Mg}^{2+} \cdot \mathrm{ha}^{-1}$. The doses of 220 and $110 \mathrm{~kg}$ of $\mathrm{Mg}^{2+} \cdot \mathrm{ha}^{-1}$ provided the heighted values in median number of banana per brunch. The relation between length/diameter presented highest values with the dose of $1.090 \mathrm{~L}_{\text {.pit }}{ }^{-1}$ of water, without magnesium, indicating low levels of the length.
\end{abstract}

Keywords: Musa spp., irrigation volumes, $\mathrm{Mg}^{2+}$ doses. 


\section{INTRODUÇÃO}

A bananicultura brasileira possui grande importância econômica e social. É uma fruta consumida por todas as classes sociais e é importante fonte nutricional, destacada principalmente como excelente fonte de potássio. O cultivo é realizado em todas as regiões, entretanto sofre restrições em alguns estados por ser intolerante à determinadas intensidades de frio. Em 2014, a produção de bananas foi de 7,1 milhões de toneladas com rendimento médio de 14,3 ton/ha (ANUÁRIO BRASILEIRO DE FRUTICULTURA, 2014).

A bananeira é uma planta muito sensível ao desequilíbrio nutricional e é muito exigente em adubação quando comparada a outras frutíferas (DAMATTO JUNIOR et al., 2006). O macronutriente magnésio $(\mathrm{Mg})$ possui papel de grande importância nas células

vegetais. É ativador de enzimas envolvidas na respiração, fotossíntese e síntese de RNA e DNA. O íon também é parte central da estrutura em anel da molécula de clorofila. Esse nutriente também é facilitador da absorção de outros elementos principalmente do potássio (K) que é o nutriente mais requerido pela bananeira. Relações $\mathrm{K} / \mathrm{Mg}$ no solo maiores que 0,6 desencadeiam distúrbios fisiológicos na bananeira (SILVA et al., 2008).

A bananeira é caracterizada por ser uma planta hidrofítica que para seu normal desenvolvimento e produção necessita em média de 100 a $180 \mathrm{~mm}$ por mês em suprimentos hídricos (SOTO BALLESTERO, 2008). Assim o manejo da irrigação, em locais onde as precipitações pluviométricas são insuficientes ou mal distribuídas, é crucial para obtenção de altas produtividades em bananeira (PAULL \& DUARTE, 2011). No sistema de irrigação por gotejamento a água é aplicada diretamente sobre o sistema radicular, em alta frequência e baixa vazão, para manter o nível de água no solo sempre próximo a capacidade de campo. Isto propicia elevada eficiência de aplicação de água e boas condições de umidade na zona radicular (COSTA et al., 2008).

No Brasil existe a prevalência de cultivos de banana do subgrupo Prata devido à tradição e aceitação comercial, entretanto a maioria dos cultivares plantados são suscetíveis às doenças: sigatoka negra Mycosphaerella fijiensis, sigatoka amarela Mycosphaerella musicola e mal-do-panamá Fusarium oxysporum f.sp. cubense (DONATO et al., 2009). A cultivar BRS conquista pertence ao grupo genômico $\mathrm{AAB}$, subgrupo cultural conquista. Possui as características de resistência à sigatoka negra Mycosphaerella fijiensis, sigatoka amarela Mycosphaerella musicola e ao mal-do-panamá Fusarium oxysporum f.sp. cubense. Pode 
apresentar, dependendo das condições de cultivo, produção de até 48 ton/ha/ciclo (PEREIRA \& GASPAROTTO, 2007).

O objetivo deste trabalho foi avaliar a produtividade e qualidade de frutos da cultivar 'BRS Conquista', em primeiro ciclo de produção, submetida a diferentes doses de magnésio e diferentes volumes de irrigação. 


\section{MATERIAIS E MÉTODOS}

\section{LOCALIZAÇÃO E CARACTERÍSTICAS DA ÁREA}

O experimento foi conduzido, no período de dezembro de 2012 a dezembro de 2014, na Fazenda Experimental Água Limpa (FAL-UnB) de propriedade da Universidade de Brasília, numa área de coordenadas geográficas médias em torno de $15^{\circ} 56^{\prime} \mathrm{S}$ e $47^{\circ} 56^{\prime} \mathrm{W}$ e altitude de $1.080 \mathrm{~m}$. A classificação climática da região, pelo método de Köppen, é do tipo CWa e apresenta duas estações climáticas bem definidas: a estação seca, que se inicia no final do mês de abril e se estende até setembro, e uma estação chuvosa, que se inicia em outubro e vai até meados do mês de abril. O solo da área do experimento é um Latossolo VermelhoAmarelo de relevo suave com $4 \%$ de declividade.

Apesar do Distrito Federal apresentar uma temperatura média favorável ao cultivo de banana em quase toda totalidade do ano, há ocorrência de temperaturas noturnas subótimas, abaixo de $12^{\circ} \mathrm{C}$ (ANEXO) durante o inverno seco (junho a setembro), coincidente com florescimento e enchimento de frutos de parte das plantas, o que favorece a ocorrência de "chilling", resultando em baixa produtividades. De acordo com Moreira (1987) a temperatura mínima suportada pela cultura está na casa dos $15^{\circ} \mathrm{C}$, dessa forma as plantas podem ter tido o seu desenvolvimento limitado pela baixa temperatura. As baixas temperaturas, coincidindo com as fases de estabelecimento da cultura podem desfavorecer o desenvolvimento das plantas.

Amostras do solo foram coletadas nas profundidades de $0-20 \mathrm{~cm}$ e $20-40 \mathrm{~cm}$, para determinação das características químicas e físicas, de acordo com os métodos da Embrapa (1997). Os resultados podem ser visualizados na Tabela 9.

De acordo com a análise físico-química, o solo onde o experimento foi implantado apresentou um elevado teor de argila (602,3 g. $\mathrm{Kg}^{-1}$ de solo), sendo classificado como um solo argiloso, de acordo com o triangulo textural proposto por Lemos \& Santos (1984). Contudo, segundo Campos et al., (2010), esse Latossolo apresenta uma condutividade hidráulica saturada $\left(\mathrm{K}_{\mathrm{s}}\right)$ de $12,7 \mathrm{~cm} \cdot \mathrm{h}^{-1}$, caracterizando-se como sendo de velocidade de infiltração básica (VIB) muito alto (VIB > 3,0 cm.h $\mathrm{h}^{-1}$ ), segundo Bernardo et al., 2009. 
Tabela 9: Resultado da análise físico-química do Latossolo Vermelho-Amarelo utilizado no experimento. Brasília, 2014.

\begin{tabular}{|c|c|c|c|c|c|c|c|c|c|}
\hline Prof & $\mathrm{pH}$ & $\mathrm{pH}$ & $\mathrm{H}+\mathrm{Al}$ & $\mathrm{Al}$ & $\mathrm{P}$ & $\mathrm{K}$ & $\mathrm{Ca}$ & $\mathrm{Mg}$ & M.O \\
\hline $\mathrm{Cm}$ & $\mathrm{H}_{2} \mathrm{O}$ & $\mathrm{CaCl}_{2}$ & $\mathrm{Me} / 100 \mathrm{cc}$ & \multicolumn{5}{|c|}{ 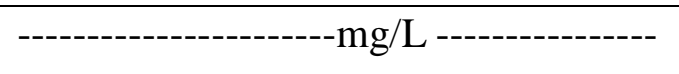 } & $(\%)$ \\
\hline $0-20$ & 6,47 & 6,26 & 3,85 & 0,18 & 4,28 & 44 & 792 & 208 & 3,7 \\
\hline $20-40$ & 6,59 & 6,34 & 7,41 & 0,27 & 0,93 & 28 & 667 & 182 & 3,3 \\
\hline \multicolumn{10}{|c|}{ Granulometria } \\
\hline & Areia & & \multicolumn{3}{|c|}{ Silte } & \multicolumn{4}{|c|}{ Argila } \\
\hline \multicolumn{10}{|c|}{-------------------- g/Kg ------------------- } \\
\hline & 277,35 & & \multicolumn{3}{|c|}{120,29} & \multicolumn{4}{|c|}{602,36} \\
\hline
\end{tabular}

\section{INSTALAÇÃO DO EXPERIMENTO}

No ensaio, foram utilizadas mudas da variedade de banana 'BRS Conquista', oriunda de cultura de tecidos. Estas, inicialmente, foram plantadas em sacos de polietileno, com capacidade de 2 litros de solo, e conduzidas em um viveiro telado da FAL-UnB. Durante esse período, as mudas foram irrigadas por aspersão convencional 3 vezes por semana, e com uma lâmina liquida de $3 \mathrm{~mm}$, totalizando uma lâmina liquida de irrigação de $9 \mathrm{~mm}$. Além disso, foram desbastadas folhas com sintomas de doenças e amareladas.

As mudas foram transplantadas em uma área previamente preparada por meio de gradagem. As covas foram abertas, com o auxílio de retroescavadeira, com um espaçamento de 3,0 m x 3,0 m e dimensões de 1,0 m x 1,0 m x 1,0 m. De acordo com os resultados da análise de solo foi realizada a correção do solo com 200 gramas de calcário dolomítico por cova e a adubação de plantio com 500 gramas de Superfostato Simples, 200 gramas de Termofosfato Magnesino e 50 gramas de FTE por cova. Doses dos nutrientes adicionados ao solo pela adubação de plantio podem ser visualizadas na Tabela 10.

Tabela 10: Doses dos nutrientes adicionados ao solo pela adubação de plantio da cultivar 'BRS CONQUISTA' em um ensaio de campo sob latossolo Vermelho-Amarelo.

\begin{tabular}{|c|c|c|c|c|c|c|c|c|c|c|}
\hline $\mathrm{Cao}$ & $\operatorname{IgO}$ & $\mathrm{P}_{2} \mathrm{O}_{5}$ & $\mathrm{~S}$ & B & $\mathrm{Cu}$ & $\mathrm{Mn}$ & $\mathrm{SiO}$ & $\mathrm{Zn}$ & $\mathrm{Fe}$ & Mo \\
\hline & & ------ & 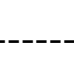 & 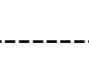 & 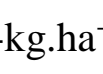 & & & & & \\
\hline 44, & 64,3 & 178 & 44 & 0,54 & 0,666 & 2,42 & 44,4 & 7,39 & 1,92 & 0,0 \\
\hline
\end{tabular}

Após o transplantio das mudas, foi instalado o sistema de irrigação que é composto por 4 unidades operacionais. Cada unidade operacional é disposta de 40 linhas laterais, sendo duas linhas para cada fileira de plantas e duas linhas de derivação. Cada linha lateral é 
constituída por tubos de polietileno com diâmetro interno de $16 \mathrm{~mm}$. Nas linhas laterais foram inseridos gotejadores cujas vazões são de 2, 4 e 8 litros por hora. Esses gotejadores foram dispostos para possibilitar as vazões de 4 ( 2 gotejadores de 2 litros por hora), 8 (4 gotejadores de 2 litros por hora), 16 (4 gotejadores de 4 litros por hora), 24 (2 gotejadores de 8 litros por hora mais 2 gotejadores de 4 litros por hora e 32 ( 4 gotejadores de 8 litros por hora) litros por hora.

Além disso, são partes integrantes do sistema uma linha principal, um cabeçal de controle e um conjunto moto-bomba. Na linha principal, foram utilizados tubos soldáveis de PVC com diâmetro interno de $50 \mathrm{~mm}$. O cabeçal de controle é composto por um filtro de discos de 120 mesh e capacidade de filtragem de $12 \mathrm{~m}^{3} \cdot \mathrm{h}^{-1}, 4$ curvas de $90^{\circ}$ com diâmetro de $50 \mathrm{~mm}$ e 2 registros de gaveta. O conjunto moto-bomba é construído por motor trifásico de 10 cv e uma bomba centrífuga. Também fazem parte desse conjunto, uma válvula de pé com crivo, um mangote de sucção de diâmetro interno de $62 \mathrm{~mm}$, uma curva de $90^{\circ}$, um registro de gaveta e uma válvula de retenção.

Pela avaliação dos índices de dano econômico e pela realidade de pouco uso de agrotóxicos pela agricultura familiar do Distrito Federal não houve necessidade de aplicação de defensivos agrícolas para o controle de pragas e doenças. Contudo, o controle de plantas daninhas foi realizado por meio de aplicação do herbicida paraquat (200g i.a./L) na dosagem de 2 litros por hectare realizado quando as plantas daninhas apresentavam-se em nível de controle. As pulverizações foram realizadas utilizando-se de pulverizador costal com capacidade de armazenar 20 litros de calda. Folhas amareladas e com sintomas de doenças foram eliminadas. No período inicial do desenvolvimento das plantas, não houve o desbaste dos perfilhos. Posteriormente o desbaste foi realizado com finalidade de adequar a condução do pomar.

\section{DELINEAMENTO E CONDUÇÃO EXPERIMENTAL}

O experimento foi conduzido em 4 blocos inteiramente casualizados e 25 tratamentos conforme disposto em anexo. $\mathrm{O}$ arranjo experimental foi em parcelas subdivididas, sendo as parcelas formadas pelos 5 volumes de irrigação (V) e as subparcelas formadas pelos 5 níveis de adubação magnesiana (Mg) . Cada subparcela consistiu em 4 covas uteis, totalizando 400 covas.

Dentre os macronutrientes exigidos pelas plantas, o magnésio $(\mathrm{Mg})$ foi sorteado como fonte de variação para a variedade 'BRS Conquista'. Os níveis de magnésio (Mg) utilizados e 
as doses do demais nutrientes, nitrogênio $(\mathrm{N})$, fósforo $\left(\mathrm{P}_{2} \mathrm{O}_{5}\right)$ e potássio $\left(\mathrm{K}_{2} \mathrm{O}\right)$ estão descritos na Tabela 11. As adubações foram realizadas em cobertura mensal e de forma manual, o que possibilita a variação nas doses do sulfato de magnésio. Os adubos foram aplicados em círculo a uma distância de $50 \mathrm{~cm}$ do pseudocaule da planta. Os fertilizantes utilizados como fonte de N, P e K foram uréia, superfosfato simples e cloreto de potássio, respectivamente e a fonte de magnésio foi o sulfato de magnésio.

Os níveis de Magnésio utilizados, bem como as doses de N, P e K foram obtidas com a média das recomendações de adubação para bananeira dos estados de Goiás CFSG (1988), Minas Gerais CFSEMG (1998), Santa Catarina CFS (2004) e São Paulo Raij et al. (1996).

Tabela 11: Doses de nutrientes $\mathrm{Mg}, \mathrm{P}, \mathrm{K}$ e $\mathrm{N}$ utilizados em cobertura na Banana 'BRS Conquista' em um ensaio de campo sob um Latossolo Vermelho-Amarelo.

\begin{tabular}{cccc}
\hline $\begin{array}{c}\text { Níveis de } \mathrm{Mg} \\
\left(\mathrm{kg} \cdot \mathrm{ha}^{-1}\right)\end{array}$ & $\begin{array}{c}\text { Dose de } \mathrm{P}_{2} \mathrm{O}_{5} \\
\left(\mathrm{Kg}^{\left.-h^{-1}\right)}\right.\end{array}$ & $\begin{array}{c}\text { Dose de } \mathrm{K}_{2} \mathrm{O} \\
\left(\mathrm{Kg}^{\left.-h h^{-1}\right)}\right.\end{array}$ & $\begin{array}{c}\text { Dose de N } \\
\left(\mathrm{kg} \cdot h a^{-1}\right)\end{array}$ \\
\hline 0 & & & \\
110 & 176 & 416 & 163 \\
220 & & \\
330 & & \\
440 & & \\
\hline
\end{tabular}

O manejo da irrigação teve início logo após o final do período chuvoso foi estendido até o início da estação chuvosa de cada ano. Portanto, no ano de 2013, as irrigações foram realizadas de 01 de julho a 10 de outubro. No ano de 2014, o intervalo em que ocorreu a irrigação foi de 01 de maio a 30 de novembro. O turno de rega, nos meses irrigados, foi de 2 dias permanecendo constantes em ambos os anos. No entanto, o tempo de irrigação e em consequência a dose de água foi variável de acordo com o desenvolvimento da cultura.

O número total de irrigação, o tempo de irrigação, bem como os volumes de água aplicados nos anos de 2013 e de 2014 estão descritos na Tabela 12. O aumento no tempo de irrigação visou o ajuste dos volumes de água aplicados na bananeira de acordo com o coeficiente da cultura $(\mathrm{Kc})$ e na tentativa de obter volumes deficientes, adequados e em excesso em relação à demanda hídrica da cultura.

Devido à ocorrência de veranicos, período de seca dentro da estação chuvosa, ocorreu o uso da irrigação suplementar quando a precipitação pluvial semanal foi menor que $30 \mathrm{~mm}$ nos meses de janeiro e fevereiro de 2014. A obtenção de colheitas economicamente viáveis 
está relacionada a precipitações de 100 a 180 mm.mês ${ }^{-1}$ (ALVES, 1999). Logo, 6 irrigações foram realizadas no mês de janeiro, e 2 irrigações no mês de fevereiro, conforme descrito na Tabela 12. A observação da precipitação pluvial foi de acordo com os dados meteorológicos oriundos da estação de agrometeorologia da FAL-UnB localizada próxima a área do experimento.

Tabela 12: Volumes de irrigação utilizados, em função da vazão aplicada por cova, do número total de irrigações, tempo de irrigação e evapotranspiração de referência $\left(\mathrm{ET}_{0}\right)$ nos períodos irrigados em Brasília nos anos de 2013 e 2014.

\begin{tabular}{|c|c|c|c|c|c|c|c|c|}
\hline \multirow{3}{*}{ Mês/ano } & \multirow{3}{*}{$\begin{array}{c}\mathrm{N}^{\circ} \text { de } \\
\text { irrigações/ } \\
\text { mês }\end{array}$} & \multirow{3}{*}{$\begin{array}{l}\text { Evapotranspiração } \\
\text { de referência }-\mathrm{ET}_{0} \\
(\mathrm{~mm}) \text { nos períodos } \\
\text { de irrigação }\end{array}$} & \multirow{3}{*}{$\begin{array}{c}\text { Tempo } \\
\text { de } \\
\text { irrigação } \\
\text { em horas }\end{array}$} & \multicolumn{5}{|c|}{$\begin{array}{l}\text { Vazões utilizadas por cova } \\
\text { (Litros/hora) }\end{array}$} \\
\hline & & & & 4 & 8 & 16 & 24 & 32 \\
\hline & & & & \multicolumn{5}{|c|}{ Volumes aplicados por cova (litros) } \\
\hline $\mathrm{Jul} / 2013$ & 16 & 79,89 & 1,00 & 64 & 128 & 256 & 384 & 512 \\
\hline Ago/2013 & 15 & 103,19 & 1,25 & 75 & 150 & 300 & 450 & 600 \\
\hline Set/2013 & 15 & 107,87 & 1,50 & 90 & 180 & 360 & 540 & 720 \\
\hline Out/2013 & 6 & 25,87 & 1,75 & 42 & 84 & 168 & 252 & 336 \\
\hline Jan/2014 & 6 & 58,87 & 1,75 & 42 & 84 & 168 & 252 & 336 \\
\hline Fev/2014 & 2 & 45,40 & 1,75 & 14 & 28 & 56 & 84 & 112 \\
\hline Mai/2014 & 16 & 79,09 & 1,75 & 112 & 224 & 448 & 672 & 896 \\
\hline Jun/2014 & 15 & 66,26 & 1,75 & 105 & 210 & 420 & 630 & 840 \\
\hline Jul/2014 & 16 & 71,23 & 1,75 & 112 & 224 & 448 & 672 & 896 \\
\hline Ago/2014 & 15 & 98,84 & 1,75 & 105 & 210 & 420 & 630 & 840 \\
\hline Set/2014 & 16 & 113,64 & 1,75 & 112 & 224 & 448 & 672 & 896 \\
\hline Out/2014 & 15 & 117,67 & 1,75 & 105 & 210 & 420 & 630 & 840 \\
\hline Nov/2014 & 16 & 93,67 & 1,75 & 112 & 224 & 448 & 672 & 896 \\
\hline Total & - & 1061,49 & - & 1090 & 2177 & 4300 & 6540 & 8720 \\
\hline
\end{tabular}

Para obter a lâmina de irrigação aplicada (LIA) em mm, em função dos volumes de água aplicados, utilizou-se a seguinte equação:

$$
\mathrm{LIA}=\frac{\mathrm{VAA}}{\mathrm{A}_{\mathrm{t}} \times \mathrm{K}_{\mathrm{L}}}
$$

em que:

VAA: Volume de água aplicado (litros); 
At: Área ocupada pela planta $\left(9 \mathrm{~m}^{2}\right)$;

$\mathrm{K}_{\mathrm{L}}$ : Fator de ajuste obtido em função do percentual da área molhada.

O manejo previsto da irrigação foi realizado pela a demanda evapotranspirométrica da cultura. Para isso, foi calculada a evapotransipiração de referência $\left(\mathrm{ET}_{0}\right)$, utilizando-se os dados climatológicos da Estação de Agroclimatologia localizada na própria FAL - UnB (Anexo). $\mathrm{A} \mathrm{ET}_{0}$ foi calculada a partir da equação de Penman-Monteith-FAO proposta por Allen et al., (2006). Os valores de $\mathrm{ET}_{0}$ calculada para os meses dos anos de 2013 e 2014 estão na Tabela 12 e os dados climatológicos utilizados encontram-se no Anexo.

Como a irrigação localizada não molha toda a área ocupada pela cova da bananeira, foi necessário considerar um fator de ajuste $\left(\mathrm{K}_{\mathrm{L}}\right)$ que leva em consideração a porcentagem da área molhada (PAM) (BERNARDO et al., 2009). Portanto, o $\mathrm{K}_{\mathrm{L}}$ foi calculado conforme as equações de Fereres (1981), abaixo:

Se $\mathrm{PAM} \geq 65 \% \rightarrow \mathrm{K}_{\mathrm{L}}=1$;

Se $20 \%<P A M<65 \% \rightarrow \mathrm{K}_{\mathrm{L}}=1,09 \frac{\mathrm{PAM}}{100}+0,30$;

Se PAM $\leq 20 \% \rightarrow K_{L}=1,94 \frac{\text { PAM }}{100}+0,1 ;$

$\mathrm{O}$ coeficiente da cultura $\left(\mathrm{K}_{\mathrm{c}}\right)$ foi utilizada para ajustar os valores da $\mathrm{ET}_{0}$ com a demanda hídrica da cultura. Os valores de $\mathrm{K}_{\mathrm{c}}$ variam com o tipo da cultura, o seu estádio de desenvolvimento e as condições climáticas locais (BERNARDO et al., 2009). Foram ajustados os valores de $\mathrm{K}_{\mathrm{c}}$ iguais a 0,70; 0,85; 1,00 e 1,10 respectivamente para os meses de julho, agosto, setembro e outubro de 2013, e constante a partir do maior valor até o mês de novembro de 2014, segundo Allen et al., (2006).

Considerando esses fatores a $\mathrm{ET}_{\mathrm{Loc}}$ foi calculada pela equação:

$E T_{L o c}=E T_{0} \times K_{c} \times K_{L}$

onde:

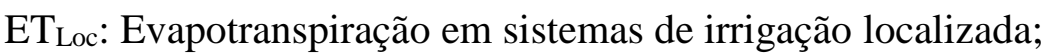

$\mathrm{K}_{\mathrm{c}}$ : Coeficiente da cultura;

$\mathrm{K}_{\mathrm{L}}$ : Fator de ajuste. 
O valor de PAM foi obtido pela divisão da área molhada $\left(\mathrm{A}_{\mathrm{m}}\right)$ pela área total $\left(9 \mathrm{~m}^{2}\right)$. As áreas molhadas foram determinadas pelas medidas realizadas no campo ao final do tempo de irrigação. Foram medidos os dois maiores diâmetros calculada a média e determinado a sua área.

Os valores de PAM calculados, em função das vazões dos gotejadores utilizados $(2,4$ e 8 litros.hora $\left.{ }^{-1}\right)$, foram obtidos pela a seguinte equação:

$\mathrm{PAM}=\frac{\mathrm{P}_{1} \times \mathrm{S}_{1}+\mathrm{P}_{2} \times \mathrm{S}_{2}}{\mathrm{~S}_{\mathrm{f}}} \times \frac{\mathrm{S}_{\mathrm{G} \text { rec }}}{\mathrm{S}_{\mathrm{G} \text { uti }}}$

em que:

$\mathrm{P}_{1}$ : proporção 1 , para o valor de $\mathrm{S}_{1}$;

$\mathrm{S}_{1}$ : maior espaçamento entre as linhas laterais que resulta em $\mathrm{P}_{1}(\mathrm{~m})$;

$\mathrm{P}_{2}$ : proporção 2, para o valor de $\mathrm{S}_{2}$;

$\mathrm{S}_{2}$ : espaçamento entre pares de laterais $\left(\mathrm{S}_{2}=\mathrm{S}_{\mathrm{f}}-\mathrm{S}_{1}\right)(\mathrm{m})$;

$\mathrm{S}_{\mathrm{f}}$ : espaçamento entre fileiras de plantas (3 metros);

$S_{\mathrm{g} \mathrm{rec}}$ : espaçamento entre gotejadores recomendado $(\mathrm{m})$;

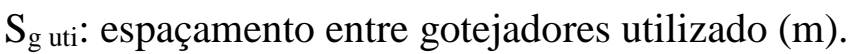

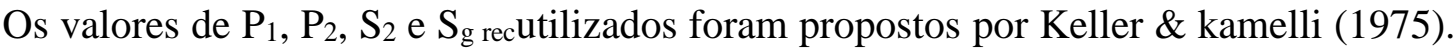
$\mathrm{O}$ espaçamento entre as linhas laterais $\left(\mathrm{S}_{1}\right)$ foi de 1,2 metros. O uso da expressão $\left(\frac{\mathrm{S}_{\mathrm{G}} \text { rec }}{\mathrm{S}_{\mathrm{G} \text { uti }}}\right)$ foi para ajustar o valor de PAM, já que o valor recomendado entre os gotejadores $\left(\mathrm{S}_{\mathrm{g}}\right.$ rec $)$ diferiu do espaçamento utilizado $\left(\mathrm{S}_{\mathrm{g}}\right.$ uti $)$.

Ressalta-se que o valor de PAM calculado para o tratamento com a vazão de 24 litros.hora $^{-1}$, composto por dois gotejadores de 4 litros.hora $^{-1}$ e dois gotejadores de 8 litros.hora ${ }^{-1}$, foi obtido pela média dos valores de PAM calculados para os gotejadores com vazões de 4 e 8 litros.hora ${ }^{-1}$.

Como os valores de $\mathrm{K}_{\mathrm{L}}$, dados pelas equações 2,3 e 4, são dependentes apenas de PAM, encontrou-se diversos valores de $\mathrm{K}_{\mathrm{L}}$, tendo em vista que os valores de PAM calculados foram em função das vazões dos gotejadores utilizados. Em função desse fato, diversos valores de lâminas foram calculados para satisfazer a demanda evapotranspirométrica da cultura. 
A partir dos valores obtidos para $\mathrm{ET}_{\mathrm{L}}, \mathrm{K}_{\mathrm{c}}$ e $\mathrm{K}_{\mathrm{L}}$, foi possível calcular as lâminas de irrigação necessária para satisfazer a demanda evapotranspirométrica da cultura. Com isso, as lâminas de irrigação totais necessárias, em mm, (LTN) foram calculadas, para cada tratamento, pela seguinte expressão:

$\mathrm{LTN}=\frac{\mathrm{ET}_{0} \times \mathrm{K}_{\mathrm{C}} \times \mathrm{K}_{\mathrm{L}}}{\mathrm{CUC}}$

em que:

$\mathrm{ET}_{0}$ : Evapotranspiração de referência $(\mathrm{mm})$

$\mathrm{K}_{\mathrm{c}}$ : Coeficiente da cultura;

$\mathrm{K}_{\mathrm{L}}$ : Fator de ajuste.

CUC: Coeficiente de uniformidade de Christiansen

O CUC foi obtido a partir da mensuração das vazões dos gotejadores utilizados pelo sistema de irrigação instalado no campo, obtendo, assim um CUC de 94\%.

A obtenção dos volumes totais necessários por cova (VTN), em litros, considerando as LTN corresponde a cada tratamento, foi calculado pela seguinte fórmula:

$\mathrm{VTN}=\mathrm{LTN} \times \mathrm{A}_{\mathrm{t}}$

em que:

LTN: lâmina total necessária $(\mathrm{mm})$;

$\mathrm{A}_{\mathrm{t}}$ área ocupada pela planta $\left(9 \mathrm{~m}^{2}\right)$.

O solo onde o experimento foi implantado apresentou um alto teor de argila, porém comportou-se como um solo arenoso devido ao fato de ter apresentado uma elevada condutividade hidráulica saturada $\left(\mathrm{K}_{\mathrm{s}}\right)$. Diante do exposto, justifica-se o fato dos valores de PAM observados serem aquém dos valores de PAM calculados, conforme a Tabela 13.

$\mathrm{Na}$ Tabela 13, estão apresentados os valores de $\mathrm{K}_{\mathrm{c}}$, considerando o estádio de desenvolvimento da cultura; de PAM calculados e seus respectivos $\mathrm{K}_{\mathrm{L}}$ calculados; de PAM observados e seus respectivos $\mathrm{K}_{\mathrm{L}}$ observados. Os valores de PAM calculados, em função dos tratamentos utilizados, diferiram entre si, sendo que o menor PAM calculado foi de $13 \%$ para o tratamento de 4 litros.hora ${ }^{-1}$ e o maior foi de $81,50 \%$ para o tratamento de 32 litros.hora ${ }^{-1}$. Observando os valores de PAM calculados e PAM observados, notou-se que os PAM 
calculados foram superiores a todos os PAM observados. Consequentemente, os valores de $\mathrm{K}_{\mathrm{L}}$ calculados foram superiores aos $\mathrm{K}_{\mathrm{L}}$ observados, tendo em vista que $\mathrm{K}_{\mathrm{L}}$ é dependente exclusivamente de PAM. Os valores idênticos de $\mathrm{K}_{\mathrm{L}}$ calculados, para os tratamentos Q 24 e Q 32, justifica-se pelo fato de PAM calculado apresentar um valor superior a $65 \%$, e com isso, foi considerado $K_{L}$ igual a 1 , conforme a equação 2. $\mathrm{O}$ fato dos $\mathrm{K}_{\mathrm{L}}$ observados serem idênticos nos tratamentos Q16 e Q24 explica-se devido os PAM observados estarem muito próximos entre si.

Considerando as lâminas calculadas notou-se que seus valores foram inferiores às das lâminas aplicadas. Isso justifica-se pelo fato dos valores de $\mathrm{K}_{\mathrm{L}}$ calculados serem superiores aos valores de $\mathrm{K}_{\mathrm{L}}$ observados. As lâminas calculadas para os tratamentos Q24 e Q32 foram idênticas devido ao fato dos valores de $\mathrm{K}_{\mathrm{L}}$ desses tratamentos serem iguais $\left(\mathrm{K}_{\mathrm{L}}=1\right)$. As lâminas aplicadas nos tratamentos Q8 e Q16 foram semelhantes para essas vazões já que Q16 equivale ao dobro de Q8 e o valor de P para Q16 ser o dobro de PAM relativo ao tratamento Q8, apesar da diferença existente entre as vazões nesses tratamentos. Contudo, os volumes de água calculados foram superiores a todos os volumes de água aplicados. Além disso, os volumes de água aplicados foram todos distintos entre si, com o intervalo de 1090 a 8720 litros.cova ${ }^{-1}$ (Tabela 14). Pelas razões expostas, decidiu-se apresentar os resultados e discutir o presente trabalho em função dos volumes de água aplicados.

Tabela 13: Percentual de área molhada calculada $\left(\mathrm{PAM}_{\mathrm{s}}\right)$ e observada $\left(\mathrm{PAM}_{\mathrm{o}}\right)$ e coeficiente de ajuste da evapotranspiração da cultura para irrigação localizada de acordo com $\operatorname{PAM}_{\mathrm{S}}\left(\mathrm{K}_{\mathrm{LS}}\right)$ e $\operatorname{PAM}_{\mathrm{o}}\left(\mathrm{K}_{\mathrm{Lo}}\right)$.

\begin{tabular}{|c|c|c|c|c|}
\hline $\begin{array}{c}\text { Vazões utilizadas } \\
\left.\text { (Litros.hora }^{-1}\right)\end{array}$ & $\operatorname{PAM}_{\mathrm{s}}(\%)$ & $\mathrm{K}_{\mathrm{Ls}}$ & $\mathrm{PAM}_{\mathrm{o}}(\%)$ & $\mathrm{K}_{\mathrm{Lo}}$ \\
\hline 4 & 13,00 & 0,35 & 4,07 & 0,18 \\
\hline 8 & 26,00 & 0,58 & 8,95 & 0,27 \\
\hline 16 & 54,60 & 0,89 & 22,18 & 0,54 \\
\hline 24 & 68,00 & 1,00 & 23,33 & 0,54 \\
\hline 32 & 81,50 & 1,00 & 38,86 & 0,72 \\
\hline
\end{tabular}


Tabela 14: Volumes e lâminas de água necessários em função do $\mathrm{K}_{\mathrm{Lc}} \mathrm{e}$ Volumes e lâminas água aplicados, em função da vazão utilizada no referido experimento.

\begin{tabular}{|c|c|c|c|c|c|c|c|c|c|c|c|c|c|c|c|c|c|c|c|c|}
\hline \multirow{3}{*}{ Mês/ano } & \multicolumn{5}{|c|}{ Vazões utilizadas (Litros/hora) } & \multicolumn{5}{|c|}{ Vazões utilizadas (Litros/hora) } & \multicolumn{5}{|c|}{ Vazões utilizadas (Litros/hora) } & \multicolumn{5}{|c|}{ Vazões utilizadas (Litros/hora) } \\
\hline & 4 & 8 & 16 & 24 & 32 & 4 & 8 & 16 & 24 & 32 & 4 & 8 & 16 & 24 & 32 & 4 & 8 & 16 & 24 & 32 \\
\hline & \multicolumn{5}{|c|}{ Volumes de água calculados (L) } & \multicolumn{5}{|c|}{ Lâminas de água calculadas (mm) } & \multicolumn{5}{|c|}{ Volumes de água aplicados (L) } & \multicolumn{5}{|c|}{ Lâminas de água aplicadas (mm) } \\
\hline $\mathrm{Jul} / 2013$ & 188 & 312 & 479 & 535 & 535 & 20,9 & 34,7 & 53,2 & 59,5 & 59,5 & 64 & 128 & 256 & 384 & 512 & 39,7 & 51,9 & 52,5 & 77,0 & 78,68 \\
\hline Ago/2013 & 296 & 490 & 751,2 & 840 & 840 & 32,8 & 54,4 & 83,5 & 93,3 & 93,3 & 75 & 150 & 300 & 450 & 600 & 46,5 & 60,8 & 61,5 & 90,2 & 92,21 \\
\hline Set/2013 & 363 & 602 & 924 & 1033 & 1033 & 40,4 & 66,9 & 102,7 & 114,8 & 114,8 & 90 & 180 & 360 & 540 & 720 & 55,9 & 73,0 & 73,8 & 108,3 & 110,65 \\
\hline Out/2013 & 96 & 159 & 244 & 272 & 272 & 10,7 & 17,6 & 27,1 & 30,3 & 30,3 & 42 & 84 & 168 & 252 & 336 & 26,1 & 34,1 & 34,4 & 50,5 & 51,64 \\
\hline Jan/2014 & 218 & 361 & 555 & 620 & 620 & 24,2 & 40,2 & 61,7 & 68,9 & 68,9 & 42 & 84 & 168 & 252 & 336 & 26,1 & 34,1 & 34,4 & 50,5 & 51,64 \\
\hline $\mathrm{Fev} / 2014$ & 168 & 279 & 428 & 478 & 478 & 18,7 & 31,0 & 47,5 & 53,1 & 53,1 & 14 & 28 & 56 & 84 & 112 & 8,7 & 11,3 & 11,5 & 16,8 & 17,21 \\
\hline Mai/2014 & 293 & 486 & 745 & 832 & 833 & 32,6 & 54,0 & 82,8 & 92,5 & 92,5 & 112 & 224 & 448 & 672 & 896 & 69,5 & 90,8 & 91,8 & 134,8 & 137,70 \\
\hline Jun/2014 & 246 & 407 & 625 & 698 & 698 & 27,3 & 45,2 & 69,4 & 77,5 & 77,5 & 105 & 210 & 420 & 630 & 840 & 65,2 & 83,2 & 86,1 & 126,3 & 129,09 \\
\hline $\mathrm{Jul} / 2014$ & 264 & 437 & 671 & 750 & 750 & 29,3 & 48,6 & 74,6 & 83,3 & 83,3 & 112 & 224 & 448 & 672 & 896 & 69,5 & 90,8 & 91,8 & 134,8 & 137,70 \\
\hline Ago/2014 & 366 & 607 & 932 & 1041 & 1041 & 40,7 & 67,4 & 103,5 & 115,7 & 115,7 & 105 & 210 & 420 & 630 & 840 & 65,2 & 83,2 & 86,1 & 126,3 & 129,09 \\
\hline Set/2014 & 421 & 698 & 1071 & 1197 & 1197 & 46,8 & 77,5 & 119,0 & 133,0 & 133,0 & 112 & 224 & 448 & 672 & 896 & 69,5 & 90,8 & 91,8 & 134,8 & 137,70 \\
\hline Out/2014 & 436 & 722 & 1109 & 1239 & 1239 & 48,5 & 80,3 & 123,2 & 137,7 & 137,7 & 105 & 210 & 420 & 630 & 840 & 65,2 & 83,2 & 86,1 & 126,5 & 129,09 \\
\hline Nov/2014 & 347 & 575 & 883 & 986 & 986 & 38,6 & 63,9 & 98,1 & 109,6 & 109,6 & 112 & 224 & 448 & 672 & 896 & 69,5 & 90,8 & 91,8 & 134,8 & 137,70 \\
\hline Total & 3704 & 6135 & 9418 & 10523 & 10523 & 411,6 & 681,7 & 1046,5 & 1169,2 & 1169,2 & 1090 & 2177 & 4300 & 6540 & 8720 & 676,6 & 882,8 & 881,5 & 1311,7 & 1340,0 \\
\hline
\end{tabular}




\section{AVALIAÇÃO DO EXPERIMENTO}

Para a avaliação do desempenho agronômico da bananeira cv. BRS Conquista sob diferentes níveis de água e doses de magnésio foram realizadas colheitas dos cachos quando os frutos atingiram o pleno desenvolvimento fisiológico, com base na redução e/ou desaparecimento das quinas ou angulosidades da superfície dos frutos (Alves et al.; 1999). Os cachos foram colhidos com um corte, realizado com um facão, na altura do engaço. Em plantas de maior porte, era realizado um corte no pseudocaule tombando, primeiramente, a planta, antes do corte do cacho. O cacho era apoiado por um trabalhador da FAL-UnB evitando que este caísse diretamente no solo, e em seguida, era realizado o corte do cacho. As operações de colheita ocorreram do período de 1 de julho de 2014 a 30 de dezembro de 2014 com o intervalo semanal entre as colheitas, totalizando 27 colheitas. No momento da colheita, os cachos foram identificados com uma etiqueta de papel na qual trazia informações sobre o bloco e os tratamentos de água e adubo a qual o cacho pertencia.

Após a colheita, os cachos foram conduzidos a um galpão onde seriam despencados. As pencas de cada cacho e os frutos de cada penca eram contabilizadas, e os valores anotados em uma ficha desenvolvida para o projeto. As pencas foram acondicionadas em caixas plásticas, com a primeira penca, a penca média e a penúltima penca em posição de destaque dentro da caixa (Figura 21).

Em seguida, as caixas plásticas contendo apenas as pencas foram pesadas em uma balança analógica (não foram pesados engaço, raquis e coração). Os pesos das pencas, desconsiderando o peso das caixas, foram anotados na mesma ficha onde foram anotadas as quantidades de pencas e frutos.

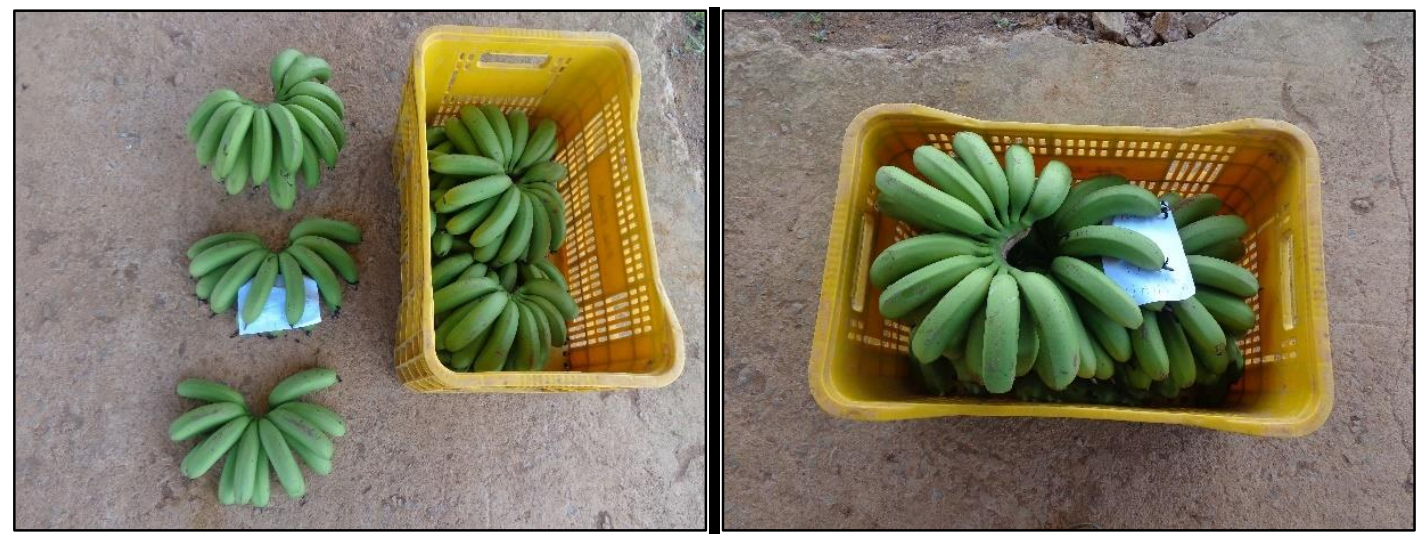

Figura 21: Acondicionamento de pencas de banana, em caixas plásticas, evidenciando a primeira penca, a penca média e penúltima penca. Brasília, 2014. 
Depois da pesagem, os frutos seguiram para a avaliação do comprimento e diâmetro. Foram retirados 5 frutos, ao acaso, da primeira penca, da penca média e da penúltima penca, totalizando 15 frutos. O comprimento do fruto foi medido, no sentido longitudinal, com o auxílio de um paquímetro digital. Quando o fruto teve um comprimento maior que a escala do paquímetro $(150 \mathrm{~mm})$, o fruto foi medido com uma régua graduada. $\mathrm{O}$ diâmetro do fruto foi obtido medindo a região central com o auxílio de um paquímetro digital (Figura 22).

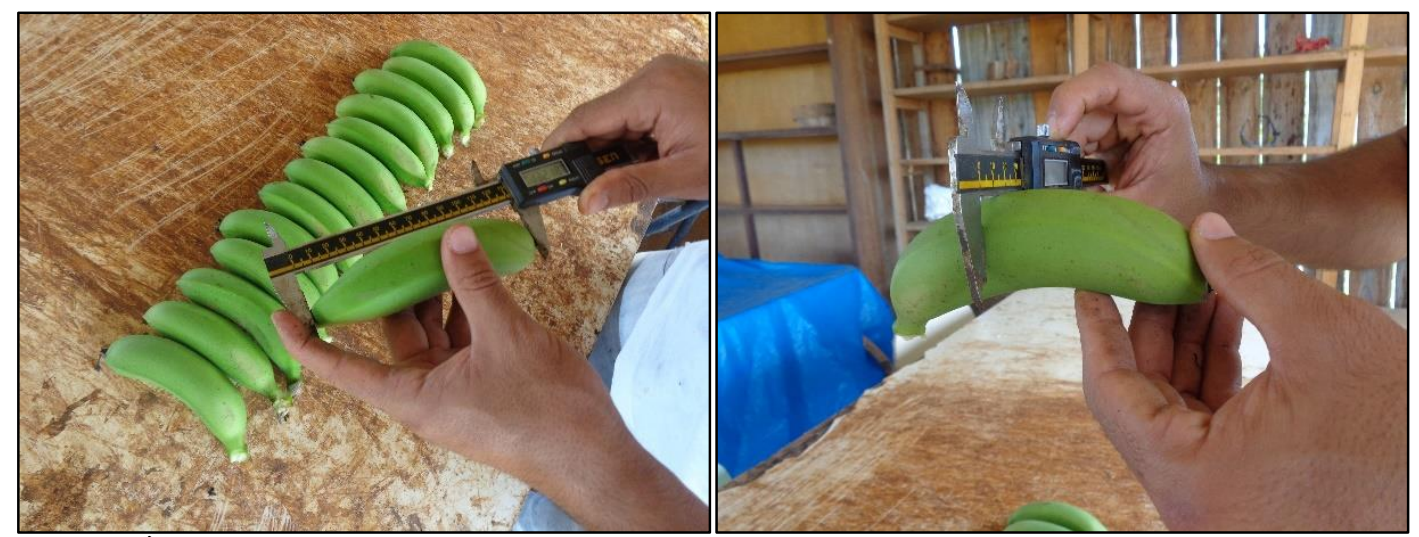

Figura 22: À esquerda: avaliação do comprimento da banana com o auxílio de um paquímetro digital. À direita: avaliação do diâmetro do fruto, na região central, com o auxílio de um paquímetro digital. Brasília, 2014.

Para avaliar a firmeza média da polpa (FMP), 10 frutos da penca média foram acondicionados em uma caixa plástica - sendo que cada caixa comportou 5 pencas - e identificados com a etiqueta do cacho correspondente. As caixas foram cobertas com uma lona plástica, com o objetivo de facilitar o amadurecimento dos frutos. As pencas, cujos frutos estavam maduros, foram retiradas e avaliadas após uma semana. Os frutos foram descascados e perfurados com um penetrômetro analógico de ponteira de $11 \mathrm{~mm}$ na sua porção central (Figura 23).

A produtividade expressa em peso de pencas por hectare (PPH), em Kg.ha- ${ }^{-1}$, foi obtida a partir da soma dos pesos das pencas colhidas na parcela multiplicada pelo número de parcelas contidas no hectare (278 parcelas.ha $\left.{ }^{-1}\right)$. $\mathrm{O}$ número de cachos por hectare $(\mathrm{NCH})$ foi obtido pela multiplicação da soma do número de cachos colhidos por parcela pelo número de parcelas contidas no hectare. 


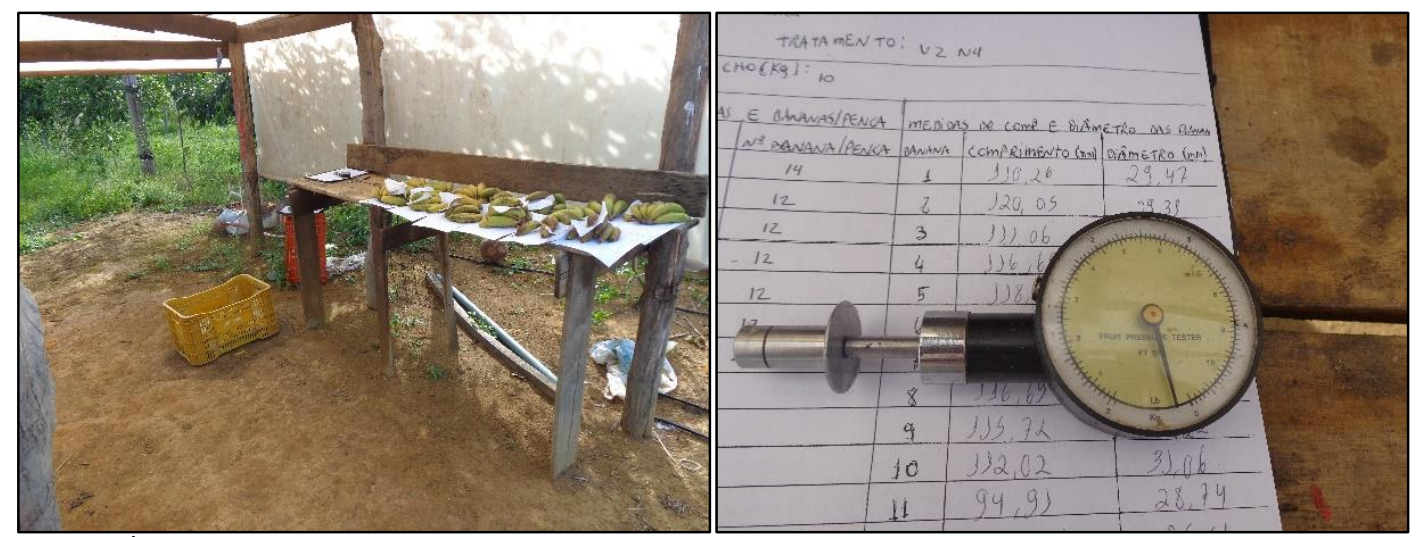

Figura 23: À esquerda: pencas de bananas com frutos madurados a serem avaliadas pelo penetrômetro. À direita: penetrômetro utilizado na avaliação da firmeza da polpa da banana. Brasília, 2014.

O número médio de pencas por cacho (NMPC) foi obtido pela média de pencas obtidas nos cachos colhidos na parcela. O número médio de bananas por cacho (NMBC) foi obtida pela média da quantidade de bananas obtidas em cada cacho colhido na parcela. A partir da divisão do NMBC pelo NMPC determinou-se a variável número médio de bananas por penca (NMBP).

O peso médio por banana (PMB), expresso em gramas, foi obtido pela relação entre o peso de pencas (PP) e total de bananas produzidas no cacho (BC). A relação entre o comprimento e o diâmetro (CD) foi obtida dividindo o comprimento médio de bananas (CMB) pelo diâmetro médio de bananas (DMB) obtido na parcela.

\section{ANÁLISE DE VARIÂNCIA}

Os dados originais coletados de todas as características foram submetidos à análise de variância (ANAVA) e as médias agrupadas pelo teste de Scott Knott $(\mathrm{P}<0,05)$. As análises foram realizadas utilizando o programa estatístico SISVAR (FERREIRA, 1998).

\section{REGRESSÃO}

Regressões polinomiais foram ajustadas entre características de produção e de qualidade de frutos em função das doses de magnésio $(\mathrm{Mg})$ e em função dos volumes de água aplicados (V). As equações foram selecionadas baseando-se na significância de seus coeficientes (ao nível de 5\% de significância) utilizando o programa SANEST (ZONTA E MACHADO, 1995).

Ressalta-se que Y pode assumir as variáveis produtividade (PPH), número de cachos por hectare $(\mathrm{NCH})$, número médio de pencas por cacho (NMPC), número médio de bananas por cacho (NMBC), número médio de bananas por penca (NMBP), peso médio de banana 
(PMB), comprimento médio de banana (CMB), diâmetro médio de banana (DMB), relação comprimento diâmetro (CD) e firmeza média da polpa (FMP).

As análises de correlação linear (Pearson), entre todas as variáveis, basearam-se na significância de seus coeficientes. A classificação de intensidade da correlação para $\mathrm{p} \leq 0,05$ foi: muito forte $(r \pm 0,91$ a $\pm 1,00)$, forte $(r \pm 0,71$ a $\pm 0,9)$, média $(r \pm 0,51$ a $\pm 0,70)$ e fraca $(r$ $\pm 0,31$ a $\pm 0,50)$ (CARVALHO et al., 2004). 


\section{RESULTADOS E DISCUSSÃO}

As variáveis foram agrupadas da seguinte forma: NCH, PPH, NMPC, NMBC, PMB e NMBP considerados como indicadores de produtividade. CMB, DMB, CD e FMP considerados como indicadores de qualidade de fruto.

Pelo resumo da análise de variância verificam-se efeitos significativos dos tratamentos na análise de todas características, com exceção de NMPC. Os níveis de água apresentaram diferenças significativas nas análises das seguintes características: NCH, PPH e PMB. As doses de Magnésio apresentaram diferenças significativas no NMBC. A interação água $\mathrm{x}$ magnésio foi significativa em todas características, a exceção de NCH, NMPC e NMBC. A interação magnésio x água não foi significativa na análise do NCH, PPH, NMPC e NMBC (Tabela 15). Os resumos das análises de variância bem como as médias de todos tratamentos encontram-se em anexo.

\section{NÚMERO DE CACHOS POR HECTARE (NCH)}

Os volumes de água de 6.540 e 4.300 L.cova $^{-1}$ proporcionaram maiores valores de $\mathrm{NCH}$. A equação de regressão quadrática ajusta os valores de $\mathrm{NCH}$ em função dos volumes de água conforme a Figura 24. Observa-se o ponto de maior valor de NCH com volume de água aplicada em torno de 5.000 litros.

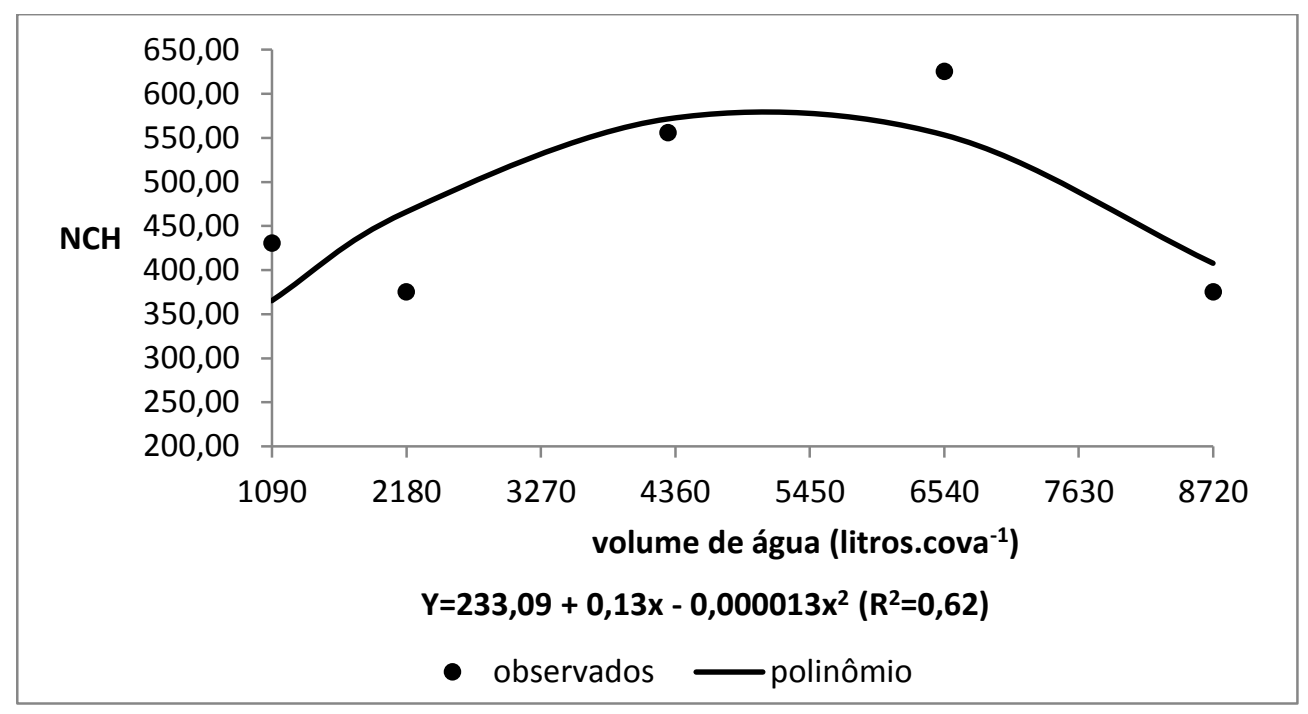

Figura 24: Números de cachos por hectare da cultivar 'BRS Conquista' observados e ajustados em função de cinco volumes de irrigação (1.090-2.177-4.300-6.540-8.720 litros.cova $\left.{ }^{-1}\right)$. Brasília, 2014. 
Tabela 15: Resumo da análise de variância da cultivar 'BRS Conquista'. Brasília, 2014.

\begin{tabular}{|c|c|c|c|c|c|c|c|c|c|c|c|}
\hline $\mathrm{FV}$ & GL & $\mathrm{PPH}$ & $\mathrm{NCH}$ & NMPC & NMBC & NMBP & PMB & $\mathrm{CMB}$ & DMB & $\mathrm{CD}$ & FMP \\
\hline BLOCO & 3 & $3618073,6^{\mathrm{NS}}$ & $34004,9^{\mathrm{NS}}$ & $3,92^{\mathrm{NS}}$ & $842,6^{\mathrm{NS}}$ & $0,76^{\mathrm{NS}}$ & $470,6^{\mathrm{NS}}$ & $157,7^{\mathrm{NS}}$ & $28,5^{\mathrm{NS}}$ & $0,02^{\mathrm{NS}}$ & $0,25^{\mathrm{NS}}$ \\
\hline VOLUME & 4 & $46625406,2 *$ & $255037,2^{*}$ & $2,83^{\mathrm{NS}}$ & $1418,4^{\mathrm{NS}}$ & $4,30^{\mathrm{NS}}$ & $1045^{*}$ & $323^{\mathrm{NS}}$ & $42,6^{\mathrm{NS}}$ & $0,07^{\mathrm{NS}}$ & $0,17^{\mathrm{NS}}$ \\
\hline MAGNÉSIO & 4 & $16141292,7^{\mathrm{NS}}$ & $79216,1^{\mathrm{NS}}$ & $2,04^{\mathrm{NS}}$ & $1265,7 *$ & $2,88^{\mathrm{NS}}$ & $263,5^{\mathrm{NS}}$ & $40,5^{\mathrm{NS}}$ & $7,47^{\mathrm{NS}}$ & $0,03^{\mathrm{NS}}$ & $0,20^{\mathrm{NS}}$ \\
\hline INTERAÇÃO & 16 & $4697305,0^{\mathrm{NS}}$ & $27532,4^{\mathrm{NS}}$ & $1,03^{\mathrm{NS}}$ & $411,9^{\mathrm{NS}}$ & $1,98^{\mathrm{NS}}$ & $350,7^{\mathrm{NS}}$ & $92,4^{\mathrm{NS}}$ & $24,8^{\mathrm{NS}}$ & $0,19^{\mathrm{NS}}$ & $0,48 * *$ \\
\hline \multicolumn{12}{|c|}{ DESDOBRAMENTOS } \\
\hline $\mathrm{V} \times \mathrm{Mg}$ & 4 & $\mathrm{Mg}_{4}-19880536,1^{*}$ & NS & NS & NS & $\operatorname{Mg}_{5} 6,14 * *$ & $\mathrm{Mg}_{2}-697 *$ & $\mathrm{Mg}_{5}-350 * *$ & $\mathrm{Mg}_{1}-59 *$ & $\operatorname{Mg}_{1}-0,6^{* *}$ & $\begin{array}{l}\mathrm{Mg}_{1}-0,9 * * \\
\mathrm{Mg}_{5}-0,7 * *\end{array}$ \\
\hline $\operatorname{Mg} \times \mathrm{V}$ & 4 & NS & NS & NS & NS & $\mathrm{V}_{3}-3,76^{*}$ & $\mathrm{~V}_{1}-948 *$ & $\mathrm{~V}_{1}-262 *$ & $\mathrm{~V}_{1}-63$ & $\mathrm{~V}_{1}-0,4^{*}$ & $\mathrm{~V}_{1}-0,9 *$ \\
\hline CV $1 \%$ & & 98 & 52 & 16 & 22 & 9,02 & 33 & 11 & 14 & 15 & 51 \\
\hline $\mathrm{CV} 2 \%$ & & 66 & 53 & 10 & 16 & 8,8 & 29 & 9 & 14 & 12 & 53 \\
\hline MÉDIA & & 3836,6 & 472,6 & 9,8 & 133,2 & 13,5 & 54,9 & 90,5 & 30 & 3,06 & 0,85 \\
\hline
\end{tabular}

$\mathrm{NS}=$ não significativo, * significativo a $5 \%$ pelo teste $\mathrm{F}$, ** significativo a $1 \%$ pelo teste $\mathrm{F}$, $\mathrm{PPH}=$ peso de pencas por hectare, $\mathrm{NCH}=$ número de cachos por hectare, $\mathrm{NMPC}=$ número médio de pencas por cacho, $\mathrm{NMBC}=$ número médio de bananas por cacho, $\mathrm{NMBP}=$ número médio de bananas por penca, $\mathrm{PMB}=$ peso médio de bananas, $\mathrm{CMB}=$ comprimento médio de bananas, diâmetro médio de bananas, $\mathrm{CD}=$ relação

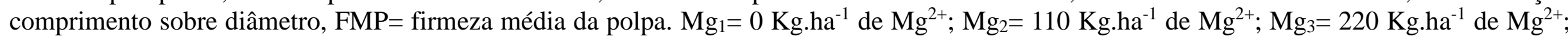
$\mathrm{Mg}_{4}=330 \mathrm{Kg} \cdot \mathrm{ha}^{-1}$ de $\mathrm{Mg}^{2+} ; \mathrm{Mg}_{5}=440 \mathrm{Kg}^{-h^{-1}}$ de $\mathrm{Mg}^{2+} . \mathrm{V}_{1}=1.090$ litros.cova ${ }^{-1} ; \mathrm{V}_{2}=2.177$ litros.cova ${ }^{-1} ; \mathrm{V}_{3}=4.300$ litros.cova ${ }^{-1} ; \mathrm{V}_{4}=6.540$ litros.cova ${ }^{-1} ; \mathrm{V}_{5}=8.720$ litros.cova $^{-1}$; 


\section{PESO DE PENCAS POR HECTARE (PPH)}

O volume de água de 6.540 L.cova $^{-1}$ apontou maior valor da produtividade. A equação de regressão quadrática ajusta os valores de produtividade em função dos volumes de água conforme observado na Figura 25. Evidencia-se o ponto de máxima produtividade em função de 5.447 L.cova ${ }^{-1}$ de água aplicada.

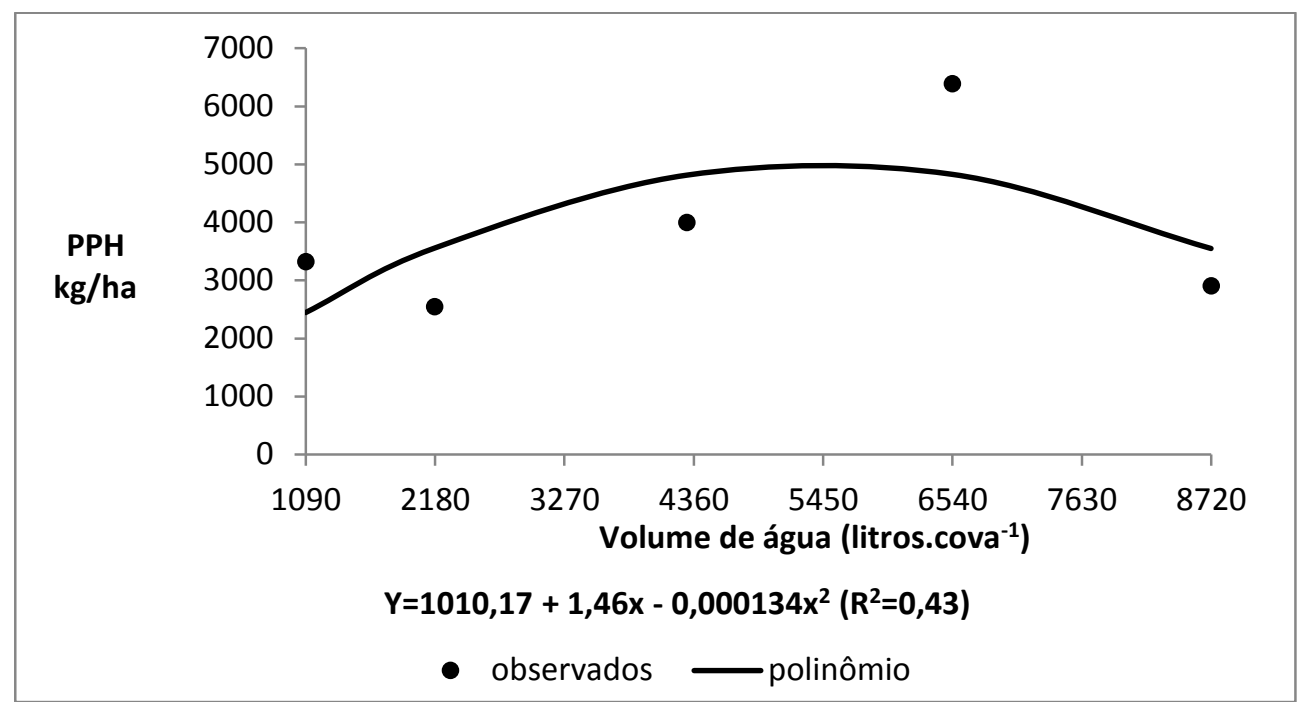

Figura 25: Pesos de pencas por hectare da cultivar 'BRS Conquista' observados e ajustados em função de cinco volumes de irrigação (1.090-2.177-4.300-6.540-8.720 litros.cova ${ }^{-1}$ ). Brasília, 2014.

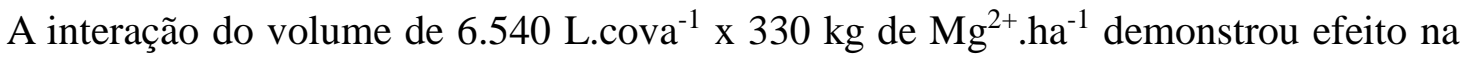
análise da produtividade. A distribuição dos valores de produtividade em função dos volumes de água na dose de $330 \mathrm{~kg}$ de $\mathrm{Mg}^{2+} \cdot \mathrm{ha}^{-1}$ pode ser visualizado na Figura 26. 


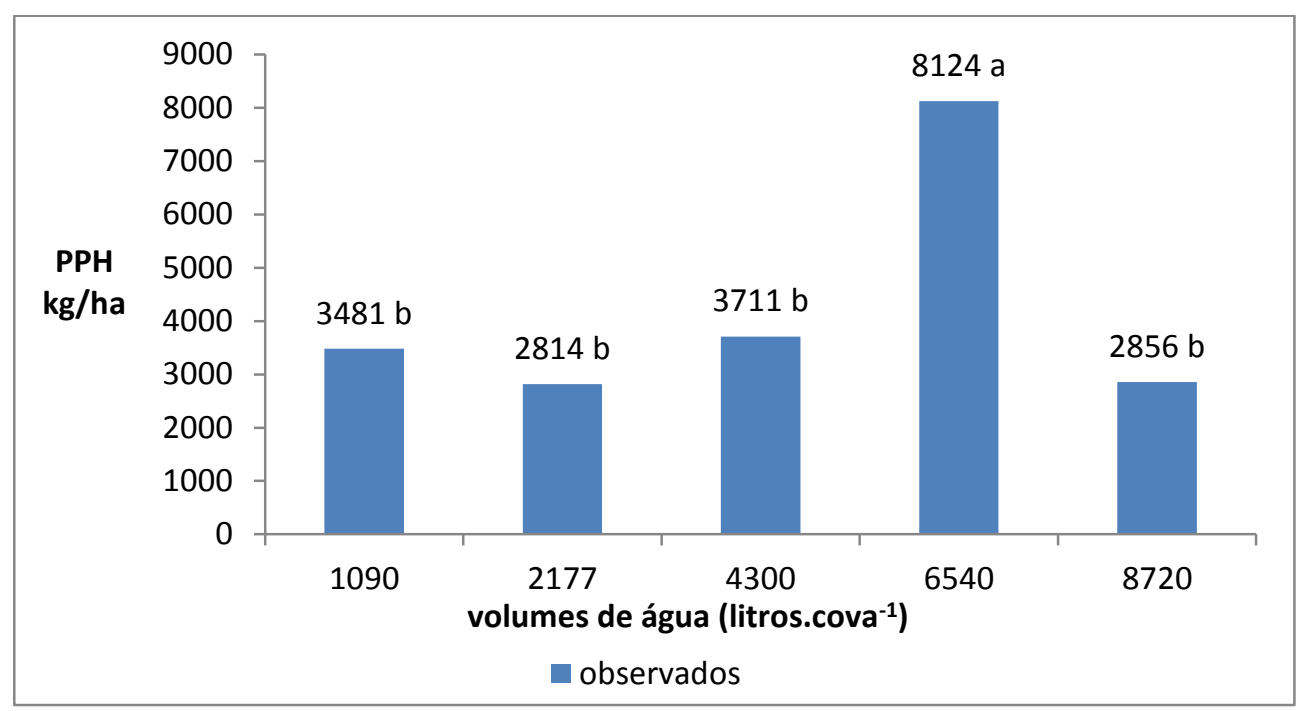

Figura 26: Pesos de pencas por hectare da cultivar 'BRS Conquista' observados em função de cinco volumes de irrigação (1.090-2.177-4.300-6.540-8.720 litros.cova $\left.^{-1}\right)$ dentro da dose de $330 \mathrm{~kg}$ de $\mathrm{Mg}^{2+} \cdot \mathrm{ha}^{-1}$ Brasília, 2014.

\section{NÚMERO MÉDIO DE BANANAS POR CACHO (NMBC)}

As doses de $220 \mathrm{~kg}$ de $\mathrm{Mg}^{2+} \cdot \mathrm{ha}^{-1}$ e $110 \mathrm{~kg}$ de $\mathrm{Mg}^{2+} \cdot \mathrm{ha}^{-1}$ indicaram maiores valores do NMBC. A equação de regressão quadrática ajusta as médias de NMBC em função das doses de magnésio conforme a Figura 27. Observa-se o ponto de máximo valor de NMBC com a dose de aproximadamente $220 \mathrm{~kg}$ de $\mathrm{Mg}^{2+} \cdot \mathrm{ha}^{-1}$.

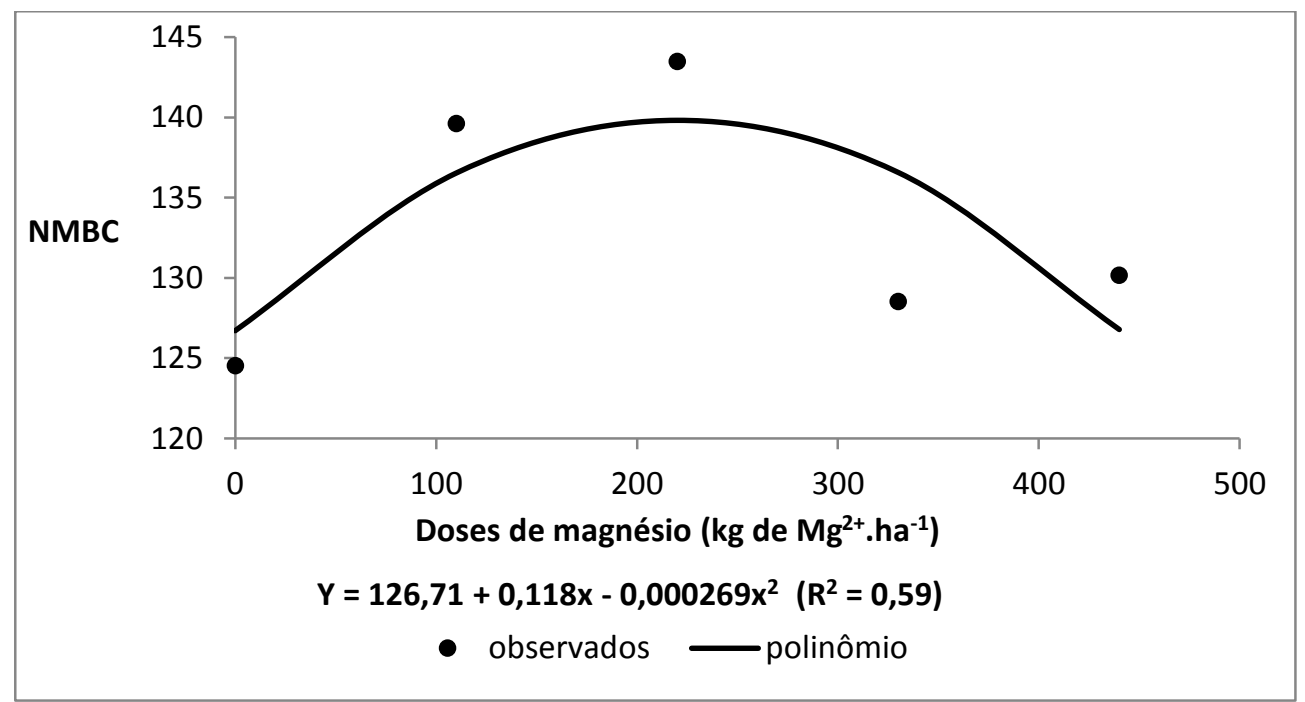

Figura 27: Números médios de bananas por cacho da cultivar 'BRS Conquista' observados e ajustados em função de cinco doses de magnésio (0-110-220-330-440 $\mathrm{kg}$ de $\mathrm{Mg}^{2+} \cdot \mathrm{ha}^{-1}$ ). Brasília, 2014. 


\section{NÚMERO MÉDIO DE BANANAS POR PENCA (NMBP)}

As interações de $440 \mathrm{~kg}$ de $\mathrm{Mg}^{2+} \cdot \mathrm{ha}^{-1} \mathrm{x}$ os volumes de água de 2.177, 1.090 e 6.540 L.cova $^{-1}$ apontaram valores superiores do NMBP. A distribuição das médias pode ser visualizada na Figura 28.

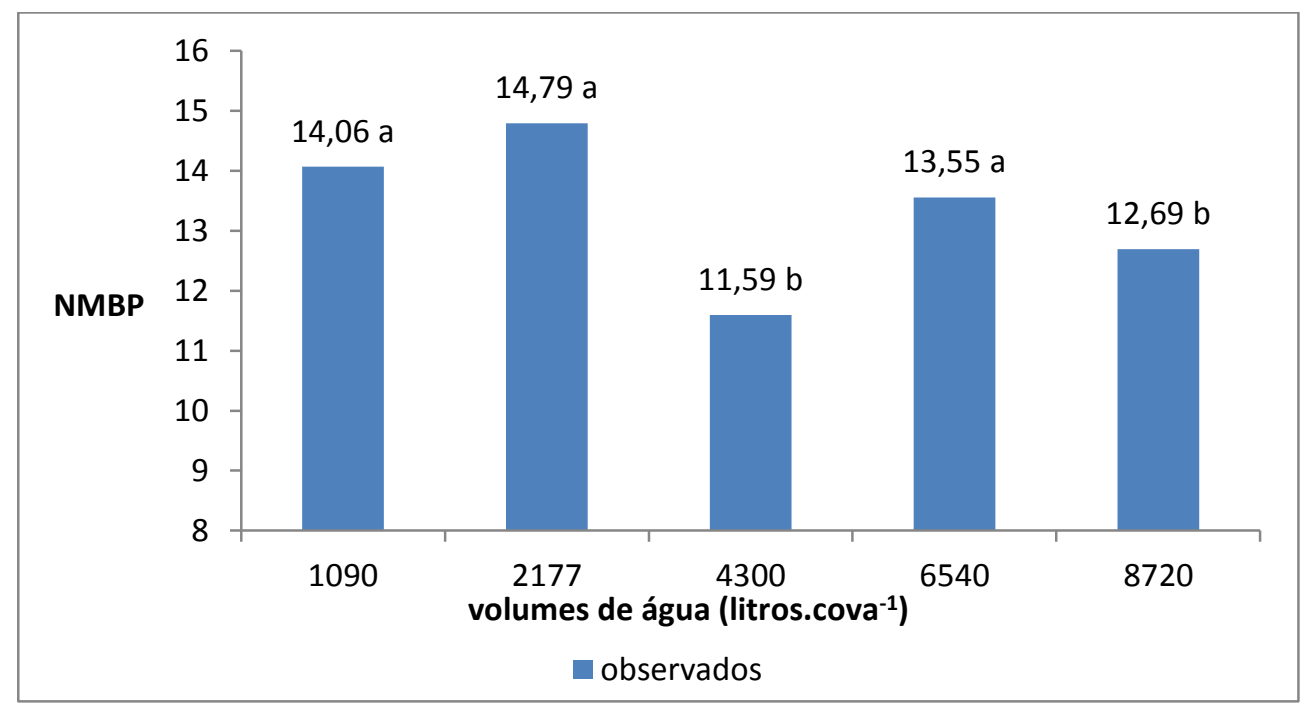

Figura 28: Números médios de bananas por penca da cultivar 'BRS Conquista' observados em função de cinco volumes de irrigação (1.090-2.177-4.300-6.540-8.720 litros.cova $\left.{ }^{-1}\right)$ dentro da dose de $440 \mathrm{~kg}$ de $\mathrm{Mg}^{2+} \cdot \mathrm{ha}^{-1}$. Brasília, 2014.

As interações do volume de água de 4.300L x 220, 110 e $330 \mathrm{~kg} \mathrm{de} \mathrm{Mg}^{2+} \cdot \mathrm{ha}^{-1}$ exibiram valores superiores do NMBP. A equação de regressão quadrática ajusta os valores de NMBP em função das doses de magnésio sob volume de água de 4.300 L.cova $^{-1}$ aplicados conforme Figura 29. Observa-se o ponto de máximo valor do NMBP em função da dose de $194 \mathrm{~kg}$ de $\mathrm{Mg}^{2+} \cdot \mathrm{ha}^{-1}$.

\section{PESO MÉDIO DE BANANAS (PMB)}

Os volumes de 6.540 e 8.720 L.cova $^{-1}$ demonstraram valores superiores na análise do PMB. A equação de regressão linear ajusta os valores de PMB em função dos volumes de água aplicados conforme a Figura 30. Para cada 1.000 litros no volume aplicado por cova espera-se aumento de 1,59 gramas por fruto. 


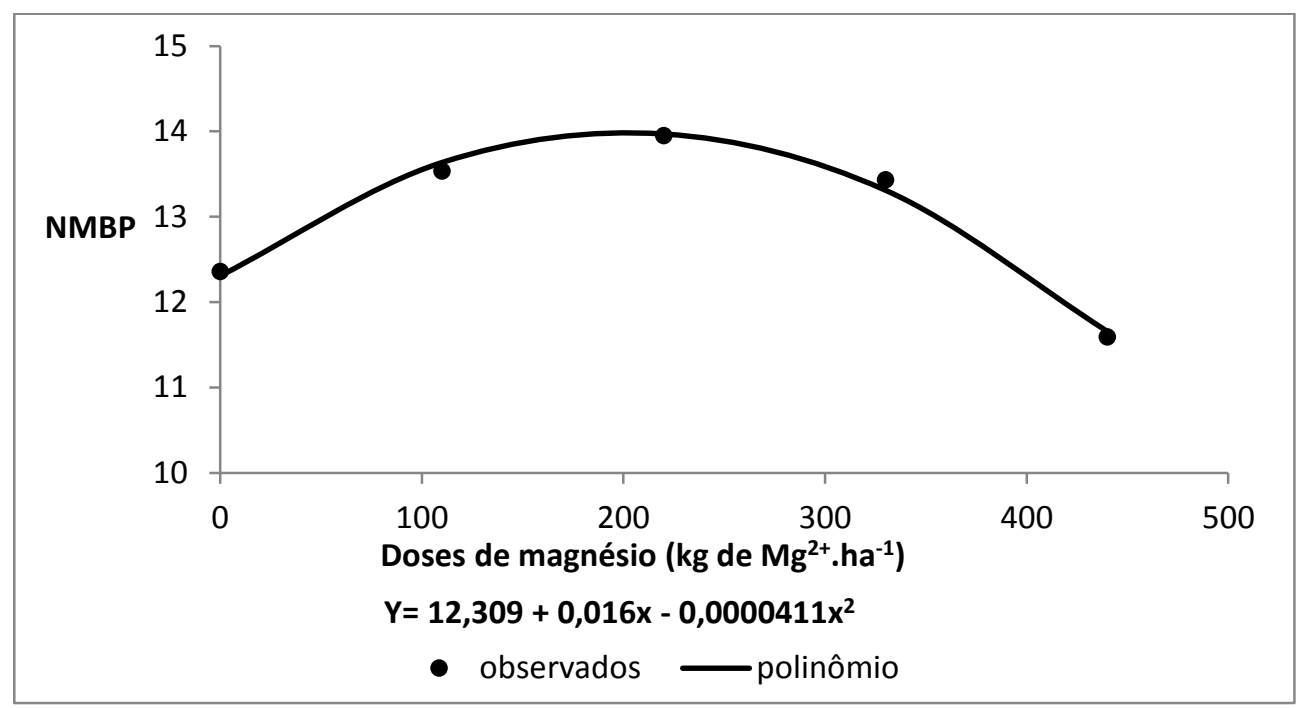

Figura 29: Números médios de bananas por penca da cultivar 'BRS Conquista' observados e ajustados em função de cinco doses de magnésio (0-110-220-330-440 $\mathrm{kg} \mathrm{Mg}^{2+}$.ha' ${ }^{-1}$ ) dentro do volume de irrigação de 4.300 litros.cova ${ }^{-1}$. Brasília, 2014.

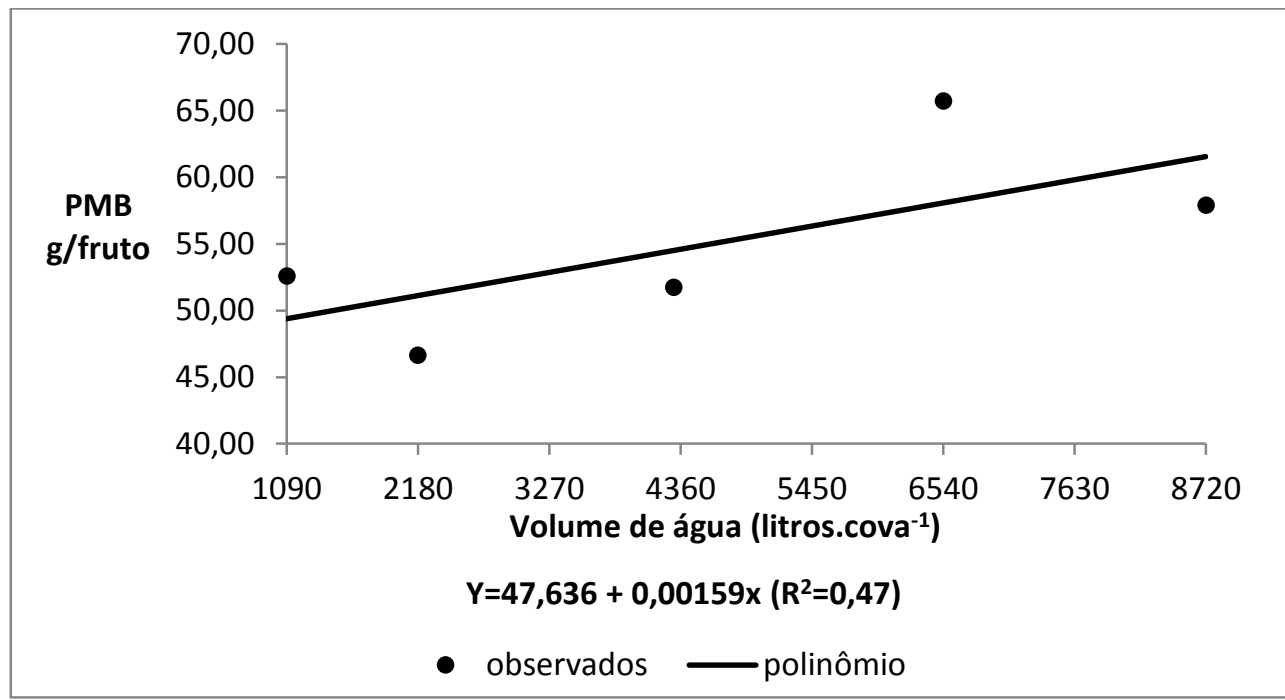

Figura 30: Pesos médios de bananas da cultivar 'BRS Conquista' observados e ajustados em função de cinco volumes de irrigação (1.090-2.177-4.300-6.540-8.720 litros.cova $\left.{ }^{-1}\right)$. Brasília, 2014.

As interações dos volumes de água de 6.540, 1.090 e 8.720 L.cova $^{-1}$ x 110 kg de $\mathrm{Mg}^{2+} \cdot \mathrm{ha}^{-1}$ apresentaram valores superiores do PMB. A equação de regressão cúbica ajusta os valores de PMB em função dos volumes na dose de $110 \mathrm{~kg} \mathrm{de} \mathrm{Mg}^{2+} \cdot \mathrm{ha}^{-1}$ conforme a Figura 31. 


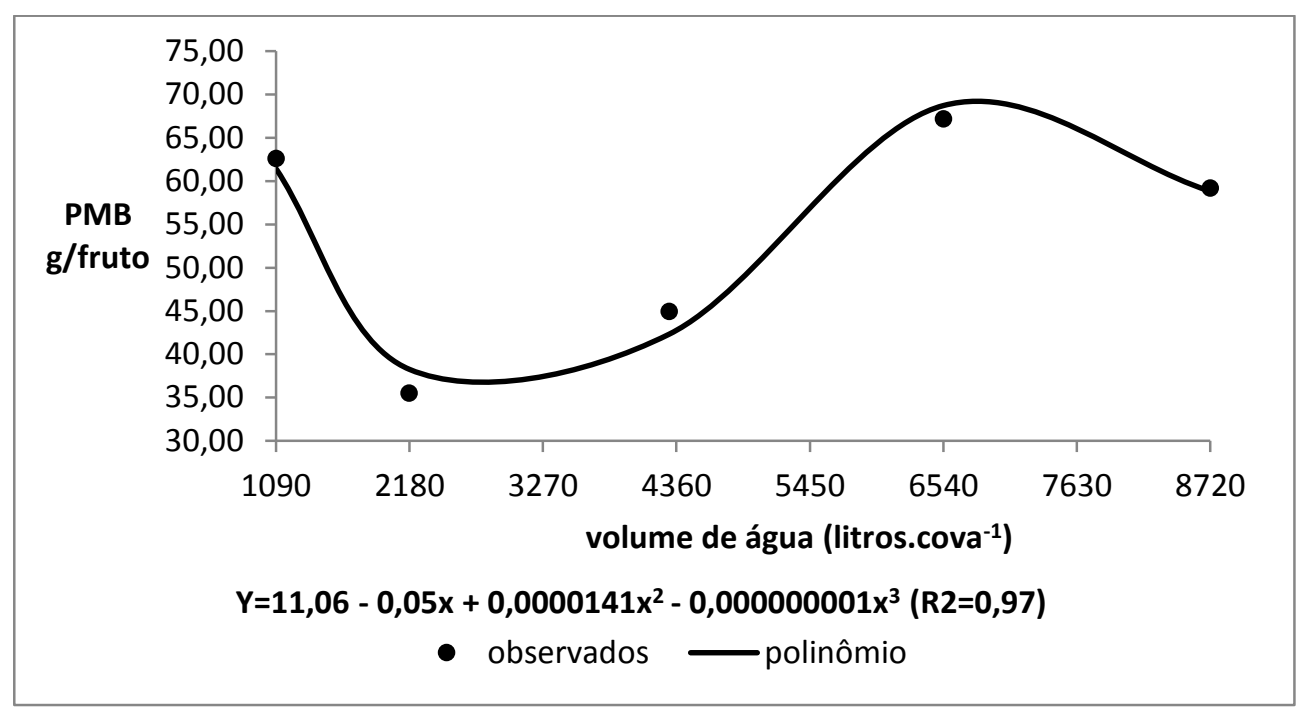

Figura 31: Pesos médios de bananas da cultivar 'BRS Conquista' observados e ajustados em função de cinco volumes de irrigação (0-1.090-2.177-4.300-6.540-8.720 litros.cova ${ }^{-1}$ ) dentro da dose de $110 \mathrm{~kg} \mathrm{Mg}^{2+}$.ha ${ }^{-1}$. Brasília, 2014.

As interações de 220 e $110 \mathrm{~kg}$ de $\mathrm{Mg}^{2+} \cdot \mathrm{ha}^{-1}$ x $1.090 \mathrm{~L}$ retrataram valores superiores do PMB. A equação de regressão quadrática ajusta os valores de PMB em função das doses de magnésio no volume de 1.090 L.cova $^{-1}$ por ciclo conforme a Figura 32. Observa-se o ponto de máximo PMB em função da dose de $219 \mathrm{~kg}$ de $\mathrm{Mg}^{2+} \cdot \mathrm{ha}^{-1}$.

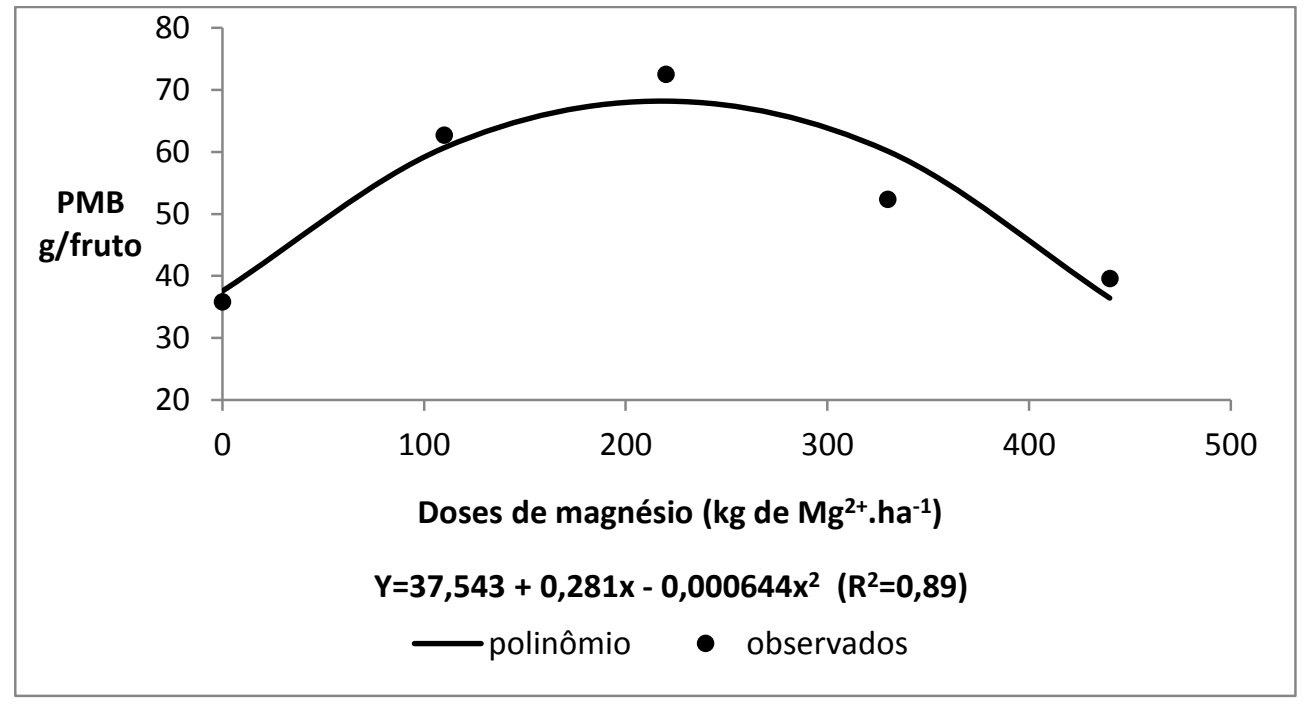

Figura 32: Pesos médios de bananas da cultivar 'BRS Conquista' observados e ajustados em

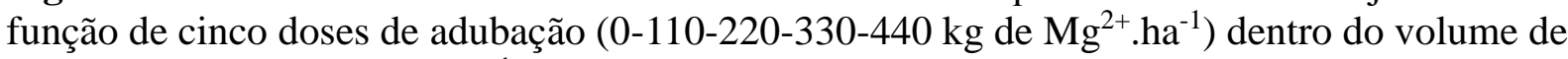
irrigação de 1.090 litros.cova ${ }^{-1}$. Brasília, 2014.

A cultivar de bananeira 'BRS Conquista' foi desenvolvida com intuito principal de substituir os cultivos tradicionais de banana no estado do Amazonas. Os cultivos tradicionais daquele estado baseados em cultivares do subgrupo prata e a cultivar Maçã são altamente suscetíveis a doença da sigatoka negra (Mycosphaerella fijiensis), praga quarentenária A2 no Amazonas, que pode provocar até $100 \%$ de perdas no rendimento destas cultivares 
(PEREIRA \& GASPAROTTO, 2007). O clima de uma região (ambiente estável) para qual determinada cultivar foi selecionada possui influência ambiental na expressão do genótipo deste material. O Distrito Federal apresenta temperatura média favorável ao cultivo de bananas em quase toda totalidade do ano, entretanto há ocorrência de temperaturas subótimas e divergentes do ambiente para qual a cultivar 'BRS Conquista' foi selecionada. Portanto diferenças na duração do ciclo, baixos indicadores de produtividade e de qualidade de frutos podem estar relacionados ao clima da região do Distrito Federal. É importante salientar que avaliações de genótipos de bananeira, durante vários ciclos de produção, são essenciais não somente aos programas de melhoramento, mas, também, para indicar cultivares adaptados ao sistema produtivo local (SILVA et al., 2013)

$\mathrm{O} \mathrm{NCH}$ e o PPH apresentaram respostas quadráticas aos volumes de água aplicados no experimento demonstrando valores superiores com volumes aplicados em torno de 6.540 L.cova ${ }^{-1}$. O aumento linear ou quadrático da produtividade, com o aumento da lâmina, também foi observado em outros trabalhos com cultivares de bananeira (COELHO et al. 2006; FIGUEIREDO et al., 2006).Os principais mecanismos de defesa da planta ao déficit hídrico no solo são a inibição da expansão foliar, a expansão do sistema radicular, o fechamento estomático, aceleração da senescência e abscisão foliar acarretando em menor acúmulo de fotoassimilados e justifica o fato das plantas que receberam menor volume de água apresentar menor peso de cacho (TAIZ \& ZEIGER, 2009).

Apesar do solo onde o experimento foi plantado apresentar alto teor de argila apresenta uma velocidade de infiltração básica muito alta afetando a dinâmica dos fluxos hídricos de superfície e subsuperfície e, consequentemente as características químicas do solo (VIDAL-TORRADO et al, 2005). De acordo com Costa et al. (2008) características vegetativas e de produção, em três ciclos de produção, de maneira geral apresentam-se menores em plantação sob gotejamento, quando comparada com sistema de aspersão convencional e microaspersão. Provavelmente esses dois últimos sistemas proporcionam maior expansão do sistema radicular, por apresentarem área de molhamento maior, com reflexos no crescimento e desenvolvimento da planta.

Apesar de não haver elevada resposta relativa à adubação neste primeiro ciclo em termos de produtividade (PPH) é altamente recomendável fazê-la, pois há elevada exportação de nutrientes pela cultura (CRISÓSTOMO et al., 2008). Além disso, o primeiro ciclo de produção da bananeira não é o momento mais adequado para analisar a massa da matéria fresca do cacho, na maioria dos genótipos, pois este caráter pode variar (aumentar) do 
primeiro até o quarto ciclo da cultura (SILVA et al., 2002). O PMB demonstrou resposta linear quanto ao volume de água aplicado durante o período do experimento apresentado valores superiores com os volumes de 6.540 e 8.720 L.cova $^{-1}$, não diferindo estatisticamente entre eles. O PMB é uma característica importante, pois possui correlação média com PPH, podendo ser utilizada como indicador de produtividade. Este trabalho corrobora com o proposto por Coelho et al. (2006) que indica o regime de irrigação correspondente ao uso da evapotranspiração da cultura a partir do coeficiente da cultura constante em 1,1 apresentandose mais adequado às cultivares de banana 'Prata Anã' e 'Grand Naine', tanto em termos de produtividade como em eficiência de uso da água.

$\mathrm{O}$ experimento apresentou efeitos médios significativas para os tratamentos de $\mathrm{Mg}$ no NMBC, onde foram observados maiores valores para esta característica nas doses aplicadas de 220 e $110 \mathrm{~kg} \mathrm{de} \mathrm{Mg}^{2+} \cdot \mathrm{ha}^{-1} \cdot \mathrm{ano}^{-1}$. O número de pencas pode estar diretamente relacionado com o número de bananas por cacho sendo um caráter muito importante para o produtor, pois o mercado usa a penca como unidade comercial. Segundo Borges et al. (2011) o peso do cacho é o produto do número de pencas por cacho, do número de bananas por penca e do peso médio de bananas. Respostas semelhantes foram observadas na análise do desdobramento de magnésio dentro do volume de $4.300{\mathrm{~L} . \mathrm{cova}^{-1}}^{-1}$ aplicado na análise do NMBP, onde as doses 220, 110 e $330 \mathrm{~kg}$ de $\mathrm{Mg}^{2+} \cdot \mathrm{ha}^{-1}$. ano $^{-1}$ apresentaram valores superiores. Este trabalho corrobora com o proposto por Coelho et al. (2013) que indicam onde o número de pencas por cacho e o número de frutos por penca, na cultivar 'Terra', apresentaram relação quadrática com a lâmina aplicada. Na maioria dos casos o suprimento de magnésio $(\mathrm{Mg})$ é feito com a utilização do calcário dolomítico na correção do solo por possuir preço mais em conta por quilo de $\mathrm{Mg}$. Posteriormente, observando-se as análises periódicas de solo, é feita a adubação de cobertura utilizando o sulfato de $\mathrm{Mg}$. O Mg também pode ser suprido via água de irrigação por existirem fontes altamente solúveis (Borges e Silva, 2002). Nota-se que os volumes de 6.540 e 8.720 L.cova $^{-1}$ promoveram os melhores resultados nessas características. Para o primeiro ciclo de colheita não houve efeitos significativos no NMPC, porém esperam-se respostas diferentes para os próximos ciclos de produção.

De uma maneira geral o estudo das características indicadoras de produtividade apresentou poucos efeitos em produtividade neste estágio inicial de produção. A produtividade foi influenciada positivamente pelos volumes de água aplicados, uma característica ambiental. 
No presente trabalho foi utilizada turno de rega de dois dias, respaldado por trabalho realizado por Coelho et al. (2006) onde afirmam não haver efeito significativo na produtividade das pencas em frequência de irrigação de quatro e seis dias em sistema de irrigação localizada.

\section{COMPRIMENTO MÉDIO DA BANANA (CMB)}

As interações dos volumes de água de 6.540 e $8.720 \mathrm{~L} \cdot \operatorname{cova}^{-1}$ x $440 \mathrm{~kg} \mathrm{de} \mathrm{Mg}^{2+} \cdot \mathrm{ha}^{-1}$ evidenciaram valores superiores do CMB. A equação de regressão ajusta os valores de CMB em função dos volumes de água para a dose de $440 \mathrm{~kg}$ de $\mathrm{Mg}^{2+} \cdot \mathrm{ha}^{-1}$ conforme a Figura 33. Para cada volume de 1000 litros acrescentados por cova espera-se o aumento de 2,06 mm no CMB.

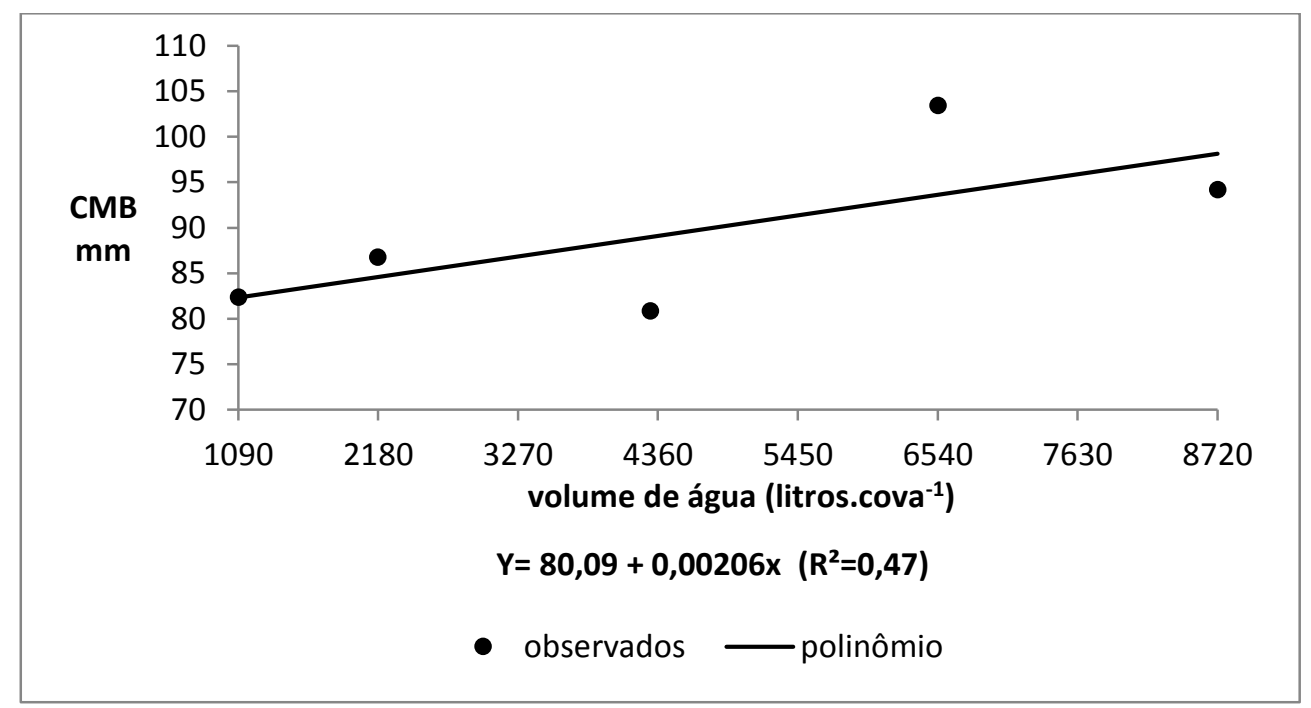

Figura 33: Comprimentos médios de bananas da cultivar 'BRS Conquista' observados e ajustados em função de cinco volumes de irrigação (0-1.090-2.177-4.300-6.540-8.720 litros.cova ${ }^{-1}$ ) dentro da dose de $440 \mathrm{~kg}$ de $\mathrm{Mg}^{2+} \cdot \mathrm{ha}^{-1}$. Brasília, 2014.

As interações das doses de 220, 330 e $110 \mathrm{~kg}$ de $\mathrm{Mg}^{2+} \cdot \mathrm{ha}^{-1} \mathrm{x}$ o volume de 1.090 litros.cova ${ }^{-1}$ apresentaram valores superiores para CMB. A equação de regressão quadrática ajusta os valores de CMB em função das doses de magnésio dentro do volume de 1.090 litros.cova ${ }^{-1}$ de água conforme Figura 34. Observa-se o ponto de máximo valor de CMB com a dose de $220 \mathrm{~kg}$ de $\mathrm{Mg}^{2+} \mathrm{ha}^{-1}$. 


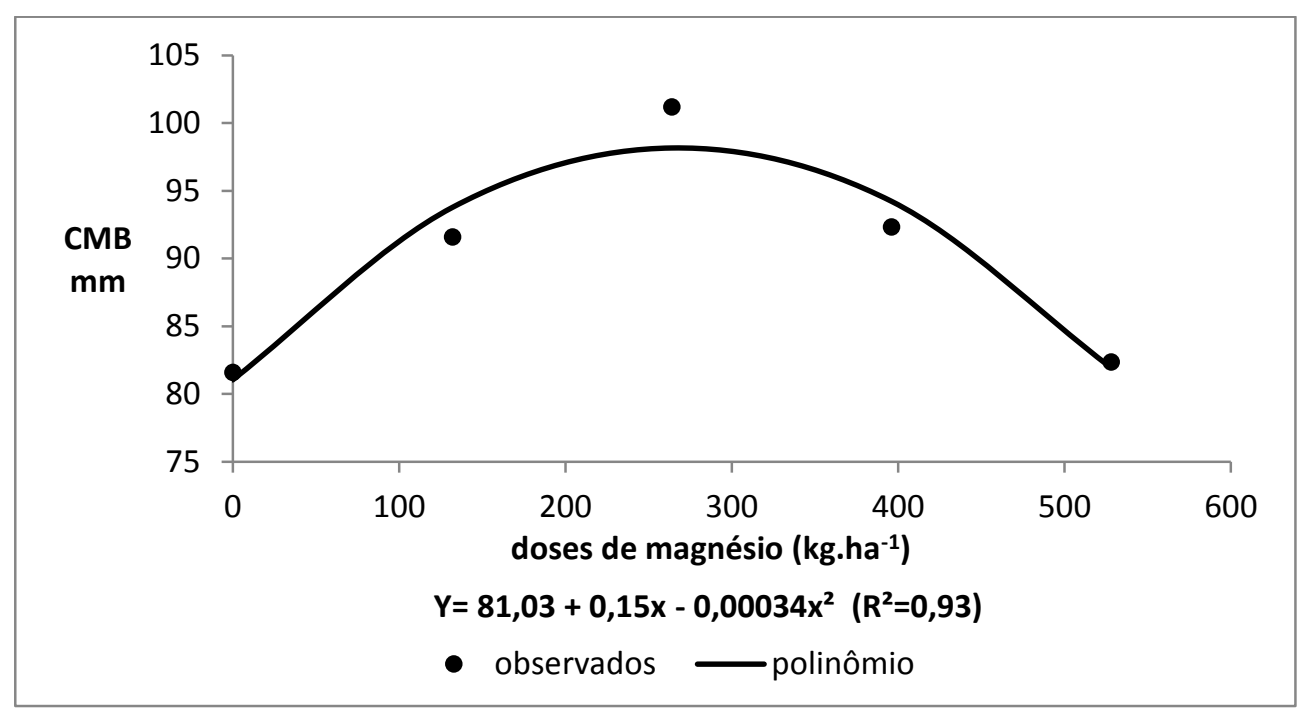

Figura 34: Comprimentos médios de bananas da cultivar 'BRS Conquista' observados e ajustados em função de cinco doses de magnésio (0-110-220-330-440 $\mathrm{kg}$ de $\mathrm{Mg}^{2+} / \mathrm{ha} / \mathrm{ano}$ ) dentro do volume de 1.090 litros.cova ${ }^{-1}$. Brasília, 2014.

\section{DIÂMETRO MÉDIO DA BANANA (DMB)}

As interações dos volumes de água de $8.720,4.300$ e 6.540 L.cova $^{-1}$ x 0 kg de $\mathrm{Mg}^{2+} \cdot \mathrm{ha}^{-1}$ denotaram maiores valores de DMB. A equação de regressão linear ajusta os valores de DMB em função dos volumes de água aplicados dentro da dose $0 \mathrm{~kg} \mathrm{Mg}^{2+} \cdot \mathrm{ha}^{-1}$ conforme a Figura 35. Para cada volume de 1.000 litros acrescentados por cova espera-se um aumento de $0,978 \mathrm{~mm}$ no DMB.

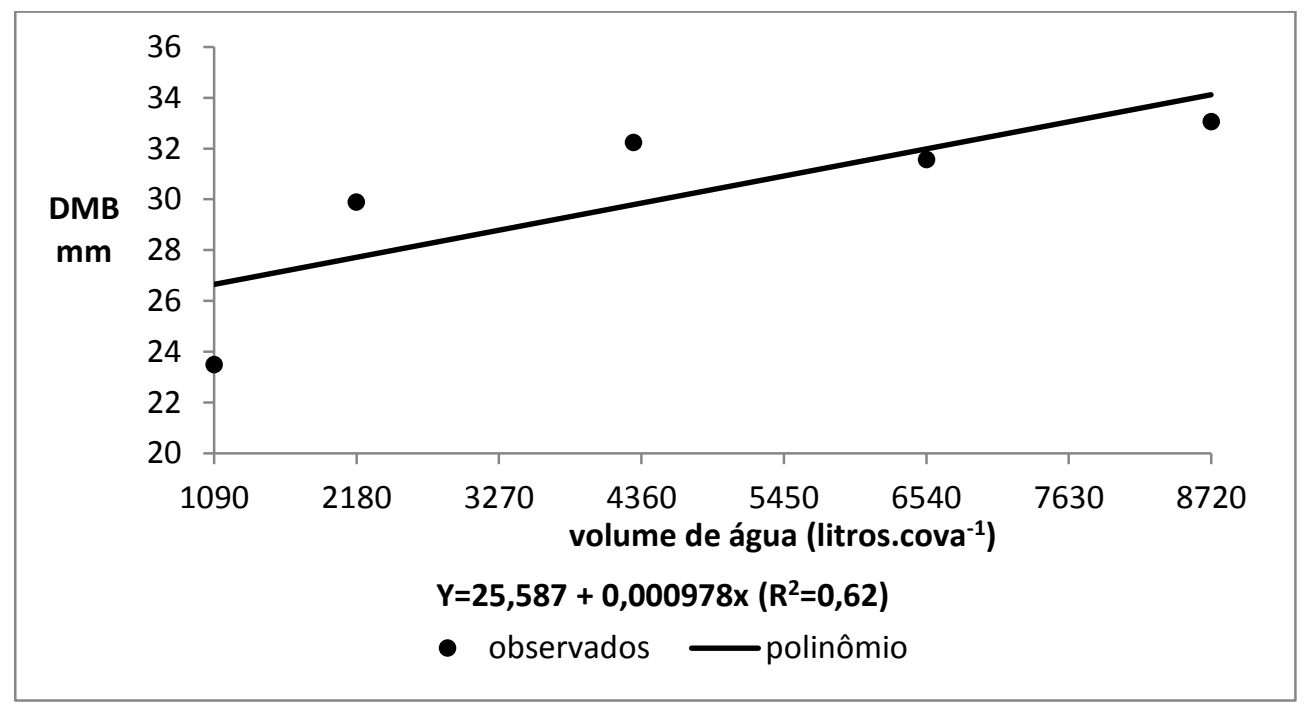

Figura 35: Diâmetros médios de bananas da cultivar 'BRS Conquista' observados e ajustados em função de cinco volumes de irrigação (1.090-2.177-4.300-6.540-8.720 litros.cova $\left.{ }^{-1}\right)$ com a dose $0 \mathrm{~kg}$ de $\mathrm{Mg}^{2+}$. há ${ }^{-1}$. Brasília, 2014. 
As interações das doses de 220, 110 e $330 \mathrm{~kg}$ de $\mathrm{Mg}^{2+} \cdot \mathrm{ha}^{-1}$ x 1.090 L.cova $^{-1}$ apresentaram valores superiores de DMB. A equação de regressão quadrática ajusta os valores de DMB em função das doses de magnésio no volume de 1.090 L.cova $^{-1}$ conforme a Figura 36. Observa-se o ponto de máximo de DMB com a dose de $253 \mathrm{~kg} \mathrm{de} \mathrm{Mg}^{2+} \cdot \mathrm{ha}^{-1}$.

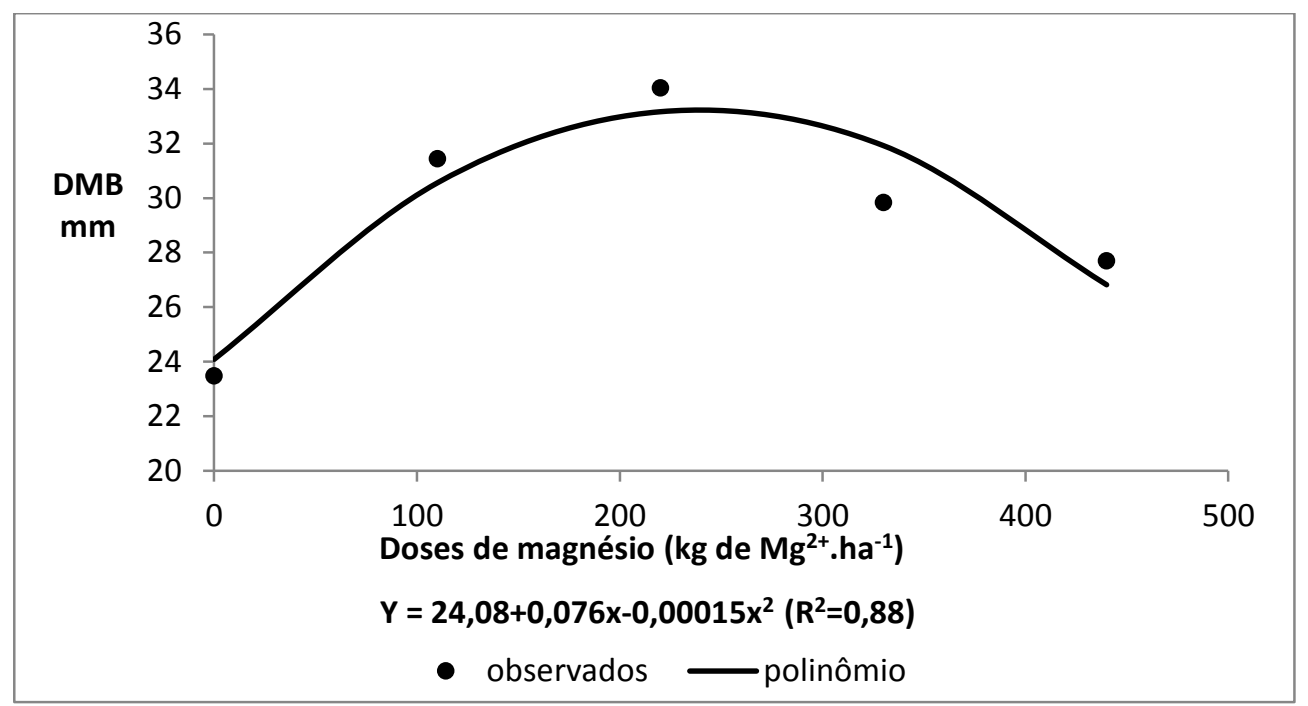

Figura 36: Diâmetros médios de bananas da cultivar 'BRS Conquista' observados e ajustados em função de cinco doses do adubo magnésio (0-110-220-330-440 $\mathrm{kg}$ de $\mathrm{Mg}^{2+} / \mathrm{ha} / \mathrm{ano}$ ) dentro do volume de irrigação de 1.090 litros.cova ${ }^{-1}$. Brasília, 2014.

\section{RELAÇÃO COMPRIMENTO/DIÂMETRO (CD)}

A interação do volume de 1.090 litros.cova ${ }^{-1}$ x 0 kg de $\mathrm{Mg}^{2+} \cdot \mathrm{ha}^{-1}$ proporcionou maior valor da realação $\mathrm{CD}$. A equação de regressão linear ajusta os valores da relação $\mathrm{CD}$ em função dos volumes de água na dose $0 \mathrm{~kg}$ de $\mathrm{Mg}^{2+} \cdot \mathrm{ha}^{-1}$ conforme a Figura 37. Com aumento de 1000 litros aplicados por cova espera-se uma diminuição de 0,096 na relação CD.

A interação de $0 \mathrm{~kg}$ de $\mathrm{Mg}^{2+} \cdot$ há ${ }^{-1}$ x $1.090 \mathrm{~L} \cdot \operatorname{cova}^{-1}$ mostrou maior valor na relação CD. A equação de regressão quadrática ajusta os valores da relação $C D$ em função das doses de magnésio no volume de 1090 L, conforme a Figura 38. Observa-se o ponto de menor valor da relação CD por volta de $283 \mathrm{~kg}$ de $\mathrm{Mg}^{2+} \cdot \mathrm{ha}^{-1}$. 


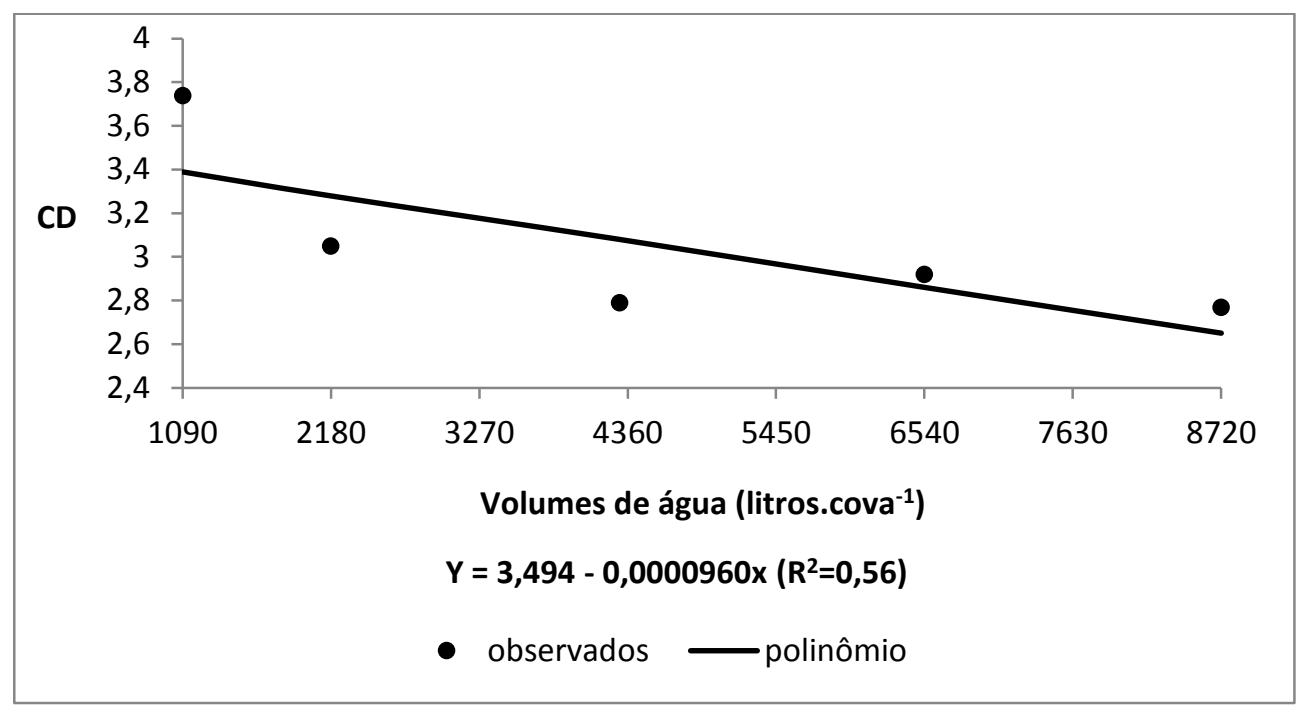

Figura 37: Relações comprimentos sobre diâmetros de bananas da cultivar 'BRS Conquista' observados e ajustados em função de cinco volumes de irrigação (1.090-2.177-4.300-6.5408.720 litros.cova ${ }^{-1}$ ) dentro da dose $\mathrm{kg}$ de $0 \mathrm{Mg}^{2+} \cdot \mathrm{ha}^{-1}$. Brasília, 2014.

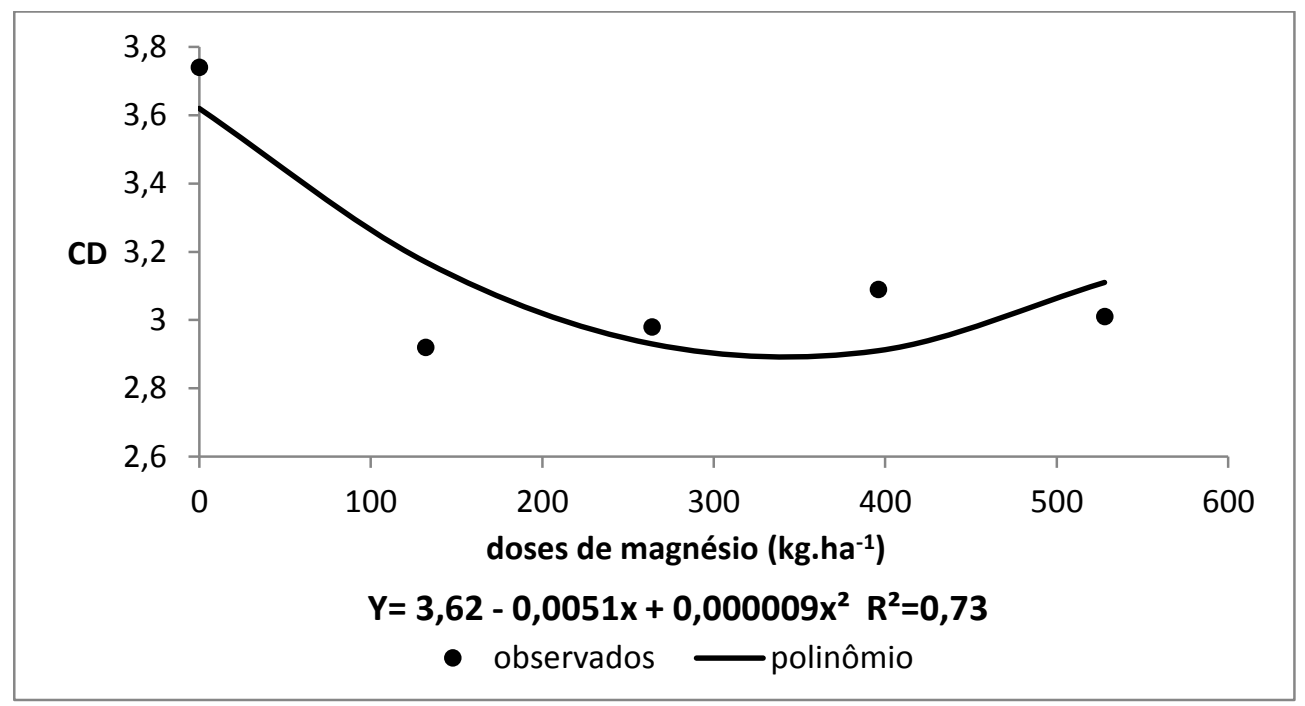

Figura 38: Relação comprimento sobre diâmetro de bananas da cultivar 'BRS Conquista' observados e ajustados em função de cinco doses de adubação com magnésio (0110-220-330-440 kg de $\mathrm{Mg}^{2+}$.ha-1 ${ }^{-1}$ dentro do volume de 1.090 litros.cova ${ }^{-1}$. Brasília, 2014.

\section{FIRMEZA MÉDIA DA POLPA (FMP)}

Os efeitos médios da interação de água versus cada nível de adubo foram significativos nas doses $0 \mathrm{~kg}$ de $\mathrm{Mg}^{2+} \cdot \mathrm{ha}^{-1}$ e $440 \mathrm{~kg} \mathrm{de} \mathrm{Mg}^{2+} \cdot \mathrm{ha}^{-1}$. A interação $1.090 \mathrm{~L} \cdot$ cova $^{-1}$ x $0 \mathrm{~kg}$ de $\mathrm{Mg}^{2+} \cdot \mathrm{ha}^{-1}$ indicou menor firmeza de polpa. A equação de regressão quadrática ajusta os valores de FMP em função dos volumes de água dentro da dose $0 \mathrm{~kg}$ de $\mathrm{Mg}^{2+} \cdot \mathrm{ha}^{-1}$ conforme a Figura 39. O ponto de máxima FMP foi observado com volume de 5.960 litros. 


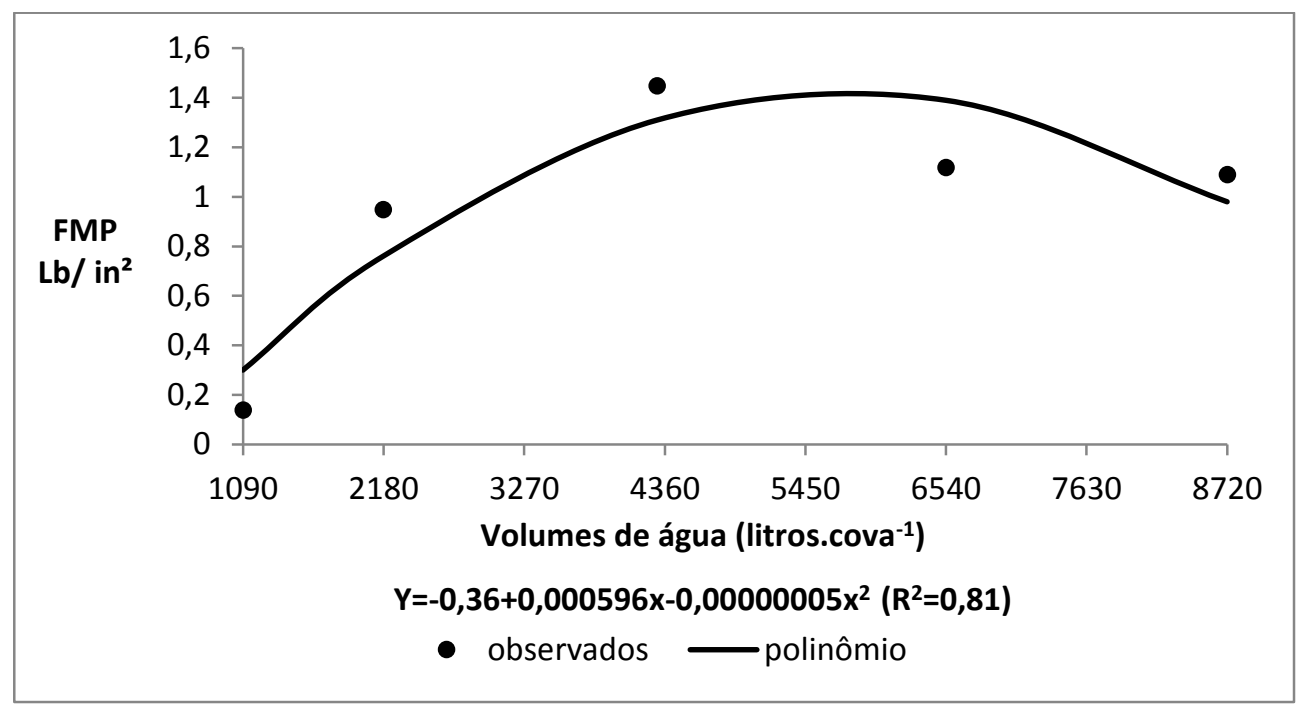

Figura 39: Firmeza média de polpa de bananas da cultivar 'BRS Conquista' observados e ajustados em função de cinco volumes de irrigação (0-1.090-2.177-4.300-6.540-8.720 litros.cova ${ }^{-1}$ ) dentro da dose de $0 \mathrm{~kg}$ de $\mathrm{Mg}^{2+} \cdot \mathrm{ha}^{-1}$. Brasília, 2014.

As interações dos volumes 1.090 e $6.540 \mathrm{~L} \cdot \operatorname{cova}^{-1}$ x $440 \mathrm{~kg} \mathrm{de} \mathrm{Mg}^{2+} \cdot \mathrm{ha}^{-1}$ evidenciaram maior firmeza de polpa. A equação de regressão cúbica ajusta os valores de FMP em função

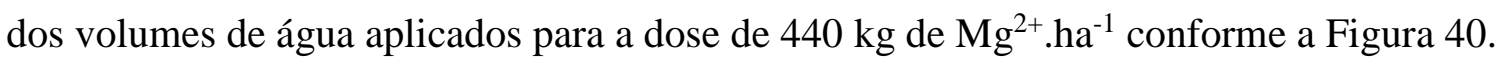

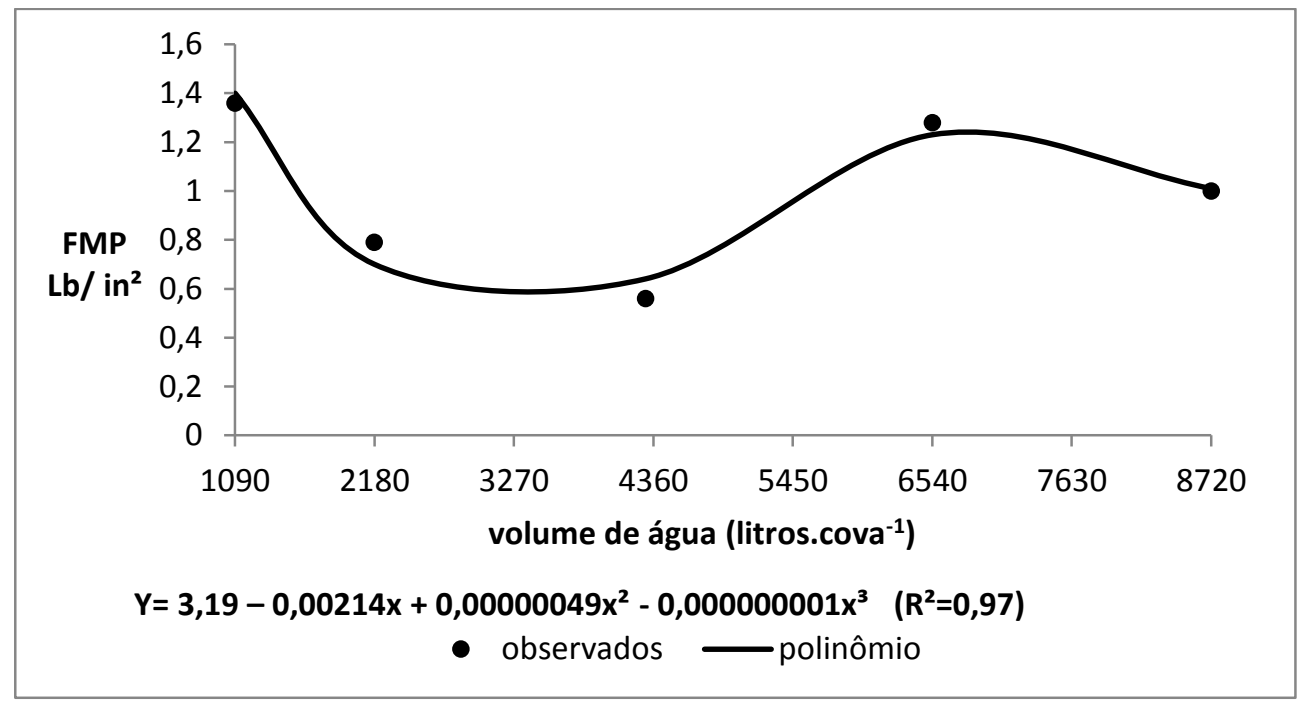

Figura 40: Firmeza média de polpa de bananas da cultivar 'BRS Conquista' observados e ajustados em função de cinco volumes de irrigação (1.090-2.177-4.300-6.540-8.720 litros.cova ${ }^{-1}$ ) dentro da dose de $440 \mathrm{~kg} \mathrm{Mg}^{2+} \cdot \mathrm{ha}^{-1}$. Brasília, 2014.

As interações de $220 \mathrm{~kg}$ de $\mathrm{Mg}^{2+} \cdot \mathrm{ha}^{-1}, 110 \mathrm{~kg}$ de $\mathrm{Mg}^{2+} \cdot \mathrm{ha}^{-1}$ e $330 \mathrm{~kg}$ de $\mathrm{Mg}^{2+} \cdot \mathrm{ha}^{-1} \mathrm{x}$ 4.300 litros.cova $^{-1}$ proporcionaram maior firmeza de polpa. A equação de regressão linear ajusta os valores de FMP em função dos níveis de adubo dentro do volume de 4.300 L.cova $^{-1}$ conforme a Figura 41. Com aumento na dose de $100 \mathrm{~kg}$ de $\mathrm{Mg}^{2+} \cdot \mathrm{ha}^{-1}$ observa-se diminuição de $0,16 \mathrm{Lb} / \mathrm{in}^{2}$ no FMP. 


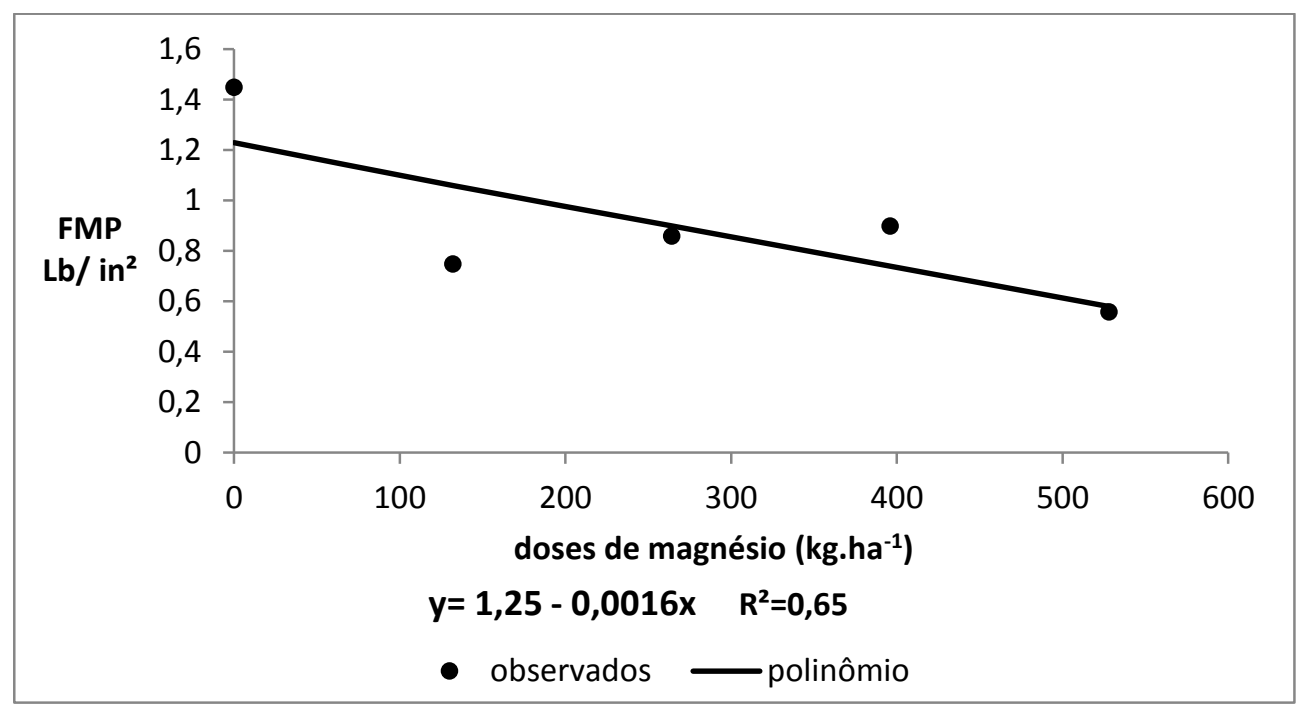

Figura 41: Firmezas médias de polpa de bananas da cultivar 'BRS Conquista' observados e ajustados em função de cinco doses de magnésio (0-110-220-330-440 $\mathrm{kg} \mathrm{Mg}^{2+}$.ha' ${ }^{-1}$ ) dentro do volume de 4.300 litros.cova ${ }^{-1}$. Brasília, 2014.

Segundo Manica (1997), nos frutos de banana do subgrupo Cavendish, o diâmetro do fruto aceito como de boa qualidade varia de 33 a $38 \mathrm{~mm}$, sendo de $34 \mathrm{~mm}$ ideal para exportação. Para os tratamentos utilizados neste estudo foram observados efeitos significativos superiores nos diâmetros dos frutos sob os tratamentos de 6.540, 4.300 e 8.720 L.cova $^{-1}$ sem adubação de magnésio. No caso do adubo magnésio estas respostas são esperadas para ciclos posteriores devido à própria demanda para o ciclo inicial da cultura. $\mathrm{Na}$ análise da característica comprimento de frutos verifica-se que os volumes com melhores respostas são 8.720 e $6.540 \mathrm{~L} \cdot \operatorname{cova}^{-1} \mathrm{x} 440 \mathrm{~kg}$ de $\mathrm{Mg}^{2+} \cdot \mathrm{ha}^{-1}$. O comprimento de fruto possui correlação positiva média com PCH principal indicador de produtividade. A precipitação total foi maior que os menores volumes aplicados. Entretanto, apesar desta superioridade, a irrigação foi utilizada na maior parte do tempo uma vez que a distribuição das chuvas é sazonal.

O DMB apresentou maiores resultados quando não houve restrição hídrica. Da mesma forma, os maiores valores observados do $\mathrm{CMB}$ foram obtidos nas parcelas submetidas aos maiores volumes de água aplicados onde a característica analisada apresentou resposta linear ao aumento de volumes aplicados. Trabalhando com banana irrigada no norte de Minas Gerais, Castricini et al. (2012) observaram que os maiores valores da massa média de frutos, diâmetro e frutos mais longos são encontrados quando a quantidade de água aplicada supri toda a ETc em todas as fases de desenvolvimento da cultura. O peso do cacho foi diretamente relacionado aos caracteres de qualidade de frutos segundo Silva et al. (2006) que encontrou 
maiores pesos de cachos relacionados a maiores comprimentos de frutos, em segundo ciclo de produção da cultivar 'Thap Maeo'.

De acordo com Soto Balestero (2000), o crescimento dos dedos por alongamento dos ovários (comprimento) inicia-se quatro dias antes da floração e mantém-se a uma taxa relativamente alta até 30 dias após o florescimento. O diâmetro aumenta até mais tarde, a depender das condições de cultivo, podendo chegar a 90 dias, sendo fortemente influenciado pelas condições climáticas vigentes no período de floração, como excesso ou deficiência de água no solo. Estas informações também são confirmadas por Castricini et al. (2012) e por este trabalho onde são observados maiores comprimentos em parcelas com maiores volumes de água aplicados.

Os caracteres de comprimento e diâmetro de frutos são importantes para o agrupamento em classes e garantem a homogeneidade de um lote proporcionando melhores condições de negociação para o produtor.

Com relação as correlações lineares observam-se correlação positiva média do PPH com PMB e CMB (Tabela 16). Por sua vez nota-se forte correlação positiva entre PPH e NCH. Nota-se forte correlação positiva entre DMB e NMPC. Houve também forte correlação positiva entre PMB e NMBC evidenciando bom indicador de produtividade. 
Tabela 16: Coeficientes de correlação de Pearson entre os parâmetros de produtividade e qualidade de fruto. Brasília, 2014.

\begin{tabular}{|c|c|c|c|c|c|c|c|c|c|c|}
\hline & PPH & NMPC & NMBC & PMB & $\mathrm{CMB}$ & DMB & FMP & $\mathrm{CD}$ & NMBP & $\mathrm{NCH}$ \\
\hline PPH & 1 & $0.42^{* *}$ & $0.51^{* *}$ & $0.63^{* *}$ & $0.60^{* *}$ & $0.46^{* *}$ & $0.23^{* *}$ & $-0.12^{\mathrm{ns}}$ & $0.38^{* *}$ & $0.84^{* *}$ \\
\hline NMPC & & 1 & $0.43^{* *}$ & $0.48^{* *}$ & $0.53^{* *}$ & $0.90^{* *}$ & $0.81^{* * *}$ & $0.42^{* *}$ & $-0.23^{* *}$ & $0.18^{\mathrm{NS}}$ \\
\hline NMBC & & & 1 & $0.98^{* *}$ & $0.25^{* *}$ & $0.34^{* *}$ & $0.37^{* *}$ & $0.22^{*}$ & $-0.06^{\mathrm{NS}}$ & $0.0^{\mathrm{NS}}$ \\
\hline PMB & & & & 1 & $0.37^{* *}$ & $0.36^{* *}$ & $0.40^{* *}$ & $0.23^{* *}$ & $-0.06^{\mathrm{NS}}$ & $0.0^{\mathrm{NS}}$ \\
\hline CMB & & & & & 1 & $0.30^{* *}$ & $0.34^{* *}$ & $0.20^{*}$ & $-0.1^{\mathrm{NS}}$ & $0.1^{\mathrm{NS}}$ \\
\hline DMB & & & & & & 1 & $0.82^{* *}$ & $0.48^{* *}$ & $-0.31^{* *}$ & $0.23^{* *}$ \\
\hline FMP & & & & & & & 1 & $0.52^{* *}$ & $-0.16^{\mathrm{NS}}$ & $0.19^{*}$ \\
\hline $\mathrm{CD}$ & & & & & & & & 1 & $-0.62^{* *}$ & $0.24^{* *}$ \\
\hline NMBP & & & & & & & & & 1 & $-0.34^{* *}$ \\
\hline $\mathrm{NCH}$ & & & & & & & & & & 1 \\
\hline
\end{tabular}

$\mathrm{NS}=$ não significativo, $*$ significativo a $5 \%, * *$ significativo a $1 \%$ pelo teste $\mathrm{t}, \mathrm{PPH}=$ peso de pencas por hectare, $\mathrm{NMPC}=$ número médio de pencas por cacho, $\mathrm{NMBC}=$ número médio de bananas por cacho, $\mathrm{PMB}=$ peso médio de bananas, $\mathrm{CMB}=$ comprimento médio de bananas, $\mathrm{DMB}=$ diâmetro médio de bananas, $\mathrm{FMP}=$ firmeza média da polpa, $\mathrm{CD}=$ relação comprimento sobre diâmetro, $\mathrm{NMBP}=$ número médio de bananas por penca, $\mathrm{NCH}=$ número de cachos por hectare. 


\section{CONCLUSÕES}

Os volumes de irrigação de 6.540 e 8.720 L.cova $^{-1}$ proporcionaram os maiores valores em produtividade e qualidade de frutos.

A maior produtividade foi observada com a dose de $6.540 \mathrm{~L} . c o v a^{-1}$ de água e $330 \mathrm{~kg}$ de $\mathrm{Mg}^{2+} \cdot \mathrm{ha}^{-1}$.

As doses de 220 e $110 \mathrm{~kg} \mathrm{de} \mathrm{Mg}^{2+} \cdot \mathrm{ha}^{-1}$ proporcionaram os maiores valores em número médio de bananas por cacho.

A relação comprimento/diâmetro apresentou maiores valores com a dose de 1.090 L.cova $^{-1}$ de água, na ausência de magnésio, indicando baixos valores do comprimento. 


\section{REFERÊNCIAS BIBLIOGRÁFICAS}

ALLEN, R.G.; PEREIRA, L.S.; RAES, D.; SMITH, M. Crop evapotranspiration: guidelines for computing crop water requirements. Rome: FAO, Irrigation and Drainage Paper 56, 301 p. 2006.

ALVES, E. J. A cultura da banana: aspectos técnicos, socioeconômicos e agroindustriais. Brasília, DF: Embrapa - SPI / Cruz das Almas: Embrapa - CNPMF. 2. ed revisada. 1999. $585 \mathrm{p}$.

ANUÁRIO BRASILEIRO DA FRUTICULTURA 2014. Santa Cruz do Sul Editora Gazeta 2013. $136 \mathrm{p}$.

Borges RS, Silva SO, Oliveira FT \& Roberto SR. Avaliação de genótipos de bananeira no norte do estado do Paraná. Revista Brasileira de Fruticultura. 2011. p. 291-296.

BORGES, A. L. ; SILVA, D. J. . Fertilizantes para fertirrigação. In: Ana Lúcia Borges; Eugênio Ferreira Coelho; Aldo Vilar Trindade. (Org.). Fertirrigação em fruteiras tropicais. Cruz das Almas, BA: Embrapa Mandioca e Fruticultura, 2002. p. 15-27.

CAMPOS, P. M; LACERDA, M. P. C; SILVA, C. L. da; SÁ, M. A. C. de; SOUSA, D. M. G. de. Drenagem interna como fator de diferenciação de Latossolos no Distrito Federal. Pesquisa Agropecuária Brasileira, Brasília, v.45, n.3. 2010. p. 306-314.

CAMPOS, P.M.; LACERDA, M.P.C.; SILVA, C.L. da; SÁ, M.A.C.de; SOUZA, D.M.G. de. Drenagem interna com fator de diferenciação de Latossolos no Distrito Federal. Pesquisa Agropecuária Brasileira, Brasília, v.45,n.3. 2010. p. 306-314.

CARVALHO, F. I. F. et al. Estimativas e implicações da correlação no melhoramento vegetal. Pelotas: Ed. Universitária da UFPel. 2004. 142p.

CASTRICINI, A.; COElho, E. F.; RODRIGUES, M. G. V.; COUTINHO, R. C. Caracterização pós-colheita de frutos de bananeira 'brs platina' de primeiro ciclo, sob regulação do déficit de irrigação. Revista Brasileira de Fruticultura, Jaboticabal - SP, v. 34, n. 4, 2012. p. 1013-1021.

COELHO, E.F.; COSTA, É.L.da; LEDO, C.A.da S.; SILVA, S de O.e. Produtividade e eficiência do usa da água das banananeira 'Prata Anã' e 'Grand Naine' sob irrigação no terceiro ciclo no norte de Minas Gerais. Irriga, v.11, n.4, 2006. p 460-468.

COELHO, E.F.; LEDO, C.A. da S.; SILVA, S. de O. Produtividade da bananeira 'Prata-anã' e 'Grande Naine' no terceiro ciclo sob irrigação por microaspersão em tabuleiros costeiros da Bahia. Revista Brasileira de Fruticultura, v.28, 2006. p.435-438.

COELHO, E.F.; OLIVEIRA, R.C.; PAMPONET, A.J.M.; Necessidades hídricas de bananeira tipo 'Terra' em condições de tabuleiros costeiros. Pesquisa Agropecuária Brasileira. V.48, n.9, 2013. p. 1260-1268.

COSTA, É.L. da; COELHO, E.F.; SIMÃO, F.R.; COELHO FILHO, M.A.; OLIVEIRA, P.M. de. Irrigação da bananeira. Informe Agropecuário, v.29, 2008. p.38-46.

COSTA, E.L.; COELHO. E.F.; SIMÃO, F.R.; FILHO, M.A.C.;DAMATTO JÚNIOR, E. R. D.; BÔAS, R.L.V.; LEONEL, S.; FERNANDES, D.M. Avaliação nutricional em folhas de 
bananeira Prata Anã adubadas com compostos orgânicos. Revista Brasileira de Fruticultura. v. 28, n. 1. 2006. p. 109-112.

CRISÓSTOMO, L. A. Influência da adubação NPK sobre a produção e qualidade dos frutos de bananeira cv. "Pacovan" 1. Revista Ciência Agronômica, v. 39, n. 01, 2008. p. 45-52.

Donato, S.R.L.; Arantes, A.M.; Silva, S.O.; Cordeiro, Z.J.M. Comportamento fitotécnico da bananeira 'Prata Anã' e de seus híbridos. PesquisaAgropecuária Brasileira. 2009. 44:16081615. 2009.

FERERES, E. Papel de la fisiología vegetal en la microirrigación. Recomendaciones para el manejo mejorado. Ponencia en IV Seminario Latinoamericano de Microirrigación. Barquisimeto, Venezuela, 1981.

FERREIRA, D. F. SISVAR - Sistema de análise de variância para dados balanceados. Lavras: UFLA, 1998. $19 \mathrm{p}$.

FIGUEIREDO, F.P. de; MANTOVANI, E.; SOARES, A.A.; COSTA, L.C.; RAMOS, M.M.; OLIVEIRA, F.G. Produtividade e qualidade da banana 'Prata-Anã', influenciada por lâminas de água, cultivada no Norte de Minas Gerais. Revista Brasileira Engenharia Agrícola e Ambiental. v.10. 2006. p. 798-803.

KELLER, J.; KARMELI, D. Trickle irrigation design. Glendora, California: Rain Bird Sprinkler. 1975. 133p.

LEMOS, R.C.; SANTOS, R.D. Manual de descrição e coleta de solo no campo. 2.ed.Campinas: Sociedade Brasileira de Ciência do Solo; Embrapa-SNLCS, 1984, 46p.

MANICA, I. Fruticultura Tropical 4, Banana. Editora Cinco Continentes. Porto Alegre. 1997. 485p.

MOREIRA, R. S. Banana: teoria e prática de cultivo. Campinas: Fundação Cargill.1987. 335 p.

OLIVEIRA, P.M. Irrigação da bananeira. Informe Agropecuário, v.29. 2008. p.38-46.

PAULL, R.E.; DUARTE, O. Tropical fruits. 2nd ed. Oxford: CAB International. v.1, 400p. (Crop production science in horticulturae series, 20). 2011.

PEREIRA J.R.C.; GASPAROTTO, L. Cultivar de bananeira-BRS Conquista. 2007

SILVA, M. J. R.; ANJOS, J.M.C.; JESUS, P.R.R.; Santos, G.S.; Lima, F.B.F.; Ribeiro, V.G.; Produção e caracterização da bananeira 'Prata Anã' (AAB) em dois ciclos de produção (Juazeiro, Bahia). Revista Ceres. 2013. 60:122-126.

SILVA, J.T.A.; SILVA, I.P.; MOURA NETO, A.; COSTA, E.L. Aplicação de potássio, magnésio e calcário em mudas de bananeira 'Prata Anã'(AAB). Revista Brasileira de Fruticultura. Jaboticabal. 2008. 30: 782-786.

SILVA, S.O.; FLORES, J.C.O. \& NETO, F.P.L. Avaliação de cultivares e híbridos de bananeira em quatro ciclos de produção. Pesquisa Agropecuária Brasileira. 2002. 37:15671574.

SILVA, S.O.; PIRES, E.T.; PESTANA, R.K.N.; ALVES, J.S. \& SILVEIRA, D.C.; Avaliação de clones de banana Cavendish. Ciência e Agrotecnologia. 2006. 30:832-837. 
SOTO BALESTERO, M. Bananos : cultivo y comercialización. 2nd ed. San José: Imprenta Lil, 2000.

SOTO BALLESTERO, M. Bananos: técnicas de producción poscocecha y comercializacion. In: Escuela de Agricultura de La region Tropical Húmeda. Guácimo, Costa Rica. 2008. 1 CD ROM. EARTH.

TAIZ, L.; ZEIGER, E. Fisiologia vegetal. 4.ed. Porto Alegre: Artmed, 2009. 848p.

VIDAL-TORRADO, P.; LEPSCH, I.F.; CASTRO, S.S. Conceitos e aplicações das relações pedologia-geomorfologia em regiões tropicais úmidas. In: VIDAL-TORRADO et al.(Org.). Tópicos em Ciência do Solo. Viçosa: Sociedade Brasileira de Ciência do Solo, 2005. v. 4, p. 145-192.

ZONTA, E.P.; MACHADO, A.A. Sistemas de análises estatísticas (SANEST) para microcomputadores. In: Simpósio de estatística aplicada à experimentação. Piracicaba. Resumos. Campinas: Fundação Cargill, 1995. p. 17-18. 


\section{ANEXOS}

Anexo 1. Resumo das análises de variância da cultivar PRATA ANÃ e BRS Conquista:

Prata Anã

\section{$\mathrm{PCH}$}

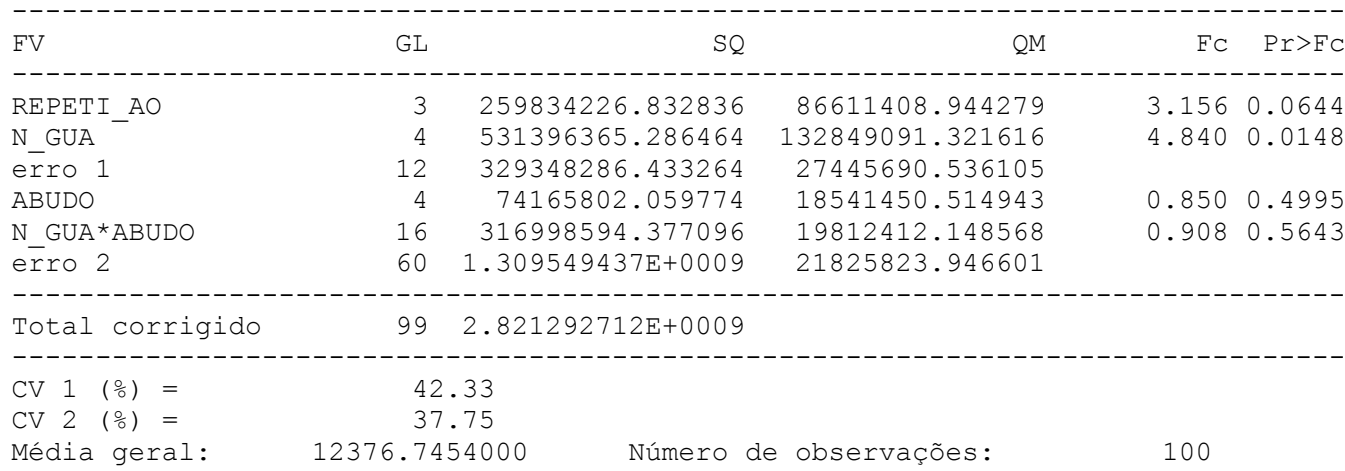

NMPC

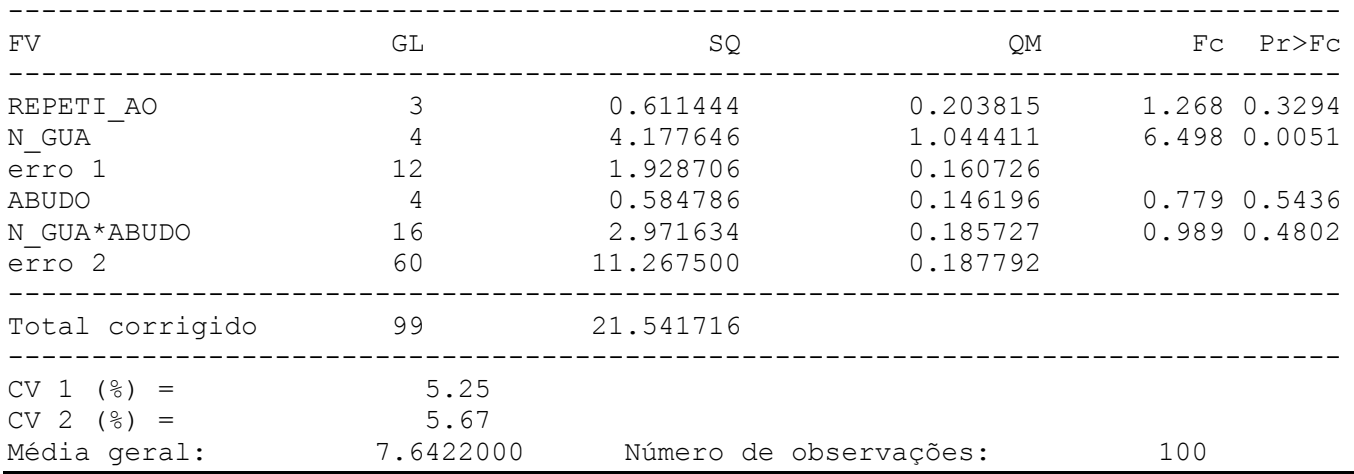

Análise do desdobramento de N_GUA dentro de cada nível de:

ABUDO

TABELA DE ANÁLISE DE VARIÂNCIA

\begin{tabular}{|c|c|c|c|c|c|c|}
\hline FV & & GL & $\mathrm{SQ}$ & $\mathrm{QM}$ & $\mathrm{EC}$ & Pr $>$ FC \\
\hline N_GUA & $/ 1$ & 4 & 2.398330 & 0.599582 & 3.288 & 0.0155 \\
\hline $\mathrm{N}^{-} \mathrm{GUA}$ & 12 & 4 & 0.631070 & 0.157767 & 0.865 & 0.4885 \\
\hline $\mathrm{N}_{-}^{-} \mathrm{GUA}$ & 13 & 4 & 2.939630 & 0.734907 & 4.030 & 0.0052 \\
\hline $\mathrm{N}_{-}^{-} \mathrm{GUA}$ & $/ 4$ & 4 & 0.486970 & 0.121742 & 0.668 & 0.6160 \\
\hline $\mathrm{N}^{-} \mathrm{GUA}$ & 15 & 4 & 0.693280 & 0.173320 & 0.950 & 0.4394 \\
\hline Exro & & 72 & 13.131247 & 0.182378 & & \\
\hline
\end{tabular}

Codificação usada para o desdobramento

cod. ABUDO

$1=0$

$2=50$

$3=100$

$4=150$

$5=200$ 


\section{NMBC}

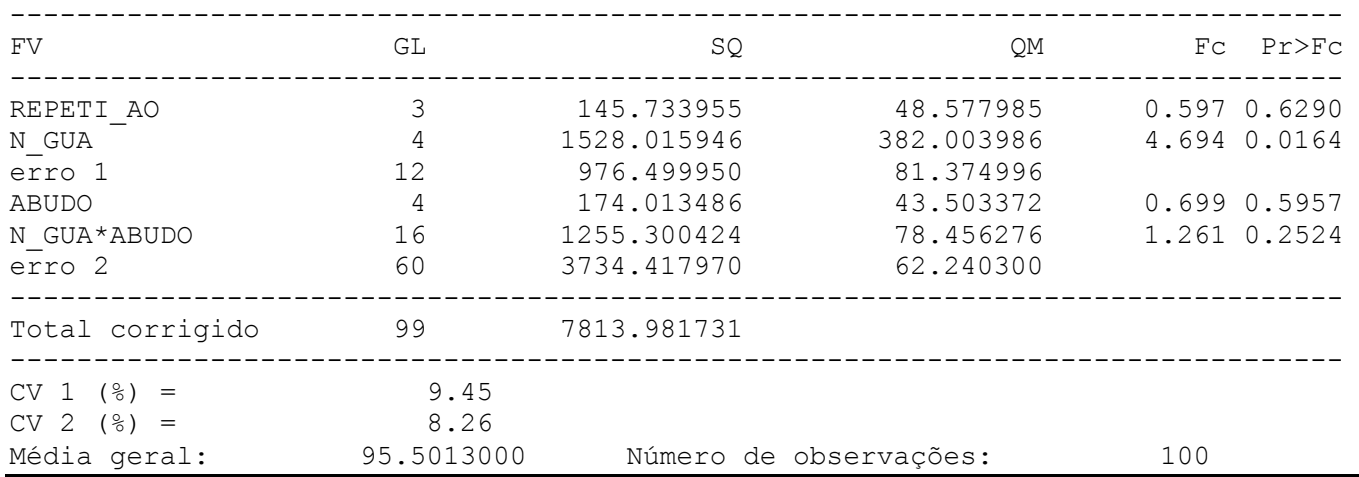

\section{PMB}

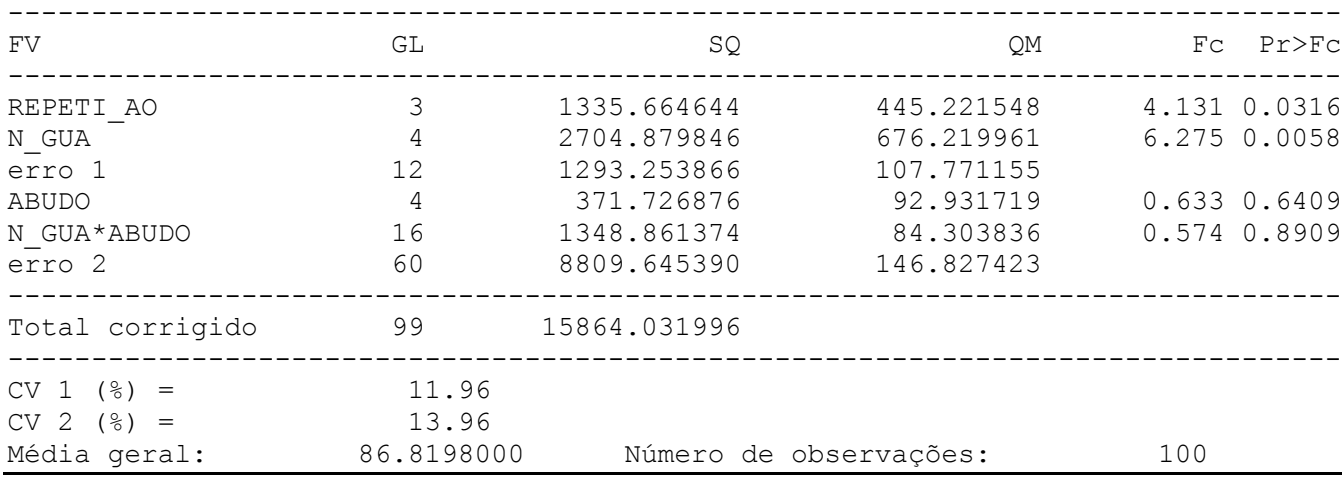

Análise do desdobramento de N GUA dentro de cada nível de:

ABUDO

TABELA DE ANÁLISE DE VARIÂNCIA

\begin{tabular}{|c|c|c|c|c|c|c|}
\hline FV & & GL & $\mathrm{SQ}$ & $\mathrm{QM}$ & $\mathrm{EC}$ & $\mathrm{Pr}>\mathrm{FC}$ \\
\hline N_GUA & $/ 1$ & 4 & 1225.056470 & 306.264118 & 2.203 & 0.0767 \\
\hline $\mathrm{N}_{-}^{-} \mathrm{GUA}$ & 12 & 4 & 977.185720 & 244.296430 & 1.757 & 0.1463 \\
\hline $\mathrm{N}_{-}^{-} \mathrm{GUA}$ & 13 & 4 & 921.169530 & 230.292382 & 1.657 & 0.1689 \\
\hline $\mathrm{N}_{-}^{-} \mathrm{GUA}$ & $/ 4$ & 4 & 169.530870 & 42.382718 & 0.305 & 0.8736 \\
\hline $\mathrm{N}_{-}^{-} \mathrm{GUA}$ & $/ 5$ & 4 & 760.798630 & 190.199658 & 1.368 & 0.2528 \\
\hline Exro & & 72 & 10009.164214 & 139.016170 & & \\
\hline
\end{tabular}

Codificação usada para o desdobramento

cod. ABUDO

$1=0$

$2=50$

$3=100$

$4=150$

$5=200$ 


\section{$\mathrm{CMB}$}

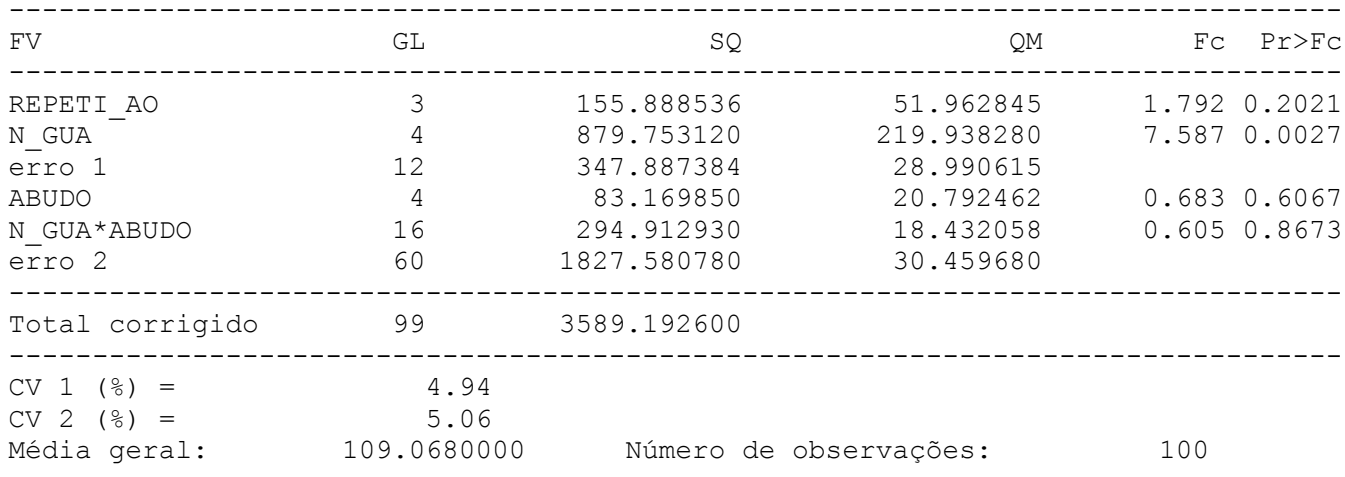

Análise do desdobramento de N GUA dentro de cada nível de:

ABUDO

TABELA DE ANÁLISE DE VARIÂNCIA

\begin{tabular}{|c|c|c|c|c|c|c|}
\hline FV & & GL & $S Q$ & $\mathrm{QM}$ & $\mathrm{FC}$ & Pr $>$ FC \\
\hline $\mathrm{N}$ GUA & $/ 1$ & 4 & 457.658530 & 114.414632 & 3.793 & 0.0074 \\
\hline $\mathrm{N}_{-}^{-} \mathrm{GUA}$ & 12 & 4 & 296.676280 & 74.169070 & 2.459 & 0.0527 \\
\hline $\mathrm{N}_{-}^{-} \mathrm{GUA}$ & 13 & 4 & 173.770450 & 43.442613 & 1.440 & 0.2289 \\
\hline $\mathrm{N}_{-}^{-} \mathrm{GUA}$ & 14 & 4 & 139.116020 & 34.779005 & 1.153 & 0.3381 \\
\hline $\mathrm{N}_{-}^{-} \mathrm{GUA}$ & $/ 5$ & 4 & 107.444770 & 26.861193 & 0.890 & 0.4735 \\
\hline Exro & & 72 & 2171.942410 & 30.165867 & & \\
\hline
\end{tabular}

Codificação usada para o desdobramento

cod. ABUDO

$1=0$

$2=50$

$3=100$

$4=150$

$5=200$

\section{DMB}

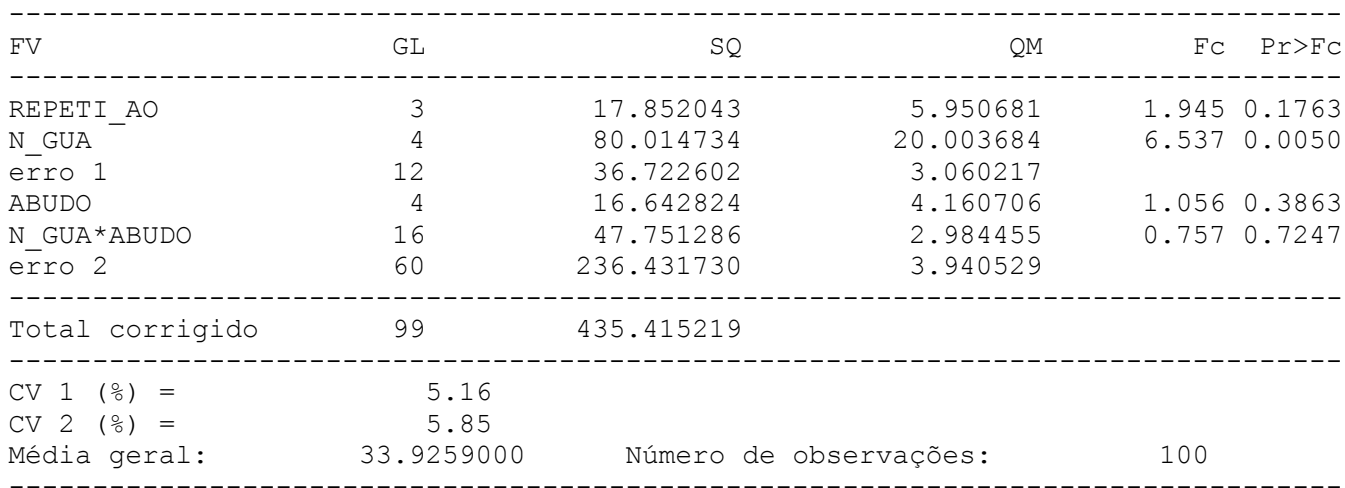


Análise do desdobramento de N GUA dentro de cada nível de:

ABUDO

TABELA DE ANÁLISE DE VARIÂNCIA

\begin{tabular}{|c|c|c|c|c|c|c|}
\hline FV & & GL & $\mathrm{SQ}$ & $\mathrm{QM}$ & FC & $\operatorname{Pr}>\mathrm{FC}$ \\
\hline N_GUA & $/ 1$ & 4 & 29.724470 & 7.431118 & 1.974 & 0.1071 \\
\hline $\mathrm{N}_{-}^{-} \mathrm{GUA}$ & 12 & 4 & 44.686420 & 11.171605 & 2.968 & 0.0249 \\
\hline $\mathrm{N}_{-}^{-} \mathrm{GUA}$ & 13 & 4 & 31.471480 & 7.867870 & 2.090 & 0.0905 \\
\hline $\mathrm{N}_{-}^{-} \mathrm{GUA}$ & $/ 4$ & 4 & 7.524930 & 1.881232 & 0.500 & 0.7356 \\
\hline $\mathrm{N}_{-}^{-} \mathrm{GUA}$ & $/ 5$ & 4 & 14.358720 & 3.589680 & 0.954 & 0.4376 \\
\hline Ērro & & 72 & 271.041583 & 3.764466 & & \\
\hline
\end{tabular}

Codificação usada para o desdobramento

cod. ABUDO

$1=0$

$2=50$

$3=100$

$4=150$

$5=200$

\section{$\mathrm{CD}$}

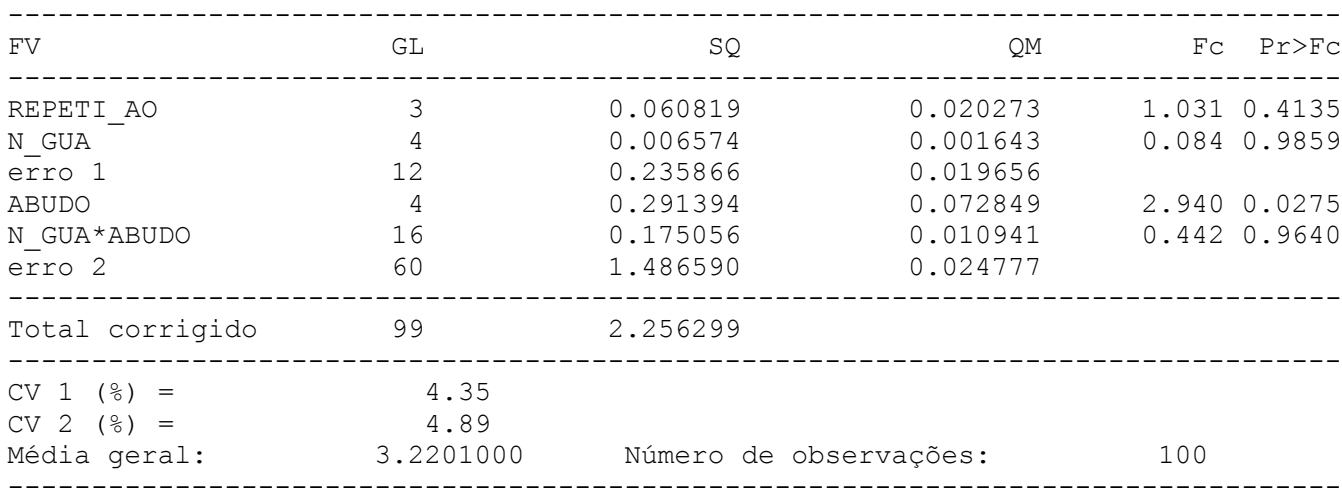

\section{NMBP}

\begin{tabular}{|c|c|c|c|c|}
\hline \multirow[t]{2}{*}{ FV } & \multirow[t]{2}{*}{ GL } & \multirow[t]{2}{*}{$\mathrm{SQ}$} & \multirow[t]{2}{*}{$Q \mathrm{M}$} & \multirow{2}{*}{ 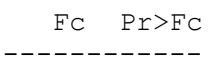 } \\
\hline & & & & \\
\hline REPETI_AO & 3 & 0.150548 & 0.050183 & 0.1180 .9476 \\
\hline N_GUA & 4 & 3.704330 & 0.926083 & 2.1850 .1323 \\
\hline exro 1 & 12 & 5.084982 & 0.423749 & \\
\hline ABUDO & 4 & 0.654670 & 0.163667 & 0.8510 .4984 \\
\hline $\mathrm{N}$ GUA *ABUDO & 16 & 4.462900 & 0.278931 & 1.4510 .1497 \\
\hline érro 2 & 60 & 11.533270 & 0.192221 & \\
\hline $\begin{array}{l}----------- \\
\text { Total corrigido }\end{array}$ & 99 & 25.590700 & -1 & -1 \\
\hline----------------- & ---- & ------ & --- & ----- \\
\hline $\mathrm{CV} 1\left(\frac{\circ}{0}\right)=$ & 5.23 & & & \\
\hline $\mathrm{CV} 2\left(\frac{\circ}{0}\right)=$ & 3.52 & & & \\
\hline Média geral: & 12.4430000 & Número de & ações: & 100 \\
\hline
\end{tabular}


$\mathrm{NCH}$

\begin{tabular}{|c|c|c|c|c|c|}
\hline FV & GL & $\mathrm{SQ}$ & $\mathrm{QM}$ & $\mathrm{FC}$ & $\mathrm{Pr}>\mathrm{FC}$ \\
\hline REPETI_AO & 3 & 2902014.200000 & 967338.066667 & 3.316 & 0.0570 \\
\hline N_GUA & 4 & 4987909.360000 & 1246977.340000 & 4.274 & 0.022 \\
\hline exro 1 & 12 & 3500965.200000 & 291747.100000 & & \\
\hline ABUDO & 4 & 845486.960000 & 211371.740000 & 1.113 & 0.3587 \\
\hline N_GUA *ABUDO & 16 & 3930664.240000 & 245666.515000 & 1.294 & 0.231 \\
\hline érro 2 & 60 & 11391661.600000 & 189861.026667 & & \\
\hline otal corrigido & 99 & 27558701.560000 & --------- & & \\
\hline $\begin{array}{l}\mathrm{CV} 1\left(\frac{\circ}{\circ}\right)= \\
\mathrm{CV} 2\left(\frac{\circ}{0}\right)= \\
\text { Média geral: }\end{array}$ & $\begin{array}{r}3 \\
3 \\
1448.3\end{array}$ & Número & observações: & 100 & \\
\hline
\end{tabular}

Análise do desdobramento de N_GUA dentro de cada nível de:

ABUDO

TABELA DE ANÁLISE DE VARIÂNCIA

\begin{tabular}{|c|c|c|c|c|c|c|}
\hline EV & & GL & $\mathrm{SQ}$ & $\mathrm{QM}$ & $\mathrm{FC}$ & $\operatorname{Pr}>\mathrm{FC}$ \\
\hline N_GUA & $/ 1$ & 4 & 1290642.800000 & 322660.700000 & 1.535 & 0.2016 \\
\hline $\mathrm{N}_{-}^{-} \mathrm{GUA}$ & 12 & 4 & 1530223.200000 & 382555.800000 & 1.820 & 0.1349 \\
\hline $\mathrm{N}_{-}^{-} \mathrm{GUA}$ & 13 & 4 & 2256692.800000 & 564173.200000 & 2.683 & 0.0386 \\
\hline $\mathrm{N}_{-}^{-} \mathrm{GUA}$ & $/ 4$ & 4 & 2357162.000000 & 589290.500000 & 2.803 & 0.0324 \\
\hline $\mathrm{N}^{-} \mathrm{GUA}$ & $/ 5$ & 4 & 1483852.800000 & 370963.200000 & 1.764 & 0.1459 \\
\hline Ērro & & 66 & 13875723.928000 & 210238.241333 & & \\
\hline
\end{tabular}

Codificação usada para o desdobramento

cod. ABUDO

$1=0$
$2=50$
$3=100$
$4=150$
$5=200$

\section{'BRS Conquista'}

\section{$\mathrm{PCH}$}

\begin{tabular}{|c|c|c|c|c|c|}
\hline FV & GL & $\mathrm{SQ}$ & $\mathrm{QM}$ & $\mathrm{FC}$ & $\operatorname{Pr}>\mathrm{EC}$ \\
\hline REPETI AO & 3 & 10854220.935600 & 3618073.645200 & 0.252 & 0.8587 \\
\hline $\mathrm{N}$ GUA & 4 & 186501625.145600 & 46625406.286400 & 3.243 & 0.0507 \\
\hline érro 1 & 12 & 172501103.014400 & 14375091.917867 & & \\
\hline ADUBO & 4 & 64565171.181600 & 16141292.795400 & 2.451 & 0.0557 \\
\hline $\mathrm{N}$ GUA *ADUBO & 16 & 75156881.554400 & 4697305.097150 & 0.713 & 0.7697 \\
\hline exrro 2 & 60 & 395191734.000000 & 6586528.900000 & & \\
\hline Total corrigido & 99 & 904770735.831600 & & & \\
\hline $\begin{array}{l}\mathrm{CV} 1\left(\frac{\circ}{0}\right) \\
\mathrm{CV} 2(\%)= \\
\text { Média geral: }\end{array}$ & $\begin{array}{r}98 \\
66 \\
3836.67\end{array}$ & $\begin{array}{l}32 \\
39 \\
0000\end{array}$ & observações: & 100 & \\
\hline
\end{tabular}

Análise do desdobramento de N_GUA dentro de cada nível de:

ADUBO 
TABELA DE ANÁLISE DE VARIÂNCIA

\begin{tabular}{|c|c|c|c|c|c|c|}
\hline FV & & GL & $\mathrm{SQ}$ & $\mathrm{QM}$ & FC & $\operatorname{Pr}>\mathrm{FC}$ \\
\hline $\mathrm{N}$ GUA & $/ 1$ & 4 & 28699258.832000 & 7174814.708000 & 0.881 & 0.4803 \\
\hline $\mathrm{N}_{-}^{-} \mathrm{GUA}$ & 12 & 4 & 57974051.612000 & 14493512.903000 & 1.780 & 0.1446 \\
\hline $\mathrm{N}^{-} \mathrm{GUA}$ & 13 & 4 & 27699513.008000 & 6924878.252000 & 0.850 & 0.4985 \\
\hline $\mathrm{N}^{-} \mathrm{GUA}$ & $/ 4$ & 4 & 79522144.640000 & 19880536.160000 & 2.441 & 0.0565 \\
\hline $\mathrm{N}_{-}^{-} \mathrm{GUA}$ & $/ 5$ & 4 & 67763538.608000 & 16940884.652000 & 2.080 & 0.0946 \\
\hline Exro & & 58 & 472366007.207253 & 8144241.503573 & & \\
\hline
\end{tabular}

Codificação usada para o desdobramento

cod. ADUBO

$1=0$

$2=110$

$3=220$

$4=330$

$5=440$

\section{NMBC}

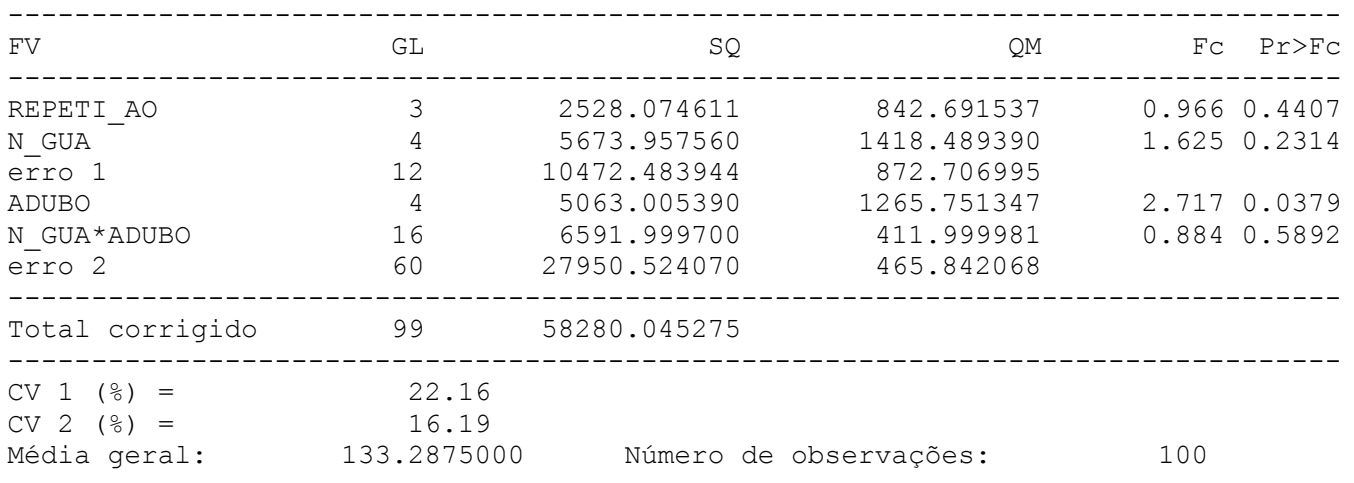

\section{PMB}

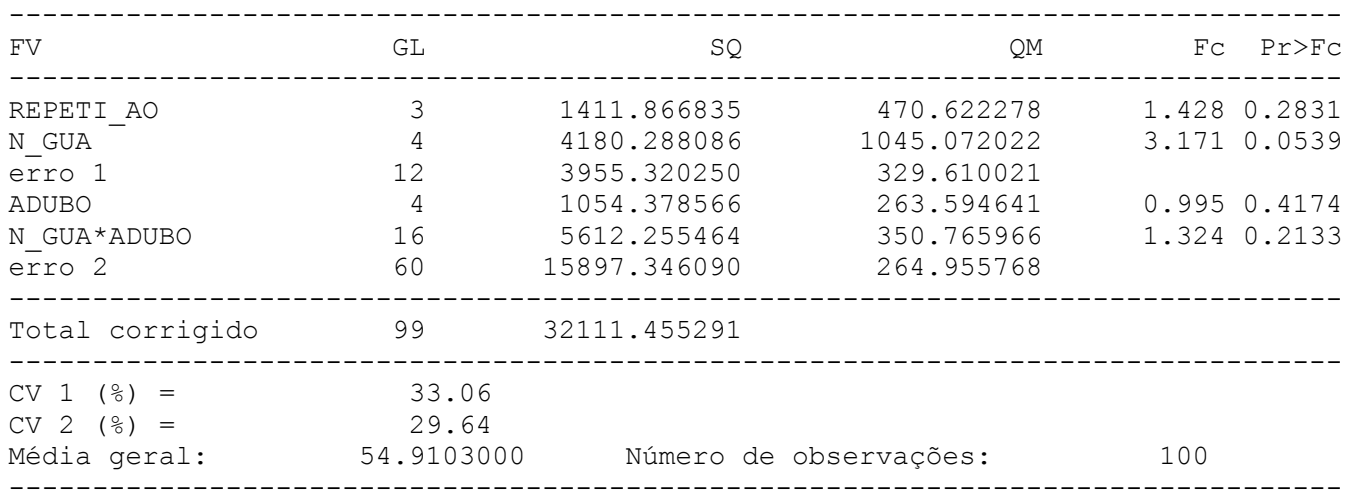

Análise do desdobramento de N_GUA dentro de cada nível de:

ADUBO

TABELA DE ANÁLISE DE VARIÂNCIA

\begin{tabular}{|c|c|c|c|c|c|c|}
\hline EV & & GL & $\mathrm{SQ}$ & $\mathrm{QM}$ & $\mathrm{EC}$ & $\operatorname{Pr}>\mathrm{FC}$ \\
\hline N GUA & $/ 1$ & 4 & 1982.664530 & 495.666132 & 1.784 & 0.1412 \\
\hline $\mathrm{N}^{-} \mathrm{GUA}$ & 12 & 4 & 2791.267150 & 697.816787 & 2.511 & 0.0491 \\
\hline
\end{tabular}




\begin{tabular}{lrrrrr} 
N_GUA & $/ 3$ & 4 & 1576.295830 & 394.073958 & 1.4180 .2363 \\
N_GUA & $/ 4$ & 4 & 1093.001570 & 273.250392 & 0.9830 .4216 \\
N_GUA & $/ 5$ & 4 & 2349.314470 & 587.328617 & 2.1140 .0878 \\
Erro & & 70 & 19452.063309 & 277.886619 & \\
\hline
\end{tabular}

Codificação usada para o desdobramento cod. ADUBO

$1=0$

$2=110$

$3=220$

$4=330$

$5=440$

Análise do desdobramento de ADUBO dentro de cada nível de:

N GUA

TABELA DE ANÁLISE DE VARIÂNCIA

\begin{tabular}{|c|c|c|c|c|c|c|}
\hline FV & & GL & $S Q$ & $Q M$ & $\mathrm{FC}$ & $\operatorname{Pr}>\mathrm{FC}$ \\
\hline ADUBO & $/ 1$ & 4 & 3792.201470 & 948.050367 & 3.412 & 0.0130 \\
\hline ADUBO & 12 & 4 & 790.934070 & 197.733517 & 0.712 & 0.5862 \\
\hline ADUBO & 13 & 4 & 1178.715530 & 294.678882 & 1.060 & 0.3819 \\
\hline ADUBO & $/ 4$ & 4 & 418.076830 & 104.519208 & 0.376 & 0.8247 \\
\hline ADUBO & $/ 5$ & 4 & 486.706130 & 121.676532 & 0.438 & 0.7805 \\
\hline Erro & & 70 & 19452.063309 & 277.886619 & & \\
\hline
\end{tabular}

Codificação usada para o desdobramento

cod. $\mathrm{N}$ GUA

$1=1090$
$2=2177$
$3=4300$
$4=6540$

$5=8720$

\section{$\mathrm{CMB}$}

\begin{tabular}{|c|c|c|c|c|c|}
\hline FV & GL & $\mathrm{SQ}$ & $\mathrm{QM}$ & FC & $\operatorname{Pr}>\mathrm{FC}$ \\
\hline REPETI_AO & 3 & 473.153907 & 157.717969 & 1.407 & 0.2888 \\
\hline $\mathrm{N}_{\text {GUA }}{ }^{-}$ & 4 & 1295.986466 & 323.996617 & 2.889 & 0.0689 \\
\hline érro 1 & 12 & 1345.585638 & 112.132136 & & \\
\hline ADUBO & 4 & 162.353846 & 40.588462 & 0.529 & 0.7149 \\
\hline N_GUA *ADUBO & 16 & 1478.948784 & 92.434299 & 1.205 & 0.2914 \\
\hline érro 2 & 60 & 4604.247930 & 76.737466 & & \\
\hline Total corrigido & 99 & 9360.276571 & --- & & \\
\hline $\begin{array}{l}\mathrm{CV} 1(\%)= \\
\mathrm{CV} 2(\%)= \\
\text { Média geral: }\end{array}$ & $\begin{array}{c}11.69 \\
9.67 \\
90.5873000\end{array}$ & Número d & rvações: & 100 & \\
\hline
\end{tabular}

Análise do desdobramento de ADUBo dentro de cada nível de:

N_GUA

TABELA DE ANÁLISE DE VARIÂNCIA

\begin{tabular}{|c|c|c|c|c|c|c|}
\hline FV & & GL & $S Q$ & $\mathrm{QM}$ & $\mathrm{FC}$ & $\operatorname{Pr}>\mathrm{FC}$ \\
\hline ADUBO & /1 & 4 & 1050.091570 & 262.522893 & 3.132 & 0.0200 \\
\hline ADUBO & 12 & 4 & 53.564630 & 13.391158 & 0.160 & 0.9578 \\
\hline ADUBO & 13 & 4 & 201.797430 & 50.449358 & 0.602 & 0.6621 \\
\hline ADUBO & $/ 4$ & 4 & 291.651650 & 72.912913 & 0.870 & 0.4860 \\
\hline
\end{tabular}




$\begin{array}{lrrrrr}\text { ADUBO } & / 5 & 4 & 44.197350 & 11.049338 & 0.132 \\ \text { Erro } & & 67 & 5615.698780 & 83.816400 & \end{array}$

\section{DMB}

\begin{tabular}{|c|c|c|c|c|c|}
\hline FV & GL & $\mathrm{SQ}$ & $\mathrm{QM}$ & $\mathrm{FC}$ & $\operatorname{Pr}>\mathrm{FC}$ \\
\hline REPETI AO & 3 & 85.639859 & 28.546620 & 1.483 & 0.2689 \\
\hline $\mathrm{N}$ GUA & 4 & 170.633834 & 42.658458 & 2.215 & 0.1285 \\
\hline érro 1 & 12 & 231.064446 & 19.255370 & & \\
\hline ADUBO & 4 & 29.886134 & 7.471534 & 0.384 & 0.8191 \\
\hline $\mathrm{N} \_\mathrm{GUA} * \mathrm{ADUBO}$ & 16 & 397.475016 & 24.842188 & 1.278 & 0.2413 \\
\hline érro 2 & 60 & 1166.690570 & 19.444843 & & \\
\hline---------------1 & -------- & ------------- & ----------- & & \\
\hline Total corrigido & 99 & 2081.389859 & & & \\
\hline $\mathrm{CV} 1(\%)=$ & 14.62 & & & & \\
\hline $\mathrm{CV} 2(\%)=$ & 14.69 & & & & \\
\hline Média geral: & 30.0121000 & Número d & vações: & 100 & \\
\hline
\end{tabular}

Análise do desdobramento de ADUBO dentro de cada nível de:

N_GUA

TABELA DE ANÁLISE DE VARIÂNCIA

\begin{tabular}{|c|c|c|c|c|c|c|}
\hline FV & & GL & SQ & $Q \mathrm{M}$ & FC & $\operatorname{Pr}>\mathrm{FC}$ \\
\hline ADUBO & $/ 1$ & 4 & 255.276070 & 63.819017 & 3.288 & 0.0156 \\
\hline ADUBO & 12 & 4 & 16.363870 & 4.090967 & 0.211 & 0.9315 \\
\hline ADUBO & 13 & 4 & 76.042270 & 19.010568 & 0.980 & 0.4236 \\
\hline ADUBO & $/ 4$ & 4 & 33.261070 & 8.315268 & 0.428 & 0.7873 \\
\hline ADUBO & 15 & 4 & 46.417870 & 11.604468 & 0.598 & 0.6648 \\
\hline Erro & & 71 & 1377.893334 & 19.406948 & & \\
\hline
\end{tabular}

Codificação usada para o desdobramento

cod. N_GUA

$1=1090$

$2=2177$

$3=4300$

$4=6540$

$5=8720$

\section{FMP}

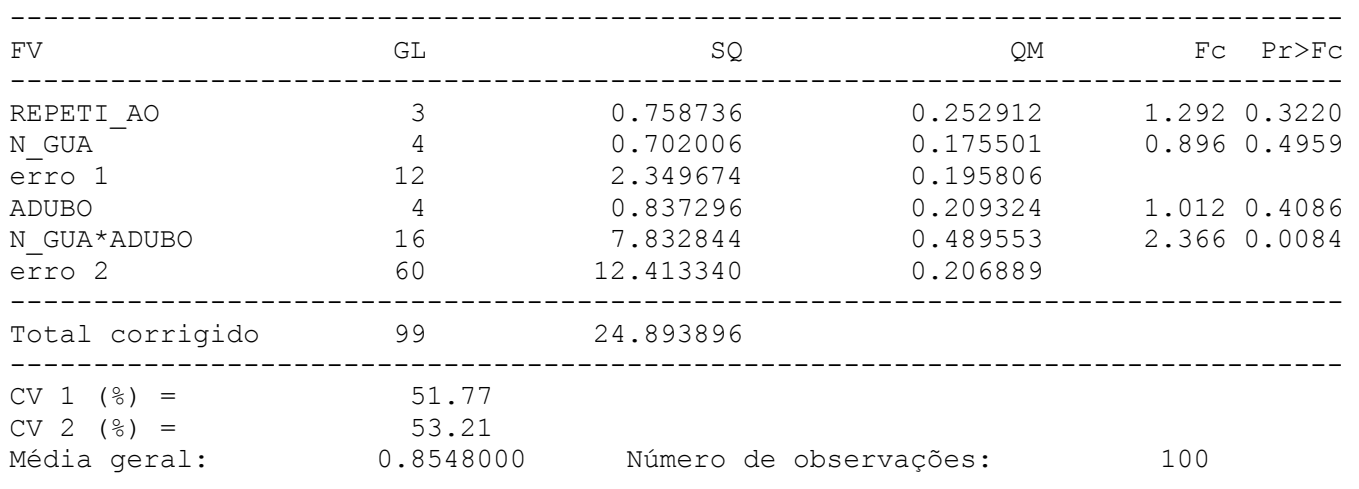

Análise do desdobramento de N_GUA dentro de cada nível de: 
TABELA DE ANÁLISE DE VARIÂNCIA

\begin{tabular}{|c|c|c|c|c|c|c|}
\hline FV & & GL & $\mathrm{SQ}$ & $\mathrm{QM}$ & FC & Pr $>$ FC \\
\hline N_GUA & $/ 1$ & 4 & 3.637600 & 0.909400 & 4.443 & 0.0029 \\
\hline $\mathrm{N}_{-}^{-} \mathrm{GUA}$ & 12 & 4 & 0.815000 & 0.203750 & 0.995 & 0.4150 \\
\hline $\mathrm{N}_{-}^{-} \mathrm{GUA}$ & 13 & 4 & 0.876350 & 0.219087 & 1.070 & 0.3768 \\
\hline $\mathrm{N}_{-}^{-} \mathrm{GUA}$ & $/ 4$ & 4 & 0.181970 & 0.045492 & 0.222 & 0.9250 \\
\hline N_GUA & $/ 5$ & 4 & 3.023930 & 0.755982 & 3.694 & 0.0085 \\
\hline Ērro & & 72 & 14.736415 & 0.204672 & & \\
\hline
\end{tabular}

Codificação usada para o desdobramento cod. ADUBO

$1=0$
$2=110$
$3=220$
$4=330$
$5=440$

Análise do desdobramento de ADUBO dentro de cada nível de:

$\mathrm{N}$ GUA

TABELA DE ANÁLISE DE VARIÂNCIA

\begin{tabular}{|c|c|c|c|c|c|c|}
\hline $\mathrm{FV}$ & & GL & $S Q$ & $Q \mathrm{M}$ & $\mathrm{FC}$ & $\mathrm{Pr}>\mathrm{FC}$ \\
\hline ADUBO & $/ 1$ & 4 & 3.685430 & 0.921357 & 4.502 & 0.0026 \\
\hline ADUBO & 12 & 4 & 0.955120 & 0.238780 & 1.167 & 0.3320 \\
\hline ADUBO & 13 & 4 & 2.115550 & 0.528887 & 2.584 & 0.0438 \\
\hline ADUBO & $/ 4$ & 4 & 0.915570 & 0.228893 & 1.118 & 0.3539 \\
\hline ADUBO & $/ 5$ & 4 & 0.998470 & 0.249617 & 1.220 & 0.3093 \\
\hline Erro & & 72 & 14.736415 & 0.204672 & & \\
\hline
\end{tabular}

Codificação usada para o desdobramento

cod. N GUA

$1=1 \overline{0} 90$

$2=2177$

$3=4300$

$4=6540$

$5=8720$

CD

Análise do desdobramento de N_GUA dentro de cada nível de:

ADUBO

TABELA DE ANÁLISE DE VARIÂNCIA

\begin{tabular}{|c|c|c|c|c|c|c|}
\hline EV & & GL & $\mathrm{SQ}$ & $\mathrm{QM}$ & $\mathrm{EC}$ & $\operatorname{Pr}>\mathrm{FC}$ \\
\hline N_GUA & $/ 1$ & 4 & 2.576970 & 0.644243 & 4.023 & 0.0055 \\
\hline $\mathrm{N}_{-}^{-} \mathrm{GUA}$ & 12 & 4 & 0.119000 & 0.029750 & 0.186 & 0.9449 \\
\hline $\mathrm{N}^{-} \mathrm{GUA}$ & 13 & 4 & 0.017320 & 0.004330 & 0.027 & 0.9985 \\
\hline $\mathrm{N}_{-}^{-} \mathrm{GUA}$ & $/ 4$ & 4 & 0.468520 & 0.117130 & 0.731 & 0.5731 \\
\hline $\mathrm{N}_{-}^{-} \mathrm{GUA}$ & 15 & 4 & 0.170750 & 0.042688 & 0.267 & 0.8983 \\
\hline Ērro & & 67 & 10.730470 & 0.160156 & & \\
\hline
\end{tabular}


Codificação usada para o desdobramento

cod. ADUBO

$1=0$

$2=110$

$3=220$

$4=330$

$5=440$

Análise do desdobramento de ADUBO dentro de cada nível de:

N_GUA

TABELA DE ANÁLISE DE VARIÂNCIA

\begin{tabular}{|c|c|c|c|c|c|c|}
\hline EV & & GL & SQ & $\mathrm{QM}$ & $\mathrm{EC}$ & $\operatorname{Pr}>F_{C}$ \\
\hline ADUBO & $/ 1$ & 4 & 1.818800 & 0.454700 & 2.839 & 0.0306 \\
\hline ADUBO & 12 & 4 & 0.087600 & 0.021900 & 0.137 & 0.9681 \\
\hline ADUBO & 13 & 4 & 0.510500 & 0.127625 & 0.797 & 0.5308 \\
\hline ADUBO & $/ 4$ & 4 & 0.433320 & 0.108330 & 0.676 & 0.6101 \\
\hline ADUBO & $/ 5$ & 4 & 0.322030 & 0.080507 & 0.503 & 0.7334 \\
\hline Erro & & 67 & 10.730470 & 0.160156 & & \\
\hline
\end{tabular}

Codificação usada para o desdobramento

cod. N GUA

$1=1 \overline{0} 90$

$2=2177$

$3=4300$

$4=6540$

$5=8720$

\section{NMBP}

Análise do desdobramento de N GUA dentro de cada nível de:

ADUBO

TABELA DE ANÁLISE DE VARIÂNCIA

\begin{tabular}{|c|c|c|c|c|c|c|}
\hline FV & & GL & $\mathrm{SQ}$ & $\mathrm{QM}$ & FC & $\operatorname{Pr}>\mathrm{FC}$ \\
\hline N_GUA & $/ 1$ & 4 & 6.547370 & 1.636842 & 1.133 & 0.3472 \\
\hline $\mathrm{N}_{-}^{-} \mathrm{GUA}$ & 12 & 4 & 4.493770 & 1.123442 & 0.778 & 0.5427 \\
\hline $\mathrm{N}_{-}^{-} \mathrm{GUA}$ & 13 & 4 & 5.493720 & 1.373430 & 0.951 & 0.4393 \\
\hline $\mathrm{N}^{-} \mathrm{GUA}$ & $/ 4$ & 4 & 7.927220 & 1.981805 & 1.372 & 0.2516 \\
\hline $\mathrm{N}_{-}^{-} \mathrm{GUA}$ & $/ 5$ & 4 & 24.573370 & 6.143343 & 4.253 & 0.0038 \\
\hline Exro & & 71 & 102.561306 & 1.444525 & & \\
\hline
\end{tabular}

Codificação usada para o desdobramento

cod. ADUBO

$1=0$
$2=110$
$3=220$
$4=330$
$5=440$

Análise do desdobramento de ADUBO dentro de cada nível de:

N_GUA

TABELA DE ANÁLISE DE VARIÂNCIA

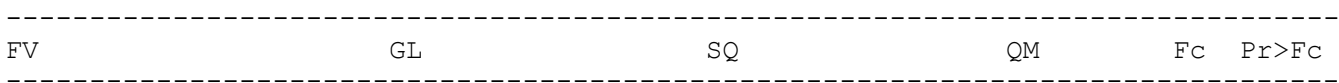




\begin{tabular}{|c|c|c|c|c|c|c|}
\hline ADUBO & $/ 1$ & 4 & 11.886920 & 2.971730 & 2.057 & 0.0951 \\
\hline ADUBO & 12 & 4 & 3.429550 & 0.857388 & 0.594 & 0.6679 \\
\hline ADUBO & 13 & 4 & 15.061420 & 3.765355 & 2.607 & 0.0425 \\
\hline ADUBO & $/ 4$ & 4 & 3.808320 & 0.952080 & 0.659 & 0.6219 \\
\hline ADUBO & 15 & 4 & 9.166470 & 2.291617 & 1.586 & 0.1867 \\
\hline Erro & & 71 & 102.561306 & 1.444525 & & \\
\hline
\end{tabular}

Codificação usada para o desdobramento

cod. N GUA

$1=1 \overline{0} 90$

$2=2177$

$3=4300$

$4=6540$

$5=8720$

\section{$\mathrm{NCH}$}

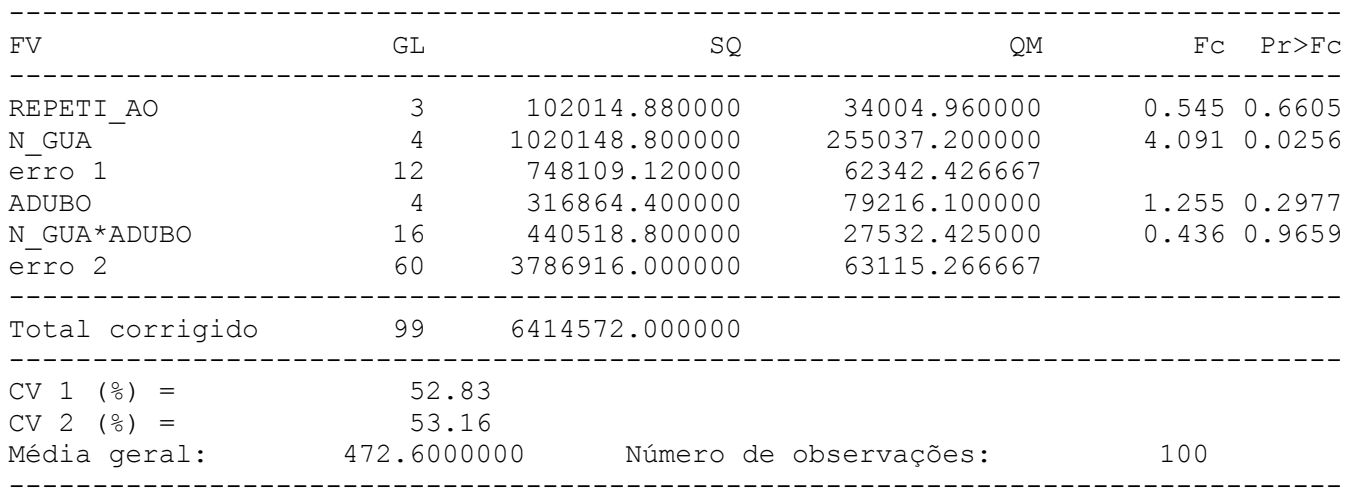




\section{Anexo 2- Croquis}

Prata anã

\begin{tabular}{|c|c|c|c|c|c|c|c|c|c|c|c|c|c|c|c|c|c|c|c|}
\hline V8P0 & V8P1 & V8P4 & V8P2 & V8P3 & V8P1 & V8P3 & V8P0 & V8P2 & V8P4 & V8P0 & V8P3 & V8P4 & V8P2 & V8P1 & V8P3 & V8P2 & V8P0 & V8P1 & V8P4 \\
\hline V8P0 & V8P1 & V8P4 & V8P2 & V8P3 & V8P1 & V8P3 & V8P0 & V8P2 & V8P4 & V8P0 & V8P3 & V8P4 & V8P2 & V8P1 & V8P3 & V8P2 & V8PO & V8P1 & V8P4 \\
\hline V24PO & V24P1 & V24P3 & V24P4 & V24P2 & V24P1 & V24P2 & V24P4 & V24P3 & V24PO & V24P1 & V24P2 & V24P3 & V24P4 & V24PO & V24P4 & V24P3 & V24PO & V24P2 & V24P1 \\
\hline V24PO & V24P1 & V24P3 & V24P4 & V24P2 & V24P1 & V24P2 & V24P4 & V24P3 & V24PO & V24P1 & V24P2 & V24P3 & V24P4 & V24PO & V24P4 & V24P3 & V24P0 & V24P2 & V24P1 \\
\hline V32P3 & V32P2 & V32P4 & V32P1 & V32PO & V32P0 & V32P1 & V32P2 & V32P3 & V32P4 & V32P2 & V32P4 & V32P3 & V32P1 & V32PO & V32P0 & V32P1 & V32P3 & V32P2 & V32P4 \\
\hline V32P3 & V32P2 & V32P4 & V32P1 & V32PO & V32P0 & V32P1 & V32P2 & V32P3 & V32P4 & V32P2 & V32P4 & V32P3 & V32P1 & V32PO & V32P0 & V32P1 & V32P3 & V32P2 & V32P4 \\
\hline V4P3 & V4P2 & V4P4 & V4P1 & V4P0 & V4P1 & V4P2 & V4P4 & V4P0 & V4P3 & V4P1 & V4P3 & V4P0 & V4P4 & V4P2 & V4P0 & V4P1 & V4P3 & V4P4 & V4P2 \\
\hline V4P3 & V4P2 & V4P4 & V4P1 & V4P0 & V4P1 & $\begin{array}{l}\text { V4P2 } \\
\end{array}$ & V4P4 & V4P0 & V4P3 & $\begin{array}{l}\text { V4P1 } \\
\end{array}$ & V4P3 & V4P0 & V4P4 & V4P2 & V4P0 & V4P1 & V4P3 & V4P4 & V4P2 \\
\hline V16P1 & V16P2 & V16P3 & V16P0 & V16P4 & V16P3 & V16P1 & V16P0 & V16P2 & V16P4 & V16P3 & V16P0 & $\mathrm{V} 16 \mathrm{P2}$ & V16P4 & $\mathrm{V} 16 \mathrm{P} 1$ & $\mathrm{~V} 16 \mathrm{P3}$ & V16P0 & V16P1 & $\mathrm{V} 16 \mathrm{P2}$ & V16P4 \\
\hline V16P1 & V16P2 & V16P3 & V16P0 & V16P4 & V16P3 & V16P1 & V16PO & $\mathrm{V} 16 \mathrm{P2}$ & $\mathrm{V} 16 \mathrm{P} 4$ & V16P3 & V16PO & V16P2 & V16P4 & V16P1 & V16P3 & V16PO & V16P1 & $\mathrm{V} 16 \mathrm{P} 2$ & V16P4 \\
\hline
\end{tabular}


BRS Conquista

\begin{tabular}{|c|c|c|c|c|c|c|c|c|c|c|c|c|c|c|c|c|c|c|c|}
\hline V24M0 & V24M3 & V24M4 & V24M1 & V24M2 & V24M4 & V24M3 & V24M1 & V24M0 & V24M2 & V24M4 & V24M3 & V24M0 & V24M2 & V24M1 & V24M0 & V24M3 & V24M4 & V24M1 & V24M2 \\
\hline V24M0 & V24M3 & V24M4 & V24M1 & V24M2 & V24M4 & V24M3 & V24M1 & V24M0 & V24M2 & V24M4 & V24M3 & V24M0 & V24M2 & V24M1 & V24M0 & V24M3 & V24M4 & V24M1 & V24M2 \\
\hline V32M0 & V32M4 & V32M3 & V32M2 & V32M1 & V32M4 & V32M3 & V32M1 & V32M0 & V32M2 & V32M0 & V32M3 & V32M2 & V32M4 & V32M1 & V32M3 & V32M4 & V32M0 & V32M1 & V32M2 \\
\hline V32M0 & V32M4 & V32M3 & V32M2 & V32M1 & V32M4 & V32M3 & V32M1 & V32M0 & V32M2 & V32M0 & V32M3 & V32M2 & V32M4 & V32M1 & V32M3 & V32M4 & V32M0 & V32M1 & V32M2 \\
\hline V16M4 & V16M1 & V16M0 & V16M2 & V16M3 & V16M1 & V16M3 & V16M0 & V16M4 & V16M2 & V16M4 & V16M3 & V16M2 & V16M1 & V16M0 & V16M3 & V16M4 & V16M2 & V16M0 & V16M1 \\
\hline V16M4 & V16M1 & V16M0 & V16M2 & V16M3 & V16M1 & V16M3 & V16M0 & V16M4 & V16M2 & V16M4 & V16M3 & V16M2 & V16M1 & V16M0 & V16M3 & V16M4 & V16M2 & V16M0 & V16M1 \\
\hline V4M0 & V4M1 & V4M2 & V4M3 & V4M4 & V4M3 & V4M0 & V4M2 & V4M4 & V4M1 & V4M2 & V4M0 & V4M1 & V4M3 & V4M4 & V4M3 & V4M4 & V4M1 & V4M2 & V4M0 \\
\hline V4M0 & V4M1 & V4M2 & V4M3 & V4M4 & V4M3 & V4M0 & V4M2 & V4M4 & V4M1 & V4M2 & V4M0 & V4M1 & V4M3 & V4M4 & V4M3 & V4M4 & V4M1 & V4M2 & V4M0 \\
\hline V8M0 & V8M4 & V8M3 & V8M1 & V8M2 & V8M4 & V8M0 & V8M1 & V8M2 & V8M3 & V8M2 & V8M4 & V8M0 & V8M3 & V8M1 & V8M3 & V8M4 & V8M2 & V8M1 & V8M0 \\
\hline V8M0 & V8M4 & V8M3 & V8M1 & V8M2 & V8M4 & V8M0 & V8M1 & V8M2 & V8M3 & V8M2 & V8M4 & V8M0 & V8M3 & V8M1 & V8M3 & V8M4 & V8M2 & V8M1 & V8M0 \\
\hline
\end{tabular}


Anexo 3- Fotos

Moto bomba

Filtro

Derivação
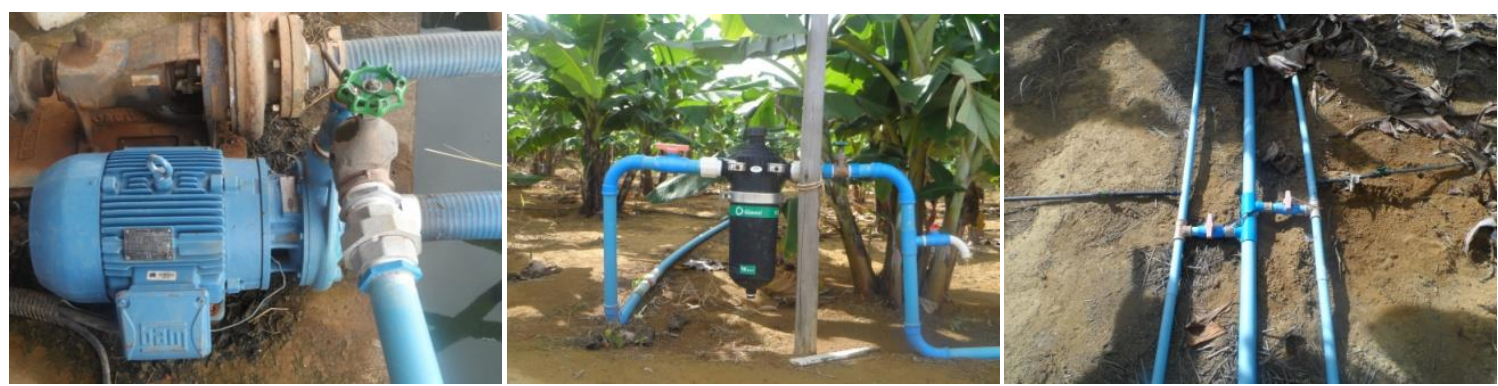

Fase inicial

Início da produção

Gotejador
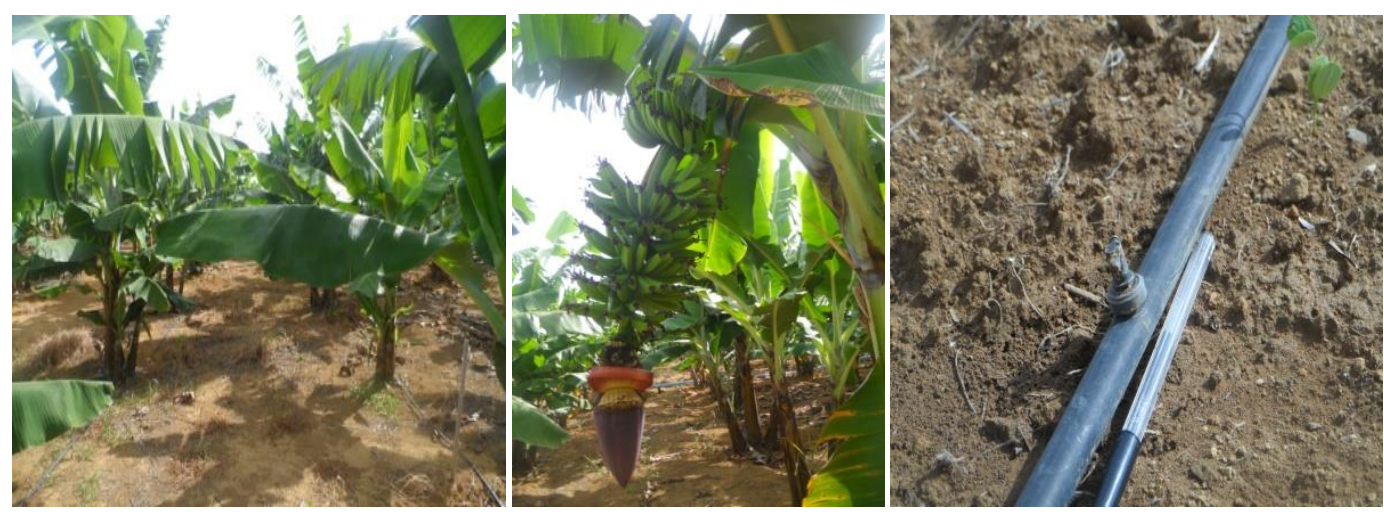

Gotejador e área molhada

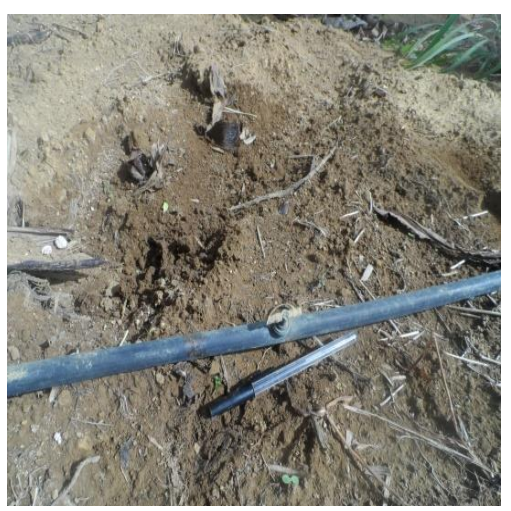

BRS Conquista

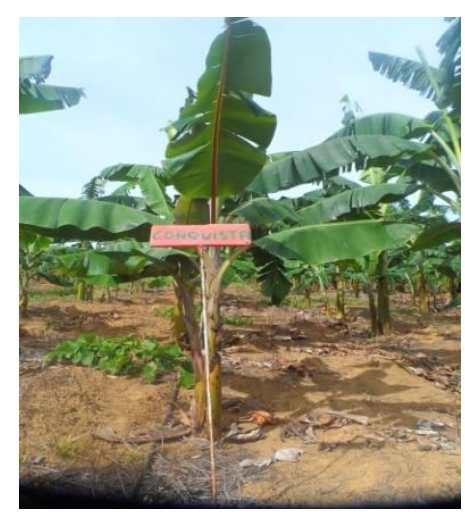

Prata anã

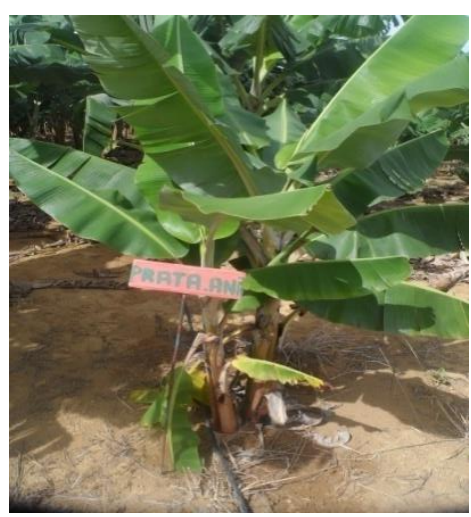


Anexo 4: Dados climatológicos

Fazenda Água Limpa - FAL-UnB

Estação Climatológica Automática

Latitu $\quad 15^{\circ} 56^{\prime} \mathrm{S} \quad$ Longit $\quad 47^{\circ} 56^{\prime} \mathrm{W}$

Ano:

2013

Mês: Janeiro

\begin{tabular}{|c|c|c|c|c|c|c|c|c|}
\hline Dia & $\begin{array}{l}\text { Prec. } \\
\mathrm{mm}\end{array}$ & $\begin{array}{c}\mathrm{T} \text { med } \\
\mathrm{oC}\end{array}$ & $\begin{array}{c}\text { T max } \\
\text { oC }\end{array}$ & $\begin{array}{c}\mathrm{T} \text { min } \\
\mathrm{oC}\end{array}$ & $\begin{array}{c}\text { UR med } \\
\%\end{array}$ & $\begin{array}{c}\text { UR max } \\
\%\end{array}$ & $\begin{array}{c}\text { UR min } \\
\%\end{array}$ & $\begin{array}{c}\text { Classe } \\
\text { A } \\
\mathrm{mm}\end{array}$ \\
\hline 1 & 0,0 & 22,1 & 31,0 & 13,8 & 69,3 & 97,5 & 33,7 & 5,7 \\
\hline 2 & 0,0 & 22,9 & 31,3 & 14,6 & 63,4 & 95,0 & 28,4 & 4,7 \\
\hline 3 & 0,0 & 23,0 & 31,5 & 14,1 & 64,8 & 96,4 & 27,5 & 8,0 \\
\hline 4 & 0,4 & 22,6 & 29,9 & 16,4 & 73,8 & 97,0 & 42,4 & 3,7 \\
\hline 5 & 0,0 & 23,1 & 30,3 & 16,5 & 70,2 & 98,5 & 38,0 & 6,3 \\
\hline 6 & 1,4 & 22,0 & 30,5 & 15,0 & 77,4 & 98,2 & 41,8 & 5,0 \\
\hline 7 & 0,0 & 22,5 & 29,4 & 16,1 & 77,7 & 98,8 & 45,9 & 4,7 \\
\hline 8 & 0,0 & 21,8 & 26,7 & 19,1 & 85,2 & 97,1 & 64,5 & 2,2 \\
\hline 9 & 40,0 & 22,0 & 29,4 & 18,4 & 83,5 & 99,0 & 52,0 & 9,7 \\
\hline 10 & 1,2 & 21,7 & 27,3 & 18,2 & 81,4 & 99,4 & 49,5 & 3,5 \\
\hline 11 & 4,8 & 19,4 & 22,6 & 18,0 & 90,1 & 98,1 & 73,0 & 4,5 \\
\hline 12 & 15,0 & 18,1 & 20,0 & 15,9 & 93,0 & 97,8 & 84,1 & 0,1 \\
\hline 13 & 3,2 & 18,8 & 21,4 & 17,4 & 89,4 & 97,7 & 72,0 & 2,4 \\
\hline 14 & 56,4 & 18,3 & 20,9 & 16,4 & 94,5 & 99,0 & 84,2 & 2,9 \\
\hline 15 & 3,2 & 19,6 & 24,4 & 17,0 & 91,6 & 99,4 & 68,7 & 2,2 \\
\hline 16 & 57,0 & 19,2 & 24,3 & 17,3 & 91,8 & 99,5 & 65,1 & 5,4 \\
\hline 17 & 11,0 & 20,8 & 26,7 & 17,1 & 84,3 & 99,2 & 56,1 & 4,2 \\
\hline 18 & 0,2 & 21,6 & 30,6 & 13,5 & 75,2 & 99,3 & 33,1 & 3,4 \\
\hline 19 & 20,8 & 21,4 & 28,9 & 16,7 & 85,6 & 98,4 & 52,5 & 5,5 \\
\hline 20 & 0,4 & 21,8 & 27,4 & 17,7 & 84,6 & 98,5 & 59,8 & 4,5 \\
\hline 21 & 2,0 & 21,1 & 24,7 & 19,2 & 86,7 & 97,8 & 71,2 & 4,0 \\
\hline 22 & 26,4 & 20,6 & 25,9 & 18,5 & 93,4 & 98,7 & 64,1 & 4,9 \\
\hline 23 & 45,4 & 21,2 & 26,2 & 18,8 & 91,1 & 99,3 & 67,1 & 6,5 \\
\hline 24 & 0,2 & 21,0 & 27,1 & 17,5 & 88,2 & 99,4 & 61,9 & 3,0 \\
\hline 25 & 11,6 & 21,1 & 25,2 & 19,1 & 88,8 & 98,8 & 66,8 & 3,0 \\
\hline 26 & 25,0 & 20,2 & 22,9 & 19,1 & 95,2 & 99,1 & 82,2 & 4,1 \\
\hline 27 & 7,6 & 21,2 & 25,4 & 19,4 & 90,9 & 99,0 & 70,3 & 0,0 \\
\hline 28 & 0,2 & 23,2 & 28,9 & 19,6 & 81,5 & 97,8 & 55,3 & 5,6 \\
\hline 29 & 26,4 & 20,7 & 26,9 & 19,0 & 94,2 & 99,2 & 62,1 & 5,1 \\
\hline 30 & 5,8 & 21,1 & 27,5 & 18,5 & 88,5 & 99,3 & 57,8 & 4,1 \\
\hline 31 & 3,2 & 20,5 & 26,5 & 17,8 & 91,4 & 98,9 & 65,0 & 1,4 \\
\hline Média & - & 21,1 & 26,8 & 17,3 & 84,4 & 98,4 & 57,9 & 4,2 \\
\hline Total & 368,8 & - & - & - & - & - & - & 130,2 \\
\hline Máximo & 57,0 & 23,2 & 31,5 & 19,6 & 95,2 & 99,5 & 84,2 & 9,7 \\
\hline Mínimo & 0,0 & 18,1 & 20,0 & 13,5 & 63,4 & 95,0 & 27,5 & 0,0 \\
\hline
\end{tabular}


Mês: Fevereiro

\begin{tabular}{|c|c|c|c|c|c|c|c|c|}
\hline Dia & $\begin{array}{c}\text { Prec. } \\
\mathrm{mm}\end{array}$ & $\begin{array}{c}\text { T med } \\
\text { oC }\end{array}$ & $\begin{array}{c}\mathrm{T} \max \\
\mathrm{oC}\end{array}$ & $\begin{array}{c}\mathrm{T} \text { min } \\
\mathrm{oC}\end{array}$ & $\begin{array}{c}\text { UR med } \\
\%\end{array}$ & $\begin{array}{c}\text { UR max } \\
\%\end{array}$ & $\begin{array}{c}\text { UR min } \\
\%\end{array}$ & $\begin{array}{c}\text { Classe } \\
\text { A } \\
\mathrm{mm}\end{array}$ \\
\hline 1 & 16,0 & 20,5 & 27,0 & 17,8 & 90,7 & 99,0 & 53,9 & 5,0 \\
\hline 2 & 4,6 & 22,1 & 28,5 & 18,0 & 83,1 & 98,6 & 51,3 & 1,1 \\
\hline 3 & 3,2 & 22,1 & 29,1 & 16,9 & 78,8 & 98,9 & 43,2 & 5,9 \\
\hline 4 & 0,0 & 22,0 & 30,0 & 14,7 & 75,0 & 99,0 & 36,2 & 5,3 \\
\hline 5 & 0,2 & 21,2 & 27,9 & 18,2 & 84,7 & 97,4 & 56,6 & 3,4 \\
\hline 6 & 0,6 & 21,1 & 25,8 & 17,9 & 83,8 & 98,8 & 60,3 & 1,9 \\
\hline 7 & 0,0 & 22,1 & 27,7 & 17,3 & 77,3 & 98,9 & 46,1 & 5,9 \\
\hline 8 & 0,2 & 22,0 & 28,4 & 16,8 & 77,7 & 98,1 & 49,8 & 3,8 \\
\hline 9 & 0,0 & 21,7 & 27,8 & 17,1 & 82,3 & 98,9 & 56,4 & 3,3 \\
\hline 10 & 0,0 & 22,4 & 29,4 & 16,1 & 75,1 & 98,7 & 47,3 & 5,9 \\
\hline 11 & 0,0 & 21,9 & 30,0 & 14,6 & 70,7 & 97,5 & 39,5 & 6,0 \\
\hline 12 & 0,0 & 21,5 & 30,6 & 12,1 & 66,1 & 97,8 & 32,7 & 6,5 \\
\hline 13 & 0,0 & 21,9 & 31,4 & 13,2 & 68,4 & 96,9 & 36,5 & 4,8 \\
\hline 14 & 0,0 & 22,4 & 31,4 & 14,4 & 72,3 & 97,5 & 38,5 & 3,5 \\
\hline 15 & 0,0 & 23,4 & 31,8 & 14,7 & 65,1 & 96,7 & 30,6 & 7,5 \\
\hline 16 & 0,0 & 22,8 & 31,0 & 14,1 & 68,6 & 97,1 & 36,4 & 6,7 \\
\hline 17 & 0,0 & 22,4 & 31,2 & 15,4 & 74,6 & 97,1 & 38,6 & 5,0 \\
\hline 18 & 0,2 & 22,6 & 31,4 & 13,9 & 70,8 & 98,7 & 37,2 & 4,6 \\
\hline 19 & 0,0 & 22,3 & 30,8 & 14,5 & 73,0 & 98,1 & 42,0 & 6,8 \\
\hline 20 & 0,0 & 22,0 & 30,3 & 14,4 & 73,6 & 98,3 & 42,8 & 6,6 \\
\hline 21 & 9,8 & 21,5 & 30,0 & 13,9 & 75,7 & 97,9 & 41,3 & 6,8 \\
\hline 22 & 0,0 & 21,9 & 30,4 & 14,8 & 70,4 & 98,2 & 31,1 & 3,7 \\
\hline 23 & 0,0 & 23,2 & 30,7 & 16,6 & 67,5 & 95,4 & 34,5 & 7,4 \\
\hline 24 & 53,4 & 20,7 & 26,8 & 16,1 & 82,9 & 98,9 & 58,0 & 4,9 \\
\hline 25 & 31,6 & 19,5 & 25,8 & 16,4 & 90,6 & 99,4 & 60,3 & 9,1 \\
\hline 26 & 8,2 & 20,5 & 29,1 & 17,0 & 87,9 & 99,4 & 50,6 & 3,2 \\
\hline 27 & 0,2 & 21,4 & 29,2 & 16,5 & 83,0 & 98,6 & 50,8 & 0,4 \\
\hline 28 & 0,0 & 22,2 & 27,6 & 17,4 & 81,2 & 98,4 & 51,9 & 5,0 \\
\hline \multicolumn{9}{|l|}{29} \\
\hline \multicolumn{9}{|l|}{30} \\
\hline \multicolumn{9}{|l|}{31} \\
\hline Média & - & 21,8 & 29,3 & 15,7 & 76,8 & 98,1 & 44,8 & 5,0 \\
\hline Total & 128,2 & - & - & - & - & - & - & 140,2 \\
\hline Máximo & 53,4 & 23,4 & 31,8 & 18,2 & 90,7 & 99,4 & 60,3 & 9,1 \\
\hline Mínimo & 0,0 & 19,5 & 25,8 & 12,1 & 65,1 & 95,4 & 30,6 & 0,4 \\
\hline
\end{tabular}




\begin{tabular}{|c|c|c|c|c|c|c|c|c|}
\hline Mês: & Março & & & & & & & \\
\hline Dia & $\begin{array}{l}\text { Prec. } \\
\text { mm }\end{array}$ & $\begin{array}{c}\text { T med } \\
\text { oC }\end{array}$ & $\begin{array}{c}\text { T max } \\
\text { oC }\end{array}$ & $\begin{array}{l}\mathrm{T} \min \\
\mathrm{oC}\end{array}$ & $\begin{array}{c}\text { UR med } \\
\%\end{array}$ & $\begin{array}{c}\text { UR max } \\
\%\end{array}$ & $\begin{array}{c}\text { UR min } \\
\%\end{array}$ & $\begin{array}{c}\text { Classe } \\
\text { A } \\
\text { mm }\end{array}$ \\
\hline 1 & 0,0 & 21,2 & 25,7 & 18,8 & 87,4 & 97,8 & 66,1 & 5,0 \\
\hline 2 & 0,4 & 22,6 & 28,9 & 18,6 & 80,7 & 99,0 & 51,8 & 4,8 \\
\hline 3 & 8,2 & 22,0 & 29,7 & 17,5 & 79,3 & 98,0 & 45,2 & 6,4 \\
\hline 4 & 0,2 & 22,8 & 30,3 & 16,6 & 74,6 & 98,1 & 40,0 & 6,3 \\
\hline 5 & 0,0 & 21,7 & 30,2 & 14,4 & 77,0 & 98,3 & 40,5 & 2,1 \\
\hline 6 & 1,4 & 22,1 & 31,4 & 15,6 & 76,9 & 97,9 & 41,1 & 5,4 \\
\hline 7 & 12,2 & 22,9 & 31,0 & 16,5 & 79,4 & 98,2 & 38,0 & 7,8 \\
\hline 8 & 0,0 & 22,7 & 31,1 & 15,4 & 78,3 & 98,8 & 43,2 & 3,4 \\
\hline 9 & 0,0 & 23,6 & 31,9 & 16,5 & 74,4 & 98,9 & 37,3 & 6,4 \\
\hline 10 & 0,0 & 23,0 & 31,2 & 17,9 & 77,6 & 98,1 & 41,9 & 5,5 \\
\hline 11 & 0,2 & 21,5 & 29,4 & 16,6 & 83,0 & 98,7 & 51,8 & 3,4 \\
\hline 12 & 2,6 & 22,8 & 31,5 & 15,9 & 77,9 & 98,6 & 41,5 & 7,1 \\
\hline 13 & 0,0 & 22,4 & 30,7 & 17,6 & 84,3 & 98,9 & 49,7 & 2,5 \\
\hline 14 & 0,0 & 21,7 & 26,9 & 17,4 & 86,8 & 97,9 & 64,7 & 3,1 \\
\hline 15 & 0,2 & 21,4 & 27,3 & 18,1 & 88,3 & 98,3 & 62,6 & 2,0 \\
\hline 16 & 0,0 & 22,5 & 29,4 & 16,8 & 75,0 & 97,9 & 44,6 & 6,3 \\
\hline 17 & 0,0 & 21,7 & 30,9 & 13,3 & 73,5 & 98,7 & 36,7 & 4,9 \\
\hline 18 & 0,0 & 23,0 & 30,8 & 14,7 & 71,5 & 98,6 & 40,4 & 4,0 \\
\hline 19 & 35,8 & 20,9 & 26,8 & 17,6 & 84,9 & 99,2 & 58,6 & 9,0 \\
\hline 20 & 37,6 & 19,0 & 22,0 & 17,7 & 95,9 & 99,5 & 82,3 & 4,3 \\
\hline 21 & 12,6 & 20,5 & 26,2 & 18,0 & 89,3 & 99,5 & 60,1 & 2,0 \\
\hline 22 & 0,0 & 21,3 & 26,9 & 18,6 & 87,9 & 98,9 & 60,2 & 0,9 \\
\hline 23 & 3,4 & 20,8 & 26,9 & 18,2 & 86,1 & 98,2 & 50,7 & 3,4 \\
\hline 24 & 5,0 & 20,8 & 27,5 & 15,5 & 85,6 & 99,0 & 52,7 & 6,5 \\
\hline 25 & 51,4 & 20,6 & 26,8 & 17,7 & 88,9 & 99,1 & 57,2 & 6,3 \\
\hline 26 & 0,2 & 21,8 & 27,8 & 18,5 & 84,0 & 99,1 & 55,9 & 4,1 \\
\hline 27 & 5,8 & 21,8 & 28,3 & 16,8 & 82,5 & 98,8 & 53,3 & 8,4 \\
\hline 28 & 3,0 & 20,5 & 25,6 & 18,3 & 91,1 & 99,0 & 67,1 & 1,0 \\
\hline 29 & 5,0 & 21,2 & 28,0 & 17,9 & 89,4 & 98,9 & 54,4 & 2,9 \\
\hline 30 & 10,2 & 20,4 & 24,7 & 18,8 & 93,9 & 98,9 & 73,3 & 2,6 \\
\hline 31 & 0,8 & 22,2 & 27,5 & 19,3 & 81,0 & 98,9 & 50,8 & 1,7 \\
\hline Média & - & 21,7 & 28,5 & 17,1 & 82,8 & 98,6 & 52,1 & 4,5 \\
\hline Total & 196,2 & - & - & - & - & - & - & 139,4 \\
\hline Máximo & 51,4 & 23,6 & 31,9 & 19,3 & 95,9 & 99,5 & 82,3 & 9,0 \\
\hline Mínimo & 0,0 & 19,0 & 22,0 & 13,3 & 71,5 & 97,8 & 36,7 & 0,9 \\
\hline
\end{tabular}


Mês: Abril

\begin{tabular}{|c|c|c|c|c|c|c|c|c|}
\hline Dia & $\begin{array}{l}\text { Prec. } \\
\mathrm{mm}\end{array}$ & $\begin{array}{c}\mathrm{T} \text { med } \\
\mathrm{oC}\end{array}$ & $\begin{array}{c}\mathrm{T} \max \\
\mathrm{oC}\end{array}$ & $\begin{array}{c}\mathrm{T} \text { min } \\
\mathrm{oC}\end{array}$ & $\begin{array}{c}\text { UR med } \\
\%\end{array}$ & $\begin{array}{c}\mathrm{UR} \max \\
\%\end{array}$ & $\begin{array}{c}\text { UR min } \\
\%\end{array}$ & $\begin{array}{c}\text { Classe } \\
\text { A } \\
\text { mm }\end{array}$ \\
\hline 1 & 0,4 & 21,5 & 28,8 & 15,0 & 81,6 & 99,4 & 48,8 & 5,3 \\
\hline 2 & 32,0 & 20,4 & 28,1 & 15,6 & 87,4 & 99,1 & 52,4 & 7,9 \\
\hline 3 & 2,0 & 21,3 & 29,6 & 16,0 & 81,9 & 98,9 & 41,3 & 0,8 \\
\hline 4 & 49,0 & 20,9 & 28,2 & 17,2 & 85,1 & 99,3 & 54,1 & 2,9 \\
\hline 5 & 2,4 & 20,9 & 27,4 & 17,0 & 87,0 & 99,0 & 58,0 & 4,2 \\
\hline 6 & 1,6 & 22,0 & 28,3 & 18,5 & 84,1 & 98,9 & 53,4 & 4,1 \\
\hline 7 & 6,6 & 21,6 & 27,7 & 18,0 & 83,6 & 99,0 & 50,8 & 2,3 \\
\hline 8 & 0,0 & 21,6 & 28,7 & 18,1 & 86,0 & 98,1 & 52,7 & 2,9 \\
\hline 9 & 0,2 & 21,5 & 26,8 & 17,2 & 88,2 & 98,9 & 64,3 & 0,8 \\
\hline 10 & 35,0 & 19,7 & 25,7 & 17,6 & 96,0 & 99,3 & 69,7 & 6,4 \\
\hline 11 & 0,0 & 20,2 & 25,2 & 17,1 & 90,7 & 99,5 & 69,0 & 1,7 \\
\hline 12 & 1,8 & 20,8 & 26,7 & 17,3 & 89,8 & 98,6 & 59,6 & 2,9 \\
\hline 13 & 0,0 & 21,3 & 28,4 & 16,0 & 85,0 & 99,3 & 54,8 & 4,1 \\
\hline 14 & 1,0 & 21,0 & 27,8 & 15,9 & 86,7 & 99,5 & 59,6 & 3,1 \\
\hline 15 & 0,0 & 21,3 & 28,8 & 15,8 & 84,6 & 99,2 & 51,4 & 3,4 \\
\hline 16 & 0,2 & 21,5 & 28,0 & 16,6 & 83,2 & 98,8 & 53,7 & 3,4 \\
\hline 17 & 0,0 & 20,2 & 27,7 & 14,7 & 78,3 & 98,5 & 47,7 & 2,2 \\
\hline 18 & 0,2 & 20,1 & 28,0 & 13,4 & 80,6 & 99,2 & 45,6 & 4,1 \\
\hline 19 & 0,0 & 20,3 & 26,2 & 15,6 & 83,9 & 98,8 & 58,6 & 3,4 \\
\hline 20 & 0,0 & 18,7 & 25,8 & 11,5 & 76,8 & 99,4 & 45,5 & 5,0 \\
\hline 21 & 0,0 & 18,2 & 25,1 & 10,4 & 74,5 & 98,5 & 48,1 & 3,8 \\
\hline 22 & 0,0 & 18,1 & 24,3 & 10,9 & 74,4 & 98,6 & 50,0 & 1,4 \\
\hline 23 & 0,2 & 17,4 & 24,3 & 10,4 & 79,8 & 98,6 & 52,0 & 3,6 \\
\hline 24 & 0,0 & 18,0 & 25,0 & 12,9 & 79,9 & 97,5 & 52,4 & 3,7 \\
\hline 25 & 0,0 & 18,0 & 25,6 & 11,6 & 81,8 & 98,7 & 52,2 & 3,0 \\
\hline 26 & 0,0 & 18,9 & 27,1 & 11,5 & 79,6 & 99,2 & 49,0 & 4,2 \\
\hline 27 & 0,0 & 18,8 & 26,5 & 11,6 & 81,8 & 99,2 & 54,5 & 3,7 \\
\hline 28 & 0,2 & 18,7 & 26,8 & 11,1 & 75,1 & 99,4 & 43,1 & 5,2 \\
\hline 29 & 0,0 & 18,3 & 27,9 & 10,2 & 76,4 & 98,9 & 43,0 & 4,4 \\
\hline 30 & 0,0 & 19,5 & 28,6 & 11,4 & 75,7 & 98,9 & 42,7 & 2,2 \\
\hline \multicolumn{9}{|l|}{31} \\
\hline Média & - & 20,0 & 27,1 & 14,5 & 82,7 & 98,9 & 52,6 & 3,5 \\
\hline Total & 132,8 & - & - & - & - & - & - & 106,3 \\
\hline Máximo & 49,0 & 22,0 & 29,6 & 18,5 & 96,0 & 99,5 & 69,7 & 7,9 \\
\hline Mínimo & 0,0 & 17,4 & 24,3 & 10,2 & 74,4 & 97,5 & 41,3 & 0,8 \\
\hline
\end{tabular}




\begin{tabular}{|c|c|c|c|c|c|c|c|c|}
\hline Dia & $\begin{array}{l}\text { Prec. } \\
\mathrm{mm}\end{array}$ & $\begin{array}{c}\text { T med } \\
\text { oC }\end{array}$ & $\begin{array}{c}\text { T max } \\
\text { oC }\end{array}$ & $\begin{array}{l}\mathrm{T} \min \\
\mathrm{oC}\end{array}$ & $\begin{array}{c}\text { UR med } \\
\%\end{array}$ & $\begin{array}{c}\text { UR max } \\
\%\end{array}$ & $\begin{array}{c}\text { UR min } \\
\%\end{array}$ & $\begin{array}{c}\text { Classe } \\
\text { A } \\
\mathrm{mm}\end{array}$ \\
\hline 1 & 0,0 & 19,4 & 28,3 & 10,2 & 71,6 & 99,4 & 35,9 & 5,5 \\
\hline 2 & 0,0 & 19,6 & 27,9 & 10,8 & 71,9 & 99,1 & 41,4 & 5,3 \\
\hline 3 & 0,2 & 18,5 & 28,3 & 10,7 & 72,8 & 98,6 & 32,6 & 5,0 \\
\hline 4 & 0,0 & 18,4 & 28,6 & 9,9 & 69,3 & 98,7 & 29,9 & 5,2 \\
\hline 5 & 0,0 & 18,8 & 28,9 & 9,4 & 70,7 & 98,6 & 34,9 & 4,6 \\
\hline 6 & 0,0 & 19,7 & 28,8 & 9,4 & 67,2 & 97,4 & 33,2 & 1,9 \\
\hline 7 & 0,0 & 20,7 & 28,0 & 13,8 & 70,8 & 96,0 & 44,5 & 4,7 \\
\hline 8 & 0,0 & 19,2 & 26,4 & 13,4 & 72,0 & 94,0 & 48,0 & 4,2 \\
\hline 9 & 0,0 & 18,7 & 28,5 & 9,5 & 73,4 & 97,9 & 37,9 & 4,4 \\
\hline 10 & 0,0 & 18,5 & 27,2 & 9,8 & 75,6 & 98,4 & 43,9 & 4,5 \\
\hline 11 & 0,0 & 18,3 & 26,9 & 9,8 & 73,4 & 98,8 & 41,8 & 4,7 \\
\hline 12 & 0,0 & 18,5 & 28,1 & 8,8 & 71,5 & 98,8 & 23,5 & 4,6 \\
\hline 13 & 0,0 & 19,0 & 27,3 & 11,7 & 77,1 & 98,0 & 47,5 & 4,1 \\
\hline 14 & 0,0 & 19,7 & 27,6 & 13,0 & 77,0 & 98,5 & 48,0 & 1,6 \\
\hline 15 & 0,0 & 19,0 & 28,1 & 11,2 & 78,1 & 99,1 & 42,3 & 4,4 \\
\hline 16 & 0,2 & 19,3 & 27,6 & 12,8 & 76,8 & 99,3 & 42,1 & 7,0 \\
\hline 17 & 0,0 & 19,3 & 27,9 & 11,7 & 73,8 & 98,9 & 39,1 & 4,6 \\
\hline 18 & 0,0 & 18,7 & 27,3 & 10,5 & 74,0 & 98,7 & 40,3 & 5,2 \\
\hline 19 & 0,0 & 18,6 & 26,0 & 11,5 & 75,9 & 98,8 & 46,3 & 4,4 \\
\hline 20 & 0,0 & 17,5 & 26,6 & 9,8 & 77,2 & 99,2 & 41,2 & 3,9 \\
\hline 21 & 0,0 & 17,8 & 27,8 & 9,2 & 75,3 & 99,2 & 35,2 & 1,1 \\
\hline 22 & 0,0 & 18,9 & 28,8 & 10,2 & 72,2 & 98,5 & 36,5 & 3,3 \\
\hline 23 & 0,0 & 18,9 & 28,8 & 10,3 & 70,0 & 97,8 & 33,0 & 4,3 \\
\hline 24 & 0,0 & 19,0 & 29,5 & 10,9 & 72,3 & 97,8 & 31,0 & 5,2 \\
\hline 25 & 0,0 & 19,2 & 27,4 & 12,4 & 75,9 & 98,6 & 43,6 & 3,0 \\
\hline 26 & 0,0 & 18,6 & 26,6 & 11,5 & 82,7 & 98,8 & 55,5 & 4,2 \\
\hline 27 & 3,8 & 19,5 & 27,9 & 14,8 & 86,8 & 98,8 & 52,3 & 6,9 \\
\hline 28 & 0,2 & 19,5 & 28,9 & 12,7 & 80,8 & 99,7 & 39,7 & 2,3 \\
\hline 29 & 0,0 & 19,3 & 28,7 & 12,9 & 83,6 & 99,2 & 44,9 & 1,1 \\
\hline 30 & 31,8 & 17,0 & 21,5 & 14,9 & 94,2 & 99,6 & 71,8 & 4,2 \\
\hline 31 & 0,0 & 19,2 & 25,8 & 14,1 & 85,0 & 99,3 & 58,4 & 1,2 \\
\hline Média & - & 18,9 & 27,6 & 11,3 & 75,8 & 98,5 & 41,8 & 4,1 \\
\hline Total & 36,2 & - & - & - & - & - & - & 126,7 \\
\hline Máximo & 31,8 & 20,7 & 29,5 & 14,9 & 94,2 & 99,7 & 71,8 & 7,0 \\
\hline Mínimo & 0,0 & 17,0 & 21,5 & 8,8 & 67,2 & 94,0 & 23,5 & 1,1 \\
\hline
\end{tabular}


Mês: Junho

\begin{tabular}{|c|c|c|c|c|c|c|c|c|}
\hline Dia & $\begin{array}{l}\text { Prec. } \\
\mathrm{mm}\end{array}$ & $\begin{array}{c}\mathrm{T} \text { med } \\
\mathrm{oC}\end{array}$ & $\begin{array}{c}\text { T max } \\
\text { oC }\end{array}$ & $\begin{array}{c}\mathrm{T} \text { min } \\
\mathrm{oC}\end{array}$ & $\begin{array}{c}\text { UR med } \\
\%\end{array}$ & $\begin{array}{c}\text { UR max } \\
\%\end{array}$ & $\begin{array}{c}\mathrm{UR} \min \\
\%\end{array}$ & $\begin{array}{c}\text { Classe } \\
\text { A } \\
\mathrm{mm}\end{array}$ \\
\hline 1 & 0,0 & 19,2 & 23,1 & 15,8 & 89,9 & 98,9 & 72,8 & 1,6 \\
\hline 2 & 0,8 & 19,8 & 26,3 & 15,8 & 88,3 & 99,5 & 57,2 & 2,8 \\
\hline 3 & 0,8 & 18,1 & 20,7 & 16,6 & 93,8 & 98,6 & 84,0 & 1,1 \\
\hline 4 & 0,2 & 17,1 & 21,6 & 13,8 & 91,0 & 99,3 & 69,8 & 0,0 \\
\hline 5 & 0,0 & 18,8 & 25,1 & 13,6 & 86,4 & 99,1 & 60,4 & 1,7 \\
\hline 6 & 0,2 & 18,7 & 26,3 & 12,5 & 85,7 & 99,4 & 53,0 & 2,9 \\
\hline 7 & 0,2 & 20,2 & 26,9 & 14,6 & 80,3 & 99,2 & 52,0 & 3,9 \\
\hline 8 & 0,0 & 20,2 & 26,3 & 16,1 & 78,5 & 93,7 & 54,7 & 3,8 \\
\hline 9 & 0,2 & 18,9 & 25,3 & 13,8 & 80,5 & 99,3 & 50,5 & 4,2 \\
\hline 10 & 0,0 & 16,9 & 23,6 & 12,1 & 86,3 & 99,1 & 59,6 & 0,5 \\
\hline 11 & 0,2 & 17,4 & 25,4 & 10,6 & 77,4 & 98,8 & 47,1 & 4,1 \\
\hline 12 & 0,0 & 17,8 & 26,9 & 9,8 & 74,2 & 99,0 & 38,5 & 4,2 \\
\hline 13 & 0,0 & 17,7 & 26,5 & 8,9 & 75,6 & 99,2 & 41,2 & 4,2 \\
\hline 14 & 0,0 & 17,4 & 26,1 & 8,3 & 75,6 & 99,0 & 41,2 & 1,6 \\
\hline 15 & 0,0 & 18,0 & 26,9 & 9,9 & 77,3 & 98,9 & 43,5 & 3,3 \\
\hline 16 & 0,0 & 18,3 & 27,0 & 11,5 & 76,8 & 98,1 & 43,8 & 4,9 \\
\hline 17 & 0,0 & 18,9 & 28,3 & 10,6 & 75,7 & 98,7 & 40,0 & 3,9 \\
\hline 18 & 0,0 & 19,7 & 28,2 & 11,9 & 73,6 & 98,7 & 41,2 & 4,9 \\
\hline 19 & 0,0 & 18,6 & 27,4 & 11,2 & 74,9 & 99,0 & 38,5 & 4,9 \\
\hline 20 & 0,0 & 17,8 & 27,1 & 10,0 & 74,9 & 98,7 & 40,1 & 5,3 \\
\hline 21 & 0,0 & 18,1 & 27,8 & 9,7 & 75,9 & 98,4 & 42,4 & 5,1 \\
\hline 22 & 0,6 & 19,6 & 29,0 & 11,7 & 78,3 & 98,8 & 35,8 & 3,8 \\
\hline 23 & 0,0 & 21,1 & 28,3 & 13,9 & 72,0 & 98,6 & 40,8 & 5,5 \\
\hline 24 & 0,0 & 19,9 & 27,2 & 13,4 & 75,0 & 98,2 & 49,8 & 5,5 \\
\hline 25 & 0,0 & 18,2 & 26,8 & 10,9 & 78,0 & 99,0 & 44,4 & 5,2 \\
\hline 26 & 0,0 & 18,0 & 27,3 & 10,5 & 78,0 & 99,1 & 44,1 & 4,7 \\
\hline 27 & 0,0 & 18,3 & 27,5 & 11,1 & 75,3 & 98,5 & 38,4 & 5,4 \\
\hline 28 & 0,0 & 18,3 & 27,7 & 10,8 & 72,3 & 97,6 & 37,9 & 4,8 \\
\hline 29 & 0,0 & 18,4 & 28,9 & 9,8 & 69,8 & 97,6 & 31,2 & 5,6 \\
\hline 30 & 0,0 & 19,2 & 28,5 & 11,4 & 63,1 & 95,6 & 26,3 & 5,0 \\
\hline \multicolumn{9}{|l|}{31} \\
\hline Média & - & 18,6 & 26,5 & 12,0 & 78,5 & 98,5 & 47,3 & 3,8 \\
\hline Total & 3,2 & - & - & - & - & - & - & 114,5 \\
\hline Máximo & 0,8 & 21,1 & 29,0 & 16,6 & 93,8 & 99,5 & 84,0 & 5,6 \\
\hline Mínimo & 0,0 & 16,9 & 20,7 & 8,3 & 63,1 & 93,7 & 26,3 & 0,0 \\
\hline
\end{tabular}




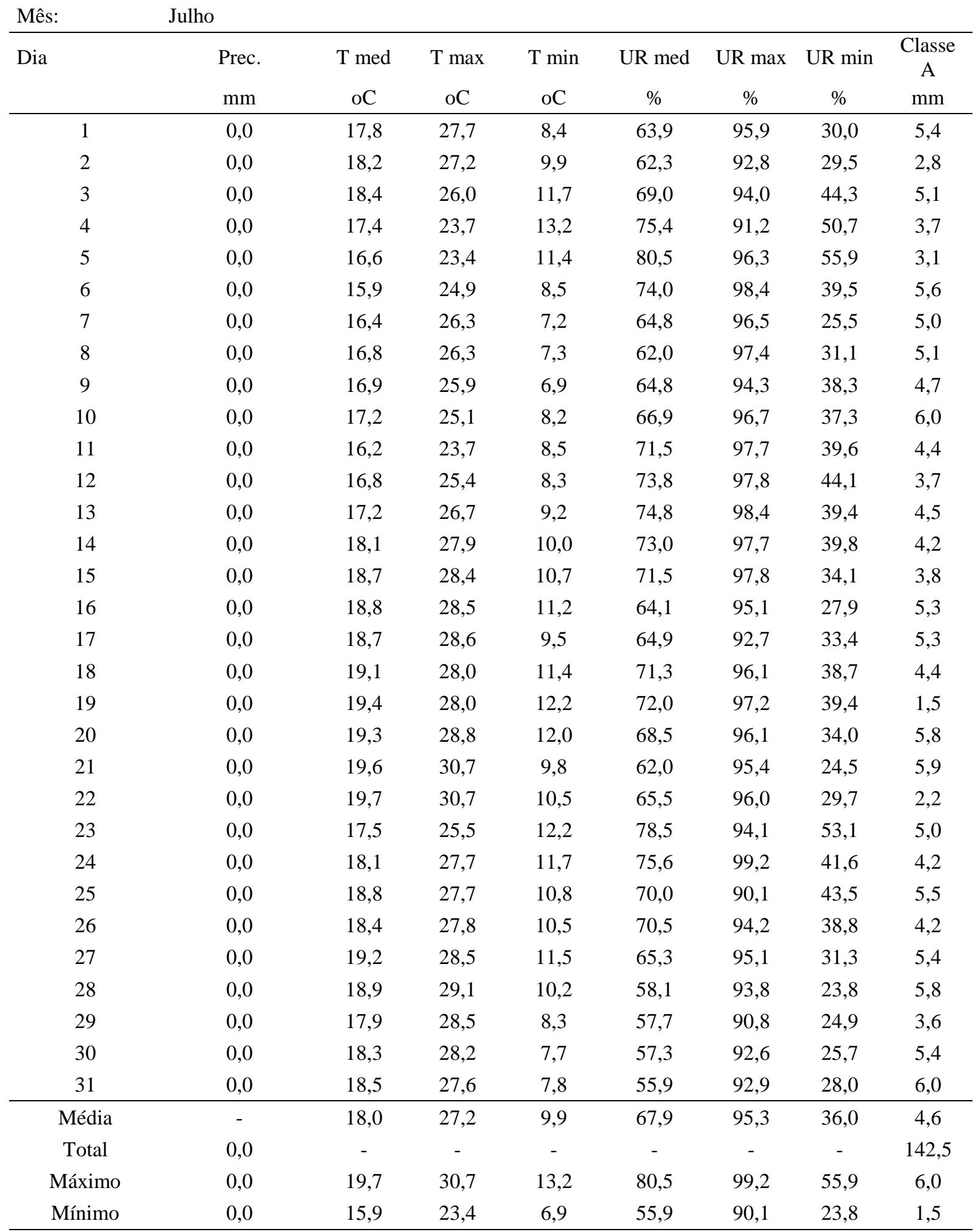


Mês: Agosto

\begin{tabular}{|c|c|c|c|c|c|c|c|c|}
\hline Dia & $\begin{array}{l}\text { Prec. } \\
\mathrm{mm}\end{array}$ & $\begin{array}{c}\mathrm{T} \text { med } \\
\text { oC }\end{array}$ & $\begin{array}{c}\mathrm{T} \max \\
\mathrm{oC}\end{array}$ & $\begin{array}{c}\mathrm{T} \text { min } \\
\mathrm{oC}\end{array}$ & $\begin{array}{c}\text { UR med } \\
\%\end{array}$ & $\begin{array}{c}\text { UR max } \\
\%\end{array}$ & $\begin{array}{c}\mathrm{UR} \min \\
\%\end{array}$ & $\begin{array}{c}\text { Classe } \\
\text { A } \\
\mathrm{mm}\end{array}$ \\
\hline 1 & 0,0 & 17,6 & 27,9 & 7,4 & 57,7 & 91,3 & 23,9 & 5,8 \\
\hline 2 & 0,0 & 17,0 & 28,7 & 5,2 & 55,4 & 95,0 & 17,3 & 5,7 \\
\hline 3 & 0,0 & 16,3 & 28,0 & 4,9 & 55,6 & 92,7 & 20,4 & 6,3 \\
\hline 4 & 0,0 & 16,8 & 28,9 & 5,1 & 56,9 & 91,8 & 24,8 & 5,2 \\
\hline 5 & 0,0 & 18,6 & 28,4 & 7,7 & 55,8 & 93,5 & 25,7 & 4,5 \\
\hline 6 & 0,0 & 18,0 & 27,7 & 8,6 & 56,3 & 87,9 & 29,5 & 6,3 \\
\hline 7 & 0,0 & 18,2 & 28,2 & 6,9 & 57,5 & 90,9 & 27,9 & 6,8 \\
\hline 8 & 0,0 & 17,4 & 27,3 & 7,2 & 61,8 & 93,6 & 31,0 & 6,3 \\
\hline 9 & 0,0 & 17,9 & 27,6 & 7,5 & 60,7 & 93,8 & 28,6 & 5,7 \\
\hline 10 & 0,0 & 17,6 & 28,6 & 7,9 & 58,4 & 91,2 & 24,1 & 5,9 \\
\hline 11 & 0,0 & 18,8 & 29,0 & 8,5 & 59,2 & 89,6 & 26,0 & 5,6 \\
\hline 12 & 0,0 & 20,6 & 29,7 & 9,2 & 53,4 & 91,5 & 25,2 & 4,0 \\
\hline 13 & 0,0 & 19,4 & 29,5 & 9,7 & 58,6 & 89,8 & 28,0 & 5,2 \\
\hline 14 & 0,0 & 20,5 & 30,9 & 10,9 & 58,0 & 90,2 & 27,3 & 6,4 \\
\hline 15 & 0,0 & 18,6 & 27,3 & 11,7 & 62,4 & 83,2 & 37,2 & 5,2 \\
\hline 16 & 0,0 & 19,9 & 29,0 & 10,1 & 61,5 & 91,8 & 32,5 & 5,5 \\
\hline 17 & 0,0 & 19,9 & 28,9 & 12,0 & 64,8 & 94,8 & 33,6 & 5,2 \\
\hline 18 & 0,0 & 20,4 & 27,3 & 15,0 & 58,4 & 87,0 & 33,7 & 6,6 \\
\hline 19 & 0,0 & 19,5 & 26,6 & 12,6 & 55,8 & 82,7 & 33,3 & 4,0 \\
\hline 20 & 0,0 & 18,5 & 26,3 & 9,6 & 55,3 & 91,8 & 23,8 & 6,4 \\
\hline 21 & 0,0 & 18,7 & 27,0 & 10,8 & 60,5 & 90,4 & 25,0 & 7,1 \\
\hline 22 & 0,0 & 19,0 & 29,7 & 9,5 & 63,2 & 94,7 & 27,3 & 6,4 \\
\hline 23 & 0,0 & 20,3 & 29,4 & 10,8 & 58,2 & 93,3 & 29,6 & 5,1 \\
\hline 24 & 0,0 & 19,9 & 29,3 & 9,7 & 54,3 & 92,0 & 27,8 & 7,9 \\
\hline 25 & 0,0 & 19,3 & 29,6 & 7,5 & 53,5 & 86,3 & 27,5 & 6,8 \\
\hline 26 & 0,0 & 20,2 & 31,2 & 9,6 & 54,3 & 91,6 & 21,8 & 5,5 \\
\hline 27 & 0,0 & 20,7 & 28,7 & 15,2 & 58,7 & 77,2 & 37,8 & 7,5 \\
\hline 28 & 0,0 & 18,8 & 28,5 & 11,3 & 46,5 & 76,2 & 21,4 & 7,0 \\
\hline 29 & 0,0 & 19,7 & 30,0 & 8,1 & 52,0 & 72,0 & 35,0 & 5,9 \\
\hline 30 & 0,0 & 21,0 & 28,5 & 13,3 & 60,5 & 91,7 & 34,3 & 3,8 \\
\hline 31 & 0,0 & 19,0 & 29,4 & 9,0 & 58,3 & 94,5 & 23,1 & 6,6 \\
\hline Média & - & 19,0 & 28,6 & 9,4 & 57,5 & 89,5 & 27,9 & 5,9 \\
\hline Total & 0,0 & - & - & - & - & - & - & 182,2 \\
\hline Máximo & 0,0 & 21,0 & 31,2 & 15,2 & 64,8 & 95,0 & 37,8 & 7,9 \\
\hline Mínimo & 0,0 & 16,3 & 26,3 & 4,9 & 46,5 & 72,0 & 17,3 & 3,8 \\
\hline
\end{tabular}




\begin{tabular}{|c|c|c|c|c|c|c|c|c|}
\hline Dia & $\begin{array}{l}\text { Prec. } \\
\mathrm{mm}\end{array}$ & $\begin{array}{c}\text { T med } \\
\text { oC }\end{array}$ & $\begin{array}{c}\mathrm{T} \max \\
\mathrm{oC}\end{array}$ & $\begin{array}{c}\mathrm{T} \min \\
\mathrm{oC}\end{array}$ & $\begin{array}{c}\text { UR med } \\
\%\end{array}$ & $\begin{array}{c}\text { UR max } \\
\%\end{array}$ & $\begin{array}{c}\text { UR min } \\
\%\end{array}$ & $\begin{array}{c}\text { Classe } \\
\text { A } \\
\mathrm{mm} \\
\end{array}$ \\
\hline 1 & 0,0 & 18,9 & 29,3 & 8,4 & 53,7 & 88,9 & 23,7 & 7,2 \\
\hline 2 & 0,0 & 19,3 & 30,1 & 8,8 & 57,9 & 92,2 & 27,6 & 4,5 \\
\hline 3 & 0,0 & 19,8 & 28,7 & 10,4 & 61,4 & 91,9 & 35,1 & 4,6 \\
\hline 4 & 0,0 & 20,0 & 26,2 & 14,5 & 68,2 & 84,9 & 44,1 & 3,5 \\
\hline 5 & 0,0 & 18,4 & 25,0 & 14,4 & 78,4 & 92,7 & 53,0 & 3,4 \\
\hline 6 & 0,0 & 19,8 & 28,2 & 14,2 & 71,8 & 96,3 & 41,7 & 2,3 \\
\hline 7 & 0,0 & 20,8 & 28,4 & 13,7 & 59,6 & 88,8 & 33,3 & 5,8 \\
\hline 8 & 0,0 & 20,6 & 29,1 & 10,7 & 55,8 & 93,4 & 27,7 & 7,2 \\
\hline 9 & 0,0 & 20,4 & 28,4 & 12,7 & 53,6 & 81,4 & 29,8 & 4,9 \\
\hline 10 & 0,0 & 20,9 & 28,0 & 15,9 & 49,4 & 63,5 & 29,3 & 7,7 \\
\hline 11 & 0,0 & 19,0 & 27,7 & 8,3 & 58,0 & 90,1 & 30,4 & 6,8 \\
\hline 12 & 0,0 & 20,1 & 27,8 & 11,6 & 47,2 & 74,3 & 23,7 & 8,2 \\
\hline 13 & 0,0 & 19,4 & 28,0 & 9,6 & 56,0 & 90,4 & 28,0 & 7,2 \\
\hline 14 & 0,0 & 20,0 & 28,2 & 10,0 & 57,2 & 92,5 & 31,3 & 5,5 \\
\hline 15 & 0,0 & 21,3 & 31,9 & 10,8 & 55,8 & 90,5 & 25,6 & 6,4 \\
\hline 16 & 0,0 & 22,6 & 32,7 & 12,9 & 56,7 & 87,7 & 28,1 & 4,1 \\
\hline 17 & 0,2 & 23,9 & 33,0 & 14,2 & 57,4 & 88,1 & 30,8 & 8,2 \\
\hline 18 & 5,4 & 19,6 & 25,7 & 16,2 & 85,1 & 97,2 & 56,7 & 3,1 \\
\hline 19 & 0,0 & 21,9 & 29,1 & 14,9 & 70,9 & 98,5 & 40,1 & 5,7 \\
\hline 20 & 0,0 & 22,2 & 29,7 & 15,5 & 62,4 & 84,3 & 35,4 & 8,2 \\
\hline 21 & 0,0 & 22,0 & 33,2 & 12,2 & 61,5 & 92,8 & 29,6 & 5,7 \\
\hline 22 & 0,0 & 23,7 & 34,1 & 13,3 & 53,8 & 89,4 & 21,2 & 7,8 \\
\hline 23 & 0,0 & 25,7 & 34,0 & 15,5 & 50,3 & 87,0 & 25,7 & 5,1 \\
\hline 24 & 3,2 & 22,8 & 31,8 & 17,9 & 69,0 & 93,9 & 40,0 & 6,3 \\
\hline 25 & 0,2 & 22,0 & 30,3 & 15,7 & 68,5 & 94,7 & 31,6 & 5,3 \\
\hline 26 & 0,0 & 23,2 & 32,7 & 14,3 & 48,6 & 75,1 & 22,7 & 7,5 \\
\hline 27 & 0,0 & 24,6 & 33,3 & 15,1 & 48,2 & 73,5 & 28,5 & 7,9 \\
\hline 28 & 4,6 & 22,6 & 31,0 & 18,0 & 71,7 & 95,7 & 40,9 & 8,3 \\
\hline 29 & 13,2 & 20,4 & 31,0 & 15,3 & 82,7 & 98,2 & 37,9 & 4,6 \\
\hline 30 & 0,4 & 22,1 & 30,5 & 15,5 & 72,9 & 98,5 & 38,9 & 4,0 \\
\hline \multicolumn{9}{|l|}{31} \\
\hline Média & - & 21,3 & 29,9 & 13,4 & 61,5 & 88,9 & 33,1 & 5,9 \\
\hline Total & 27,2 & - & - & - & - & - & - & 176,9 \\
\hline Máximo & 13,2 & 25,7 & 34,1 & 18,0 & 85,1 & 98,5 & 56,7 & 8,3 \\
\hline Mínimo & 0,0 & 18,4 & 25,0 & 8,3 & 47,2 & 63,5 & 21,2 & 2,3 \\
\hline
\end{tabular}




\begin{tabular}{|c|c|c|c|c|c|c|c|c|}
\hline Dia & $\begin{array}{l}\text { Prec. } \\
\mathrm{mm}\end{array}$ & $\begin{array}{c}\text { T med } \\
\text { oC }\end{array}$ & $\begin{array}{c}\mathrm{T} \max \\
\mathrm{oC}\end{array}$ & $\begin{array}{l}\mathrm{T} \min \\
\mathrm{oC}\end{array}$ & $\begin{array}{c}\text { UR med } \\
\%\end{array}$ & $\begin{array}{c}\text { UR max } \\
\%\end{array}$ & $\begin{array}{c}\text { UR min } \\
\%\end{array}$ & $\begin{array}{c}\text { Classe } \\
\text { A } \\
\mathrm{mm}\end{array}$ \\
\hline 1 & 7,4 & 20,0 & 24,1 & 17,9 & 88,2 & 97,2 & 69,5 & 2,9 \\
\hline 2 & 0,2 & 21,8 & 30,5 & 17,2 & 78,4 & 98,0 & 35,3 & 3,5 \\
\hline 3 & 3,8 & 21,0 & 27,8 & 17,4 & 81,3 & 96,9 & 49,5 & 3,2 \\
\hline 4 & 22,2 & 21,3 & 29,3 & 17,0 & 83,2 & 97,9 & 46,9 & 8,4 \\
\hline 5 & 0,4 & 21,1 & 28,0 & 17,1 & 81,2 & 98,9 & 47,1 & 1,5 \\
\hline 6 & 4,4 & 20,4 & 28,7 & 15,8 & 82,7 & 98,3 & 46,8 & 6,3 \\
\hline 7 & 5,2 & 19,7 & 27,4 & 15,6 & 89,6 & 98,4 & 53,4 & 3,8 \\
\hline 8 & 28,2 & 20,4 & 26,6 & 16,5 & 82,4 & 98,8 & 54,8 & 10,4 \\
\hline 9 & 0,0 & 18,5 & 24,6 & 16,1 & 86,2 & 98,6 & 61,5 & 3,1 \\
\hline 10 & 0,0 & 19,4 & 26,4 & 14,1 & 72,8 & 95,1 & 43,0 & 6,4 \\
\hline 11 & 0,0 & 20,0 & 27,9 & 11,4 & 68,2 & 98,3 & 39,6 & 7,1 \\
\hline 12 & 0,0 & 20,3 & 28,6 & 11,4 & 64,6 & 96,1 & 35,6 & 6,8 \\
\hline 13 & 0,0 & 20,5 & 29,6 & 10,8 & 60,6 & 94,6 & 28,8 & 6,8 \\
\hline 14 & 0,0 & 20,9 & 30,5 & 11,2 & 60,7 & 94,9 & 25,5 & 4,6 \\
\hline 15 & 0,0 & 21,7 & 31,4 & 10,6 & 56,2 & 92,4 & 27,1 & 6,9 \\
\hline 16 & 0,0 & 23,4 & 32,1 & 14,8 & 57,7 & 89,6 & 29,2 & 7,5 \\
\hline 17 & 2,2 & 19,8 & 22,8 & 16,9 & 84,7 & 97,0 & 58,0 & 2,2 \\
\hline 18 & 0,0 & 19,9 & 25,6 & 15,0 & 84,7 & 97,6 & 62,3 & 1,6 \\
\hline 19 & 0,0 & 21,5 & 29,5 & 16,5 & 79,4 & 97,8 & 46,3 & 4,4 \\
\hline 20 & 0,0 & 21,3 & 28,1 & 16,1 & 79,0 & 97,3 & 51,8 & 4,5 \\
\hline 21 & 4,6 & 21,4 & 31,3 & 14,2 & 77,4 & 98,0 & 35,9 & 6,3 \\
\hline 22 & 18,8 & 21,4 & 29,5 & 15,0 & 78,1 & 98,4 & 41,4 & 1,1 \\
\hline 23 & 0,0 & 22,5 & 30,3 & 15,6 & 67,3 & 98,7 & 33,6 & 5,3 \\
\hline 24 & 0,0 & 22,3 & 31,1 & 12,0 & 57,5 & 92,6 & 27,4 & 6,4 \\
\hline 25 & 0,0 & 22,4 & 31,3 & 12,2 & 56,4 & 94,5 & 26,1 & 7,1 \\
\hline 26 & 0,0 & 23,0 & 31,8 & 13,0 & 54,8 & 89,0 & 26,8 & 7,8 \\
\hline 27 & 0,0 & 23,6 & 32,6 & 13,7 & 58,3 & 92,3 & 29,2 & 7,2 \\
\hline 28 & 8,0 & 22,7 & 31,8 & 18,2 & 75,2 & 98,1 & 38,4 & 5,7 \\
\hline 29 & 5,8 & 21,0 & 25,1 & 18,8 & 87,8 & 98,8 & 58,0 & 0,3 \\
\hline 30 & 37,0 & 20,5 & 28,6 & 16,2 & 84,4 & 99,2 & 40,2 & 3,8 \\
\hline 31 & 12,6 & 20,4 & 26,5 & 16,2 & 84,2 & 99,2 & 51,2 & 3,0 \\
\hline Média & - & 21,1 & 28,7 & 15,0 & 74,3 & 96,5 & 42,6 & 5,0 \\
\hline Total & 160,8 & - & - & - & - & - & - & 155,7 \\
\hline Máximo & 37,0 & 23,6 & 32,6 & 18,8 & 89,6 & 99,2 & 69,5 & 10,4 \\
\hline Mínimo & 0,0 & 18,5 & 22,8 & 10,6 & 54,8 & 89,0 & 25,5 & 0,3 \\
\hline
\end{tabular}




\begin{tabular}{|c|c|c|c|c|c|c|c|c|}
\hline Mês: & Novembro & & & & & & & \\
\hline Dia & $\begin{array}{l}\text { Prec. } \\
\text { mm }\end{array}$ & $\begin{array}{c}\text { T med } \\
\text { oC }\end{array}$ & $\begin{array}{c}\mathrm{T} \max \\
\mathrm{oC}\end{array}$ & $\begin{array}{l}\mathrm{T} \min \\
\mathrm{oC}\end{array}$ & $\begin{array}{c}\text { UR med } \\
\%\end{array}$ & $\begin{array}{c}\text { UR max } \\
\%\end{array}$ & $\begin{array}{c}\text { UR min } \\
\%\end{array}$ & $\begin{array}{c}\text { Classe } \\
\text { A } \\
\text { mm }\end{array}$ \\
\hline 1 & 0,0 & 21,7 & 28,8 & 14,9 & 77,4 & 97,9 & 48,5 & 6,2 \\
\hline 2 & 0,0 & 22,3 & 28,8 & 17,4 & 72,5 & 93,2 & 47,0 & 6,5 \\
\hline 3 & 0,2 & 21,4 & 29,5 & 13,9 & 71,2 & 97,5 & 39,8 & 5,7 \\
\hline 4 & 0,0 & 22,1 & 29,1 & 13,5 & 67,6 & 96,8 & 39,0 & 0,4 \\
\hline 5 & 18,6 & 18,5 & 21,3 & 16,8 & 92,4 & 98,3 & 78,2 & 4,2 \\
\hline 6 & 17,0 & 18,7 & 23,9 & 17,3 & 92,4 & 98,9 & 62,7 & 4,1 \\
\hline 7 & 10,2 & 19,9 & 25,6 & 16,5 & 85,5 & 98,9 & 55,9 & 4,9 \\
\hline 8 & 0,2 & 20,8 & 27,1 & 17,0 & 86,2 & 98,9 & 57,5 & 1,1 \\
\hline 9 & 7,4 & 22,6 & 30,3 & 15,7 & 77,1 & 98,8 & 44,3 & 7,7 \\
\hline 10 & 0,2 & 23,4 & 30,8 & 18,2 & 79,0 & 98,9 & 45,4 & 2,8 \\
\hline 11 & 0,2 & 22,4 & 31,0 & 15,7 & 78,4 & 98,6 & 41,7 & 4,8 \\
\hline 12 & 7,0 & 21,9 & 29,6 & 16,5 & 81,4 & 98,4 & 50,0 & 5,9 \\
\hline 13 & 15,4 & 19,9 & 26,1 & 16,5 & 92,0 & 98,9 & 70,1 & 0,8 \\
\hline 14 & 0,0 & 21,4 & 25,6 & 18,2 & 81,9 & 93,2 & 65,6 & 2,4 \\
\hline 15 & 0,0 & 21,7 & 28,5 & 16,5 & 76,4 & 97,7 & 43,8 & 6,5 \\
\hline 16 & 0,0 & 21,8 & 29,3 & 15,5 & 71,1 & 97,6 & 41,3 & 6,9 \\
\hline 17 & 2,2 & 21,4 & 29,6 & 16,9 & 75,9 & 95,1 & 40,6 & 5,6 \\
\hline 18 & 10,6 & 20,4 & 27,5 & 16,8 & 83,1 & 98,9 & 54,6 & 7,7 \\
\hline 19 & 0,2 & 21,6 & 29,3 & 13,3 & 72,4 & 99,3 & 41,8 & 5,3 \\
\hline 20 & 0,0 & 22,4 & 30,3 & 13,2 & 65,0 & 96,7 & 33,2 & 7,3 \\
\hline 21 & 0,0 & 22,0 & 30,7 & 13,4 & 66,0 & 97,2 & 30,0 & 7,6 \\
\hline 22 & 0,0 & 22,3 & 30,0 & 15,5 & 70,4 & 93,3 & 38,0 & 6,6 \\
\hline 23 & 18,0 & 20,5 & 28,9 & 17,4 & 85,2 & 98,9 & 51,4 & 6,9 \\
\hline 24 & 17,8 & 19,2 & 23,1 & 17,0 & 91,8 & 98,8 & 71,9 & 1,7 \\
\hline 25 & 17,8 & 20,1 & 25,6 & 17,3 & 89,8 & 99,0 & 53,7 & 4,0 \\
\hline 26 & 5,4 & 21,0 & 27,4 & 17,4 & 84,1 & 99,1 & 54,3 & 4,8 \\
\hline 27 & 28,6 & 21,7 & 28,2 & 17,7 & 84,3 & 99,3 & 50,7 & 3,9 \\
\hline 28 & 22,8 & 20,8 & 26,3 & 17,4 & 89,9 & 99,2 & 63,4 & 3,1 \\
\hline 29 & 0,2 & 21,6 & 28,7 & 14,9 & 82,2 & 99,3 & 50,0 & 4,7 \\
\hline 30 & 7,2 & 20,4 & 26,7 & 17,3 & 89,0 & 98,2 & 61,2 & 6,6 \\
\hline \multicolumn{9}{|l|}{31} \\
\hline Média & - & 21,2 & 27,9 & 16,2 & 80,4 & 97,8 & 50,9 & 4,9 \\
\hline Total & 207,2 & - & - & - & - & - & - & 146,7 \\
\hline Máximo & 28,6 & 23,4 & 31,0 & 18,2 & 92,4 & 99,3 & 78,2 & 7,7 \\
\hline Mínimo & 0,0 & 18,5 & 21,3 & 13,2 & 65,0 & 93,2 & 30,0 & 0,4 \\
\hline
\end{tabular}




\begin{tabular}{|c|c|c|c|c|c|c|c|c|}
\hline Dia & $\begin{array}{l}\text { Prec. } \\
\mathrm{mm}\end{array}$ & $\begin{array}{c}\text { T med } \\
\text { oC }\end{array}$ & $\begin{array}{c}\text { T max } \\
\text { oC }\end{array}$ & $\begin{array}{l}\mathrm{T} \min \\
\mathrm{oC}\end{array}$ & $\begin{array}{c}\text { UR med } \\
\%\end{array}$ & $\begin{array}{c}\text { UR max } \\
\%\end{array}$ & $\begin{array}{c}\text { UR min } \\
\%\end{array}$ & $\begin{array}{c}\text { Classe } \\
\text { A } \\
\mathrm{mm}\end{array}$ \\
\hline 1 & 0,6 & 21,0 & 27,8 & 17,0 & 86,6 & 99,3 & 53,7 & 0,6 \\
\hline 2 & 25,6 & 21,3 & 29,0 & 17,0 & 84,6 & 98,6 & 49,0 & 7,5 \\
\hline 3 & 9,4 & 20,8 & 28,1 & 15,4 & 86,9 & 98,9 & 52,3 & 3,6 \\
\hline 4 & 0,2 & 22,5 & 31,1 & 15,6 & 76,9 & 99,0 & 34,2 & 5,1 \\
\hline 5 & 3,8 & 22,1 & 30,6 & 16,7 & 82,1 & 98,6 & 45,9 & 7,1 \\
\hline 6 & 29,0 & 20,0 & 25,8 & 17,3 & 88,8 & 98,9 & 60,2 & 7,3 \\
\hline 7 & 1,0 & 21,1 & 27,7 & 16,6 & 83,5 & 98,6 & 55,1 & 2,9 \\
\hline 8 & 13,4 & 21,2 & 28,3 & 17,8 & 86,3 & 98,5 & 52,8 & 7,7 \\
\hline 9 & 5,6 & 20,5 & 26,6 & 18,0 & 91,0 & 99,2 & 62,4 & 2,8 \\
\hline 10 & 0,6 & 21,4 & 27,8 & 17,5 & 82,8 & 98,8 & 54,6 & 2,9 \\
\hline 11 & 1,4 & 22,7 & 28,1 & 18,2 & 75,9 & 95,2 & 52,8 & 8,0 \\
\hline 12 & 6,8 & 21,1 & 27,1 & 18,7 & 87,6 & 98,6 & 60,9 & 5,5 \\
\hline 13 & 1,4 & 21,0 & 26,1 & 18,1 & 85,1 & 96,1 & 57,0 & 1,7 \\
\hline 14 & 0,2 & 21,7 & 28,4 & 18,1 & 83,2 & 97,8 & 52,2 & 4,6 \\
\hline 15 & 9,2 & 22,0 & 29,0 & 18,0 & 83,9 & 99,2 & 52,6 & 5,6 \\
\hline 16 & 7,0 & 21,6 & 25,6 & 19,5 & 87,9 & 98,5 & 67,5 & 6,8 \\
\hline 17 & 4,2 & 22,4 & 28,1 & 18,3 & 83,2 & 98,3 & 56,4 & 4,3 \\
\hline 18 & 11,6 & 21,5 & 26,7 & 18,3 & 86,8 & 98,9 & 60,9 & 3,8 \\
\hline 19 & 0,4 & 21,0 & 27,5 & 17,0 & 86,7 & 98,6 & 56,8 & 0,5 \\
\hline 20 & 19,8 & 20,9 & 27,0 & 18,0 & 89,8 & 98,9 & 57,2 & 7,5 \\
\hline 21 & 21,4 & 20,0 & 26,4 & 17,8 & 92,5 & 98,8 & 63,2 & 8,3 \\
\hline 22 & 33,4 & 20,0 & 26,1 & 17,6 & 93,0 & 99,0 & 67,1 & 4,1 \\
\hline 23 & 3,0 & 20,6 & 26,4 & 17,8 & 87,8 & 98,9 & 62,2 & 4,0 \\
\hline 24 & 2,6 & 20,0 & 24,9 & 17,6 & 86,5 & 97,9 & 65,6 & 2,6 \\
\hline 25 & 0,2 & 22,1 & 29,3 & 16,8 & 80,4 & 98,6 & 50,5 & 6,8 \\
\hline 26 & 0,0 & 23,3 & 30,5 & 16,0 & 76,7 & 99,0 & 46,0 & 4,2 \\
\hline 27 & 64,0 & 21,1 & 26,9 & 17,0 & 85,0 & 98,7 & 54,5 & 3,5 \\
\hline 28 & 3,4 & 20,3 & 26,4 & 15,1 & 84,4 & 98,7 & 58,3 & 4,8 \\
\hline 29 & 0,0 & 22,1 & 28,5 & 17,9 & 79,3 & 97,4 & 51,3 & 5,2 \\
\hline 30 & 17,6 & 20,8 & 28,4 & 16,9 & 88,0 & 98,8 & 50,6 & 4,0 \\
\hline 31 & 0,6 & 21,8 & 26,9 & 17,9 & 85,0 & 98,9 & 58,0 & 0,3 \\
\hline Média & - & 21,3 & 27,6 & 17,4 & 85,1 & 98,5 & 55,5 & 4,6 \\
\hline Total & 297,4 & - & - & - & - & - & - & 143,9 \\
\hline Máximo & 64,0 & 23,3 & 31,1 & 19,5 & 93,0 & 99,3 & 67,5 & 8,3 \\
\hline Mínimo & 0,0 & 20,0 & 24,9 & 15,1 & 75,9 & 95,2 & 34,2 & 0,3 \\
\hline
\end{tabular}


Ano: 2014

\begin{tabular}{|c|c|c|c|c|c|c|c|c|}
\hline Mês: & Janeiro & & & & & & & \\
\hline Dia & $\begin{array}{c}\text { Prec. } \\
\mathrm{mm}\end{array}$ & $\begin{array}{c}\text { T med } \\
\text { oC }\end{array}$ & $\begin{array}{c}\mathrm{T} \max \\
\mathrm{oC}\end{array}$ & $\begin{array}{c}\mathrm{T} \min \\
\mathrm{oC}\end{array}$ & $\begin{array}{c}\text { UR med } \\
\%\end{array}$ & $\begin{array}{c}\text { UR max } \\
\%\end{array}$ & $\begin{array}{c}\text { UR min } \\
\%\end{array}$ & $\begin{array}{c}\text { Classe A } \\
\mathrm{mm}\end{array}$ \\
\hline 1 & 9,8 & 21,9 & 30,3 & 16,1 & 82,5 & 98,9 & 47,3 & 4,2 \\
\hline 2 & 0,0 & 22,8 & 30,7 & 15,6 & 76,5 & 98,7 & 41,5 & 5,8 \\
\hline 3 & 0,0 & 22,8 & 30,7 & 15,5 & 67,5 & 98,5 & 28,3 & 7,7 \\
\hline 4 & 0,0 & 22,5 & 31,0 & 13,0 & 63,5 & 96,8 & 29,5 & 7,5 \\
\hline 5 & 0,0 & 22,3 & 30,2 & 12,7 & 64,0 & 96,8 & 31,9 & 6,4 \\
\hline 6 & 0,0 & 21,3 & 29,6 & 13,1 & 70,7 & 95,8 & 39,8 & 3,7 \\
\hline 7 & 0,0 & 21,5 & 29,4 & 13,9 & 71,9 & 98,5 & 39,4 & 6,7 \\
\hline 8 & 0,0 & 20,9 & 29,2 & 12,5 & 68,6 & 97,8 & 36,4 & 7,3 \\
\hline 9 & 0,0 & 21,6 & 29,4 & 14,0 & 67,4 & 97,9 & 34,9 & 4,7 \\
\hline 10 & 0,0 & 21,5 & 29,2 & 14,3 & 71,8 & 97,0 & 40,4 & 7,2 \\
\hline 11 & 0,0 & 21,4 & 29,7 & 14,4 & 73,7 & 96,9 & 38,7 & 6,0 \\
\hline 12 & 0,0 & 22,1 & 30,2 & 15,5 & 73,7 & 96,9 & 43,9 & 5,5 \\
\hline 13 & 0,0 & 22,8 & 30,8 & 15,4 & 70,1 & 97,1 & 34,4 & 3,9 \\
\hline 14 & 0,0 & 22,0 & 30,2 & 13,8 & 70,2 & 97,7 & 39,8 & 6,9 \\
\hline 15 & 15,4 & 20,5 & 30,0 & 14,2 & 78,0 & 97,7 & 39,4 & 4,1 \\
\hline 16 & 0,2 & 21,2 & 28,9 & 16,3 & 77,1 & 95,8 & 45,5 & 2,1 \\
\hline 17 & 0,4 & 20,8 & 29,0 & 16,8 & 83,9 & 97,8 & 46,6 & 3,8 \\
\hline 18 & 0,6 & 20,6 & 27,2 & 17,1 & 86,7 & 98,0 & 55,3 & 3,8 \\
\hline 19 & 21,0 & 20,0 & 26,0 & 17,7 & 90,9 & 98,8 & 62,1 & 1,7 \\
\hline 20 & 8,2 & 20,4 & 24,4 & 17,0 & 87,6 & 99,1 & 61,2 & 2,5 \\
\hline 21 & 11,2 & 20,8 & 27,4 & 17,7 & 86,6 & 98,5 & 55,8 & 3,7 \\
\hline 22 & 12,8 & 19,9 & 27,1 & 16,9 & 89,2 & 98,8 & 58,2 & 2,9 \\
\hline 23 & 0,0 & 20,7 & 29,2 & 16,3 & 84,2 & 99,0 & 47,9 & 2,7 \\
\hline 24 & 15,6 & 18,6 & 27,4 & 14,3 & 88,4 & 99,1 & 54,3 & 4,4 \\
\hline 25 & 0,0 & 19,7 & 26,2 & 13,7 & 81,6 & 98,5 & 52,4 & 1,1 \\
\hline 26 & 4,6 & 19,7 & 27,8 & 13,2 & 82,0 & 97,9 & 49,3 & 4,1 \\
\hline 27 & 0,0 & 20,1 & 27,4 & 15,3 & 81,2 & 98,5 & 52,2 & 3,0 \\
\hline 28 & 1,8 & 20,5 & 28,0 & 14,7 & 77,2 & 98,1 & 43,6 & 6,9 \\
\hline 29 & 0,0 & 21,4 & 28,6 & 14,1 & 68,7 & 96,6 & 43,7 & 6,9 \\
\hline 30 & 0,0 & 21,8 & 29,3 & 15,1 & 73,4 & 96,0 & 49,7 & 5,6 \\
\hline 31 & 0,0 & 21,7 & 29,4 & 13,7 & 70,0 & 97,6 & 38,7 & 7,3 \\
\hline Média & - & 21,1 & 28,8 & 15,0 & 76,7 & 97,8 & 44,6 & 4,8 \\
\hline Total & 101,6 & - & - & - & - & - & - & 150,2 \\
\hline Máximo & 21,0 & 22,8 & 31,0 & 17,7 & 90,9 & 99,1 & 62,1 & 7,7 \\
\hline Mínimo & 0,0 & 18,6 & 24,4 & 12,5 & 63,5 & 95,8 & 28,3 & 1,1 \\
\hline
\end{tabular}




\begin{tabular}{|c|c|c|c|c|c|c|c|c|}
\hline Mês: & Fevereiro & & & & & & & \\
\hline Dia & $\begin{array}{c}\text { Prec. } \\
\mathrm{mm}\end{array}$ & $\begin{array}{l}\text { T med } \\
\mathrm{oC}\end{array}$ & $\begin{array}{c}\mathrm{T} \max \\
\mathrm{oC}\end{array}$ & $\begin{array}{c}\mathrm{T} \min \\
\mathrm{oC}\end{array}$ & $\begin{array}{c}\text { UR med } \\
\%\end{array}$ & $\begin{array}{c}\text { UR max } \\
\%\end{array}$ & $\begin{array}{c}\text { UR min } \\
\%\end{array}$ & $\begin{array}{c}\text { Classe A } \\
\mathrm{mm}\end{array}$ \\
\hline 1 & 0,0 & 21,2 & 28,7 & 12,9 & 66,7 & 97,4 & 38,0 & 7,0 \\
\hline 2 & 0,0 & 20,7 & 29,3 & 11,9 & 67,8 & 96,5 & 41,0 & 6,0 \\
\hline 3 & 0,0 & 21,4 & 29,5 & 12,7 & 66,3 & 95,6 & 37,5 & 4,3 \\
\hline 4 & 0,0 & 21,3 & 28,2 & 12,9 & 63,7 & 96,0 & 32,8 & 6,5 \\
\hline 5 & 0,0 & 22,0 & 31,1 & 14,0 & 67,1 & 91,8 & 35,3 & 5,9 \\
\hline 6 & 0,0 & 21,9 & 29,2 & 13,4 & 69,0 & 97,6 & 43,2 & 7,9 \\
\hline 7 & 0,0 & 21,8 & 30,3 & 12,8 & 65,7 & 94,6 & 36,1 & 3,9 \\
\hline 8 & 0,0 & 21,9 & 30,8 & 13,7 & 68,5 & 96,7 & 28,8 & 6,5 \\
\hline 9 & 0,0 & 21,6 & 29,5 & 14,3 & 72,1 & 96,7 & 42,2 & 5,9 \\
\hline 10 & 0,0 & 21,7 & 29,9 & 15,7 & 70,6 & 96,3 & 33,4 & 6,3 \\
\hline 11 & 0,0 & 22,3 & 29,0 & 16,4 & 69,1 & 93,9 & 39,9 & 5,6 \\
\hline 12 & 0,4 & 20,2 & 29,0 & 13,8 & 80,1 & 97,3 & 47,2 & 3,8 \\
\hline 13 & 15,0 & 19,7 & 27,2 & 16,6 & 90,2 & 98,2 & 55,0 & 5,5 \\
\hline 14 & 0,4 & 20,5 & 28,3 & 16,6 & 85,3 & 98,8 & 49,8 & 0,5 \\
\hline 15 & 29,4 & 20,3 & 27,4 & 17,9 & 89,4 & 99,0 & 56,7 & 4,6 \\
\hline 16 & 0,0 & 20,7 & 24,9 & 18,2 & 89,6 & 99,4 & 68,3 & 0,0 \\
\hline 17 & 14,6 & 21,5 & 27,8 & 17,7 & 84,0 & 99,3 & 53,5 & 4,4 \\
\hline 18 & 24,4 & 20,2 & 26,0 & 18,1 & 92,1 & 99,2 & 62,4 & 4,5 \\
\hline 19 & 0,2 & 20,6 & 27,1 & 17,7 & 87,6 & 98,4 & 53,8 & 1,6 \\
\hline 20 & 0,2 & 20,4 & 25,4 & 16,9 & 87,5 & 98,5 & 64,3 & 3,4 \\
\hline 21 & 28,0 & 19,8 & 25,9 & 17,0 & 92,1 & 98,7 & 61,4 & 6,4 \\
\hline 22 & 1,8 & 20,1 & 25,5 & 17,3 & 87,3 & 98,7 & 65,9 & 1,8 \\
\hline 23 & 4,2 & 20,4 & 27,2 & 16,5 & 86,5 & 98,5 & 57,2 & 3,1 \\
\hline 24 & 5,6 & 21,5 & 29,0 & 15,2 & 78,5 & 98,0 & 49,1 & 8,1 \\
\hline 25 & 1,6 & 20,7 & 27,2 & 17,0 & 84,3 & 98,7 & 53,7 & 0,5 \\
\hline 26 & 0,0 & 21,9 & 28,6 & 15,7 & 75,7 & 98,4 & 46,7 & 6,3 \\
\hline 27 & 0,0 & 21,2 & 30,5 & 12,9 & 71,9 & 98,6 & 33,6 & 6,5 \\
\hline 28 & 5,6 & 20,2 & 26,0 & 14,8 & 86,7 & 99,0 & 59,7 & 4,5 \\
\hline \multicolumn{9}{|l|}{29} \\
\hline \multicolumn{9}{|l|}{30} \\
\hline \multicolumn{9}{|l|}{31} \\
\hline Média & - & 21,0 & 28,2 & 15,4 & 78,4 & 97,5 & 48,1 & 4,7 \\
\hline Total & 131,4 & - & - & - & - & - & - & 131,3 \\
\hline Máximo & 29,4 & 22,3 & 31,1 & 18,2 & 92,1 & 99,4 & 68,3 & 8,1 \\
\hline Mínimo & 0,0 & 19,7 & 24,9 & 11,9 & 63,7 & 91,8 & 28,8 & 0,0 \\
\hline
\end{tabular}




\begin{tabular}{|c|c|c|c|c|c|c|c|c|}
\hline Mês: & Março & & & & & & & \\
\hline Dia & $\begin{array}{c}\text { Prec. } \\
\mathrm{mm}\end{array}$ & $\begin{array}{c}\text { T med } \\
\text { oC }\end{array}$ & $\begin{array}{c}\mathrm{T} \max \\
\mathrm{oC}\end{array}$ & $\begin{array}{c}\mathrm{T} \text { min } \\
\mathrm{oC}\end{array}$ & $\begin{array}{c}\text { UR med } \\
\%\end{array}$ & $\begin{array}{c}\text { UR max } \\
\%\end{array}$ & $\begin{array}{c}\text { UR min } \\
\%\end{array}$ & $\begin{array}{c}\text { Classe A } \\
\mathrm{mm}\end{array}$ \\
\hline 1 & 35,2 & 19,9 & 27,5 & 15,8 & 87,4 & 99,3 & 49,1 & 5,0 \\
\hline 2 & 2,0 & 20,9 & 28,4 & 15,0 & 84,3 & 99,6 & 52,6 & 2,4 \\
\hline 3 & 33,0 & 20,4 & 26,6 & 16,9 & 89,1 & 99,3 & 60,6 & 3,8 \\
\hline 4 & 4,6 & 21,8 & 27,0 & 18,2 & 84,3 & 99,1 & 56,9 & 3,3 \\
\hline 5 & 12,6 & 21,6 & 27,3 & 19,1 & 88,7 & 98,3 & 62,9 & 5,2 \\
\hline 6 & 4,4 & 20,7 & 26,4 & 17,7 & 90,6 & 98,8 & 61,4 & 4,9 \\
\hline 7 & 39,6 & 20,3 & 26,3 & 18,2 & 91,1 & 99,0 & 63,0 & 6,0 \\
\hline 8 & 7,4 & 21,0 & 27,9 & 17,5 & 88,6 & 99,2 & 58,4 & 4,5 \\
\hline 9 & 16,0 & 20,7 & 27,5 & 15,9 & 88,2 & 99,1 & 60,1 & 4,2 \\
\hline 10 & 0,8 & 21,2 & 28,4 & 15,2 & 83,0 & 99,1 & 52,3 & 4,8 \\
\hline 11 & 0,0 & 21,2 & 28,0 & 15,0 & 80,8 & 98,8 & 52,8 & 5,6 \\
\hline 12 & 16,0 & 22,1 & 28,2 & 16,6 & 77,3 & 99,3 & 46,0 & 5,4 \\
\hline 13 & 0,0 & 20,9 & 29,3 & 12,5 & 76,2 & 98,3 & 41,8 & 5,5 \\
\hline 14 & 2,8 & 21,2 & 29,3 & 14,6 & 78,8 & 98,5 & 42,5 & 4,3 \\
\hline 15 & 0,8 & 21,1 & 28,6 & 14,5 & 76,8 & 99,2 & 40,6 & 4,5 \\
\hline 16 & 0,0 & 21,1 & 28,7 & 14,6 & 74,4 & 97,6 & 39,9 & 6,2 \\
\hline 17 & 0,0 & 20,4 & 28,5 & 15,1 & 82,2 & 98,1 & 49,9 & 0,9 \\
\hline 18 & 6,4 & 19,6 & 27,0 & 16,4 & 89,6 & 99,1 & 55,4 & 3,0 \\
\hline 19 & 5,8 & 19,8 & 29,0 & 14,0 & 86,9 & 99,5 & 50,5 & 0,9 \\
\hline 20 & $13.6 * *$ & 21,6 & 29,6 & 15,6 & 82,0 & 99,3 & 43,7 & 5,2 \\
\hline 21 & 23,0 & 20,6 & 29,1 & 17,0 & 91,6 & 99,4 & 53,6 & 2,4 \\
\hline 22 & 31,8 & 20,7 & 29,2 & 16,8 & 88,9 & 99,5 & 54,8 & 1,6 \\
\hline 23 & 40,8 & 20,1 & 28,6 & 15,8 & 91,0 & 99,6 & 58,1 & 1,0 \\
\hline 24 & 76,0 & 20,1 & 24,3 & 17,8 & 92,6 & 99,6 & 70,6 & 4,2 \\
\hline 25 & 0,0 & 21,1 & 26,8 & 17,8 & 85,9 & 98,7 & 60,0 & 3,2 \\
\hline 26 & 5,0 & 20,8 & 26,9 & 18,5 & 89,9 & 98,9 & 59,6 & 2,6 \\
\hline 27 & 23,4 & 19,7 & 24,2 & 17,8 & 95,3 & 99,3 & 74,3 & 2,4 \\
\hline 28 & 0,8 & 19,8 & 26,1 & 16,9 & 91,3 & 99,1 & 63,2 & 1,3 \\
\hline 29 & 0,2 & 21,0 & 27,8 & 17,5 & 85,4 & 98,8 & 48,4 & 4,6 \\
\hline 30 & 1,6 & 20,4 & 25,8 & 17,6 & 89,6 & 98,7 & 62,7 & 2,1 \\
\hline 31 & 6,4 & 21,0 & 26,8 & 17,6 & 86,7 & 98,1 & 59,3 & 4,2 \\
\hline Média & - & 20,7 & 27,6 & 16,4 & 86,1 & 99,0 & 55,0 & 3,7 \\
\hline Total & 407,4 & - & - & - & - & - & - & 115,4 \\
\hline Máximo & 76,0 & 22,1 & 29,6 & 19,1 & 95,3 & 99,6 & 74,3 & 6,2 \\
\hline Mínimo & 0,0 & 19,6 & 24,2 & 12,5 & 74,4 & 97,6 & 39,9 & 0,9 \\
\hline
\end{tabular}




\begin{tabular}{|c|c|c|c|c|c|c|c|c|}
\hline Mês: & Abril & & & & & & & \\
\hline Dia & $\begin{array}{c}\text { Prec. } \\
\text { mm }\end{array}$ & $\begin{array}{c}\text { T med } \\
\text { oC }\end{array}$ & $\begin{array}{c}\mathrm{T} \max \\
\mathrm{oC}\end{array}$ & $\begin{array}{c}\mathrm{T} \min \\
\mathrm{oC}\end{array}$ & $\begin{array}{c}\text { UR med } \\
\%\end{array}$ & $\begin{array}{c}\text { UR max } \\
\%\end{array}$ & $\begin{array}{c}\text { UR min } \\
\%\end{array}$ & $\begin{array}{c}\text { Classe A } \\
\mathrm{mm}\end{array}$ \\
\hline 1 & 40,8 & 21,3 & 28,7 & 17,1 & 86,7 & 99,0 & 53,1 & 2,8 \\
\hline 2 & 11,8 & 21,8 & 29,0 & 17,2 & 84,1 & 99,3 & 51,3 & 1,0 \\
\hline 3 & 43,0 & 19,1 & 23,4 & 16,6 & 96,1 & 99,0 & 73,7 & 1,2 \\
\hline 4 & 10,0 & 20,9 & 28,7 & 15,4 & 85,6 & 99,1 & 53,6 & 5,1 \\
\hline 5 & 0,4 & 22,2 & 28,6 & 18,5 & 85,3 & 99,1 & 58,4 & 1,8 \\
\hline 6 & 0,2 & 22,0 & 28,3 & 17,6 & 84,6 & 99,0 & 57,2 & 4,3 \\
\hline 7 & 0,6 & 22,1 & 29,7 & 15,4 & 80,3 & 99,3 & 44,5 & 5,1 \\
\hline 8 & 1,6 & 22,6 & 28,9 & 19,0 & 82,5 & 98,2 & 50,5 & 2,8 \\
\hline 9 & 17,8 & 22,6 & 30,3 & 16,3 & 80,5 & 99,1 & 44,9 & 8,4 \\
\hline 10 & 0,2 & 21,9 & 29,1 & 18,4 & 83,9 & 98,6 & 47,8 & 2,6 \\
\hline 11 & 13,2 & 21,5 & 28,6 & 17,1 & 86,1 & 99,0 & 51,4 & 7,8 \\
\hline 12 & 7,4 & 20,8 & 27,4 & 16,9 & 89,6 & 99,3 & 59,2 & 3,6 \\
\hline 13 & 0,0 & 21,5 & 29,0 & 15,5 & 81,9 & 99,6 & 51,4 & 1,9 \\
\hline 14 & 0,0 & 22,3 & 30,1 & 15,8 & 78,1 & 99,0 & 44,7 & 5,1 \\
\hline 15 & 0,2 & 22,0 & 28,9 & 16,1 & 81,7 & 99,6 & 50,5 & 4,8 \\
\hline 16 & 1,6 & 20,7 & 25,5 & 17,1 & 87,4 & 98,5 & 58,0 & 2,4 \\
\hline 17 & 0,0 & 21,4 & 28,7 & 15,7 & 83,3 & 99,3 & 49,7 & 3,4 \\
\hline 18 & 6,0 & 21,3 & 28,7 & 16,0 & 84,5 & 99,2 & 47,2 & 7,1 \\
\hline 19 & 0,0 & 21,3 & 29,0 & 14,7 & 75,6 & 99,4 & 37,2 & 4,8 \\
\hline 20 & 0,0 & 21,1 & 30,3 & 13,7 & 76,8 & 98,9 & 41,7 & 4,8 \\
\hline 21 & 0,0 & 21,5 & 28,8 & 15,5 & 81,7 & 98,9 & 53,0 & 4,8 \\
\hline 22 & 2,2 & 21,3 & 28,8 & 15,0 & 83,8 & 99,2 & 49,0 & 2,9 \\
\hline 23 & 9,6 & 20,0 & 25,1 & 16,3 & 92,0 & 99,3 & 67,1 & 1,5 \\
\hline 24 & 0,8 & 19,9 & 25,9 & 14,6 & 89,5 & 99,6 & 65,5 & 0,5 \\
\hline 25 & 38,8 & 20,4 & 27,0 & 16,9 & 89,6 & 99,5 & 60,8 & 5,0 \\
\hline 26 & 0,2 & 20,3 & 26,9 & 15,9 & 84,6 & 99,5 & 56,4 & 1,5 \\
\hline 27 & 0,0 & 19,7 & 27,7 & 13,9 & 82,7 & 99,5 & 49,1 & 3,5 \\
\hline 28 & 0,0 & 18,5 & 25,8 & 10,9 & 76,9 & 99,6 & 45,4 & 5,4 \\
\hline 29 & 0,0 & 17,3 & 24,0 & 11,4 & 75,4 & 98,0 & 47,1 & 5,1 \\
\hline 30 & 0,0 & 16,0 & 24,7 & 7,8 & 73,4 & 97,4 & 42,3 & 5,5 \\
\hline \multicolumn{9}{|l|}{31} \\
\hline Média & - & 20,8 & 27,8 & 15,6 & 83,5 & 99,1 & 52,1 & 3,9 \\
\hline Total & 206,4 & - & - & - & - & - & - & 116,4 \\
\hline Máximo & 43,0 & 22,6 & 30,3 & 19,0 & 96,1 & 99,6 & 73,7 & 8,4 \\
\hline Mínimo & 0,0 & 16,0 & 23,4 & 7,8 & 73,4 & 97,4 & 37,2 & 0,5 \\
\hline
\end{tabular}




\begin{tabular}{|c|c|c|c|c|c|c|c|c|}
\hline Mês: & Maio & & & & & & & \\
\hline Dia & $\begin{array}{c}\text { Prec. } \\
\mathrm{mm}\end{array}$ & $\begin{array}{c}\text { T med } \\
\text { oC }\end{array}$ & $\begin{array}{c}\mathrm{T} \max \\
\mathrm{oC}\end{array}$ & $\begin{array}{c}\mathrm{T} \min \\
\mathrm{oC}\end{array}$ & $\begin{array}{c}\text { UR med } \\
\%\end{array}$ & $\begin{array}{c}\text { UR max } \\
\%\end{array}$ & $\begin{array}{c}\text { UR min } \\
\%\end{array}$ & $\begin{array}{c}\text { Classe A } \\
\mathrm{mm}\end{array}$ \\
\hline 1 & 0,0 & 16,5 & 27,0 & 7,5 & 74,5 & 98,7 & 35,1 & 4,4 \\
\hline 2 & 0,0 & 17,7 & 27,0 & 8,2 & 72,2 & 98,9 & 39,7 & 4,8 \\
\hline 3 & 0,0 & 18,5 & 26,8 & 9,8 & 70,6 & 97,3 & 41,1 & 4,8 \\
\hline 4 & 0,0 & 18,7 & 27,2 & 11,3 & 74,4 & 97,9 & 44,3 & 4,9 \\
\hline 5 & 0,0 & 18,5 & 27,0 & 10,1 & 75,5 & 98,9 & 44,3 & 1,7 \\
\hline 6 & 0,0 & 18,9 & 27,6 & 11,6 & 74,2 & 98,7 & 41,1 & 4,9 \\
\hline 7 & 0,0 & 19,6 & 28,0 & 10,4 & 74,5 & 98,7 & 42,9 & 5,2 \\
\hline 8 & 0,0 & 19,2 & 26,1 & 12,8 & 85,7 & 99,2 & 58,1 & 1,1 \\
\hline 9 & 0,0 & 20,3 & 27,1 & 14,5 & 79,4 & 99,1 & 48,7 & 0,7 \\
\hline 10 & 0,0 & 19,2 & 27,2 & 13,5 & 75,4 & 97,9 & 43,4 & 4,2 \\
\hline 11 & 0,0 & 19,3 & 26,7 & 11,9 & 75,4 & 97,4 & 51,0 & 5,1 \\
\hline 12 & 0,0 & 18,6 & 24,1 & 12,7 & 77,0 & 97,8 & 54,8 & 4,7 \\
\hline 13 & 0,0 & 17,6 & 24,9 & 12,1 & 76,7 & 98,5 & 47,8 & 4,2 \\
\hline 14 & 0,0 & 16,4 & 25,8 & 7,7 & 73,2 & 99,3 & 33,6 & 4,7 \\
\hline 15 & 0,0 & 17,4 & 27,6 & 8,8 & 72,5 & 98,8 & 30,7 & 2,0 \\
\hline 16 & 0,0 & 18,5 & 28,4 & 9,8 & 76,1 & 99,0 & 42,9 & 3,3 \\
\hline 17 & 0,0 & 20,0 & 27,9 & 11,8 & 75,3 & 98,5 & 45,4 & 4,4 \\
\hline 18 & 2,0 & 19,9 & 27,1 & 14,0 & 79,9 & 98,7 & 51,3 & 4,2 \\
\hline 19 & 0,2 & 20,0 & 27,8 & 14,9 & 82,6 & 99,3 & 50,9 & 2,5 \\
\hline 20 & 0,0 & 19,9 & 27,0 & 13,8 & 77,0 & 98,6 & 48,1 & 4,3 \\
\hline 21 & 0,0 & 18,4 & 27,4 & 11,6 & 75,6 & 98,2 & 37,4 & 5,3 \\
\hline 22 & 0,0 & 19,0 & 28,5 & 11,2 & 74,6 & 98,5 & 39,6 & 4,0 \\
\hline 23 & 0,0 & 19,3 & 29,4 & 12,3 & 75,9 & 97,9 & 32,9 & 3,3 \\
\hline 24 & 0,0 & 20,8 & 28,5 & 15,6 & 79,1 & 98,8 & 43,8 & 3,9 \\
\hline 25 & 1,6 & 21,5 & 28,9 & 15,7 & 77,6 & 98,9 & 42,9 & 5,1 \\
\hline 26 & 8,6 & 19,7 & 28,7 & 13,2 & 84,1 & 98,6 & 49,2 & 4,8 \\
\hline 27 & 0,2 & 20,0 & 26,9 & 15,6 & 87,2 & 99,5 & 58,9 & 0,1 \\
\hline 28 & 0,0 & 18,7 & 26,8 & 12,3 & 71,7 & 98,0 & 32,7 & 4,8 \\
\hline 29 & 0,0 & 16,6 & 27,0 & 6,7 & 68,4 & 98,9 & 26,2 & 5,1 \\
\hline 30 & 0,0 & 16,5 & 26,1 & 7,8 & 70,0 & 98,7 & 35,0 & 4,1 \\
\hline 31 & 0,0 & 17,8 & 26,1 & 10,9 & 81,3 & 99,3 & 51,4 & 3,2 \\
\hline Média & - & 18,8 & 27,2 & 11,6 & 76,4 & 98,6 & 43,4 & 3,9 \\
\hline Total & 12,6 & - & - & - & - & - & - & 120,1 \\
\hline Máximo & 8,6 & 21,5 & 29,4 & 15,7 & 87,2 & 99,5 & 58,9 & 5,3 \\
\hline Mínimo & 0,0 & 16,4 & 24,1 & 6,7 & 68,4 & 97,3 & 26,2 & 0,1 \\
\hline
\end{tabular}




\begin{tabular}{|c|c|c|c|c|c|c|c|c|}
\hline Mês: & unho & & & & & & & \\
\hline Dia & $\begin{array}{c}\text { Prec. } \\
\mathrm{mm}\end{array}$ & $\begin{array}{c}\text { T med } \\
\text { oC }\end{array}$ & $\begin{array}{c}\mathrm{T} \max \\
\mathrm{oC}\end{array}$ & $\begin{array}{c}\mathrm{T} \min \\
\mathrm{oC}\end{array}$ & $\begin{array}{c}\text { UR med } \\
\%\end{array}$ & $\begin{array}{c}\text { UR max } \\
\%\end{array}$ & $\begin{array}{c}\text { UR min } \\
\%\end{array}$ & $\begin{array}{c}\text { Classe A } \\
\mathrm{mm}\end{array}$ \\
\hline 1 & 0,0 & 18,8 & 27,9 & 10,5 & 77,6 & 99,3 & 37,3 & 3,9 \\
\hline 2 & 0,0 & 19,1 & 25,5 & 14,1 & 77,7 & 95,4 & 48,6 & 3,1 \\
\hline 3 & 4,4 & 17,9 & 26,1 & 11,9 & 86,6 & 99,3 & 54,2 & 4,9 \\
\hline 4 & 0,2 & 18,1 & 27,6 & 11,4 & 84,8 & 99,7 & 50,0 & 0,6 \\
\hline 5 & 0,0 & 18,6 & 27,2 & 11,7 & 83,3 & 99,5 & 48,3 & 2,8 \\
\hline 6 & 0,0 & 18,7 & 28,7 & 11,1 & 79,3 & 99,5 & 37,1 & 4,5 \\
\hline 7 & 0,0 & 18,8 & 27,5 & 11,3 & 74,4 & 98,1 & 40,2 & 3,7 \\
\hline 8 & 0,0 & 18,2 & 26,7 & 10,3 & 72,2 & 97,7 & 37,5 & 3,8 \\
\hline 9 & 0,0 & 18,3 & 26,9 & 9,3 & 67,1 & 97,2 & 33,6 & 3,1 \\
\hline 10 & 0,0 & 19,0 & 26,5 & 11,9 & 68,7 & 95,3 & 43,2 & 5,3 \\
\hline 11 & 0,0 & 17,7 & 25,7 & 10,3 & 74,6 & 97,8 & 46,2 & 4,2 \\
\hline 12 & 0,0 & 16,9 & 24,8 & 9,1 & 77,9 & 99,0 & 41,4 & 3,4 \\
\hline 13 & 0,0 & 16,4 & 24,4 & 10,2 & 85,0 & 99,0 & 55,7 & 2,3 \\
\hline 14 & 0,0 & 17,4 & 25,2 & 10,9 & 79,8 & 99,0 & 48,8 & 3,8 \\
\hline 15 & 0,0 & 17,5 & 25,0 & 11,9 & 82,5 & 98,9 & 52,0 & 2,4 \\
\hline 16 & 0,0 & 18,4 & 26,3 & 12,4 & 76,0 & 98,6 & 42,6 & 4,9 \\
\hline 17 & 0,0 & 18,3 & 25,4 & 11,9 & 78,4 & 98,7 & 48,4 & 3,4 \\
\hline 18 & 0,0 & 18,7 & 24,9 & 12,8 & 78,0 & 97,6 & 52,8 & 0,3 \\
\hline 19 & 0,0 & 19,6 & 27,8 & 12,1 & 72,0 & 98,2 & 36,4 & 3,9 \\
\hline 20 & 0,0 & 17,8 & 26,6 & 10,3 & 74,3 & 98,6 & 39,3 & 4,0 \\
\hline 21 & 0,0 & 17,2 & 26,4 & 9,4 & 70,4 & 97,9 & 34,0 & 5,0 \\
\hline 22 & 0,0 & 16,4 & 25,0 & 8,5 & 72,0 & 97,5 & 40,1 & 5,1 \\
\hline 23 & 0,0 & 16,0 & 22,9 & 10,1 & 82,9 & 98,1 & 57,8 & 2,3 \\
\hline 24 & 0,0 & 16,3 & 25,9 & 8,5 & 76,8 & 99,5 & 42,3 & 1,4 \\
\hline 25 & 0,0 & 16,4 & 27,0 & 7,5 & 72,7 & 99,0 & 35,0 & 4,1 \\
\hline 26 & 0,0 & 16,1 & 26,5 & 7,3 & 71,6 & 98,4 & 33,6 & 4,4 \\
\hline 27 & 0,0 & 16,4 & 26,8 & 6,8 & 68,1 & 99,2 & 29,8 & 4,8 \\
\hline 28 & 0,0 & 16,2 & 27,6 & 6,5 & 68,4 & 98,2 & 26,4 & 4,1 \\
\hline 29 & 0,0 & 16,6 & 28,1 & 6,2 & 67,3 & 97,9 & 31,8 & 4,2 \\
\hline 30 & 0,0 & 17,4 & 27,2 & 8,6 & 70,9 & 98,5 & 36,8 & 4,2 \\
\hline \multicolumn{9}{|l|}{31} \\
\hline Média & - & 17,6 & 26,3 & 10,2 & 75,7 & 98,4 & 42,0 & 3,6 \\
\hline Total & 4,6 & - & - & - & - & - & - & 107,9 \\
\hline Máximo & 4,4 & 19,6 & 28,7 & 14,1 & 86,6 & 99,7 & 57,8 & 5,3 \\
\hline Mínimo & 0,0 & 16,0 & 22,9 & 6,2 & 67,1 & 95,3 & 26,4 & 0,3 \\
\hline
\end{tabular}




\begin{tabular}{|c|c|c|c|c|c|c|c|c|}
\hline Dia & $\begin{array}{c}\text { Prec. } \\
\mathrm{mm}\end{array}$ & $\begin{array}{c}\text { T med } \\
\text { oC }\end{array}$ & $\begin{array}{c}\mathrm{T} \max \\
\mathrm{oC}\end{array}$ & $\begin{array}{c}\mathrm{T} \text { min } \\
\mathrm{oC}\end{array}$ & $\begin{array}{c}\text { UR med } \\
\%\end{array}$ & $\begin{array}{c}\text { UR max } \\
\%\end{array}$ & $\begin{array}{c}\text { UR min } \\
\%\end{array}$ & $\begin{array}{c}\text { Classe A } \\
\mathrm{mm}\end{array}$ \\
\hline 1 & 0,0 & 17,9 & 28,1 & 9,7 & 70,6 & 98,5 & 32,6 & 3,9 \\
\hline 2 & 0,0 & 18,2 & 28,3 & 9,6 & 67,0 & 96,2 & 31,3 & 4,9 \\
\hline 3 & 0,0 & 17,7 & 27,8 & 9,3 & 63,7 & 94,9 & 29,3 & 3,6 \\
\hline 4 & 0,0 & 17,0 & 26,9 & 8,7 & 60,9 & 92,2 & 26,1 & 6,0 \\
\hline 5 & 0,0 & 15,5 & 25,6 & 6,2 & 66,5 & 96,6 & 30,0 & 5,4 \\
\hline 6 & 0,0 & 15,8 & 26,0 & 6,6 & 68,9 & 96,2 & 34,3 & 3,5 \\
\hline 7 & 0,0 & 18,6 & 25,5 & 11,9 & 62,4 & 89,3 & 35,1 & 4,8 \\
\hline 8 & 0,0 & 17,6 & 25,2 & 10,5 & 68,0 & 93,4 & 35,1 & 4,3 \\
\hline 9 & 0,0 & 16,5 & 25,7 & 8,5 & 72,7 & 97,8 & 37,4 & 3,2 \\
\hline 10 & 0,0 & 17,2 & 26,8 & 9,2 & 73,6 & 98,4 & 35,4 & 3,3 \\
\hline 11 & 0,0 & 18,1 & 27,2 & 9,8 & 69,6 & 97,7 & 37,0 & 1,6 \\
\hline 12 & 0,0 & 18,3 & 26,5 & 10,1 & 68,2 & 96,4 & 36,0 & 3,4 \\
\hline 13 & 0,0 & 16,8 & 26,0 & 8,8 & 71,7 & 97,7 & 38,2 & 4,9 \\
\hline 14 & 0,0 & 16,3 & 24,8 & 7,7 & 70,0 & 98,0 & 38,0 & 4,7 \\
\hline 15 & 0,0 & 15,8 & 25,5 & 6,6 & 70,9 & 97,6 & 38,6 & 4,7 \\
\hline 16 & 0,0 & 16,1 & 26,9 & 7,2 & 69,9 & 97,3 & 25,9 & 4,5 \\
\hline 17 & 0,0 & 16,7 & 26,9 & 8,6 & 69,4 & 97,4 & 33,5 & 4,4 \\
\hline 18 & 0,0 & 17,3 & 27,7 & 8,3 & 64,5 & 95,6 & 25,2 & 4,8 \\
\hline 19 & 0,0 & 17,7 & 27,6 & 8,0 & 66,8 & 97,7 & 29,7 & 4,7 \\
\hline 20 & 0,0 & 18,9 & 27,6 & 11,0 & 65,7 & 96,0 & 32,8 & 5,0 \\
\hline 21 & 0,0 & 18,8 & 27,5 & 11,3 & 65,5 & 92,8 & 35,7 & 5,3 \\
\hline 22 & 0,0 & 17,5 & 26,4 & 9,2 & 68,6 & 96,4 & 38,1 & 3,5 \\
\hline 23 & 0,0 & 17,0 & 25,8 & 8,8 & 72,0 & 95,2 & 41,5 & 5,1 \\
\hline 24 & 0,0 & 18,0 & 27,8 & 9,5 & 71,6 & 96,8 & 37,5 & 5,0 \\
\hline 25 & 1,0 & 16,9 & 21,8 & 13,2 & 83,1 & 95,0 & 61,4 & 2,1 \\
\hline 26 & 0,0 & 16,0 & 23,9 & 8,8 & 80,1 & 98,4 & 52,0 & 3,2 \\
\hline 27 & 0,2 & 13,8 & 19,9 & 9,2 & 90,1 & 98,4 & 66,3 & 1,3 \\
\hline 28 & 0,2 & 15,2 & 22,0 & 7,3 & 83,2 & 99,4 & 57,6 & 2,5 \\
\hline 29 & 0,0 & 18,2 & 26,4 & 11,9 & 75,8 & 99,0 & 41,3 & 4,8 \\
\hline 30 & 0,0 & 18,0 & 26,0 & 10,6 & 71,2 & 98,4 & 32,0 & 4,7 \\
\hline 31 & 0,0 & 17,0 & 26,4 & 9,0 & 68,9 & 97,8 & 34,0 & 5,1 \\
\hline Média & - & 17,1 & 26,0 & 9,2 & 70,7 & 96,5 & 37,4 & 4,1 \\
\hline Total & 1,4 & - & - & - & - & - & - & 128,2 \\
\hline Máximo & 1,0 & 18,9 & 28,3 & 13,2 & 90,1 & 99,4 & 66,3 & 6,0 \\
\hline Mínimo & 0,0 & 13,8 & 19,9 & 6,2 & 60,9 & 89,3 & 25,2 & 1,3 \\
\hline
\end{tabular}




\begin{tabular}{|c|c|c|c|c|c|c|c|c|}
\hline Mês: & Agosto & & & & & & & \\
\hline Dia & $\begin{array}{c}\text { Prec. } \\
\text { mm }\end{array}$ & $\begin{array}{c}\text { T med } \\
\text { oC }\end{array}$ & $\begin{array}{c}\mathrm{T} \max \\
\mathrm{oC}\end{array}$ & $\begin{array}{c}\mathrm{T} \text { min } \\
\mathrm{oC}\end{array}$ & $\begin{array}{c}\text { UR med } \\
\%\end{array}$ & $\begin{array}{c}\text { UR max } \\
\%\end{array}$ & $\begin{array}{c}\text { UR min } \\
\%\end{array}$ & $\begin{array}{c}\text { Classe A } \\
\mathrm{mm}\end{array}$ \\
\hline 1 & 0,0 & 17,9 & 28,2 & 9,8 & 66,1 & 94,1 & 29,2 & 4,5 \\
\hline 2 & 0,0 & 18,1 & 27,1 & 10,2 & 68,8 & 95,0 & 36,5 & 3,7 \\
\hline 3 & 0,0 & 18,9 & 29,5 & 9,7 & 64,5 & 95,2 & 28,7 & 5,4 \\
\hline 4 & 0,0 & 19,3 & 29,5 & 10,8 & 62,3 & 92,1 & 26,7 & 1,1 \\
\hline 5 & 0,0 & 20,4 & 30,3 & 10,2 & 51,9 & 90,8 & 21,8 & 6,4 \\
\hline 6 & 0,0 & 19,3 & 27,1 & 9,6 & 52,5 & 88,1 & 30,9 & 7,0 \\
\hline 7 & 0,0 & 17,6 & 25,6 & 8,6 & 59,8 & 93,1 & 31,7 & 5,8 \\
\hline 8 & 0,0 & 16,9 & 26,8 & 7,7 & 49,5 & 87,5 & 13,6 & 6,0 \\
\hline 9 & 0,0 & 15,6 & 26,4 & 3,5 & 52,5 & 87,2 & 25,9 & 5,6 \\
\hline 10 & 0,0 & 16,3 & 27,1 & 5,4 & 56,3 & 88,7 & 27,8 & 5,1 \\
\hline 11 & 0,0 & 17,2 & 28,7 & 6,6 & 59,0 & 93,1 & 26,3 & 5,3 \\
\hline 12 & 0,0 & 17,7 & 28,7 & 8,4 & 56,0 & 88,5 & 23,2 & 6,1 \\
\hline 13 & 0,0 & 18,0 & 29,7 & 6,7 & 55,6 & 91,5 & 23,4 & 5,6 \\
\hline 14 & 0,0 & 18,4 & 29,6 & 8,9 & 54,3 & 85,9 & 24,1 & 7,4 \\
\hline 15 & 0,0 & 19,4 & 26,4 & 11,4 & 50,9 & 78,3 & 31,4 & 5,1 \\
\hline 16 & 0,0 & 18,1 & 25,4 & 12,7 & 65,2 & 91,1 & 34,4 & 5,3 \\
\hline 17 & 0,0 & 19,0 & 26,8 & 12,0 & 57,4 & 85,9 & 29,2 & 6,0 \\
\hline 18 & 0,0 & 17,2 & 27,5 & 8,1 & 63,9 & 95,8 & 31,7 & 5,2 \\
\hline 19 & 0,0 & 18,8 & 28,8 & 8,8 & 60,8 & 94,2 & 29,2 & 6,0 \\
\hline 20 & 0,0 & 19,5 & 28,5 & 9,6 & 56,2 & 90,2 & 30,0 & 6,2 \\
\hline 21 & 0,0 & 19,0 & 27,3 & 10,0 & 53,6 & 83,3 & 29,4 & 5,5 \\
\hline 22 & 0,0 & 18,3 & 29,1 & 8,6 & 55,8 & 91,3 & 22,2 & 6,7 \\
\hline 23 & 0,0 & 18,6 & 28,9 & 7,8 & 49,8 & 89,3 & 19,4 & 7,3 \\
\hline 24 & 0,0 & 17,6 & 28,9 & 6,7 & 50,7 & 84,0 & 19,7 & 7,2 \\
\hline 25 & 0,0 & 18,8 & 30,2 & 7,9 & 54,6 & 87,9 & 23,4 & 2,5 \\
\hline 26 & 0,0 & 20,6 & 31,3 & 10,1 & 54,0 & 89,5 & 23,4 & 6,1 \\
\hline 27 & 0,0 & 20,8 & 31,5 & 11,6 & 51,6 & 84,6 & 20,3 & 6,8 \\
\hline 28 & 0,0 & 20,3 & 32,2 & 10,1 & 52,9 & 85,5 & 20,6 & 6,2 \\
\hline 29 & 0,0 & 22,5 & 32,6 & 13,2 & 50,1 & 83,1 & 24,3 & 6,0 \\
\hline 30 & 0,0 & 22,5 & 32,9 & 12,5 & 50,0 & 83,8 & 20,1 & 7,0 \\
\hline 31 & 0,0 & 22,0 & 32,5 & 11,7 & 55,6 & 87,4 & 25,6 & 6,7 \\
\hline Média & - & 18,9 & 28,9 & 9,3 & 56,2 & 88,9 & 25,9 & 5,7 \\
\hline Total & 0,0 & - & - & - & - & - & - & 176,6 \\
\hline Máximo & 0,0 & 22,5 & 32,9 & 13,2 & 68,8 & 95,8 & 36,5 & 7,4 \\
\hline Mínimo & 0,0 & 15,6 & 25,4 & 3,5 & 49,5 & 78,3 & 13,6 & 1,1 \\
\hline
\end{tabular}




\begin{tabular}{|c|c|c|c|c|c|c|c|c|}
\hline Mês: & etembro & & & & & & & \\
\hline Dia & $\begin{array}{c}\text { Prec. } \\
\mathrm{mm}\end{array}$ & $\begin{array}{c}\text { T med } \\
\text { oC }\end{array}$ & $\begin{array}{c}\mathrm{T} \max \\
\mathrm{oC}\end{array}$ & $\begin{array}{c}\mathrm{T} \text { min } \\
\mathrm{oC}\end{array}$ & $\begin{array}{c}\text { UR med } \\
\%\end{array}$ & $\begin{array}{c}\text { UR max } \\
\%\end{array}$ & $\begin{array}{c}\text { UR min } \\
\%\end{array}$ & $\begin{array}{c}\text { Classe A } \\
\mathrm{mm}\end{array}$ \\
\hline 1 & 0,0 & 24,0 & 31,9 & 16,1 & 56,0 & 82,3 & 31,6 & 3,2 \\
\hline 2 & 0,0 & 22,4 & 31,5 & 14,3 & 63,4 & 92,1 & 28,6 & 3,7 \\
\hline 3 & 4,0 & 20,6 & 31,2 & 16,1 & 74,5 & 96,9 & 39,5 & 4,9 \\
\hline 4 & 0,0 & 22,0 & 30,6 & 14,2 & 67,0 & 97,4 & 35,1 & 2,5 \\
\hline 5 & 0,0 & 23,0 & 30,6 & 14,5 & 58,3 & 86,0 & 37,5 & 8,2 \\
\hline 6 & 0,0 & 20,1 & 27,8 & 12,3 & 54,8 & 75,7 & 29,5 & 7,2 \\
\hline 7 & 0,0 & 17,4 & 27,8 & 5,8 & 53,6 & 90,1 & 23,5 & 6,8 \\
\hline 8 & 0,0 & 17,8 & 27,7 & 6,6 & 54,6 & 93,2 & 24,6 & 4,7 \\
\hline 9 & 0,0 & 18,5 & 30,0 & 7,3 & 55,0 & 90,5 & 16,8 & 6,6 \\
\hline 10 & 0,0 & 20,2 & 30,6 & 9,4 & 53,3 & 87,7 & 24,7 & 6,6 \\
\hline 11 & 0,0 & 20,7 & 31,2 & 9,7 & 51,3 & 89,6 & 19,3 & 5,2 \\
\hline 12 & 0,0 & 21,3 & 30,6 & 10,7 & 41,6 & 77,3 & 16,2 & 8,5 \\
\hline 13 & 0,0 & 20,5 & 30,6 & 9,2 & 50,0 & 84,0 & 26,4 & 6,8 \\
\hline 14 & 0,0 & 21,6 & 31,9 & 10,8 & 51,6 & 88,8 & 24,1 & 7,7 \\
\hline 15 & 0,0 & 21,2 & 32,3 & 11,2 & 51,7 & 84,9 & 24,4 & 6,9 \\
\hline 16 & 0,0 & 21,9 & 32,2 & 11,3 & 53,9 & 86,7 & 25,1 & 3,2 \\
\hline 17 & 0,0 & 23,8 & 34,2 & 13,4 & 48,3 & 88,5 & 20,1 & 8,3 \\
\hline 18 & 0,0 & 24,2 & 33,6 & 14,2 & 43,6 & 76,7 & 20,9 & 9,0 \\
\hline 19 & 0,0 & 21,8 & 32,6 & 11,0 & 48,1 & 86,3 & 17,8 & 8,9 \\
\hline 20 & 0,0 & 21,5 & 32,8 & 9,7 & 49,8 & 83,7 & 20,8 & 6,5 \\
\hline 21 & 0,0 & 23,9 & 32,4 & 16,0 & 58,7 & 89,4 & 30,1 & 6,9 \\
\hline 22 & 1,2 & 23,2 & 31,8 & 17,3 & 63,3 & 88,6 & 33,6 & 4,4 \\
\hline 23 & 0,4 & 23,1 & 30,9 & 15,8 & 64,9 & 95,0 & 36,6 & 6,7 \\
\hline 24 & 0,0 & 22,0 & 31,4 & 13,7 & 62,0 & 89,3 & 33,8 & 7,1 \\
\hline 25 & 0,0 & 22,9 & 31,5 & 15,6 & 63,5 & 92,5 & 30,6 & 5,6 \\
\hline 26 & 0,0 & 23,7 & 32,0 & 15,1 & 59,1 & 94,4 & 28,7 & 6,7 \\
\hline 27 & 0,0 & 25,2 & 31,9 & 19,5 & 55,8 & 81,2 & 33,6 & 6,6 \\
\hline 28 & 0,0 & 24,4 & 33,4 & 15,4 & 49,4 & 85,4 & 22,9 & 8,8 \\
\hline 29 & 0,0 & 24,6 & 33,8 & 15,2 & 48,2 & 81,2 & 24,9 & 6,1 \\
\hline 30 & 6,0 & 22,7 & 33,6 & 17,5 & 69,9 & 96,0 & 35,2 & 7,2 \\
\hline \multicolumn{9}{|l|}{31} \\
\hline Média & - & 22,0 & 31,5 & 13,0 & 55,8 & 87,7 & 27,2 & 6,4 \\
\hline Total & 11,6 & - & - & - & - & - & - & 191,6 \\
\hline Máximo & 6,0 & 25,2 & 34,2 & 19,5 & 74,5 & 97,4 & 39,5 & 9,0 \\
\hline Mínimo & 0,0 & 17,4 & 27,7 & 5,8 & 41,6 & 75,7 & 16,2 & 2,5 \\
\hline
\end{tabular}




\begin{tabular}{|c|c|c|c|c|c|c|c|c|}
\hline Mês: & Outubro & & & & & & & \\
\hline Dia & $\begin{array}{c}\text { Prec. } \\
\mathrm{mm}\end{array}$ & $\begin{array}{c}\text { T med } \\
\text { oC }\end{array}$ & $\begin{array}{c}\mathrm{T} \max \\
\mathrm{oC}\end{array}$ & $\begin{array}{c}\mathrm{T} \min \\
\mathrm{oC}\end{array}$ & $\begin{array}{c}\text { UR med } \\
\%\end{array}$ & $\begin{array}{c}\text { UR max } \\
\%\end{array}$ & $\begin{array}{c}\text { UR min } \\
\%\end{array}$ & $\begin{array}{c}\text { Classe A } \\
\mathrm{mm}\end{array}$ \\
\hline 1 & 0,6 & 21,6 & 33,9 & 14,9 & 76,9 & 95,2 & 31,2 & 2,6 \\
\hline 2 & 7,0 & 23,0 & 32,6 & 15,9 & 73,3 & 98,0 & 36,3 & 3,8 \\
\hline 3 & 0,0 & 23,0 & 30,1 & 18,6 & 60,9 & 95,2 & 31,8 & 5,6 \\
\hline 4 & 0,0 & 22,0 & 28,9 & 16,0 & 48,3 & 66,5 & 32,4 & 8,8 \\
\hline 5 & 0,0 & 20,2 & 28,9 & 9,6 & 51,5 & 91,4 & 25,4 & 7,9 \\
\hline 6 & 0,0 & 19,0 & 27,9 & 9,9 & 47,4 & 84,8 & 20,4 & 5,6 \\
\hline 7 & 0,0 & 18,3 & 29,0 & 6,4 & 51,2 & 88,5 & 25,5 & 6,7 \\
\hline 8 & 0,0 & 20,3 & 30,2 & 11,1 & 51,0 & 80,2 & 24,6 & 6,9 \\
\hline 9 & 0,0 & 21,6 & 31,7 & 11,6 & 50,4 & 83,1 & 23,9 & 7,5 \\
\hline 10 & 0,0 & 23,0 & 32,3 & 13,9 & 46,0 & 79,8 & 21,4 & 5,7 \\
\hline 11 & 0,0 & 22,5 & 33,3 & 11,7 & 43,4 & 80,7 & 16,4 & 8,6 \\
\hline 12 & 0,0 & 21,1 & 33,2 & 10,1 & 48,0 & 79,0 & 22,0 & 7,2 \\
\hline 13 & 0,0 & 23,2 & 33,7 & 11,8 & 45,5 & 80,7 & 18,7 & 8,6 \\
\hline 14 & 0,0 & 23,4 & 34,5 & 12,0 & 45,2 & 83,8 & 18,8 & 8,6 \\
\hline 15 & 0,0 & 24,3 & 36,2 & 11,4 & 39,8 & 79,1 & 15,3 & 6,7 \\
\hline 16 & 0,0 & 23,7 & 34,8 & 13,1 & 41,7 & 73,9 & 14,5 & 8,4 \\
\hline 17 & 0,0 & 23,5 & 34,5 & 11,2 & 45,7 & 81,1 & 21,5 & 7,4 \\
\hline 18 & 0,0 & 24,1 & 35,6 & 13,2 & 47,4 & 85,2 & 16,7 & 7,4 \\
\hline 19 & 0,0 & 23,4 & 34,8 & 13,1 & 50,6 & 78,8 & 20,3 & 6,8 \\
\hline 20 & 0,0 & 24,4 & 33,7 & 16,3 & 54,2 & 81,3 & 29,5 & 5,6 \\
\hline 21 & 7,6 & 23,6 & 32,7 & 18,1 & 68,4 & 97,2 & 34,7 & 7,1 \\
\hline 22 & 0,4 & 21,5 & 28,6 & 17,3 & 78,1 & 98,0 & 47,0 & 3,9 \\
\hline 23 & 0,0 & 20,7 & 27,6 & 16,4 & 78,6 & 96,5 & 48,4 & 4,2 \\
\hline 24 & 0,0 & 22,0 & 30,9 & 14,0 & 67,7 & 96,3 & 34,2 & 6,2 \\
\hline 25 & 0,0 & 21,7 & 28,8 & 17,4 & 72,2 & 88,4 & 38,8 & 5,2 \\
\hline 26 & 18,6 & 20,3 & 27,8 & 16,5 & 84,0 & 99,1 & 47,0 & 6,5 \\
\hline 27 & 14,8 & 21,1 & 28,0 & 16,7 & 83,8 & 99,2 & 51,4 & 4,5 \\
\hline 28 & 10,2 & 22,3 & 31,8 & 16,6 & 80,1 & 98,9 & 36,9 & 8,6 \\
\hline 29 & 0,0 & 21,8 & 27,9 & 17,3 & 81,5 & 98,4 & 52,3 & 2,1 \\
\hline 30 & 9,8 & 19,7 & 26,0 & 15,5 & 87,4 & 98,2 & 61,5 & 5,7 \\
\hline 31 & 0,4 & 20,5 & 25,8 & 17,4 & 84,5 & 98,4 & 61,6 & 1,0 \\
\hline Média & - & 22,0 & 31,2 & 14,0 & 60,8 & 88,2 & 31,6 & 6,2 \\
\hline Total & 69,4 & - & - & - & - & - & - & 191,5 \\
\hline Máximo & 18,6 & 24,4 & 36,2 & 18,6 & 87,4 & 99,2 & 61,6 & 8,8 \\
\hline Mínimo & 0,0 & 18,3 & 25,8 & 6,4 & 39,8 & 66,5 & 14,5 & 1,0 \\
\hline
\end{tabular}




\begin{tabular}{|c|c|c|c|c|c|c|c|c|}
\hline Mês: & Novembro & & & & & & & \\
\hline Dia & $\begin{array}{c}\text { Prec. } \\
\mathrm{mm}\end{array}$ & $\begin{array}{c}\text { T med } \\
\text { oC }\end{array}$ & $\begin{array}{c}\mathrm{T} \max \\
\mathrm{oC}\end{array}$ & $\begin{array}{c}\mathrm{T} \min \\
\mathrm{oC}\end{array}$ & $\begin{array}{c}\text { UR med } \\
\%\end{array}$ & $\begin{array}{c}\text { UR max } \\
\%\end{array}$ & $\begin{array}{c}\text { UR min } \\
\%\end{array}$ & $\begin{array}{c}\text { Classe A } \\
\mathrm{mm}\end{array}$ \\
\hline 1 & 0,0 & 21,5 & 29,1 & 17,8 & 80,3 & 97,7 & 42,8 & 5,3 \\
\hline 2 & 0,0 & 23,2 & 30,3 & 17,7 & 69,9 & 97,3 & 40,1 & 7,1 \\
\hline 3 & 0,0 & 23,3 & 31,2 & 15,9 & 68,4 & 97,4 & 35,1 & 7,6 \\
\hline 4 & 64,8 & 21,1 & 29,4 & 16,3 & 83,6 & 98,9 & 47,0 & 4,7 \\
\hline 5 & 3,6 & 21,7 & 29,0 & 17,2 & 78,4 & 98,3 & 46,7 & 5,7 \\
\hline 6 & 0,2 & 22,9 & 30,7 & 15,9 & 70,3 & 96,1 & 40,8 & 6,7 \\
\hline 7 & 0,0 & 23,9 & 31,9 & 16,8 & 67,1 & 95,0 & 34,1 & 6,9 \\
\hline 8 & 1,6 & 22,4 & 28,6 & 18,5 & 77,2 & 96,3 & 51,1 & 5,2 \\
\hline 9 & 0,8 & 22,7 & 30,1 & 18,9 & 76,2 & 94,2 & 45,1 & 4,2 \\
\hline 10 & 7,0 & 21,7 & 26,9 & 18,8 & 83,5 & 96,9 & 56,5 & 4,5 \\
\hline 11 & 44,0 & 21,1 & 28,6 & 15,6 & 85,0 & 99,1 & 52,0 & 7,3 \\
\hline 12 & 4,8 & 20,4 & 28,5 & 15,9 & 87,2 & 98,5 & 50,5 & 4,9 \\
\hline 13 & 3,0 & 20,5 & 25,8 & 17,4 & 88,4 & 98,5 & 62,9 & 3,6 \\
\hline 14 & 2,4 & 20,8 & 26,7 & 17,6 & 87,7 & 98,2 & 62,3 & 4,0 \\
\hline 15 & 11,0 & 21,4 & 27,8 & 17,5 & 87,1 & 98,9 & 56,3 & 6,2 \\
\hline 16 & 0,2 & 21,8 & 28,6 & 16,3 & 80,9 & 99,5 & 48,7 & 1,9 \\
\hline 17 & 3,4 & 21,2 & 29,4 & 16,2 & 81,1 & 98,7 & 38,2 & 6,7 \\
\hline 18 & 38,8 & 19,9 & 25,6 & 15,9 & 85,5 & 98,6 & 55,1 & 6,6 \\
\hline 19 & 0,0 & 20,7 & 27,9 & 14,5 & 77,2 & 98,5 & 44,9 & 3,7 \\
\hline 20 & 0,0 & 20,8 & 29,4 & 13,2 & 69,7 & 95,2 & 37,9 & 1,6 \\
\hline 21 & 0,0 & 21,8 & 30,7 & 13,5 & 71,0 & 95,4 & 37,0 & 6,3 \\
\hline 22 & 3,0 & 20,9 & 26,9 & 17,3 & 88,8 & 97,8 & 60,4 & 3,2 \\
\hline 23 & 35,6 & 20,4 & 26,2 & 18,2 & 91,0 & 99,2 & 64,2 & 8,1 \\
\hline 24 & 0,2 & 21,2 & 27,4 & 18,0 & 85,1 & 99,2 & 50,7 & 2,4 \\
\hline 25 & 80,4 & 21,0 & 26,8 & 17,9 & 87,5 & 99,5 & 56,8 & 3,1 \\
\hline 26 & 4,0 & 21,2 & 26,6 & 17,7 & 86,6 & 99,7 & 58,3 & 3,6 \\
\hline 27 & 22,2 & 20,7 & 26,2 & 18,2 & 90,9 & 99,4 & 61,3 & 6,5 \\
\hline 28 & 52,6 & 19,6 & 26,0 & 17,2 & 91,9 & 98,9 & 58,6 & 5,8 \\
\hline 29 & 0,2 & 21,6 & 29,4 & 15,7 & 82,5 & 99,4 & 47,3 & 2,4 \\
\hline 30 & 54,0 & 21,8 & 29,8 & 17,3 & 83,8 & 99,1 & 51,8 & 5,4 \\
\hline \multicolumn{9}{|l|}{31} \\
\hline Média & - & 21,4 & 28,4 & 16,8 & 81,5 & 98,0 & 49,8 & 5,0 \\
\hline Total & 437,8 & - & - & - & - & - & - & 151,1 \\
\hline Máximo & 80,4 & 23,9 & 31,9 & 18,9 & 91,9 & 99,7 & 64,2 & 8,1 \\
\hline Mínimo & 0,0 & 19,6 & 25,6 & 13,2 & 67,1 & 94,2 & 34,1 & 1,6 \\
\hline
\end{tabular}




\begin{tabular}{|c|c|c|c|c|c|c|c|c|}
\hline Dia & $\begin{array}{c}\text { Prec. } \\
\mathrm{mm}\end{array}$ & $\begin{array}{c}\text { T med } \\
\text { oC }\end{array}$ & $\begin{array}{c}\mathrm{T} \max \\
\mathrm{oC}\end{array}$ & $\begin{array}{c}\mathrm{T} \min \\
\mathrm{oC}\end{array}$ & $\begin{array}{c}\text { UR med } \\
\%\end{array}$ & $\begin{array}{c}\text { UR max } \\
\%\end{array}$ & $\begin{array}{c}\text { UR min } \\
\%\end{array}$ & $\begin{array}{c}\text { Classe A } \\
\mathrm{mm}\end{array}$ \\
\hline 1 & 4,4 & 20,7 & 24,2 & 18,2 & 86,7 & 99,1 & 64,8 & 7,1 \\
\hline 2 & 4,0 & 19,1 & 20,8 & 18,0 & 91,3 & 96,8 & 79,3 & 3,9 \\
\hline 3 & 0,0 & 20,9 & 28,3 & 14,4 & 77,0 & 99,1 & 41,3 & 3,1 \\
\hline 4 & 16,6 & 21,5 & 29,5 & 14,8 & 77,9 & 98,7 & 41,1 & 4,0 \\
\hline 5 & 3,0 & 20,2 & 28,3 & 17,0 & 87,1 & 98,8 & 51,6 & 1,2 \\
\hline 6 & 4,6 & 19,1 & 25,4 & 16,9 & 89,0 & 98,8 & 58,3 & 3,9 \\
\hline 7 & 9,0 & 19,1 & 23,7 & 17,1 & 90,1 & 98,8 & 64,0 & 2,8 \\
\hline 8 & 6,0 & 18,6 & 21,2 & 16,8 & 92,5 & 97,9 & 78,4 & 1,5 \\
\hline 9 & 8,8 & 19,2 & 22,9 & 17,0 & 90,9 & 98,1 & 70,8 & 1,9 \\
\hline 10 & 2,2 & 20,5 & 25,9 & 16,9 & 85,6 & 99,1 & 61,3 & 2,5 \\
\hline 11 & 12,0 & 20,0 & 27,2 & 16,6 & 88,7 & 99,0 & 54,2 & 6,6 \\
\hline 12 & 4,6 & 19,2 & 24,5 & 16,9 & 92,3 & 99,2 & 66,8 & 1,8 \\
\hline 13 & 0,6 & 20,8 & 26,9 & 17,2 & 82,5 & 97,2 & 55,1 & 1,6 \\
\hline 14 & 0,0 & 22,1 & 28,0 & 17,9 & 81,0 & 97,7 & 54,2 & 4,9 \\
\hline 15 & 14,8 & 21,3 & 26,6 & 19,0 & 89,4 & 98,5 & 59,7 & 6,0 \\
\hline 16 & 39,0 & 21,8 & 27,8 & 17,9 & 87,7 & 98,9 & 57,4 & 1,4 \\
\hline 17 & 2,2 & 20,9 & 27,7 & 15,7 & 87,5 & 99,1 & 59,3 & 2,1 \\
\hline 18 & 1,6 & 21,2 & 26,9 & 18,0 & 88,2 & 98,7 & 61,3 & 2,3 \\
\hline 19 & 3,8 & 20,3 & 25,9 & 16,7 & 90,9 & 98,8 & 66,9 & 1,8 \\
\hline 20 & 0,4 & 21,5 & 28,2 & 15,9 & 83,2 & 99,0 & 55,7 & 3,8 \\
\hline 21 & 11,4 & 21,2 & 27,9 & 18,7 & 87,1 & 98,7 & 56,5 & 6,7 \\
\hline 22 & 5,2 & 21,2 & 27,0 & 18,7 & 90,0 & 99,1 & 58,1 & 2,8 \\
\hline 23 & 30,2 & 20,0 & 24,0 & 17,3 & 93,0 & 98,9 & 76,6 & 3,8 \\
\hline 24 & 4,4 & 21,0 & 28,0 & 16,1 & 84,6 & 99,0 & 51,0 & 2,4 \\
\hline 25 & 0,0 & 22,4 & 29,0 & 16,4 & 73,6 & 98,7 & 40,8 & 6,9 \\
\hline 26 & 0,0 & 22,4 & 29,5 & 15,1 & 74,8 & 98,0 & 45,7 & 7,0 \\
\hline 27 & 0,2 & 22,3 & 29,0 & 13,8 & 67,5 & 98,0 & 37,7 & 8,7 \\
\hline 28 & 0,0 & 21,7 & 30,8 & 12,3 & 67,2 & 97,5 & 25,1 & 6,6 \\
\hline 29 & 0,0 & 22,9 & 31,7 & 13,9 & 67,7 & 97,4 & 31,8 & 6,4 \\
\hline 30 & 0,0 & 22,6 & 31,8 & 15,6 & 72,3 & 98,2 & 35,1 & 5,7 \\
\hline 31 & 0,6 & 21,9 & 30,4 & 16,4 & 76,6 & 96,2 & 33,7 & 5,3 \\
\hline Média & - & 20,9 & 27,1 & 16,6 & 83,7 & 98,4 & 54,6 & 4,1 \\
\hline Total & 189,6 & - & - & - & - & - & - & 126,5 \\
\hline Máximo & 39,0 & 22,9 & 31,8 & 19,0 & 93,0 & 99,2 & 79,3 & 8,7 \\
\hline Mínimo & 0,0 & 18,6 & 20,8 & 12,3 & 67,2 & 96,2 & 25,1 & 1,2 \\
\hline
\end{tabular}


Médias obtidas de cada tratamento em todas as variáveis estudadas na cultivar Prata Anã.

\begin{tabular}{|c|c|c|c|c|c|c|c|c|c|c|}
\hline atamentos & $\mathrm{PPH}$ & NMPC & NMBC & PMB & CMB & DMB & FMP & NMBP & $\mathrm{NCH}$ & $C D$ \\
\hline V1P1 & 8652,75 & 7,16 & 85,22 & 77,99 & 103,27 & 31,5 & 1,86 & 11,82 & 1251 & 3,29 \\
\hline V2P1 & 9792,55 & 7,37 & 89,4 & 88,34 & 111,27 & 33,97 & 1,97 & 2,08 & 112 & 3,27 \\
\hline V3P1 & 11835,85 & 7,48 & 89,94 & 75,94 & 105,47 & 32,8 & 2,37 & 11,95 & 1737 & 3,21 \\
\hline V4P1 & 14381,86 & 8,02 & 104,61 & 96,64 & 112,14 & 34,48 & 2,21 & 13,01 & 1390 & 3,25 \\
\hline V5P1 & 15971,1 & 8 & 102 & 90,72 & 116,57 & 34,83 & 2,12 & 12,69 & 1737 & 3,34 \\
\hline V1P2 & 8826,5 & 7,41 & 91,95 & 88,86 & 108,28 & 32,67 & 2,07 & 12,34 & 1112 & 3,31 \\
\hline $\mathrm{V} 2 \mathrm{P} 2$ & 15074,55 & 7,83 & 101,23 & 82,52 & 109,52 & 33,22 & 2,03 & 12,88 & 1668 & 3,3 \\
\hline V3P2 & 11842,8 & 7,33 & 89,91 & 77,57 & 103,71 & 31,49 & 2,19 & 12,21 & 1668 & 3,29 \\
\hline V4P2 & 18417,49 & 7,66 & 96,18 & 97,74 & 114,78 & 35,94 & 2,28 & 12,51 & 1946 & 3,19 \\
\hline 2 & 1127 & & , 2 & 91,26 & 112,94 & 34,14 & 2,01 & 12,65 & 1737 & 3,3 \\
\hline V1P3 & 9132,3 & 7,18 & 86,6 & 72,03 & 104,02 & 32,35 & 2,09 & 12,01 & 1320 & 3,21 \\
\hline V2P3 & 8048,1 & 7,66 & 96,09 & 82,11 & 109,54 & 34,6 & 1,79 & 12,5 & 903 & 3,18 \\
\hline V3P3 & 14150,2 & 7,17 & 89,35 & 83,64 & 106,06 & 34,54 & 1,9 & 12,41 & 1876 & 3,08 \\
\hline V4P3 & 14073,75 & 7,86 & 99,48 & 89,34 & 111 & 35,12 & 2,04 & 12,56 & 1598 & 3,16 \\
\hline V5P3 & 11363,25 & 8,15 & 104,38 & 91,43 & 111,68 & 36,19 & 1,93 & 12,78 & 1181 & 3,08 \\
\hline V1P4 & 7832,65 & 7,39 & 89,78 & 86,89 & 106,14 & 34,06 & 2,24 & 12,11 & 1042 & 3,11 \\
\hline V2P4 & 10188,7 & 7,65 & 94,84 & 84,52 & 105,79 & 33,35 & 2,13 & 12,37 & 1112 & 3,17 \\
\hline V3P4 & 16346,39 & 7,54 & 94,3 & 84,73 & 105,15 & 32,96 & 2,05 & 12,5 & 2015 & 3,19 \\
\hline V4P4 & 12998,15 & 7,81 & 99,38 & 92,53 & 112,38 & 34,64 & 2 & 12,71 & 1390 & 3,24 \\
\hline V5P4 & 11981,8 & 7,78 & 96,33 & 88,04 & 108,3 & 34,26 & 2,18 & 12,3 & 1390 & 3,16 \\
\hline V1P5 & 11245,1 & 7,82 & 99,17 & 83,26 & 108,19 & 33,88 & 2,06 & 12,57 & 1390 & 3,19 \\
\hline V2P5 & 9333,85 & 7,59 & 94,05 & 95,72 & 112,22 & 35 & 2,04 & 12,3 & 973 & 3,2 \\
\hline V3P5 & 10557,05 & 7,68 & 96,93 & 80,94 & 105,96 & 32,71 & 1,92 & 12,53 & 1320 & 3,24 \\
\hline V4P5 & 18169,6 & 8,13 & 104,6 & 94,81 & 111,16 & 34,33 & 1,99 & 12,84 & 1807 & 3,24 \\
\hline V5P5 & 13990,3 & 7,7 & 95,5 & 92,84 & 111,14 & 34,99 & 2,34 & 12,37 & 1529 & 3,18 \\
\hline
\end{tabular}

V1=1.090 L.cova ${ }^{-1}$, V2= 2.177 L.cova ${ }^{-1}$, V3=4300 L.cova ${ }^{-1}$, V4=6540 L.cova ${ }^{-1}$, V5= 8720 L.cova $^{-1}, \mathrm{P} 1=0 \mathrm{~kg} \cdot \mathrm{ha}^{-1}$ de $\mathrm{P}_{2} \mathrm{O}_{5}, \mathrm{P} 2=50 \mathrm{~kg} \cdot \mathrm{ha}^{-1}$ de $\mathrm{P}_{2} \mathrm{O}_{5}, \mathrm{P} 3=100 \mathrm{~kg} \cdot \mathrm{ha}^{-1}$ de $\mathrm{P}_{2} \mathrm{O}_{5}, \mathrm{P} 4=150$ kg.ha ${ }^{-1}$ de $\mathrm{P}_{2} \mathrm{O}_{5}, \mathrm{P} 5=200 \mathrm{~kg} \cdot \mathrm{ha}^{-1}$ de $\mathrm{P}_{2} \mathrm{O}_{5}$. 
Médias obtidas de cada tratamento em todas as variáveis estudadas na cultivar BRS Conquista.

\begin{tabular}{|c|c|c|c|c|c|c|c|c|c|c|}
\hline tratamentos & $\mathrm{PPH}$ & NMPC & NMBC & PMB & $\mathrm{CMB}$ & DMB & FMP & NMBP & $\mathrm{NCH}$ & $C D$ \\
\hline V1Mg1 & 1202,35 & 9,2 & 117,5 & 35,8 & 81,6 & 23,4 & 0,1 & 12,6 & 278 & 3,7 \\
\hline V2Mg1 & 2057,2 & 10 & 141,5 & 49 & 90,2 & 29,8 & 0,7 & 14 & 278 & 3 \\
\hline V3Mg1 & 4510,5 & 8,9 & 110,9 & 63,8 & 89,6 & 32,2 & 1,4 & 12,3 & 625 & 2,7 \\
\hline V4Mg1 & 3565,3 & 9,2 & 125,5 & 60,3 & 92 & 31,5 & 0,8 & 13,3 & 417 & 2,9 \\
\hline V5Mg1 & 1994,6 & 9,7 & 127,2 & 56,7 & 91,7 & 33 & 0,8 & 13 & 278 & 2,7 \\
\hline V1Mg2 & 4031 & 9,6 & 127,1 & 62,6 & 91,6 & 31,4 & 0,8 & 13,1 & 486 & 2,9 \\
\hline V2Mg2 & 2001 & 10 & 137,7 & 35,5 & 88,2 & 29,1 & 0,3 & 13,6 & 417 & 3,1 \\
\hline V3Mg2 & 3329 & 10,2 & 138,3 & 44,9 & 83,3 & 27,6 & 0,7 & 13,5 & 486 & 3 \\
\hline V4Mg2 & 7082 & 10,6 & 156 & 67,2 & 94,8 & 30,9 & 0,8 & 14,5 & 695 & 3 \\
\hline V5Mg2 & 3245 & 9,8 & 138 & 59,2 & 93,3 & 30,8 & 0,8 & 14 & 417 & 3 \\
\hline V1Mg3 & 6227 & 10,2 & 153,2 & 72,5 & 101,2 & 34 & 1,1 & 14,9 & 556 & 2,9 \\
\hline V2Mg3 & 3238 & 9,7 & 157,6 & 48,8 & 87,9 & 29,4 & 0,9 & 14,1 & 347 & 3 \\
\hline V3Mg3 & 4816 & 9,5 & 134,4 & 51,3 & 85,6 & 28,7 & 0,8 & 13,9 & 625 & 2,9 \\
\hline V4Mg3 & 6435 & 9,7 & 131,8 & 60,4 & 95,2 & 31,3 & 0,6 & 13,4 & 625 & 3 \\
\hline V5Mg3 & 4517 & 10,3 & 140,3 & 66,1 & 92,5 & 30,4 & 1,2 & 13,5 & 486 & 3 \\
\hline V1Mg4 & 3481 & 9,4 & 129,3 & 52,3 & 92,3 & 29,8 & 0,9 & 13,6 & 486 & 3 \\
\hline V2Mg4 & 2814 & 9,3 & 128,2 & 54,5 & 91,2 & 29,6 & 0,9 & 13,7 & 417 & 3,1 \\
\hline V3Mg4 & 3711 & 8,8 & 120,7 & 56 & 88,2 & 27,9 & 0,9 & 13,4 & 486 & 3,2 \\
\hline V4Mg4 & 8124 & 10,4 & 144,3 & 71,4 & 96 & 34,5 & 1 & 13,7 & 764 & 2,7 \\
\hline V5MG4 & 2856 & 9,9 & 120 & 51 & 89,9 & 28,4 & 0,7 & 12 & 417 & 3,1 \\
\hline V1Mg5 & 1674 & 8,6 & 120,5 & 39,5 & 82,3 & 27,7 & 1,3 & 14 & 347 & 3 \\
\hline V2Mg5 & 2654 & 10,1 & 149 & 45,2 & 86,7 & 27,3 & 0,6 & 14,7 & 417 & 3,1 \\
\hline V3Mg5 & 3641 & 9,3 & 110 & 42,5 & 80,8 & 26,4 & 0,4 & 11,5 & 556 & 3,1 \\
\hline V4Mg5 & 6755 & 10,8 & 147,6 & 69,1 & 103,4 & 32 & 1,2 & 13,5 & 625 & 3,2 \\
\hline V5Mg5 & 1946 & 9,7 & 123,7 & 55,9 & 94,2 & 31,8 & 0,5 & 12,6 & 278 & 3 \\
\hline
\end{tabular}

